\title{
Historical Background on Assessing the Performance of the Waste Isolation Pilot Plant
}

Prepared by

WIPP Performance Assessment Department, 6849

at Sandia National Laboratories

Albuquerque, New Mexico 87185 and

Livermore, California 94550

Sandia is a multiprogram laboratory operated by

Sandia Corporation, a Lockheed Martin Company, for the United States Department of Energy under Contract DE-AC04-94AL85000

Approved for public release; further dissemination unlimited

SAND98-2708

Unlimited Release

Printed June 1999 
Issued by Sandia National Laboratories, operated for the United States Department of Energy by Sandia Corporation.

NOTICE: This report was prepared as an account of work sponsored by an agency of the United States Government. Neither the United States Government, nor any agency thereof, nor any of their employees, nor any of their contractors, subcontractors, or their employees, make any warranty, express or implied, or assume any legal liability or responsibility for the accuracy, completeness, or usefulness of any information, apparatus, product, or process disclosed, or represent that its use would not infringe privately owned rights. Reference herein to any specific commercial product, process, or service by trade name, trademark, manufacturer, or otherwise, does not necessarily constitute or imply its endorsement, recommendation, or favoring by the United States Government, any agency thereof, or any of their contractors or subcontractors. The views and opinions expressed herein do not necessarily state or reflect those of the United States Government, any agency thereof, or any of their contractors.

Printed in the United States of America. This report has been reproduced directly from the best available copy.

Available to DOE and DOE contractors from

Office of Scientific and Technical Information

P.O. Box 62

Oak Ridge, TN 37831

Prices available from (703) 605-6000

Web site: http://www.ntis.gov/ordering.htm

Available to the public from

National Technical Information Service

U.S. Department of Commerce

5285 Port Royal Rd

Springfield, VA 22161

NTIS price codes

Printed copy: A10

Microfiche copy: A01

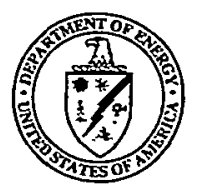




\section{DISCLAIMER}

Portions of this document may be illegible in electronic image products. Images are produced from the best available original document. 


\title{
Historical Background on Assessing the Performance of the Waste Isolation Pilot Plant
}

\author{
Rob P. Rechard \\ Performance Assessment Department \\ Sandia National Laboratories \\ P.O. Box 5800 \\ Albuquerque, New Mexico 87185-0779
}

\begin{abstract}
In 1979, six years after selecting the Delaware Basin as a potential disposal area, Congress authorized the U.S. Department of Energy to build the Waste Isolation Pilot Plant (WIPP) near Carlsbad, New Mexico, as a research and development facility for the safe management, storage, and disposal of waste contaminated with transuranic radioisotopes. In 1998, 19 years after authorization and 25 years after site selection, the U.S. Environmental Protection Agency (EPA) certified that the WIPP disposal system complied with its regulations. The EPA's decision was primarily based on the results from a performance assessment conducted in 1996. This performance assessment was the culmination of four preliminary performance assessments conducted between 1989 and 1992. This report provides a historical setting and context for how the performance of the deep geologic repository at the WIPP was analyzed. Also included is background on political forces acting on the project. For example, the federal requirement to provide environmental impact statements and negotiated agreements with the State of New Mexico influenced the type of scientific areas that were investigated and the engineering analysis prior to 1989 for the WIPP.
\end{abstract}




\section{Acknowledgments}

This report is a greatly expanded version of a figure showing milestones originally prepared for a report on the performance assessment process (Rechard, 1995). The figure was updated and presented separately in 1998 (Rechard, 1998). The original figure included technical milestones, but emphasized the political and policy turmoil acting upon the WIPP Project. Although the information from that figure is included here, the emphasis in this report is on the technical aspects of the project. The WIPP has benefited from continuity in the technical support provided by Sandia National Laboratories (in addition to the strong community support by Carlsbad and management support by Westinghouse); thus, more technical information has been added and the information on the original figure has been rearranged into several different figures covering specific technical aspects. The usefulness of this history is due in part to D. E. Munson, M. S. Tierney, and W. D. Weart, of Sandia, who reviewed the text; D. Brewer of Sandia, who compiled the WIPP budget history; F. C. Allan and S. Halliday, librarians at Sandia who helped with searches; C. S. Crawford, of ASAP, Inc., who verified references; and Tech Reps, Inc. personnel, J. M. Chapman, who edited the text, S. K. Best, who generated the figures, and L. C. Tartaglia, who provided desktop publishing. 


\section{Contents}

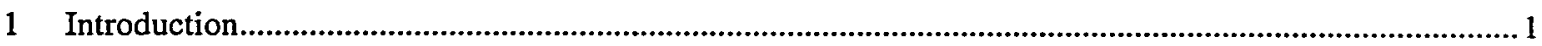

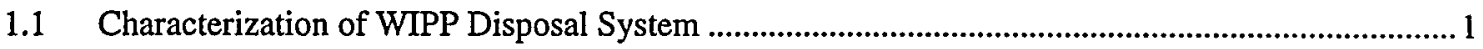

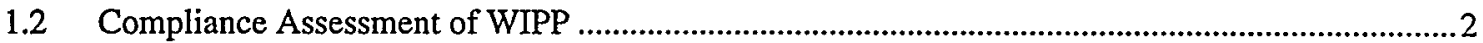

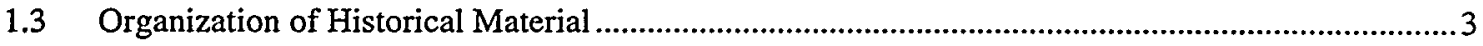

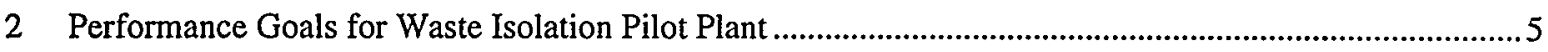

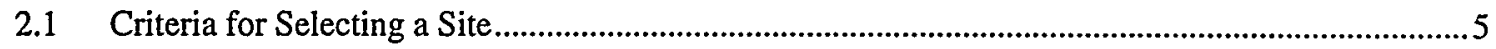

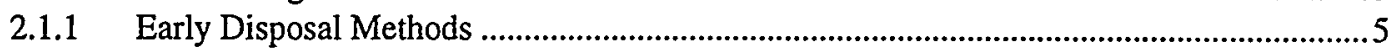

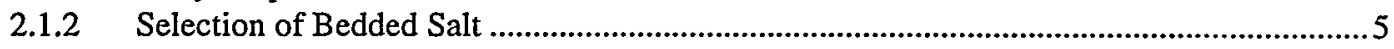

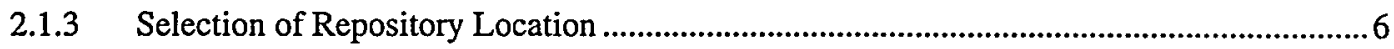

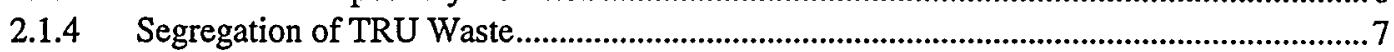

2.2 Preparation of Environmental Impact Statement .....................................................................

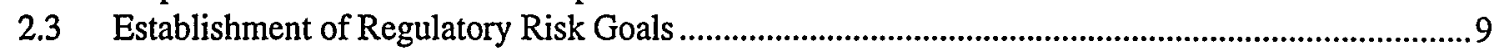

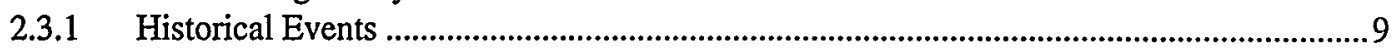

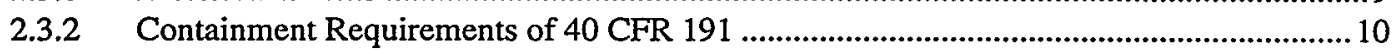

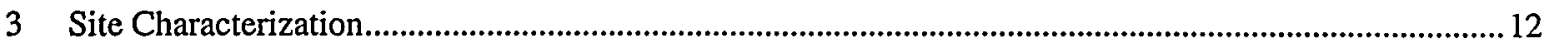

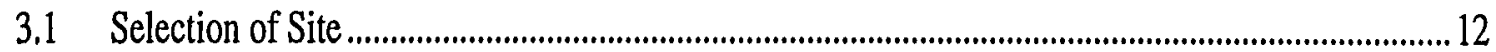

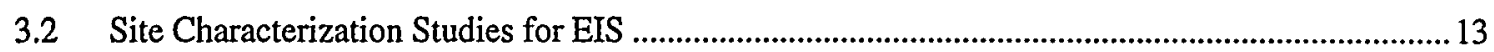

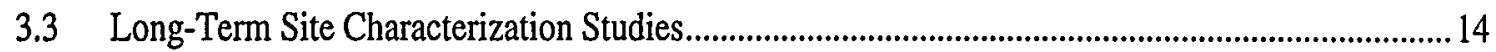

3.3.1 Site Characterization Studies at Repository Horizon ........................................................... 14

3.3.2 Site Characterization Studies for Stipulated Agreement ....................................................... 16

3.4 Site Characterization Studies for CCA ……...................................................................................... 18

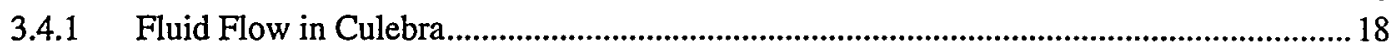

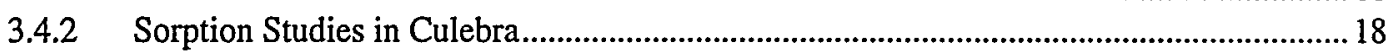

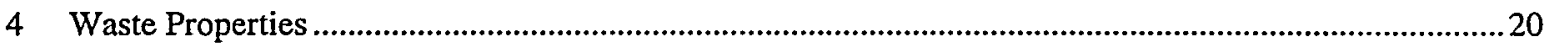

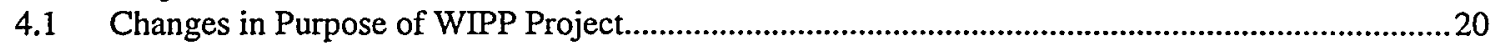

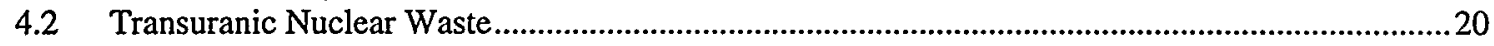

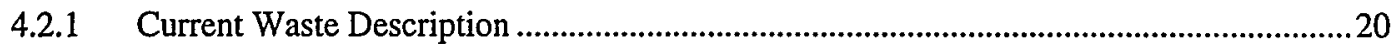

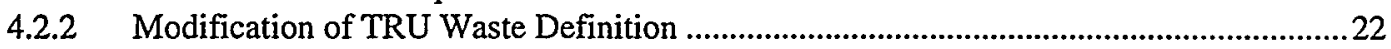

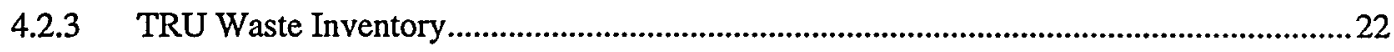

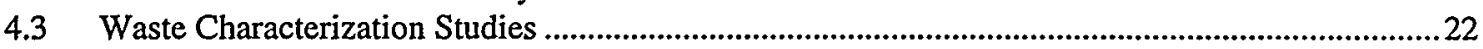

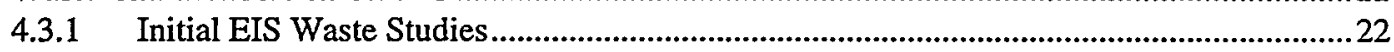

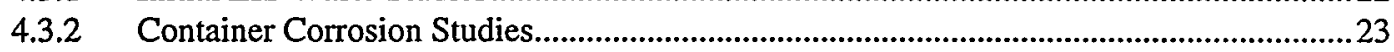

4.3.3 Characterization for Performance Assessment Studies ..................................................23

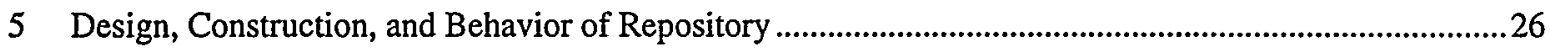

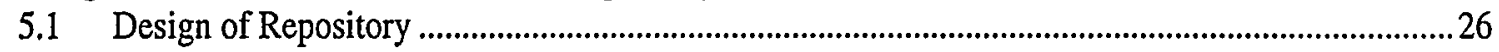

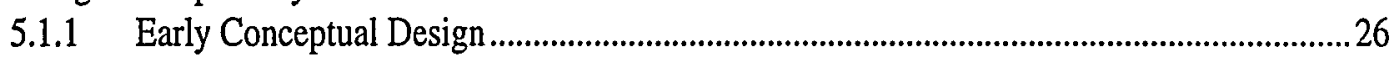

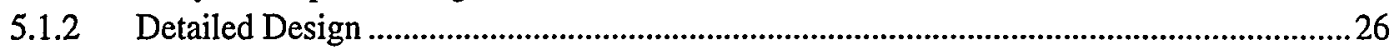

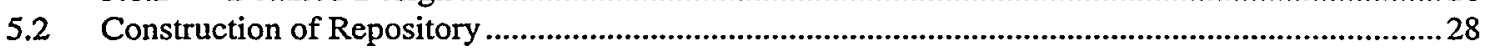

5.3 Experiments and Model Development of Repository Behavior ...................................................29

5.3.1 Experiments with Salt Creep Behavior …….............................................................................29

5.3.2 Modeling of Repository Behavior ……................................................................................... 30

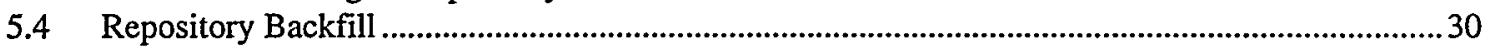

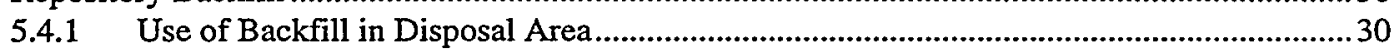

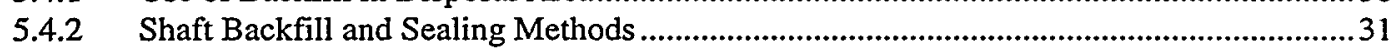

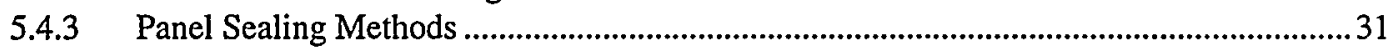




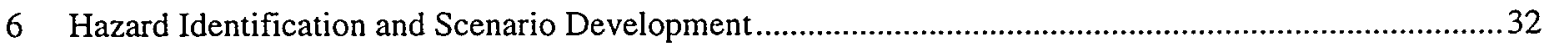

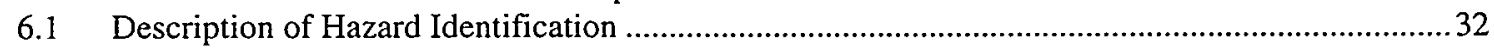

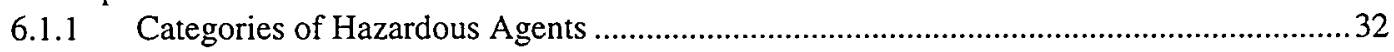

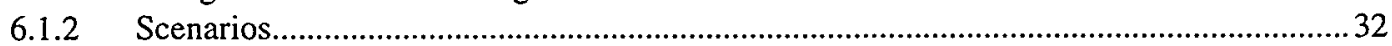

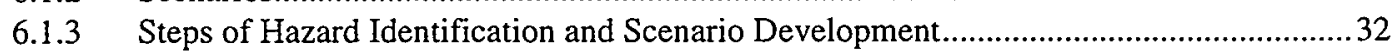

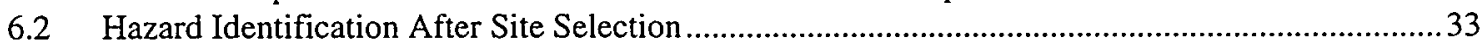

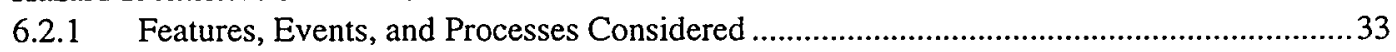

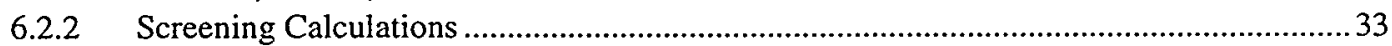

6.3 Hazard Identification and Scenario Development for EIS ...........................................................33

6.3.1 Features, Events, and Processes Considered .........................................................................3

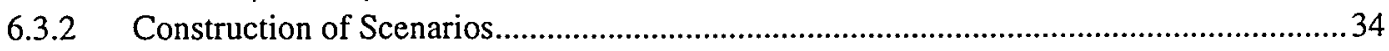

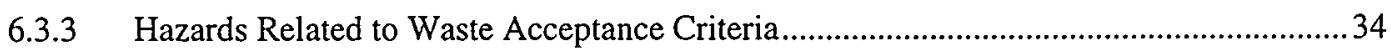

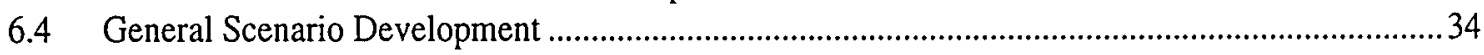

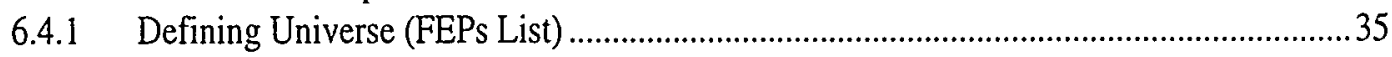

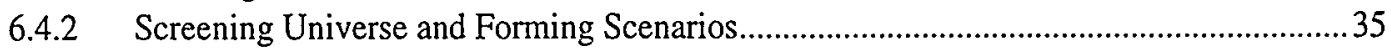

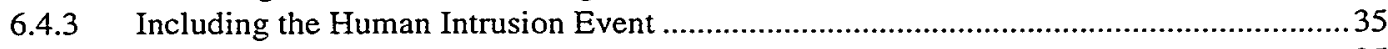

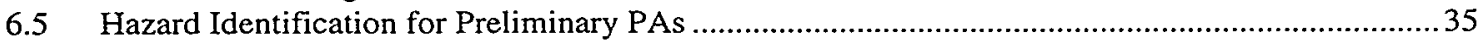

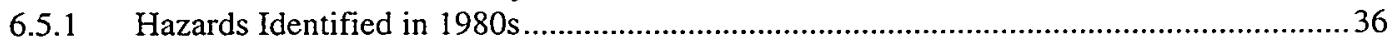

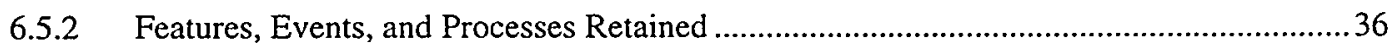

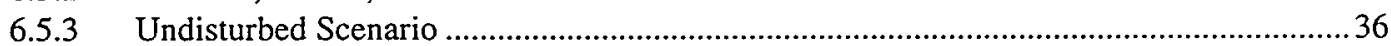

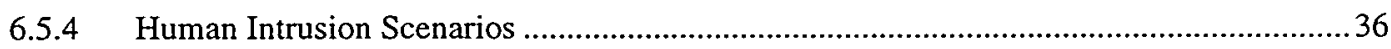

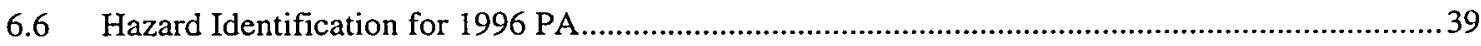

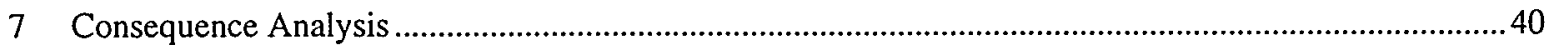

7.1 Description of Consequence Analysis for the WIPP .................................................................... 40

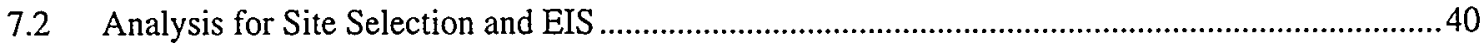

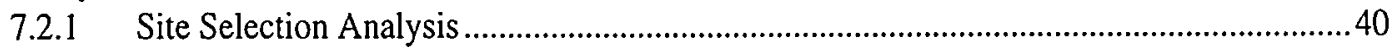

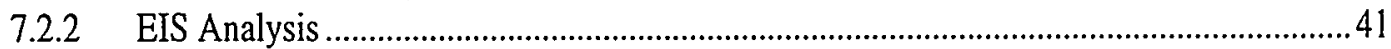

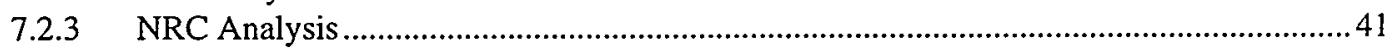

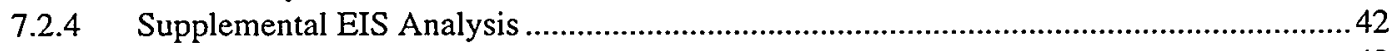

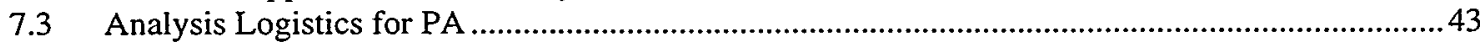

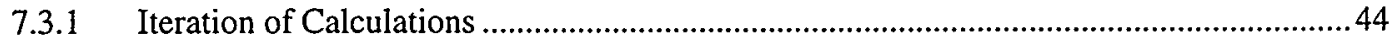

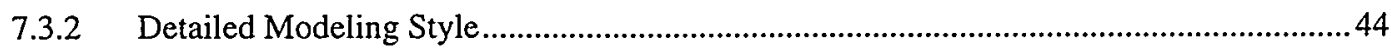

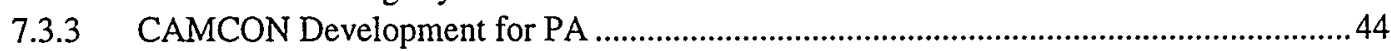

7.4 Consequence Models in Performance Assessments ............................................................................45

7.4.1 Direct Cutting and Brine Release Modeling ....................................................................... 47

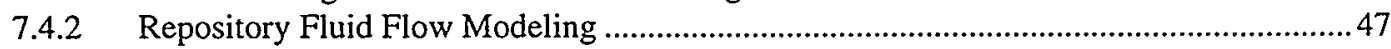

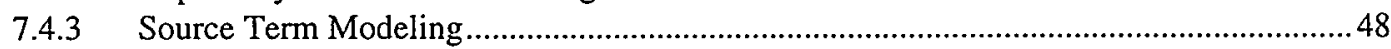

7.4.4 Culebra Transmissivity Modeling …….................................................................................49

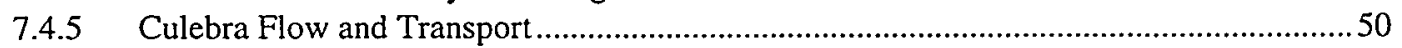

8 Probability Evaluation and Sensitivity Analysis .............................................................................51

8.1 Scenario Probabilities and Parameter Selection for the EIS ......................................................51

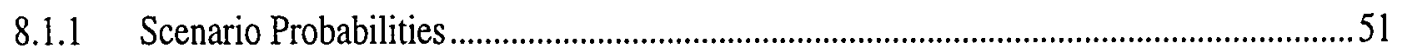

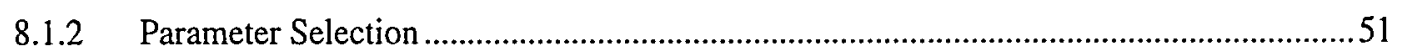

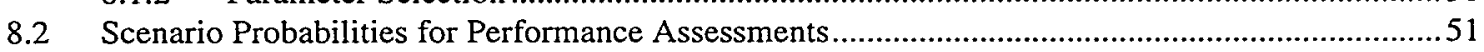

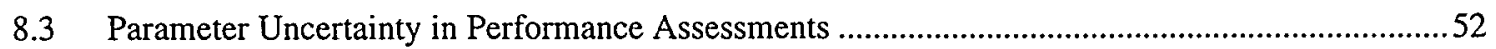

8.3.1 Data Bases for Model Parameters and Results................................................................52

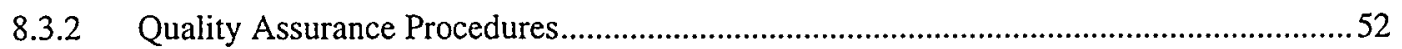

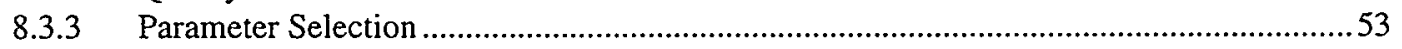

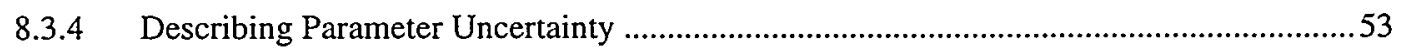

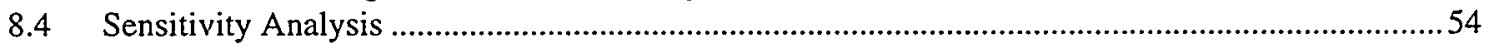

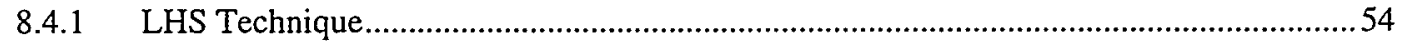


8.4.2 Sensitive Parameters........................................................................................................55

8.4.3 Project Guidance from Sensitivity Analyses..........................................................................55

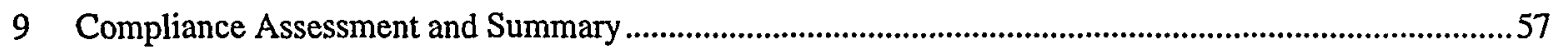

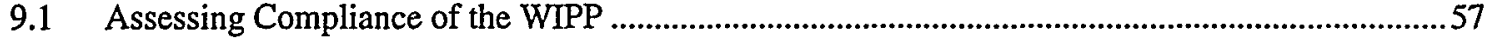

9.1.1 Predicted Doses for EIS........................................................................................................57

9.1.2 Releases from Preliminary Performance Assessments......................................................57

9.1.3 Performance Assessment for CCA ..........................................................................57

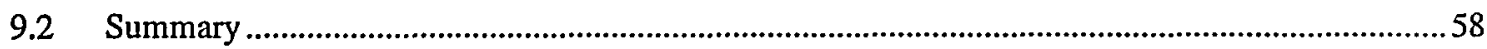

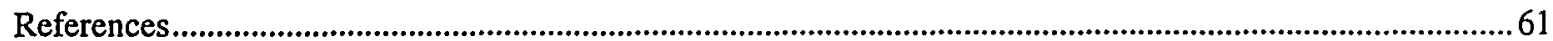




\section{Figures}

1-1 Juxtaposition of several categories of events for the WIPP ..........................................................

2-1 Early history of nuclear waste disposal related to the WIPP....................................................... 6

2-2 Performance goals were added or changed several times over the 25-yr history

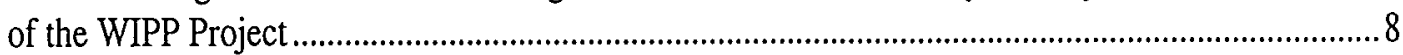

2-3 Uncertainty in model parameters $\mathrm{p}$ (expressed as a probability density function [PDF],

or cumulative distribution function $[C D F]$ ) results in uncertainty in the results ............................. 10

3-1 Physical setting of the WIPP in Delaware Basin .................................................................. 13

3-2 Well tests conducted to characterize transmissivities of the Culebra Dolomite

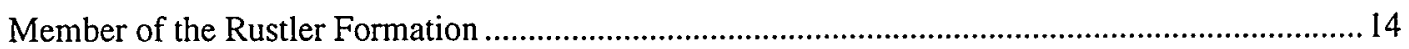

3-3 Stratigraphy above and below the WIPP repository....................................................................... 15

3-4 Estimated permeability of Salado Formation near repository horizon continued to decrease

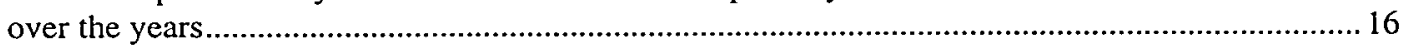

3-5 Site characterization studies at the WIPP …............................................................................... 17

3-6 Stratigraphic subdivisions of Culebra Dolomite Member of Rustler Formation discerned

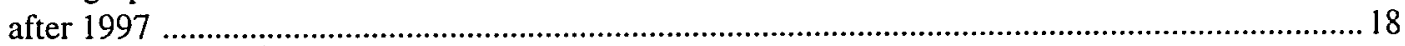

3-7 Ranges of $\mathrm{K}_{\mathrm{d}} \mathrm{s}\left(\mathrm{m}^{3} / \mathrm{kg}\right)$ for plutonium and uranium in 1991, 1992, and 1996 performance

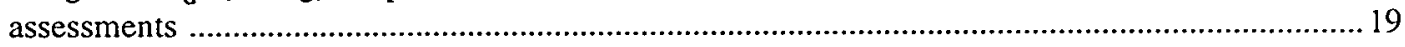

4-1 Development of project goals and characterization of waste properties .......................................21

4-2 Solubility of radioisotopes used in calculations between 1989 and 1996 for (a) plutonium

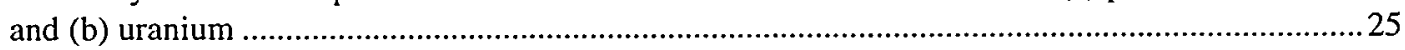

5-1 Designs for the WIPP repository, including (a) 1977 conceptual design

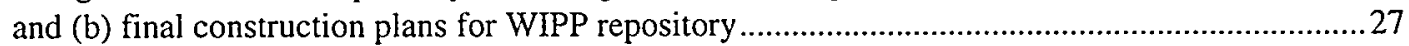

5-2 Events associated with design, construction, and modeling of the WIPP repository .......................28

5-3 Comparison of measured and calculated creep closure in Room D ................................................30

6-1 Technique to construct scenarios from various features, events, and processes changed between WIPP Environmental Impact Statement in 1979 and performance assessment

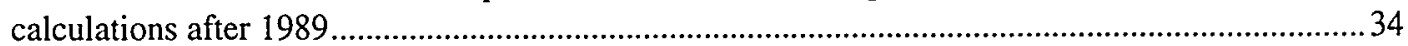

6-2 Engineering analysis of the illustrated behavior of the disposal system ........................................37

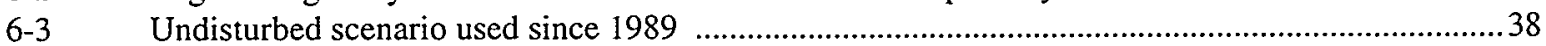

6-4 ElE2 human intrusion scenario used since 1990. Intrusion borehole plugs are placed

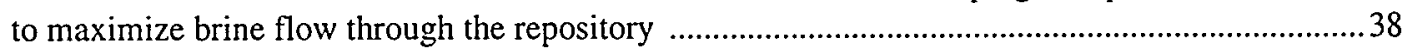

7-1 Boundaries of models constructed for analysis of groundwater flow and transport of

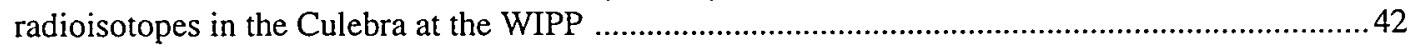

7-2 Schematic of CAMCON modeling system completed in 1991. By 1996, CAMCONexec was replaced by computer specialists for run control and management of files ..................................46

7-3 Changes in components of the exposure pathway ("consequence") model for immediate releases after exploratory drilling for evaluating compliance of the WIPP ......................................47

7-4 Changes in components of the exposure pathway model for long-term releases via leaking borehole and Culebra brine aquifer

9-1 Changes in the distribution of cumulative releases (normalized by the EPA limits) for

(a) direct releases to the surface during drilling and (b) releases via groundwater pathway

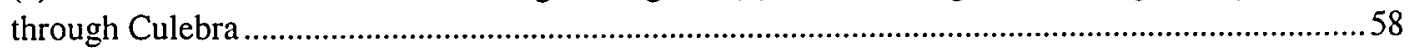

9-2 Annual outlays for construction and assessments of the Waste Isolation Pilot Plant (WIPP) (private communication with D. Brewer, SNL, from Sandia budget records) ...........60

9-3 History of expenditures and human resources for WIPP Project at Sandia National

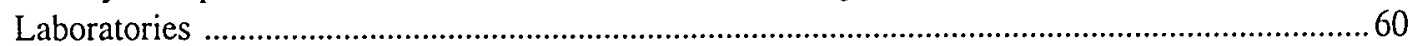




\subsection{Introduction}

In 1998, 25 years after selection of the Delaware Basin in southeastern New Mexico as a potential disposal site for radioactive waste, the U.S. Environmental Protection Agency (EPA) certified that the Waste Isolation Pilot Plant (WIPP), an underground geologic disposal system, complied with its regulations. This report presents a historical summary of the system characterization, engineering analyses, and scientific investigations undertaken by the WIPP Project over the past 25 years. Many paths were followed to discern which phenomena were important at the WIPP, and often these paths were initiated in response to evolving notions of what kind of scientific information was significant, what level of understanding was required, and how society could use this scientific information to decide whether deep geologic disposal of nuclear waste was acceptable.

\subsection{Characterization of WIPP Disposal System}

The choice of New Mexico as a potential disposal site for nuclear waste in 1973 (Claiborne and Gera, 1974) was one in a series of episodes in which New Mexico had figured prominently with regard to nuclear phenomena. In 1942, the Manhattan Engineering District selected New Mexico for assembling the scientists, engineers, and technicians who would develop the first atomic bomb. The location selected later became what is now known as Los Alamos National Laboratory and Sandia National Laboratories ${ }^{1}$. As a direct consequence of that development, the first atomic explosion took place in 1945 in the desert near Alamogordo, New Mexico (Serber, 1992). Sixteen years later, in 1961, scientists with the Gnome Project detonated a device in the Delaware Basin in bedded salt near Carlsbad, New Mexico, as part of the Plowshare Program, which was exploring nonmilitary uses of nuclear explosives (Teller, 1959; Gard, 1968). Several months after the explosion, as part of the test, engineers made an excavation in the cavity that had been created.
After a potential disposal site in bedded salt in Kansas had been rejected in the early 1970s, New Mexico citizens invited the Atomic Energy Commission (precursor to the U.S. Department of Energy ${ }^{2}$ ) to consider the bedded salt deposits in the Delaware Basin in southeastern New Mexico. The search for a specific site in the basin occurred between 1973 and 1976 (Powers et al., eds., 1978). The site was then characterized by Sandia National Laboratories for the U.S. Department of Energy (DOE) in support of its Draft Environmental Impact Statement (EIS), which was completed in 1979 (DOE, 1979).

Nearly ten years later, in December 1979, Congress authorized the DOE to construct the WIPP for eventual disposal of radioactive waste (Public Law 96-164). Shortly before October 1979, Bechtel National had begun designing the surface and underground facilities. The first shaft was drilled in 1981, and full construction began in 1983. Construction of the WIPP facility was substantially complete at the end of 1988.

The wastes intended for the WIPP included waste contaminated with transuranic (TRU) nuclear elements and hazardous chemicals generated during the production of nuclear weapons. The Atomic Energy Commission (AEC) has been segregating and storing these wastes above ground for eventual disposal since 1970 (Perge, 1982).

Along with construction, a suite of characterization studies were initiated in the $1980 \mathrm{~s}$ in response to agreements with the State of New Mexico. The final site characterization studies were completed in the 1990s. The characterization of the WIPP provided input for the 1996 performance assessment, an engineering analysis documented in the Compliance Certification Application (CCA), which was submitted to the EPA in October 1996 (DOE, 1996a; EPA, 1996b).

1 Los Alamos National Laboratory, a multiprogram laboratory in Los Alamos, NM, was first known informally as Los Alamos Laboratory; it was officially named the Los Alamos Scientific Laboratory in 1948 and then renamed the Los Alamos National Laboratory in 1979. Sandia National Laboratories is the multiprogram laboratory located in Albuquerque, NM, and Livermore, CA. The Albuquerque laboratory was originally referred to as Los Alamos' Z Division, and then as the Sandia branch of Los Alamos. It became Sandia Laboratories in 1949 and Sandia National Laboratories in 1979.

2 The Atomic Energy Commission (AEC) was formed by the Atomic Energy Act of 1946 (Public Law 79-585). The Energy Research and Development Agency (ERDA) and the Nuclear Regulatory Commission (NRC) were formed by splitting the Atomic Energy Commission in the Energy Reorganization Act of 1974 (Public Law 93-438). ERDA became the U.S. Department of Energy (DOE) in the 1977 Department of Energy Organization Act (Public Law 95-91). 


\subsection{Compliance Assessment of WIPP}

Over the past 25 years, the process for assessing performance of a deep geologic repository for radioactive waste developed concurrently with the characterization of the WIPP in New Mexico. The WIPP Project's first major analysis was for the EIS in 1979 (DOE, 1979). In 1985 , the $\mathrm{EPA}^{3}$ promulgated its radiation protection standard for the management and disposal of spent nuclear fuel, high-level and transuranic wastes, in Title 40 of the Code of Federal Regulations Part 191 (40 CFR 191) (EPA, 1985a). In 1986, the DOE asked Sandia to assess the performance of the WIPP (Krenz, 1986). The assessment process that evolved by 1996 for this regulation included developing a scientific understanding of the current status of the repository and the surrounding geologic barrier (the disposal system) through sufficient site characterization. Yet, an important aspect of the regulatory assessment was a set of calculations illustrating possible behavior well into the future. The assessment also required that the calculations include uncertainty concerning model parameters and model form; hence, the analysis was probabilistic.

The overall process of assessing whether a nuclear waste disposal system meets a set of performance criteria is known as a performance assessment, a term defined in 40 CFR 191. Similar to other risk assessments, the performance assessment process consists of determining the answers to the following three questions (Kaplan and Garrick, 1981; Helton et al., 1997c, 1993b; Rechard, 1995):

1. What hazards can occur?

Process: Identify sources of unwanted outcomes through hazard identification and scenario development.

2. What are the consequences potentially caused by these hazards?

Process: Evaluate the consequences or unwanted outcomes by determining

- the pathway by which a hazard reaches a receptor (e.g., humans or the general environment) and

- the response (e.g., fatality, injury, or no effect) to the level of hazard that eventually reaches the receptor
3. What is the probability of these unwanted outcomes?

Process: Evaluate the probability of consequences by determining the probabilistic description of the uncertainty in both the pathway to the receptor and the response of the receptor.

Describing and quantifying the answers to these three basic questions are the three main steps of a performance assessment. Four other steps complement them. First, if performance of a system is being evaluated for the first time, then an initial step must determine appropriate performance measures. Then, the system must be characterized or otherwise defined. After probabilities and consequences have been calculated, a separate step is to combine them for use as input to management decisions. In the case of a compliance assessment for a nuclear waste repository, the results are compared with probabilistic risk criteria so that a decision can be made on whether society will accept the nuclear waste disposal site. Finally, a sensitivity analysis on the model parameters is run, if appropriate, to identify significant parameters for use by decision makers. In summary, a performance assessment includes up to seven steps:

0. Definition of performance criteria

1. System definition and/or characterization

2. Hazard identification and scenario development

3. Probability evaluation

4. Consequence evaluation

5. Performance characterization and compliance assessment

6. Sensitivity analysis

As with any scientific modeling or policy process, steps may overlap. More importantly, an analyst may need to cycle through several of the steps when building an appropriate model. Hence, the steps are not always truly sequential. However, the discretization is useful as a means of describing the process and so is used here. The computational mechanics of the seven-step process are described in Rechard (1995).

Because the main purpose of a performance assessment is to serve as input to a management decision, it is an engineering analysis with constraints on time and resources specified by the decision makers (or tolerated by representatives of society) rather than a scientific

3 Congress formed the U.S. Environmental Protection Agency in 1970, transferring to it from other agencies the responsibilities of research, monitoring, standard setting, and enforcement activities related to the environment. 
analysis, which is in principle constrained only by human curiosity.

\subsection{Organization of Historical Material}

The historical events summarized above are more fully described in the following sections according to the steps of a performance assessment. The discussion begins with the definition of performance goals. Next discussed is characterization of the three main compo- nents of the disposal system, i.e., site, waste and facility. Site characterization for the WIPP (Section 3) includes identifying and selecting a specific site and studying its geologic and hydrologic setting. The waste characterization studies (Section 4) describe the amounts and types of waste intended for the WIPP, and examining its various properties. Facility design studies (Section 5) evaluate the thermal/mechanical properties of the salt and also various engineering components such as backfill and shaft sealing. The engineering analysis of the WIPP disposal system is then presented according to the remaining steps of a performance assessment (Figure $1-1)$. 


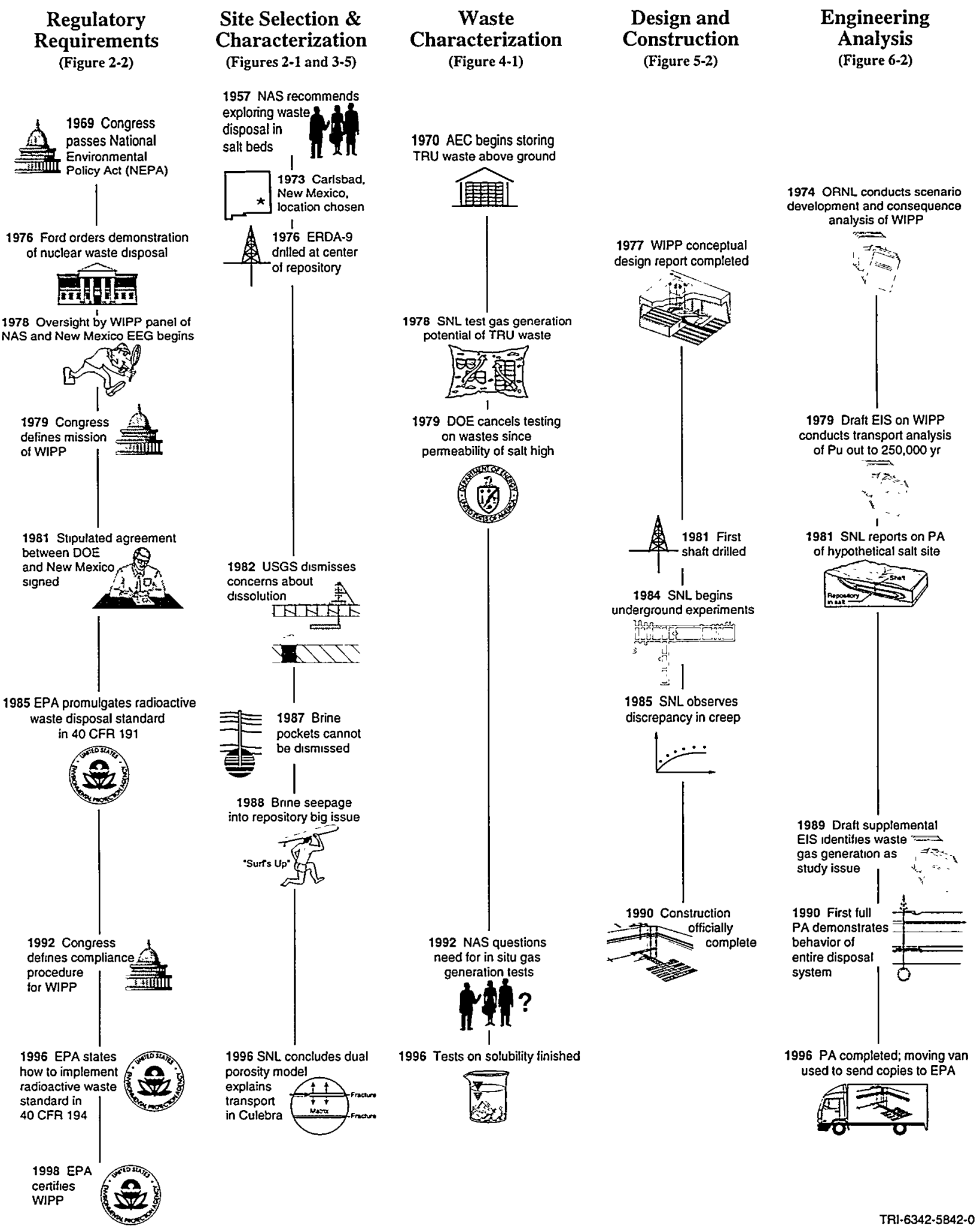

Figure 1-1. Juxtaposition of several categories of events for the WIPP. 


\subsection{Performance Goals for Waste Isolation Pilot Plant}

From 1955 through the 1960s, the AEC explored options for storage and disposal of nuclear waste. The scientific and engineering studies for deep geologic disposal in salt eventually led to the selection of the salt beds of New Mexico. Later, in the mid 1970s through the early 1980s, an assessment process and risk-based performance criteria evolved to determine the acceptability of the risk of the WIPP disposal system.

\subsection{Criteria for Selecting a Site}

\subsubsection{Early Disposal Methods}

In the early years of nuclear research, it was very important to recover all of the radioisotopes produced, particularly ${ }^{239} \mathrm{Pu}$ and ${ }^{235} \mathrm{U}$. At that time, many members of the staff at various facilities were analytical chemists whose primary task was to detect and retain isotopes (Perge, 1982). At Los Alamos National Laboratory, the site and methods for disposal of waste that remained were initially the same as for any other waste: it was disposed of in nearby canyons. Around 1944, the Manhattan Engineering District decided to bury solid nuclear waste in shallow trenches and augered holes at Los Alamos (NAS/NRC, 1957) and in railroad cars, trenches, and underground caissons at the Hanford Reservation in Washington state.

The AEC, formed in 1946 (Public Law 79-585), continued the practices of the Manhattan Engineering District. The AEC also constructed storage tanks in the late 1940s at Hanford and completed a nuclear waste storage complex, the Radioactive Waste Management Complex (RWMC) at Idaho National Engineering and Environmental Laboratory ${ }^{1}$ (INEEL) in 1952 . By the mid-1950s, eight reactors were operating at Hanford and five were running at the Savannah River Plant, decreasing the need to recover every detected gram of plutonium. Furthermore, in the late 1950s and early 1960s, the AEC began to refurbish, modify, and clean up its facilities, e.g., Los Alamos began to replace its temporary wooden buildings, and so the amount of plutonium- contaminated waste in need of disposal rapidly increased. Initially, waste had been kept near the facilities and test sites where it was produced (by the mid1950s Hanford had 30 burial grounds [Perge, 1982]). However, in the 1960s the AEC did try to reduce the number of burial grounds at the facilities to help manage the wastes.

\subsubsection{Selection of Bedded Salt}

Studies of permanent disposal options began in 1955 when the AEC asked the National Academy of Sciences (NAS) to examine the disposal issue. In 1957, the NAS reported that while various options and disposal sites were feasible, disposal in salt was the most promising method to explore (NAS/NRC, 1957). NAS reaffirmed that recommendation in 1961 (Carter, 1987, p. 64; Boffey, 1975; Claiborne and Gera, 1974). By 1966, frustration at the lack of a formal waste policy at the AEC provoked strong criticism from the NAS about the AEC's disposal practices (Carter, 1987, p. 64; Boffey, 1975; Claiborne and Gera, 1974). At that time, the reasons for using salt beds were as follows: (1) salt can be found in regions of tectonic stability, (2) the existence of salt demonstrates the absence of fresh circulating groundwater, (3) salt is easy to mine, and (4) fractures are readily healed (i.e., salt readily consolidates and entombs the waste as the result of its plastic properties). From 1961 through the early 1970s, Oak Ridge National Laboratory ${ }^{2}$ (ORNL) conducted radioactive-waste disposal experiments, most notably Project Salt Vault in an abandoned salt mine near Lyons, Kansas, from 1963 to 1967. Some of the experiments had used actual spent nuclear fuel, which was retrieved afterwards and sent back to INEEL (Bradshaw and McClain, eds., 1971) (Figure 2-1). Based on the results of these tests, the Committee on Radioactive Waste Management, which had been established in 1968 at the request of the AEC and later became a permanent board, concluded in their 1970 report that bedded salt was satisfactory and the safest choice then available for nuclear waste disposal (U.S. Congress, 1970a; 1970b; NAS/ NRC, 1970).

1 Idaho National Engineering and Environmental Laboratory (INEEL), a multiprogram laboratory in Idaho Falls, Idaho, originated as the National Reactor Testing Station in 1949. It was named the Idaho National Engineering Laboratory in 1974, and then renamed the Idaho National Engineering and Environmental Laboratory in early 1997.

2 Oak Ridge National Laboratory, a multiprogram laboratory in Oak Ridge, Tennessee, was originaily named the Clinton Engineering Works in 1942. It was renamed the Clinton National Laboratory in 1947, and the Oak Ridge National Laboratory in 1948. 


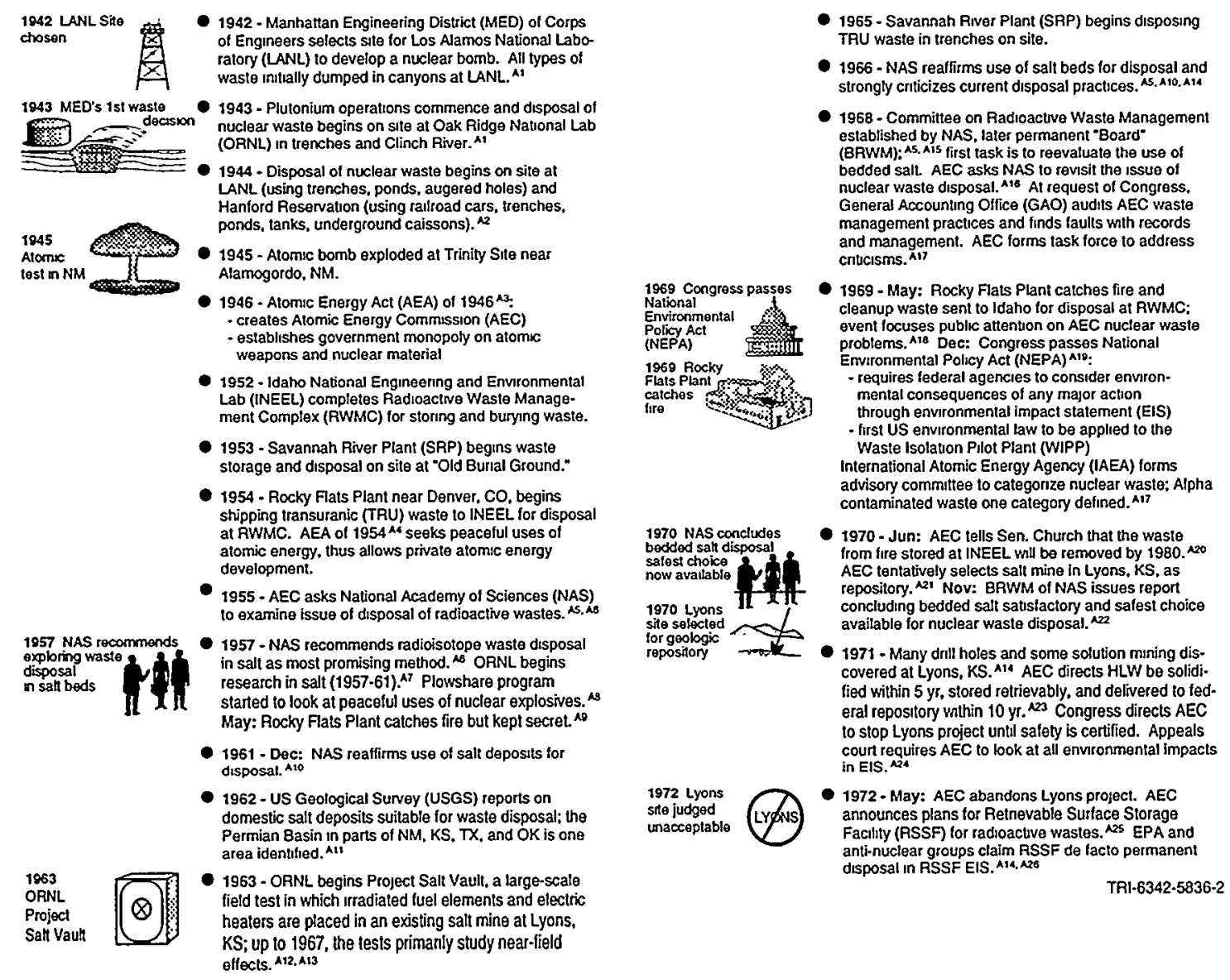

Figure 2-1. Early history of nuclear waste disposal related to the WIPP.

\subsubsection{Selection of Repository Location}

In May 1969, the Rocky Flats Plant, built by the $A E C$ in 1951 to machine plutonium and other metals for nuclear weapons, caught fire. Located only $26 \mathrm{~km}$ (16 mi) from Denver, Colorado, the fire and subsequent cleanup attracted public attention. The press reported that the waste from the cleanup was eventually to be sent to Idaho (Carter, 1987, p. 66). For the first time, the public and many Idaho state officials learned that TRU waste from the Rocky Flats Plant had been routinely buried in Idaho since 1954. Media attention over the events created high visibility for the issue of waste disposal from nuclear weapons production. Officials of the State of Idaho complained that the state was becoming the nation's waste disposal site for defense-related waste by default; in addition, the Radioactive Waste Management Complex there was not ideal for long-term disposal of nuclear waste because of its location near the Snake River and its associated aquifer. These problems were described in reports to Senator Church of Idaho by the U.S. Geological Survey (USGS), the U.S. Public
Health Service, the Federal Water Quality Commission (later part of the EPA), and the Bureau of Sport Fisheries and Wildlife (Perge, 1982); hence, the AEC quickly moved to find a more suitable site. The AEC assured Senator Church that the waste from Rocky Flats stored in Idaho would be removed by 1980 (Lipschutz, 1980). In June 1970, the AEC tentatively selected the abandoned Kansas salt mine at Lyons, the site of the ORNL experiments, as a demonstration repository (AEC, 1971).

Although salt has many advantages, a disadvantage is the coexistence of economic minerals, which are deposited along with the salts, and hydrocarbons. In 1971, a large number of previously unknown drill holes for mineral exploration and some solution mining were discovered very near the proposed repository (Carter, 1987, p. 69). Already faced with general opposition to the site from Kansas state officials and anti-nuclear groups, the AEC now had a technical reason to look for a new site. Soon after, Congress directed the AEC to stop work on the Lyons project until safety was certified. 
In May 1972, the AEC officially abandoned the Lyons project and announced plans for a Retrievable Surface Storage Facility primarily for high-level waste (Metlay, 1978); however, anti-nuclear groups and the EPA, through comments on the draft EIS for the facility, claimed the storage facility as de facto permanent disposal (MRSRC, 1989). Although the RSSF plan was not officially withdrawn until formation of ERDA in January 1975 , the early criticism prompted the AEC to continue to search for a suitable disposal site for the less controversial TRU waste (Anderson et al., 1973; Jones et al., 1973, Carter, 1987, p. 177; Brokaw et al., 1972; Mytton, 1973; Bachman et al., 1973; Merewether et al., 1973; Hite and Lohman, 1973; Bachman, 1973). At the time, several states offered to host the TRU waste in other abandoned mines (Perge, 1982). New Mexico citizens, with the tacit approval of Governor Bruce King, invited the AEC to consider the salt beds of southeastern New Mexico. Based on previous experience with the Gnome project, ORNL and the USGS were able to recommend to the AEC the extensive salt beds of the Delaware Basin (Barnes, 1974).

The experience at Lyons provided two important site-selection criteria: (1) an absence of boreholes or solution mining near the repository, which meant ensuring minimal conflicts with other mineral resources by means of a buffer zone of one mile (ORNL originally used two miles) from existing deep wells, five miles from existing potash mines, and avoidance of known hydrocarbons and potash reserves, and (2) the presence of advantageous political characteristics such as public and government support in the area, low population density, and few or no land use conflicts. These two criteria were added to other criteria such as presence of high quality salt at a depth between 300 and $800 \mathrm{~m}$ to avoid potential problems with erosion, dissolution, or rapid salt creep.

\subsubsection{Segregation of TRU Waste}

In 1968, the Government Accounting Office (GAO) evaluated waste management practices within the AEC (Perge, 1982). Like the 1966 NAS Committee, the GAO criticized the documentation and organizational aspects of the AEC's disposal practices, especially for high-level waste. In response, the AEC formed a management task force that eventually recommended that liquid highlevel waste be solidified and that low level waste, and what was then called plutonium-contaminated waste (now TRU waste), be studied further. The AEC promulgated regulations (10 CFR 50) that directed that highlevel waste be solidified within five years, stored retriev- ably at all DOE facilities, and delivered to a federal repository within 10 years (AEC, 1970).

Several events created a situation in which it became important to define TRU waste. First, after planes carrying nuclear weapons had crashed in Spain in 1966 and Greenland, concerns were raised about how much contaminated soil and ice should be returned to the United States. Second, the International Atomic Energy Agency (IAEA) formed an advisory committee to develop categories of radioactive waste, one of which was "Alpha contaminated waste." Finally, the 1969 fire at the Rocky Flats Plant near Denver, Colorado, increased concern about this waste. Then the AEC's decision to accelerate the Lyons, Kansas, repository specifically for this waste became an impetus for defining this waste category.

The AEC defined TRU waste using a bounding definition: any contaminated material with an activity density of greater than $10 \mathrm{nCi} / \mathrm{g}$ (which is about the activity density of ${ }^{226} \mathrm{Ra}$ in the earth's crust). The AEC's definition of TRU waste purposely used mass as its basis to avoid the issue of dilution, in contrast to the volume basis used by the IAEA (Perge, 1982). Also, in March 1970, the AEC directed that TRU waste be stored so that it could be retrieved, rather than disposed of in trenches with low-level waste (Hollingsworth, 1970). Thereafter, it was stored on the surface in Idaho and elsewhere.

\subsection{Preparation of Environmental Impact Statement}

The National Environmental Policy Act of 1969 (NEPA, Public Law 91-190), signed in January 1970 by President Nixon, and its implementing regulations 40 CFR 1500-1508 required federal agencies to consider the environmental consequences of any major action through an EIS (environmental impact statement). NEPA was the first environmental statute applied to the WIPP.

Although NEPA required that federal agencies prepare an EIS, it did not provide specifics regarding content nor did it list criteria for making decisions on the acceptability of a project. Hence, during the 1970s, the courts, the executive branch, and federal agencies wrestled with the proper scope and extent of an EIS. For example, in response to NEPA, the AEC prepared an EIS on the Calvert Cliffs reactor that discussed only direct environmental impacts, but was quickly sued by citizen groups opposed to its construction (the Calvert Cliffs Coordinating Committee) because they, among other objections, considered its focus too narrow. The 


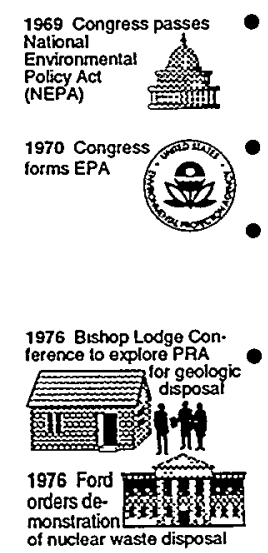

1969 - National Environmental Policy Act (NEPA) ${ }^{B 1}$ : - requires federal agencies to consider environmental consequences of any major action through environmental impact statement (EIS)

- first environmental law to be applied to the WIPP

1970 - Congress forms Environmental Protection Agency (EPA) and transfers to it research, monitonng, standard setting, and enforcement activities. ${ }^{82} \mathrm{B3}$ 1974 - AEC promises Idaho that wastes will be shipped
out of Idaho in the 1980's. Oct: Energy Reorganizasion (NRC) and Energy Research and Development Agency (ERDA) effective January 1975.

1976 - ERDA funds conference on modeling of geologic disposal systems to bring engineers and geologists together to explore predicting geological features, events. and processes (FEPS). orders expansion of ERDA program to demonstrate develop applicable standards. ${ }^{\text {B6. }}{ }^{87}$ Resource, Conservation and Recovery Act (RCRA) seeks to reduce hazardous waste generaton. Dec: EPA announces

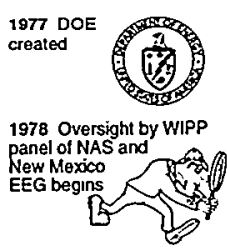

- 1977 - Oct: DOE Organization Act ${ }^{\text {B10 }}$ creates Department of Energy (DOE) from ERDA. Feb: EPA conducts 1st pubtic workshop to understand public concems and technical issues of waste disposal. ${ }^{\mathrm{B} 6}$, ${ }_{11}$

- 1978 - DOE Deputy Sec. Jerry O'Leary promises NM Congressional delegation "if NM did not wish to have the WIPP, then it could veto the plan." DOE Gener Counsels state O'Leary powerless to grant "state veto." $\mathrm{B12}$ Jan: EPA announces public fonm to develop protection cntena for radioactive wastes. Bt" Jun: In response to DOE request to review scientfic aspects of WIPP Project, WIPP Panel of BRWM of NAS holds first meeting. ${ }^{B 13}$ Nov: EPA publishes "Cnteria for Radiog tive Wastes" as guidance for federal agencies and seeks cormments. lish Environmental Evalualion Group (EEG) an independent state assessment of WIPP.

1979 Congress
defunes mission 1979- Dec: Congress defines mission ${ }^{815}$ of WIPP: defunes mission
of WIPP

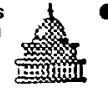
- sets up WIPP as a research and developmen lacility for disposal of only DOE TRU was - exempts WIPP from NRC licensing - requires DOE to sign a "Consullation \& Cooperation" (C\&C) Agreement with NM.

- 1980 - NM and DOE begin negotlations on C\&C Agreement to define procedures and process of cooperation

1981 Stiputated agreement between DOE ment between DoE signed

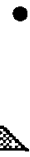

1981 - Jan: DOE decides to proceed with Site and Preliminary Design Validation (SPDV). In response: - Mar: Citizens for Altematives 10 Radioactive Dumping (CARD) asks for preliminary injunction. ${ }^{816} 817$ ing (CARD) asks for prelımınary injunction. (DOI) alleging violations of federal and state laws. ${ }^{117}$ (DOI) alleging violations of tederal and state laws. - Jul: Southwest Research \& Information Center (SWRIC) files lawsuit ${ }^{817}$ merous interrogatories to which DOE must respond. merous interrogatories to which DOE must respond
In response to lawsuits, 817 DOE Sec. Edwards visits NM to talk to Gov. King and accedes in a "Stipulated NM to talk to Gov. King and accedes in a "Stipulated Agreement (SA)" for (1) geotechnical experiments, (2) SNL report on 17 technical issues, (3) state \& public review of WiPP changes, and (4) creation of a state federal task force to oversee transportation issues (e. emergency response and highway upgrades). CaC Agreement attached as Appendix A: "Working Agreement" as Appendix B. ${ }^{817}$ U.S. Dist. Judge Burciaga stays lawsuits. Mar: Developing generic disposal developing standards for each waste type. ${ }^{810}$

- 1982 - EPA publishes working draft 20 as proposed 40 CFR 191. ${ }^{\text {200 }}$ Dec: Supplemental SA signed committing DOE (1) to seek funds for upgrading high ways in NM, (2) to more geotechnical studies, and (3) liablity for WIPP-related accidents. 82

- 1983 - In response to questions by EEG. DOE concludes draft 40 CFR 191 applies to disposal phase but not test phase of WIPP. May: Oak Ridge complex admits releasing $2 \times 10^{6} \mathrm{Ib}$ of $\mathrm{Hg}$ from $\mathrm{Y}-12$ plant between 1950 and 1977. Revelation prompts Natural Iween 1950 and 1977 . Revelation prompls Nalural resources Defense Councl (NRDC) and Legal Envi-

- 1984 - Feb: EPA Scientufic Advisory Board (SAB) endorses probabilistic approach of 40 CFR 191 but states criteria too restrictive and recommends changes. sates criteria too restrictive and recommends changes. requirements though $A E A$ exempted $O O E$ from human requirements
health laws.
- 1984 - (con't) Nov: Hazardous \& Solid Waste Amendments (HSWA) ${ }^{B 24}$ to RCRA ban land disposal of hazardous waste whthout treatment unless disposal site and generator demonstrate "no migration" of constit ents for as long as waste remains hazardous. Ist modfication to $\mathrm{C} \& \mathrm{C}$ Agreement limiting
(RH) TRU waste amount to $5.1 \times 10^{6} \mathrm{Ci}$. promulgates 0 . promulgates 2 mandated in NWPA. Ses: EPA promulgates CFR 191 for disposal of SNF. HLW, and TRU ${ }^{\text {Be. }}$ - probabilistic cntena indirectly based on population health nsk - requires inciusion of all uncertainty Nov: DOE attempts to define "by-product matenal" to include mixed waste and thus exclude EPA regulation.

1986 EPA states mixed 1986 - EPA states that mixed waste (radioactive waste waste subject with hazardous waste) is subject to RCRA regula. to RCRA

(polentially $60 \%$ of 2 water and individual protection standards in 40 CFR 191.

1987 - May: DOE defines "by-product malerial" to exclude everything except radionuclides, and thereby TRU waste is subject to RCRA. ${ }^{\text {B27 }}$ Jul: In response to NRDC lawsult, Court of Appeals for 1st Crrcult in Boston vacates and remands all of 40 CFR 191. 025 Aug: 2nd moditication to CaC Agreement commits DOE to comply with all applicable laws; to use 40 CFR 191 as
1st issued for evaluating WIPP compliance untul reissued by EPA; and apply NRC and Department o Transportation (DOT) regulations to TRU transport. Sep: Court reinstates Subpart A of 40 CFR 191 in response to EPA request.

- 1988 - Oct: 10 Gov. Andnus bans shipments of radioactive waste into state because WIPP not open. With continued technical problems (e.g.. TRUPACT-II not yet licensed), NM Congressional delegation cannot get consensus among themselves and WIPP Land With drawal Act dies. Congressman Richardson insisted upon full compliance of WIPP with 40 CFR 191 before receipt of any waste and funding for roads attached to bill). Dec: ID Gov. Andrus, CO Gov. Romer, and NM Gov. Camuthers meet in Salt Lake City to discuss WIPP and options to avert shutdown of Rocky Flats Plant from lack of storage imposed by $\mathrm{CO}$, and inability to ship to ID; DOE agrees to pursue both administrative and legislative land withdrawal for WIPP. Bzo

- 1989 - Westinghouse completes "no-migration" pettion for RCRA variance for WIPP pilot phase. ${ }^{B 30}$

- 1990 - EPA issues no migratıon variance for test phase. 831

- 1991 - Weslinghouse completes Parts A \& B of RCRA permit application to state. ${ }^{\mathrm{B} 2} \mathrm{E33}$

1992 Congress 1992 -Oct: WIPP Land Withdrawal ACt (LWA ${ }^{\text {B34: }}$

passes Land -transfers land from DOI to DOE

- establishes EPA as regulator for WIPP

- requires recertifying site every 5 y

- reinstates Subpart B of 40 CFR 191 except disputed individual and groundwater requirements - requires DOE cooperation with EEG - New Mexico given $\$ 600$ million over 30 years

1993 EPA 1993 - Dec: In response to court remand and WIPP repromulgates 9 LWA, EPA repromulgates 40 CFR 191 - no influential changes for WIPP.

1995 - Jan: EPA proposes compliance criteria for WIPP in 40 CFR 194 BSE

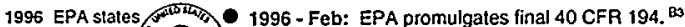
how to imple- 20 -requires analysis and peer review of waste ment radioactive sW charactenzation, engineered barrier evaluation waste standard and conceptual models - requires a monitonng system - speafies requirements on quality assurance (QA), peer review, and expent judgment Sep: Congress amends WIPP LWA and relieves WIPP of need to comply with land disposal restinctions of RCRA, but other requirements of RCRA still apply. ${ }^{830}$

- 1997 - Oct: EPA issues draft rule to approve WIPP with conditions: requires use of panel seals used in PA; design requires $Q A$ for waste generators; lists requirements for using process knowledge to characterize ments for using process knowledge to characienze trols; denies any protective credit for passive controls: and 120 -day public comment period begins. ${ }^{335}$

TRI-6342-5837-2

Figure 2-2. Performance goals were added or changed several times over the 25-yr history of the WIPP Project. 
Appeals Court for the District of Columbia agreed, stating that all impacts-environmental, economic, and cultural-should be included in the EIS (CCCC, 1971). However, the level of detail required was still not clear. Consequently, preparing the first EIS for the WIPP was particularly difficult and was delayed several times as the nation's notion of such a document changed from an initial expectation of a relatively short, 10-page report to an extensive document of several thousand pages.

For the WIPP, three EISs were prepared: one in 1979-80 during deliberations on whether to proceed with the construction phase (DOE, 1979; 1980a), a supplement in 1989-90 to decide whether to proceed with a pilot phase (DOE, 1989b; 1990c), and a supplement in 1996-97 (DOE, 1996b; 1997) to decide whether to proceed with the disposal phase (Figure 2-2).

\subsection{Establishment of Regulatory Risk Goals}

\subsubsection{Historical Events}

In 1976, President Gerald Ford requested that the EPA accelerate development of applicable standards for proposed waste repositories (EPA, 1985a; Ford, 1976). In response, the EPA conducted several public meetings to develop societal consensus on regulatory criteria (EPA, 1978a, 1978b). In 1978, the EPA proposed generic criteria on all radioactive waste, but after receiving an unfavorable response, it withdrew the proposed regulations in March 1981 (EPA, 1985b) and began to develop standards for individual categories of radioactive waste.

In 1982, in response to a requirement in the Nuclear Waste Policy Act (NWPA) of 1982 (Public Law 97-425), the EPA officially published a draft of the disposal regulation for high-level nuclear waste, $40 \mathrm{CFR}$ 191 (EPA, 1982), which had seen more than 20 revisions. One year later, the DOE stated in letters to the Environmental Evaluation Group (EEG), an oversight group for the WIPP established by the DOE in 1978, that the WIPP would comply with the requirements in 40 CFR 191 once the facility moved from a test phase to an operational phase but did not consider them applicable in the test phase; the latter interpretation contributed to a growing opposition against the test phase of the project. The EPA did not promulgate the final version of
40 CFR 191 until 1985, three years after submitting the proposed regulation and then only after drawing a lawsuit to hasten promulgation (EPA, 1985a). The 1985 Standard established criteria for the disposal system as a whole, and defined the term "performance assessment" (PA) as the type of calculations to be used to show compliance with this regulation. ${ }^{3}$

The 1985 final version of 40 CFR 191 involved some changes from the 1982 draft that included Individual and Groundwater Protection Requirements. These requirements led to a lawsuit by the same group, the Natural Resources Defense Council (NRDC), that had sued earlier to accelerate promulgation. The courts remanded the regulation shortly thereafter (NRDC vs. EPA et al., 1987), but the EPA repromulgated the Standard in 1993 without changes to the Containment Requirements (EPA, 1993b). These Containment Requirements strongly influenced the type of calculations necessary for the performance assessment.

In 1992, Congress defined the process by which WIPP compliance would be evaluated, transferred ownership of the WIPP site to the DOE, and designated the EPA as the regulator of the WIPP. The law officially marked the transition from the construction and system characterization phase to the compliance and testing phases, although the latter phases had already begun, informally, when the EPA issued 40 CFR 191 in 1985 and when Sandia first demonstrated the performance assessment process using the EPA standard in 1989 (Marietta et al., 1989; Bertram-Howery et al., 1989). In 1996, the EPA promulgated 40 CFR 194 (EPA, 1996a), a regulation to implement its 40 CFR 191 standard specifically for the WIPP, which imposed several new requirements and interpretations on modeling style. Basically, however, 40 CFR 194 adopted a process and methodology very similar to that used by Sandia for conducting performance assessments of the WIPP between 1989 and 1992 (Helton, 1993a; 1994; Helton et al., 1993a; 1997c).

Besides complying with 40 CFR 191, waste intended for the WIPP also came under a legal ruling in 1984 (LEAF v. Hodel, 1984) and subsequent changes in the EPA's and DOE's definitions of mixed waste (in 1986 and 1987 [EPA, 1986; DOE, 1987]), causing as much as $60 \%$ of the waste destined for the WIPP to be designated as chemically hazardous. Thus, the WIPP had to comply with a set of regulations for hazardous waste (40 CFR 260-270 and analogous New Mexico

3 During this period, the term performance assessment (PA) was adopted internationally to describe a general process of evaluating whether a geologic disposal system performed adequately and complied with regulatory criteria. Because the topic of this report is assessing compliance of WIPP with the EPA regulation, performance assessment, herein, refers to the specific EPA process. 
regulations) promulgated in response to the Resource, Conservation, and Recovery Act (RCRA) (Public Law 98-616) and its major 1984 amendment (Public Law 94-580). In anticipation of the pilot phase for the WIPP, the DOE completed a No Migration Petition for a variance to RCRA regulations (DOE, 1989a), which the EPA granted for the test phase in 1990. In 1996, Congress eliminated the need for the WIPP to seek a no-migration variance from RCRA requirements for the disposal phase (Public Law 104-201), since the petition would have required calculations similar to those already provided for compliance with 40 CFR 191. However, other RCRA requirements as implemented in 40 CFR 260-270 still applied, such as specifying the types and amounts of waste in permits.

\subsubsection{Containment Requirements of 40 CFR 191}

Although dose calculations to humans were still of interest to the WIPP Panel of NAS and were used in supplemental EIS reports for the WIPP in 1989 (DOE, $1989 b ; 1989 c ; 1990 \mathrm{c}$ ) and 1996 (DOE, 1996b; 1997), 40 CFR 191 required the evaluation of the cumulative release of radioisotopes $(R)$ to the accessible environment. Furthermore, the definition of performance assessment stated that "these estimates [of releases] shall be incorporated into an overall probability distribution of cumulative release to the extent practicable." That is, uncertainty was treated quantitatively, which in turn indirectly required a stochastic model for the geologic disposal system. To elaborate, if $R(\bullet)$ is a function of parameters $\mathrm{x}=\left\{x_{1}, x_{2}, \ldots x_{n P}\right\}$, where $n P$ is the total number of model parameters, and parameters $\mathbf{x}$ are uncertain or imprecisely known (i.e., the parameters cannot be assigned a single, universally accepted value, and thus are described by a probability model by means of a distribution with a range of values), then the consequences $R(\mathbf{x})$ will also have a range and distribution (Figure 2-3). Uncertainty analysis involves determining the shape of the distribution $R(\mathbf{x})$.

The risk measure for a performance assignment was not the expected value of the results, as in simple insurance calculations, nor the variance of the results, as in financial risk analysis of stock portfolios (Markowitz, 1952). Rather the entire distribution of the results was used. Hence, in the United States, performance assessment became a stochastic simulation of possible longterm behaviors of a real system by means of a computerimplemented mathematical model. In this respect, performance assessment remained similar to probabilistic risk assessments (PRAs) for nuclear reactors.
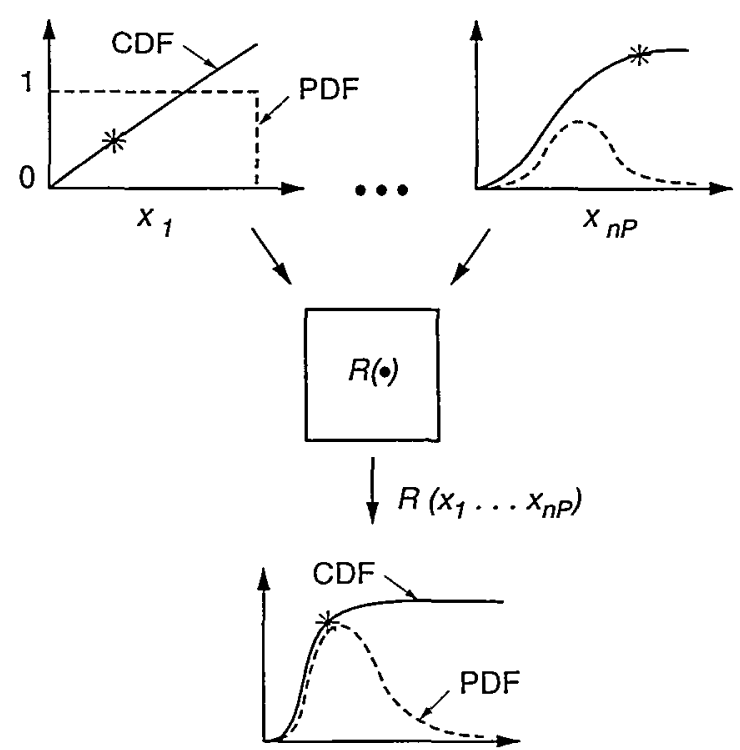

OR

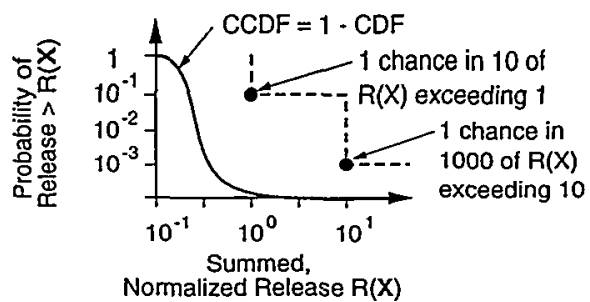

TR1-6342-5892-2

Figure 2-3. Uncertainty in model parameters $p$ (expressed as a probability density function $[P D F]$, or cumulative distribution function $[C D F])$ results in uncertainty in the results. This uncertainty (expressed as a complementary distribution function $C C D F$ or 1-CDF) is compared to the probabilistic limits in 40 CFR 191.

The Containment Requirements of 40 CFR 191 established a 10,000-year regulatory period, during which system performance (such as actinide radioisotope transport in groundwater) had to be modeled. In 40 CFR 191, the Containment Requirements specified (a) limits $\left(L_{i}\right)$ on the total activity (curies) that could be released from the disposal system for individual radioisotopes or (b) the chance that these limits could be exceeded (i.e., have less than 1 chance in 10 of exceeding $L_{i}$ or less than 1 chance in 1000 of exceeding $10 L_{i}$ ) (Figure 2-3). For a mix of radioisotopes, the release $(R)$ for each radioisotope $(i)$ was normalized with respect to its radioisotope limit $\left(L_{i}\right)$. 


$$
\begin{aligned}
R & =\frac{1}{f_{w}}\left(\frac{Q_{1}}{L_{1}}+\frac{Q_{2}}{L_{2}}+\ldots \frac{Q_{n R}}{L_{n R}}\right) \\
& \left.=\frac{1}{f_{w}} \sum_{i=1}^{n R}\left(\frac{Q_{i}}{L_{i}}\right) \leq 1 \text { (or } 10\right)
\end{aligned}
$$

where

$f_{w}=$ waste unit factor, various factors are defined (e.g., for transuranic waste $f_{w}=\sum A / 10^{6} \mathrm{Ci}$ where $\mathrm{A}$ is activity $(\mathrm{Ci})$ of alpha-emitting transuranic radioisotopes in the repository with half-lives greater than $20 \mathrm{yr}$ )

$L_{i}=$ The release limit specified by the EPA for radioisotope $i$ in 40 CFR 191

$n R=$ number of radioisotopes contributing to release to the accessible boundary

$R=$ total normalized release ("EPA sum")

$Q_{i}=$ cumulative release of radioisotope $i$ to accessible boundary

$$
=\int_{0}^{10,000 y r} q_{i} d t
$$

The Containment Requirements specified the radioisotope limits $\left(L_{i}\right)$; in other words, as customary, the regulatory agency had performed the dose-response assessment. ${ }^{4}$ Because the Containment Requirements used cumulative releases of radioisotopes $\left(Q_{i}\right)$, the EPA dose-response assessment, through crude calculations, converted from dose, which depends upon rate of release (rather than cumulative release), to obtain the EPA limits $\left(L_{i}\right)$ (EPA, 1985b).

Bear in mind, however, that the calculations were intended to be illustrative rather than truly predictive. The EPA standards are an examination of the characteristics of geologic disposal system under a specified set of hypothetical circumstances (e.g., intrusion into the repository in the future, such as year 2500 , by a drilling crew exploring for hydrocarbons with 500-yr-old technology). These circumstances are not the actual future expected by the EPA any more than the exam problem by a professor is the exact problem a student will encounter in his or her future. But the calculations in a performance assessment for a geologic repository were designed to demonstrate whether the disposal system had sufficient desirable characteristics given a normal evolution over geologic time to mitigate the release of radioisotopes.

4 This dose-response assessment depended on bounding type dose evaluations that sought to limit deaths to no more than would have occurred from an unmined uranium ore body, i.e., less than 1000 deaths over 10,000 yr. Thus, a performance assessment is not entirely probabilistic. 


\subsection{Site Characterization}

To model a system, it is necessary first to define the system, regardless of whether the model's purpose is to gain insight or anticipate future behavior. System definition essentially describes the parameter space $\boldsymbol{X}$ and the relationship of those parameters through a model. The model may be only conceptual, but for the WIPP Project it was a mathematical model. In a mechanical system, the various parts of a system are defined. With a radioactive waste disposal system, however, the existing geologic parts must be characterized. Characterization of the subsystems of the WIPP was undertaken as soon as the site was selected, even before safety goals and a compliance process for waste disposal were established.

Before the late 1980s, site characterization activities were undertaken (1) to satisfy needs for the draft EIS in 1979 (DOE, 1979) and Supplemental EISs in 1989 (DOE, 1989c, 1990c), (2) to satisfy negotiated agreements with the State of New Mexico (State of NM, 1981; Documents, 1982), and (3) to develop a general understanding of natural phenomena significant to nuclear waste disposal. These site characterization studies investigated dissolution areas, breccia pipes, salt permeability, and radioisotope sorption.

\subsection{Selection of Site}

With the encouragement of Carlsbad's politicians and citizens, and the tacit approval of New Mexico's governor Bruce King, Oak Ridge National Laboratory (ORNL) examined for the AEC a portion of the Permian Basin called the Delaware Basin in southeastern New Mexico in the early 1970 s for a suitable disposal site for nuclear waste. The citizens of Carlsbad were open to the idea of building a repository, because of the declining potash mining industry. During the 1960s, sylvite and langeinite had been extensively extracted from nearby potash mines for use in fertilizer production, but many had since closed because of foreign competition. The area was semiarid with little potable water and no significant, highly permeable aquifers near the surface. At that time, the area was being considered for disposal of both high-level waste and TRU waste generated during production of nuclear weapons. A potential site near the edge of the basin along the Capitan Reef was identified in 1973 (Figure 3-1).

ORNL drilled two wells, AEC-7 and AEC-8, in March 1974 near the northeastern and southwestern corners of the rectangular site for the first large-scale field test in the basin (Powers et al., eds., 1978). (Prior to this test, the USGS had conducted some tests for the AEC in 1961 for the Gnome Project and so some data on aquifers was already available [Gard, 1968; Cooper and Glanzman, 1971].) The cores from the two wells indicated fairly predictable stratigraphy. However, the work by ORNL was suspended two months later for several reasons. First, the AEC wished to emphasize the Retrievable Surface Storage Facility as its primary option. Also, because of the oil embargo, AEC Chairman Dixie Lee Ray would not withdraw the land around the site from oil exploration. Finally, Congress was considering a major reorganization of the AEC; legislation signed in October 1974 split the AEC into the Energy Research and Development Administration (ERDA) and the Nuclear Regulatory Commission (NRC), effective January 1975.

One of New Mexico's ERDA laboratories, Sandia National Laboratories, began work at the site selected by ORNL in January 1975. In late March of that year, Sandia received funding and officially became the lead laboratory to characterize the site (Powers et al., eds., 1978), develop the conceptual design (Sandia, 1977), initiate scientific studies on nuclear waste disposal in bedded salt, and draft an EIS (DOE, 1979), accompanied with instructions not to study "things to death" (Armstrong, 1975). In May 1975, Sandia drilled a combination geologic and exploratory well, ERDA-6, at the northwestern corner of the proposed site (Sandia and USGS, 1983). The well encountered up to $75^{\circ}$ dipping beds near the planned lower level of the repository and, at a depth of $826 \mathrm{~m}$, artesian brine and $\mathrm{H}_{2} \mathrm{~S}$ gas, causing genuine dismay on the part of ERDA staff who, as former AEC officials, had earlier struggled with difficulties at the Lyons, Kansas, site.

But the large Delaware Basin had other areas that met the various selection criteria, that is, a distance of at least a mile from boreholes, high purity salt at depths between 300 and $800 \mathrm{~m}$, a lack of dissolution at the top of the Salado Formation, an avoidance of known oil and gas trends, and a minimal amount of state land, private land, and potash zones (Powers et al., eds., 1978). In late 1975, after examining the stratigraphy shown in the ERDA wells, along with confidential stratigraphic and geophysical seismic data from numerous private wells owned by oil companies, Sandia recommended locating the potential repository site nearer the basin center. The USGS independently suggested a similar location. The new site was about $11 \mathrm{~km}$ southeast of the first location with more predictable horizontal stratigraphy, i.e., away 


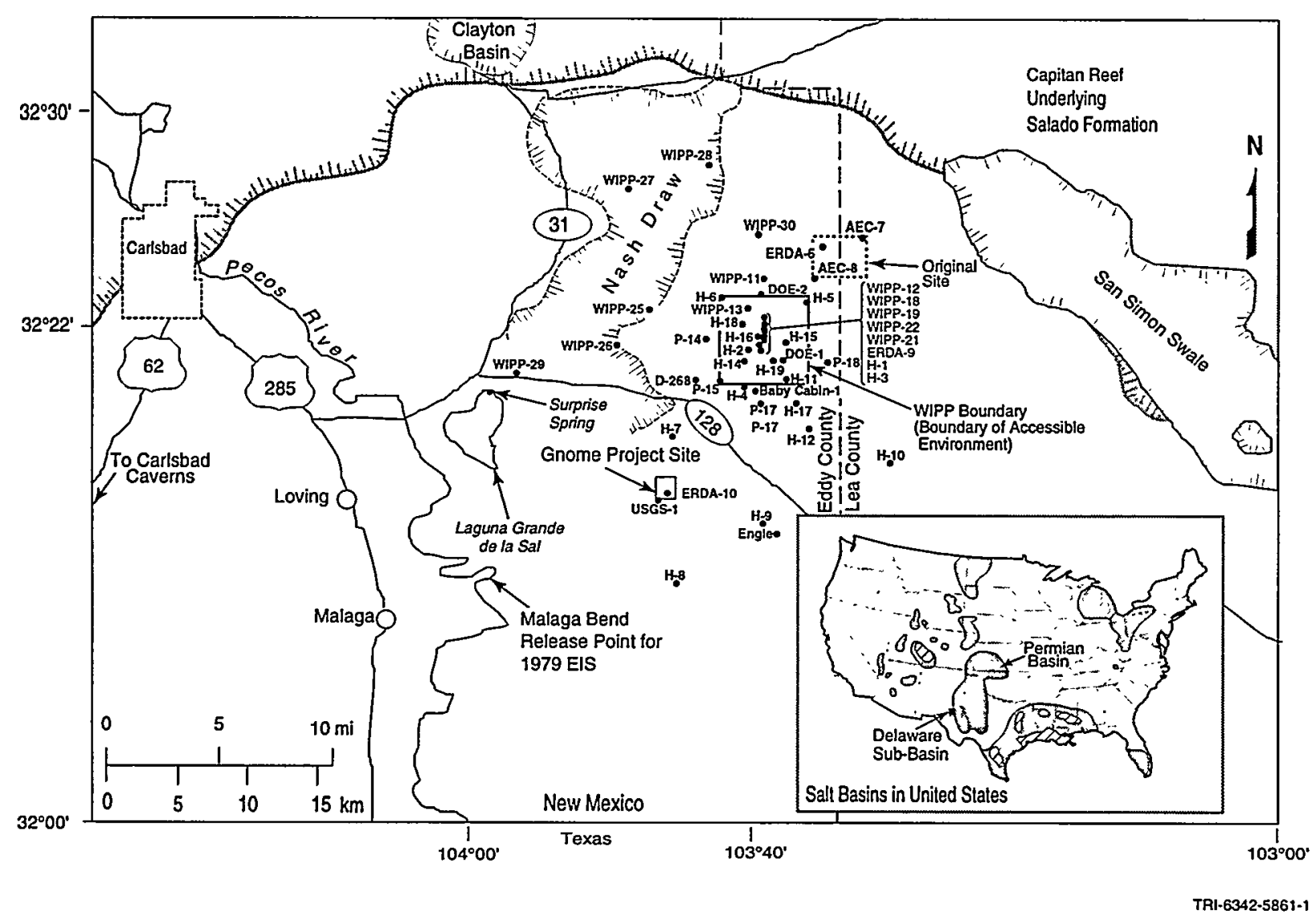

Figure 3-1. Physical setting of the WIPP in Delaware Basin (after Rechard, 1995, Figure 2.1-1).

from the $\sim 10-\mathrm{km}$ band around the Capitan Reef where deformation of the salt beds had occurred (Powers et al., eds., 1978). In April 1976, Sandia drilled ERDA-9 through the Salado Formation into the Castile Formation (hereafter shortened to Salado and Castile) at the center of the proposed site, which was $42 \mathrm{~km}$ from the town of Carlsbad, New Mexico. The stratigraphy was horizontal and no brine was encountered. This site became the Waste Isolation Pilot Plant (WIPP), which had been officially named four months earlier (NAS/NRC, 1984) (Figure 3-1).

\subsection{Site Characterization Studies for EIS}

The EIS process, as required by NEPA (Public Law 91-190), exerted its influence on the characterization process during the 1970s as the AEC (then the ERDA, in 1975 , and ultimately the DOE) continued investigations on bedded salt in New Mexico. Because of ERDA's eagerness, the deadline for the EIS draft was originally
October 1976, but a more immediate need was for Sandia to spend its resources locating a new site. Also, the nature of the EIS changed nearly as often as the official mission of the WIPP (as discussed in Section 4) and ultimately contributed to a 3-year delay in publishing the EIS. During this time Sandia collected data on the ecological, meteorological, and archaeological features of the region and its socioeconomic facets (Weart, 1979). Sandia's major description of the geology and hydrology (Powers et al., eds., 1978) drew upon information from Sandia's geologists (Griswold, 1977) and the USGS reports, which had been prepared when the USGS was searching for a regional site location (Pierce and Rich, 1962; Brokaw et al., 1972; Bachman et al., 1973; Jones et al., 1973; Bachman, 1973; Barnes, 1974).

During site selection, interest in fluid flow in waterbearing units of the area had focused on its effects on dissolution; after selection, interest shifted to the role of these units as potential pathways for radionuclide release. Also 75 new line miles of seismic reflection data and 9000 resistivity measurements were collected across the site (Powers et al., eds., 1978). In addition, 
47 boreholes were completed under the direction of the USGS: 12 boreholes for evaluating geologic stratigraphy and cores, e.g., the 2 AEC wells, the 2 ERDA wells, and new wells designated as WIPP-\#, such as WIPP-11; 21 boreholes for evaluating potash reserves, designated P1 through P21; and 14 boreholes for evaluating the permeability of various layers, usually the Rustler Formation, designated H\#, e.g., H1. Four potash boreholes, P14 through P18, were also converted to hydrologic boreholes (Mercer and Orr, 1979). In the 1980s, other wells were also used to observe water drawdown from large-scale pumping tests (Figure 3-2).

USGS geohydrologists had suggested that the Magenta and Culebra Members of the Rustler Formation (hereafter shortened to Magenta, Culebra, or Rustler) and the Rustler/Salado contact zone were potential pathways for radionuclide release. At the time, the relative importance of these units was unknown, so the first tests targeted all three. The Rustler/Salado contact was confirmed to be transmissive in Nash Draw but did not yield significant quantities of water at the site and thus did not represent a significant pathway for fluid movement for either radionuclide transport or dissolution. The Culebra was more transmissive than the Magenta, and the transmissivities of these units varied by several orders of magnitude (Powers et al., eds., 1978; Mercer and Orr, 1979).

Experimental activities included determining the mineralogy of the bedded salts and the overlying formations (Powers et al., eds., 1978). Also, the sorptive properties of the clays in the salt and overlying dolomitic rocks in the Rustler were evaluated (Serne et al., 1977; Dosch and Lynch, 1978; Dosch, 1979), and the geochemical composition of the waters in the Rustler was determined (Powers et al., eds., 1978). The stability of the salt was also examined by determining whether $\mathrm{Rb}-\mathrm{Sr}$ isotope ratios suggested any significant recystallization or brine flow through the formation since its deposition about 255 million years ago (Powers et al., eds., 1978; Weart, 1979) (Figure 3-3).

\subsection{Long-Term Site Characterization Studies}

\subsubsection{Site Characterization Studies at Repository Horizon}

Data needs for the EIS engendered several characterization studies. Although the results were not ready to be reported in the supporting documents for the EIS,

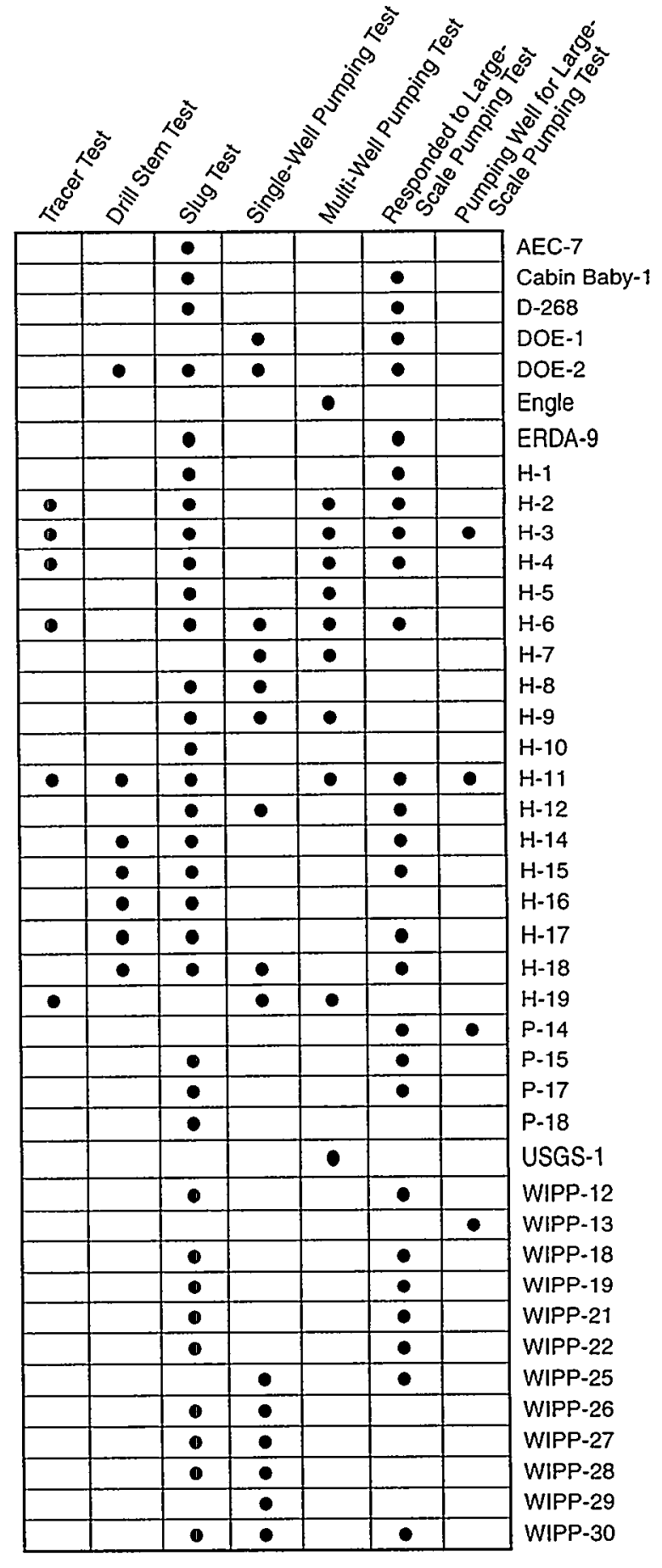

TRI-6342-5896-0

Figure 3-2. Well tests conducted to characterize transmissivities of the Culebra Dolomite Member of the Rustler Formation (WIPP PA Division, 1991/1992, Vol. 3, Figure 2.6-3; Hill et al., 1997). 


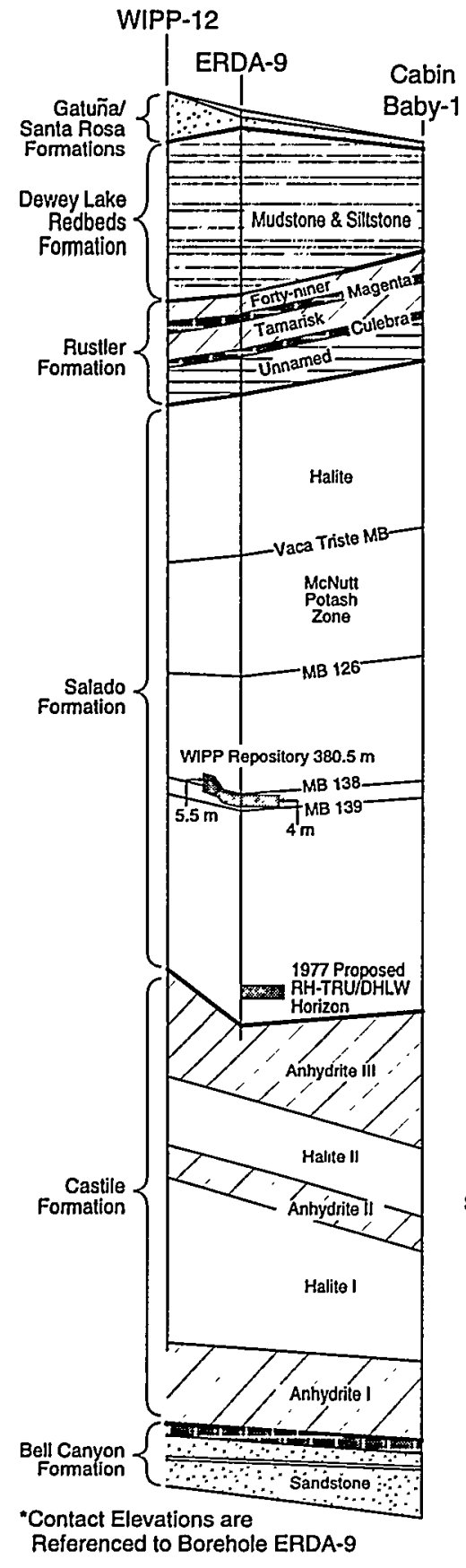

"Elevation (m)

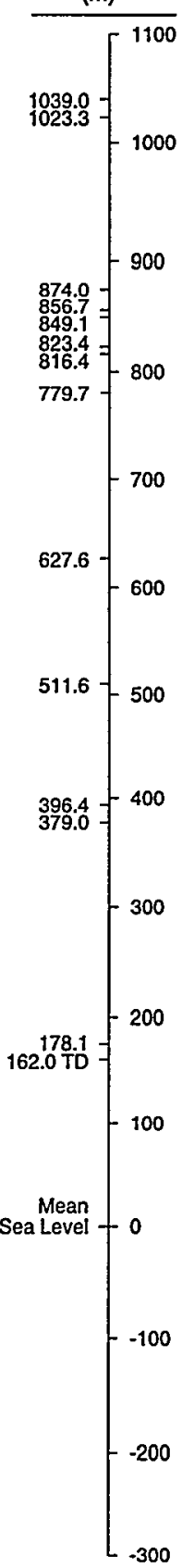

TRI-6342-4843-3

Figure 3-3. Stratigraphy above and below the WIPP repository (after Rechard, 1995, Figure 2.1-2) some data were available soon afterwards. For example, with regard to waste acceptance criteria, the potential magnitude of the pressure from gas generated by waste from microbial degradation of organic material was not known; thus in 1979 Sandia tested the AEC-7 well to determine the permeability of the Salado in order to ascertain the ability of the repository to contain gas (Christensen et al., 1980). The test, using compressed air flow measurements, indicated a formation permeability over a $30-\mathrm{m}$ test section between $5 \times 10^{-19}$ and $2 \times 10^{-17} \mathrm{~m}^{2}$ (permeability at an elevation of $427 \mathrm{~m}$ [depth of $690 \mathrm{~m}$ ] and at an elevation of $548 \mathrm{~m}$, respectively) (Tyler et al., 1988). ${ }^{1}$ The range of in situ permeability, in turn, suggested that if gas from microbial action (and anoxic corrosion) from brine migration to hot canisters were generated by TRU waste at less than $5 \mathrm{~mole} / \mathrm{drum} / \mathrm{yr}$, the gas would dissipate into the rock without reaching lithostatic pressure; thus the TRU waste would be acceptable in the WIPP repository without incineration. Accordingly, a fledgling program to characterize gas generation, begun in 1978, was canceled after 1979 (see also Section 4).

Sandia did not originally intend to use the experimental region of the WIPP repository to study the permeability of the Salado. TRU waste generates relatively little heat, and so migration of brine because of a thermal gradient was of little concern after 1979 when highlevel waste was excluded from the WIPP. Yet Sandia conducted three tests of fluid migration in a nearby potash mine in 1981 (Molecke and Torres, 1984) because of continued interest in high-level waste disposal in salt beds elsewhere and as part of the sealing and waste canister programs (see also Section 5).

Sandia first measured injected nitrogen flow around a WIPP drift in 1984 to determine the extent of the disturbed zone and corresponding permeability of the Salado. In 1986, Sandia conducted similar measurements using injected brine to evaluate the permeability of the intact salt. The predicted permeability ranged between $10^{-21}$ and $10^{-20} \mathrm{~m}^{2}$, a factor of about 1000 less than the previously measured range in AEC-7 of $5 \times 10^{-19}$ to $2 \times 10^{-17} \mathrm{~m}^{2}$. Several factors contributed to the early erroneous data, such as leakage around the packers through the disturbed rock zone, the short duration of the in situ tests, and the inability in laboratory experiments to measure permeabilities of less than $5 \times 10^{-20}$ $\mathrm{m}^{2}$ on the small ERDA-9 cores (Tyler et al., 1988) (Figure 3-4).

1 This range was higher than that encountered in laboratory tests using argon, nitrogen, and hydrogen gases which ranged between $1.5 \times 10^{-17}$ and an experimental limit of $5 \times 10^{-20} \mathrm{~m}^{2}$. 


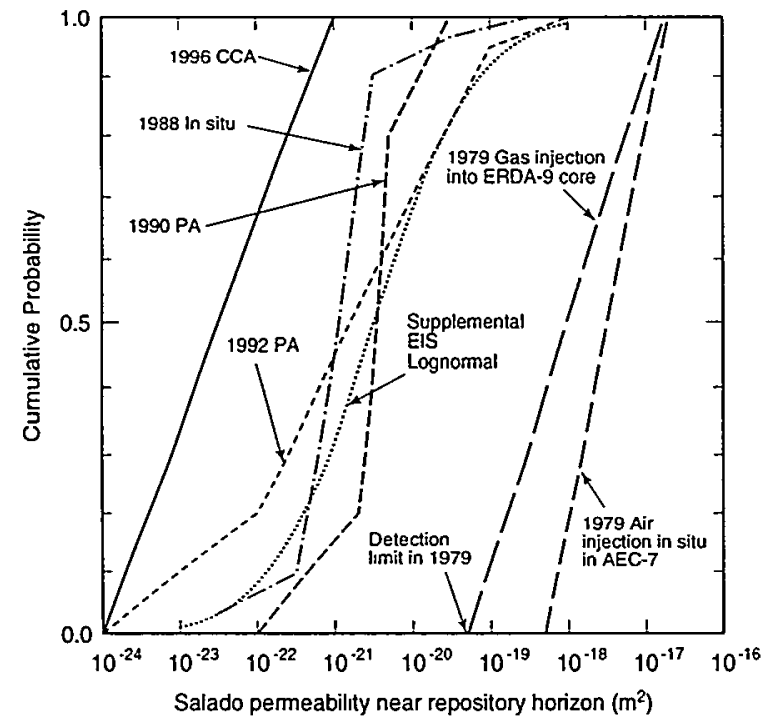

TRI.6342.5845.0

Figure 3-4. Estimated permeability of Salado Formation near repository horizon continued to decrease over the years.

In May 1987, Sandia reported that much more brine had migrated to the simulated high-level waste canisters than had been expected. Furthermore, a rough scoping calculation to evaluate repository performance identified inflow of intergranular Salado brine to the repository from a pressure gradient (rather than thermal gradient) as a concern for long-term performance if a human should inadvertently intrude into the repository with an exploratory well (Brush and Anderson, 1989). By December, the national press was reporting on the issue of brine flow into the repository (Begley and Miller, 1987). In January 1988, New Mexico's congressional delegation asked the full Board of Radioactive Waste Management (BRWM) of the NAS to study the brine inflow controversy.

However also in 1987, Sandia made a concerted effort to theoretically study thermoelastic behavior of the salt and found that the seemingly contradictory in situ measurements of lower permeability but higher brine flow to simulated high-level waste canisters could be explained. The new theoretical model predicted less than $43 \mathrm{~m}^{3}(<0.5 \%$ of the original volume of a disposal room) would enter over the first 100 yr (Nowak et al., 1988). Given the resolution of measurements and the small amount of brine, the BRWM concluded that not enough brine would seep into the rooms to form a slurry of radioactive waste before the rooms had closed through salt creep. The NAS also proposed a verification test in a circular tunnel designated as Room Q. On the other hand, the lower permeability of the Salado had implications for gas generation, as discussed below.

\subsubsection{Site Characterization Studies for Stipulated Agreement}

Long-term characterization studies beyond the EIS were motivated by two requirements. First, Sandia was assigned to develop a scientific understanding of natural phenomena as deemed prudent by its scientists and members of the WIPP Panel of NAS. Second, 17 geotechnical experiments were undertaken during the 1980 s to satisfy agreements with the State of New Mexico.

Although the political climate in New Mexico toward waste disposal was initially positive, the reevaluation of nuclear waste disposal by the Carter administration and the possibility of placement of commercial waste at the WIPP led the State of New Mexico to distrust DOE's intentions. To help with resolution of issues, the enabling legislation clearly stated the purpose of the WIPP and required a Consultation and Cooperation Agreement with the State of New Mexico. However, negotiations to reach such a cooperative agreement between New Mexico and the DOE were arduous. Thus, when DOE decided to proceed to preliminary design and construction in January 1981, the State of New Mexico sued along with several other parties. In response to the lawsuit, a Stipulated Agreement was negotiated between Governor King and Secretary of Energy Edwards in late summer of 1981, which included the Consultation and Cooperation Agreement. The new agreement defined the relationship of the WIPP Project with the State of New Mexico and itemized required geotechnical experiments based on state concerns from the final EIS (DOE, 1980a) (see Figure 2-2).

As part of the negotiated settlement with the State of New Mexico, the DOE deepened WIPP-12 into the Castile in November 1981 (Figure 3-5). The WIPP Project encountered a brine reservoir with pressure high enough that brine could flow to the surface. The discovery of the reservoir prompted the rotation of the waste panels from their planned location north of the experimental area to south of the shafts in 1982, thus moving the disposal region $\sim 1800 \mathrm{~m}$ to the south, the current configuration. This well was extensively tested through 1983 (Lappin et al., eds., 1989). Also, geophysical studies indicated that a brine reservoir could also extend to the south of WIPP-12. DOE-1 was drilled in 1982 to obtain geologic data and evaluate the brine reservoirs in the Castile. No brine was found, and the well was later used to test hydraulic conditions in the Culebra. Both 


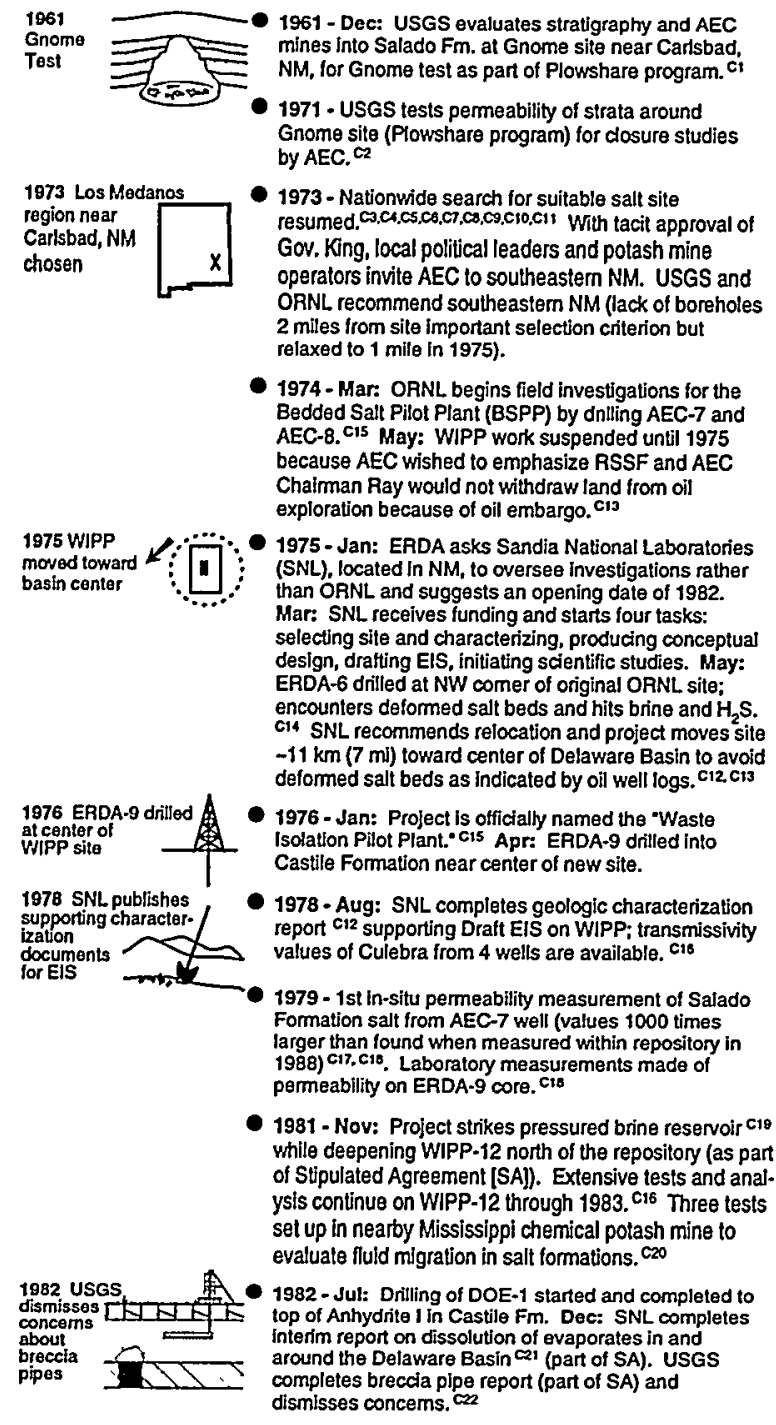

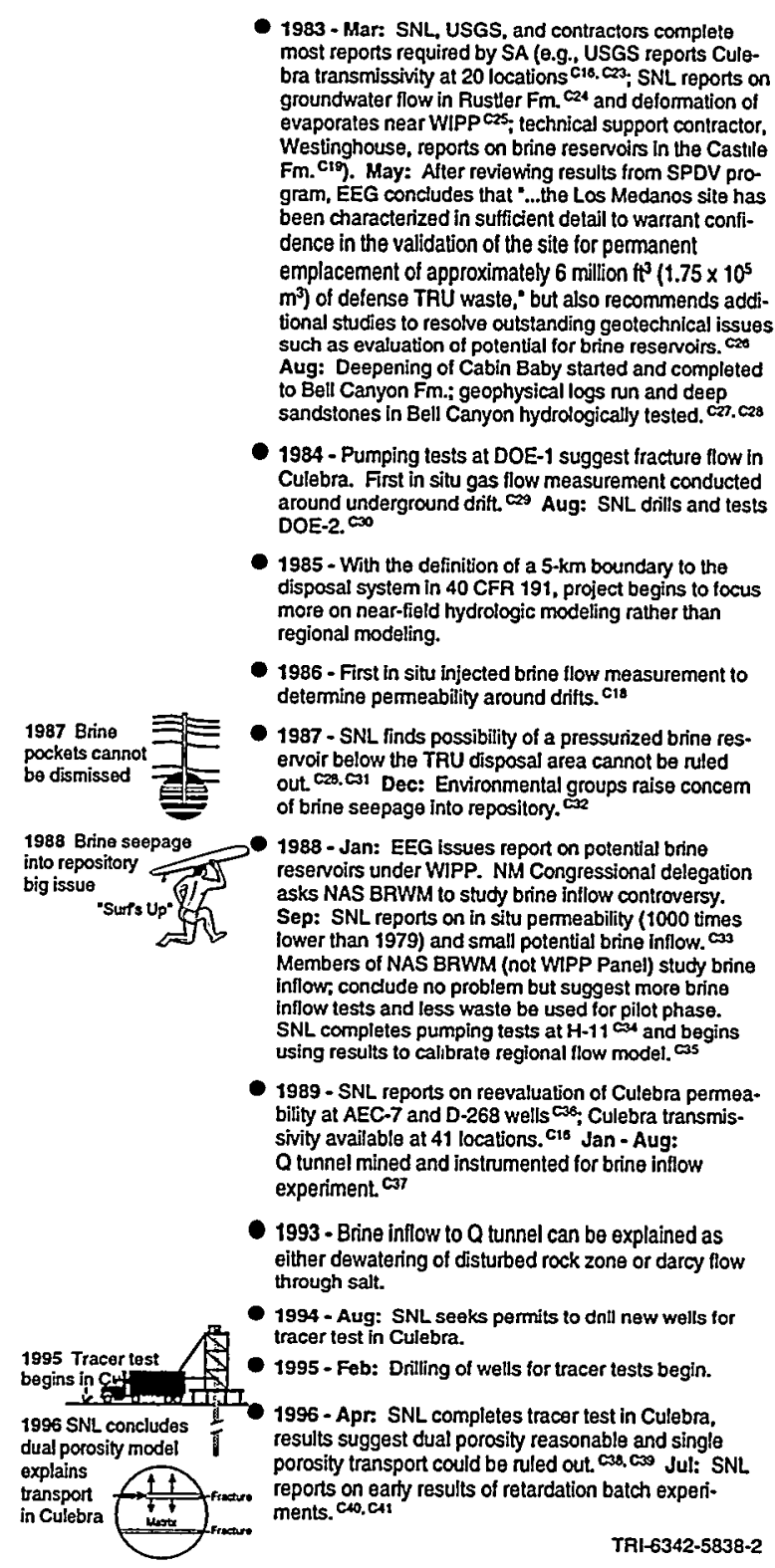

Figure 3-5. Site characterization studies at the WIPP.

the DOE and the EEG conducted consequence analyses of a drilling encounter with a brine reservoir similar to that found in WIPP-12, concluding that the health consequences were minor (Woolfolk, 1982; Channell, 1982). In addition, several new geophysical techniques were used to determine whether such brine reservoirs might exist under the waste panels, but by 1987 , these studies were inconclusive. A zone of lower resistivity in the Castile existed under a portion of the waste disposal area and could be interpreted as brine; however, the zone was beneath the upper anhydrite layer in the Castile where brine had been encountered earlier (Lappin, 1988; Earth Technology Corp., 1988; WIPP PA Division, 1991/1992, Vol. 3).
In the 1980s, hydrologic characterization focused on the Culebra. Mercer (1983) had provided additional information on the transmissivities of the Culebra as part of the Stipulated Agreement. In 1984, pumping tests at DOE-1 suggested fracture flow in the Culebra. By 1987, Sandia had estimated the Culebra transmissivity at 15 new locations and re-estimated the transmissivity of 7 wells (Mercer, 1983). By 1989, Sandia had estimated Culebra transmissivity at 41 locations in a $860-\mathrm{km}^{2}$ area around the WIPP site (Lappin et al., eds., 1989; Lappin, 1988) (see Figure 3-2). 


\subsection{Site Characterization Studies for CCA}

As summarized below, additional site characterization studies were conducted in the 1990s for PA calculations needed for the CCA (Compliance Certification Application) to the EPA.

\subsubsection{Fluid Flow in Culebra}

In the 1990s, tests were conducted to characterize the Culebra at two relatively high-permeability locations. These high-quality tests included the seven-well tracer test conducted at the newly drilled well, $\mathrm{H}-19$, multiwell retesting at $\mathrm{H}-11$, and single-well injection and withdrawal tests at both $\mathrm{H}-19$ and $\mathrm{H}-11$. The purpose of the tests was to evaluate the complex fracture flow (Meigs and McCord, 1996; Meigs et al., 1997).

In 1996, hydraulic tests and well logging at the H-19 hydropad suggested that the permeability of the upper portion of the Culebra was significantly lower than the permeability of the lower portion. In addition, the 1996 tracer tests at $\mathrm{H}-19$ suggested that the upper portion of the Culebra did not substantially contribute to solute transport. These findings confirmed two previous observations. In 1979, Mercer and Orr (1979) reported that based on ${ }^{131}$ I tracer tests at the $\mathrm{H}-3$ hydropad, $100 \%$ of the flow came from the lower $3 \mathrm{~m}$ of the Culebra. In a description of the Culebra in the Air Intake Shaft in 1990, Holt and Powers (1990) noted that most of the fluid observed came from the lower portion of the Culebra. Therefore, the hydrologic effective thickness of Culebra in the 1996 PA for the CCA was taken as $\sim 4 \mathrm{~m}$ (7 $\mathrm{m}$ less the $3 \mathrm{~m}$ for the upper portion of the Culebra) (Meigs and McCord, 1996) (Figure 3-6).

\subsubsection{Sorption Studies in Culebra}

Sandia conducted several laboratory studies of sorption in the 1980s (Dosch, 1979; 1980; 1981; Lynch and Dosch, 1980; Lynch et al., 1981; Tien et al., 1983). These empirical studies used a variety of sorbents (dolomitic, anhydritic, and clay-rich rocks) and solutions (Salado, Castile, and Culebra brines), and in some cases included the effects of dissolved organics on sorption.

Because the State of New Mexico felt the early sorption studies were deficient, the DOE and the State of New Mexico modified the Consultation and Cooperation Agreement in 1988 to require New Mexico concurrence on any sorption distribution coefficients $\left(\mathrm{K}_{d} \mathrm{~s}\right)$ recommended for use in the final performance assess-

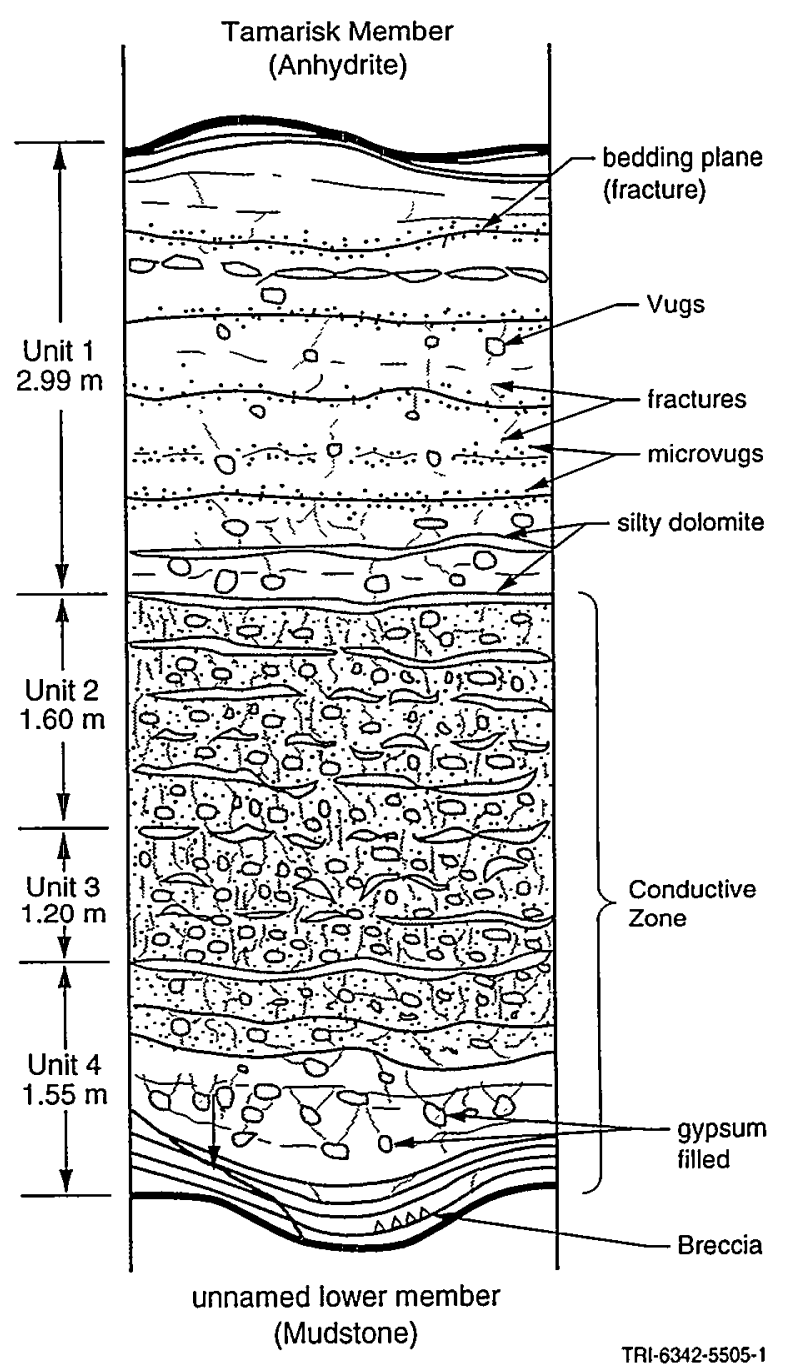

Figure 3-6. Stratigraphic subdivisions of Culebra Dolomite Member of Rustler Formation discerned after 1997 (after Holt, 1997, Figure 1-2).

ment of the WIPP. While experimental data were being obtained, Sandia convened a panel of staff members to estimate ranges and probability distributions of $\mathrm{K}_{\mathrm{d}} \mathrm{s}$ in support of two preliminary performance assessments (Trauth et al., 1992). In addition, an experimental program sought to develop a mechanistic surface-complexation model for the sorption of uranium by corrensite, a clay mineral found in the Culebra (Lappin et al., eds., 1989; Siegel et al., 1990; Park et al., 1995). However, by 1996 , the only model available was of the sorption of U(VI). Thus, retardation of radioisotopes in the Culebra was more thoroughly studied in the laboratory. Early results from a batch experimental program using crushed dolomite were used in the CCA (Brush and Storz, 1996; Papenguth and Behl, 1996) (Figure 3-7). 


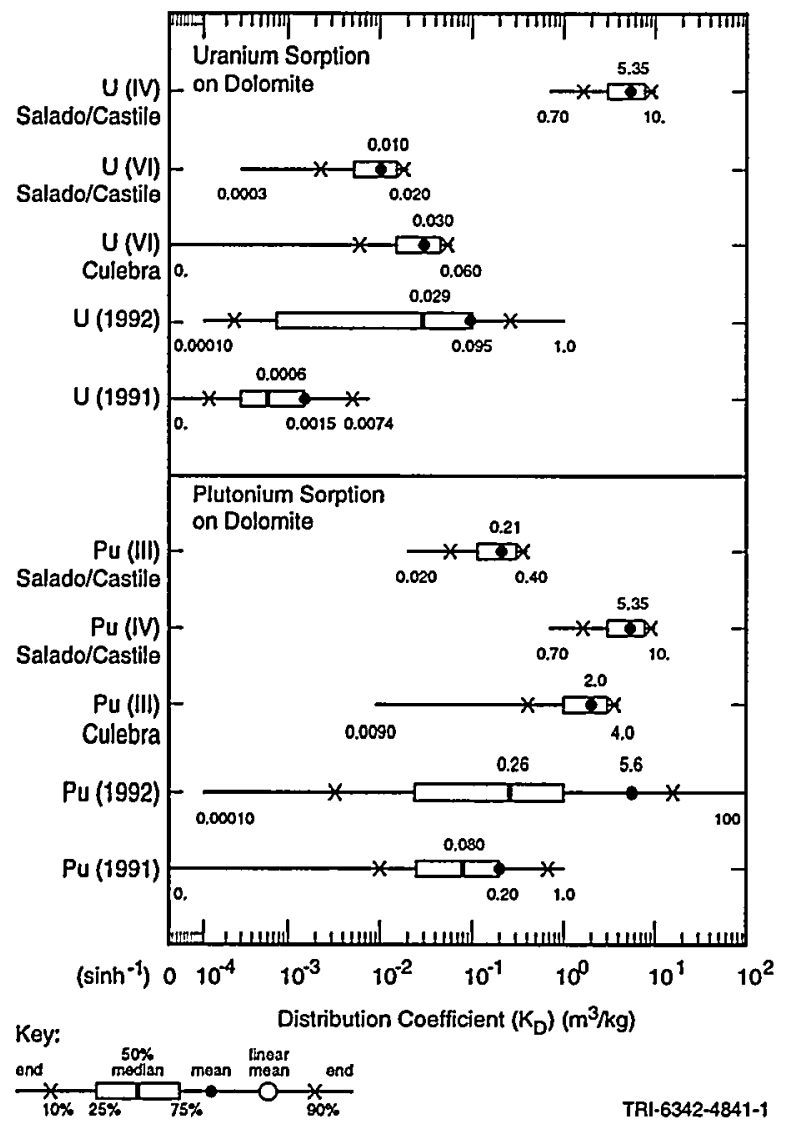

Figure 3-7. Ranges of $K_{d} s\left(m^{3} / \mathrm{kg}\right)$ for plutonium and uranium in 1991, 1992, and 1996 performance assessments (WIPP PA Division, 1991/1992, Vol. 3; WIPP PA Department, 1992/1993, Vol. 3; Brush and Storz, 1996). 


\subsection{Waste Properties}

Two aspects of the TRU (transuranic) waste destined for the WIPP were important to characterize for the compliance calculations: the estimated inventory of radioisotopes in the waste, ${ }^{1}$ and the mobility of these radioisotopes within the disposal system. Properties of the waste that influence the chemical environment within the disposal system, and thereby radioisotope mobility, include the amount of iron and microbial nutrients such as wood, plastic, rubber, nitrates, and sulfates. Only defense TRU waste was planned for disposal at the WIPP after December 1979, when the purpose of the WIPP Project was clearly defined. But up until then, other types of nuclear waste had also been considered.

\subsection{Changes in Purpose of WIPP Project}

Although the purpose of the WIPP as a general disposal site for radioactive waste was clear, decisions about what kind of waste would be sent there fluctuated throughout the 1970s. Under consideration were three kinds of waste-TRU waste, high-level waste from reprocessing spent nuclear fuel, and direct disposal of spent nuclear fuel-and whether the waste originated from defense or commercial activities. The initial focus of the AEC in the 1950s and 1960s with regard to disposal was on nuclear waste from reprocessing spent nuclear fuel (or high-level waste as it came to be called), because uranium was thought to be in such short supply that it would be necessary to recycle commercial fuel. The initial screening analysis of scenarios for the WIPP assumed 75,000 canisters of high-level waste, enough to accommodate the anticipated volume of high-level waste from all commercial reactors through the year 2000 (Claiborne and Gera, 1974). However by 1975, the emphasis of the WIPP was disposal of TRU defense waste, because of the prominence of the latter as a result of the Rocky Flats Plant fire, and the WIPP was offcially removed from the commercial repository program within ERDA.

Yet the public expectation remained that the government should be responsible for disposal of wastes from commercial reactors, as prompted by the Atomic Energy Act of 1954 (Public Law 83-703). During the 1970 s, the lack of a proven waste disposal scheme for high-level waste was presented by the public, through comments on the EIS and at licensing hearings, as an argument against construction of nuclear plants. Furthermore, California passed a law in 1976 banning construction of nuclear power plants until disposal of highlevel waste was demonstrated (Carter, 1987, p. 86; Perge, 1982). Therefore, once the RSSF for high-level waste was officially abandoned in 1975, the DOE seriously considered disposal of commercial waste at the WIPP between 1977 and 1979, at least as a means of demonstrating the disposal concept. Conceptual drawings of the WIPP repository in 1977 showed two levels: one for the cooler contact-handled TRU (CH-TRU) waste, $640 \mathrm{~m}$ below the surface, ${ }^{2}$ and the other for remote-handled TRU (RH-TRU) waste and the hotter high-level waste, $790 \mathrm{~m}$ below the surface (Weart, 1979; Sandia, 1977).

In March 1979, the Interagency Review Group formed by the Carter administration suggested that the WIPP be a candidate for commercial spent fuel, i.e., no distinction be made between commercial and defense radioactive waste. However, the then powerful House Armed Services Committee strongly opposed commercial waste disposal at the WIPP and regulation by the NRC. In response, Congress clearly defined the mission of the WIPP in December 1979 (Public Law 96-164) as a "...research and development facility to demonstrate the safe disposal of radioactive waste resulting from the defense activities and programs of the United States exempted from regulation by the Nuclear Regulatory Commission" (Figure 4-1).

\subsection{Transuranic Nuclear Waste}

\subsubsection{Current Waste Description}

Wastes destined for the WIPP consist of laboratory and production materials such as glassware, worn-out equipment and tools, scrap metal and wood, disposable

1 About 60 percent of the wastes may be co-contaminated with other hazardous constituents as defined under the Resource Conservation and Recovery Act of 1976 (Public Law 94-580 and subsequent amendments). For compliance with EPA regulations, hazardous waste constituents are no longer important because Congress exempted the DOE from demonstrating "no migration" of hazardous components above health concentration standards. However, the types of hazardous constituents are important for disposal permits with the State of New Mexico.

2 In 1984, the single level of the WIPP repository was built $655 \mathrm{~m}$ below the surface. 


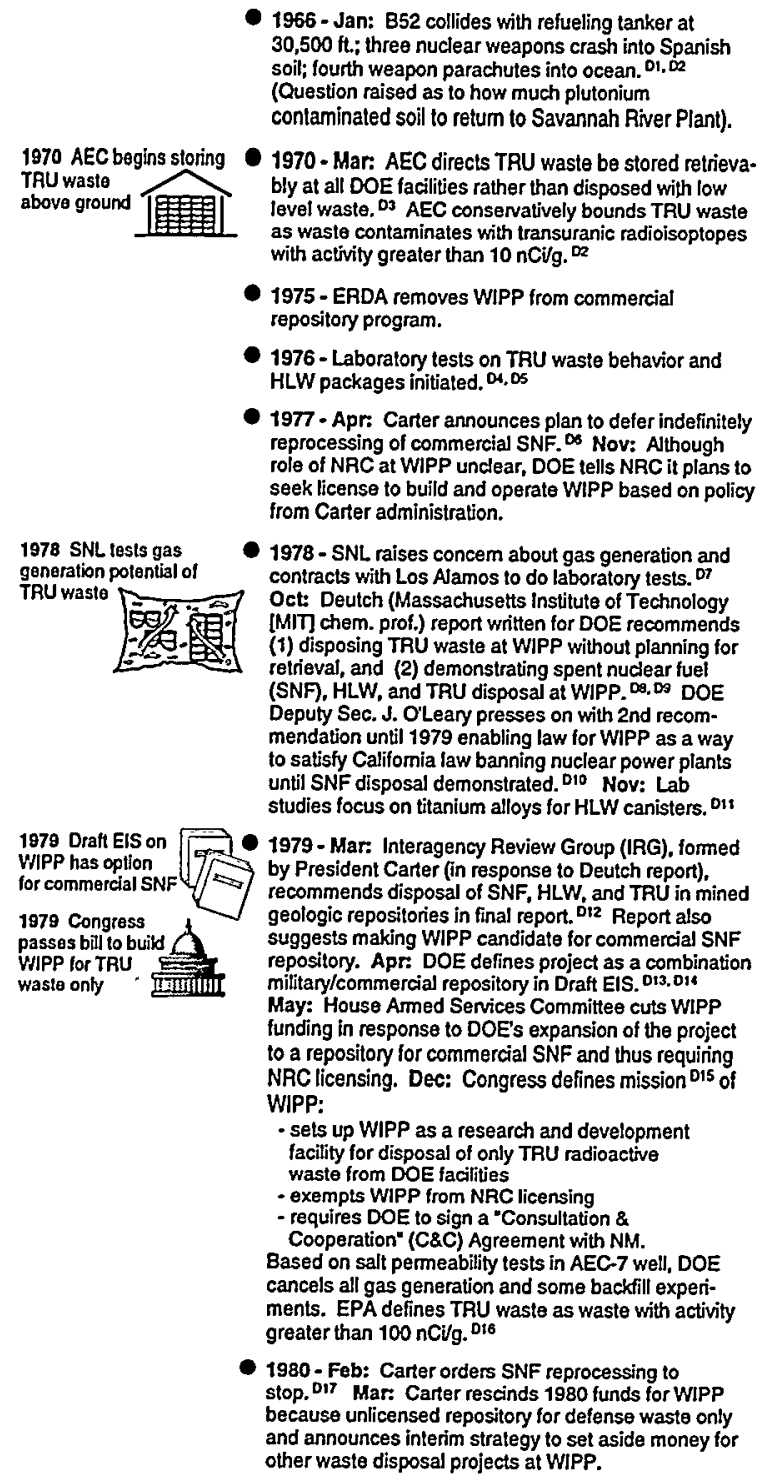

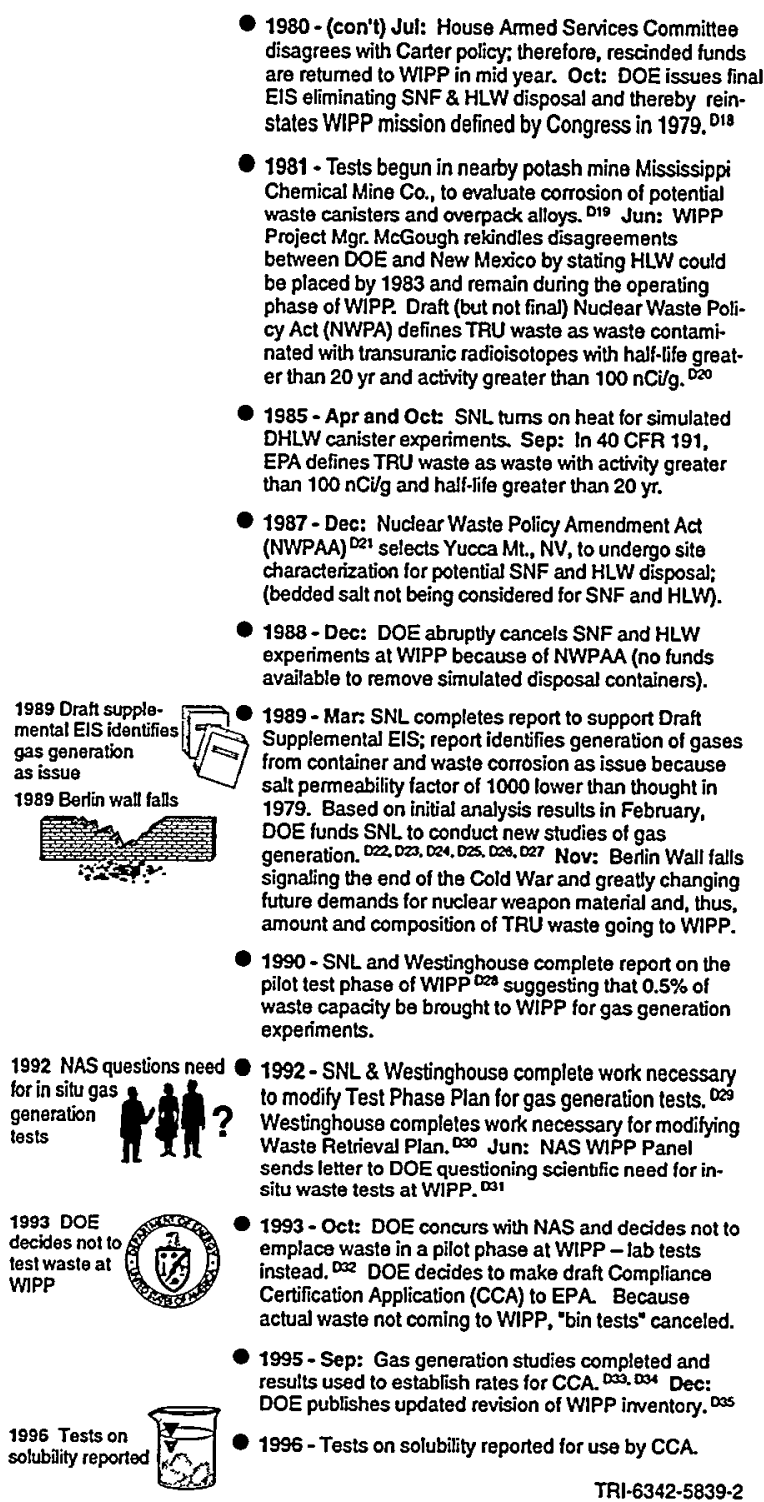

1980 - (con't) Jul: House Armed Senvices Committee disagrees with Carter policy; therefore, rescinded funds EIS eliminating SNF \& HLW disposal and thersyes final states WIPP mission defined by Congress in 1979. ${ }^{019}$

1981 - Tests begun in nearby potash mino Mississippi Chemical Mine Co., to evaluate corrosion of potential waste canisters and overpadx alloys. ${ }^{19}$ Jun: WIPP Project Mgr. McGough rekindles disagreements be placed by 1983 and remain during the operating phase of WIPP. Draft (but not final) Nuclear Waste Policy Act (NWPA) defines TRU waste as waste contamier than $20 \mathrm{yr}$ and activity greater than $100 \mathrm{nCi} / \mathrm{g}$. 020

1985 - Apr and Oct: SNL turns on heat for simulated DHLW canister experiments. Sep: In 40 CFR 191, than $100 \mathrm{nCi} / \mathrm{g}$ and half-jife greater than $20 \mathrm{yr}$.

1987 - Dec: Nuclear Waste Policy Amendment Act (NWPAA) ${ }^{\text {D21 }}$ selects Yucca Mt., NV, to undergo site (bedded salt not being considered for SNF and HLW)

1988 - Dec: DOE abruptly cancels SNF and HLW available to remove simulated disposal containers). Supplemental EIS; report identifies generation of gases salt permeability factor of 1000 lower than thought in 1979. Based on initial analysis results in February, DOE funds SNL to conduct new studies of gas generation. 022, 023, 024,023,026,027 Nov: Berlin Wall falls signaling the end of the Cold War and greatly changing amount and cor tor

1990 - SNL and Westinghouse complete report on the pilot test phase of WIPP ves suggesting that $0.5 \%$ of waste capacily be brought ro WPP for gas generation

1992 NAS questions need 1992 - SNL \& Westinghouse complete work necessary for in situ gas 10 to modify Test Phase Plan for gas generation tests. 029 Westinghouse completes work necessary for modifyin Waste Retrieval Plan. 030 Jun: NAS WIPP Panel situ waste tests at WIPP.

Figure 4-1. Development of project goals and characterization of waste properties. laboratory clothing, cleaning rags, spent solvents that were sorbed or solidified, and solidified sludges, which have been contaminated with TRU radioisotopes. Any waste contaminated by alpha-emitting TRU radionuclides with half-lives greater than $20 \mathrm{yr}$ and activities greater than $100 \mathrm{nCi} / \mathrm{g}$, is considered TRU waste in the United States. ${ }^{3}$ Most waste with less than this activity per mass is considered low-level waste.

The DOE classifies TRU waste as either contacthandled $(\mathrm{CH})$ or remotely handled $(\mathrm{RH})$ based on dose at the surface of the waste container. If this surface dose is less than or equal to $200 \mathrm{mrem} / \mathrm{hr}$, the waste is defined as CH-TRU; if the dose is greater than $200 \mathrm{mrem} / \mathrm{hr}$, the waste and its container are defined as RH-TRU (DOE, 1990c). The WIPP Land Withdrawal Act (LWA), passed in 1992 (Public Law 102-579), ratified previous agreements between the State of New Mexico and the DOE on the volume of $\mathrm{CH}-\mathrm{TRU}$ in the original Consultation and Cooperation Agreement, signed in 1981, and was the first modification of this Agreement concerning the RH-TRU content as signed in 1984 (see Figure 2-2). That is, the total combined volumes of $\mathrm{CH}-\mathrm{TRU}$ and RH-TRU waste were not to exceed 6.2 million cubic

3 TRU waste is also known as Alpha-Bearing or Intermediate Level Waste in other countries. The minimum defining activity varies between 0.3 and $1000 \mathrm{nCi} / \mathrm{g}$. 
feet, and the emplaced RH-TRU waste was not to exceed a total activity of $5.1 \times 10^{6}$ curies or a total activity concentration of 23 curies per liter (averaged over the volume of the canister). Only RH-TRU waste producing a dose of less than or equal to $1000 \mathrm{rem} / \mathrm{hr}$ is eligible for disposal at the WIPP (DOE, 1996a). Furthermore, no more than $5 \%$ of the emplaced RH-TRU waste was to exhibit a dose in excess of $100 \mathrm{rem} / \mathrm{hr}$. While the capacity for CH-TRU waste is adequate for all of the DOE's TRU waste produced after 1970 , the legal limit is too small to include the CH-TRU waste buried prior to 1970 (Weart, 1979; DOE, 1979; 1980a). The final amount of RH-TRU in the DOE complex is not known at this time because it depends on how some future waste will be treated and packaged.

\subsubsection{Modification of TRU Waste Definition}

As noted in Section 2, the definition of TRU waste as a material contaminated with TRU radioisotopes with an activity of $10 \mathrm{nCi} / \mathrm{g}$ was quickly proposed and used as a temporary but safe bound by the AEC in 1970 (Perge, 1982). In its early attempts at nuclear waste standards, the EPA, through simple calculations on resuspended plutonium in soil, concluded in 1979 that a limit of $100 \mathrm{nCi} / \mathrm{g}$ would keep doses below $500 \mathrm{mrem} / \mathrm{yr}$ and thus increased the bound by an order of magnitude (Sjoblom, 1982). In 1980 and 1981, the early legislative drafts of the Nuclear Waste Policy Act (NWPA) of 1982 adopted this activity threshold for defining TRU waste but also added a half-life threshold of 5 years. In 40 CFR 191, promulgated in 1985 by the EPA, this latter threshold was increased to a 20-year half-life (EPA, 1985a). The change in the definition by the EPA required that the DOE reclassify $\sim 20 \%$ of the TRU waste that existed between 10 and $100 \mathrm{nCi} / \mathrm{g}$. The activity of most waste was around $10^{4} \mathrm{nCi} / \mathrm{g}$ (Smith, 1982; WIPP PA Division, 1991/1992, Vol. 3).

\subsubsection{TRU Waste Inventory}

For preliminary performance assessments between 1989 and 1992, waste activities and mass were estimated from the Integrated Data Base (e.g., IDB, 1990), produced annually by ORNL for the DOE, and from requests for supplemental information by Westinghouse directly to the waste generator sites (see for example, WIPP PA Division, 1991/1992, Vol. 3). For the CCA, the DOE assembled a baseline inventory, referred to as the Transuranic Waste Baseline Inventory Report (TWBIR) (DOE, 1995b). This baseline included esti- mates of the radioisotope inventory for 569 stored or tobe-generated waste streams for CH-TRU waste and over 400 waste streams for RH-TRU waste. Waste-related input parameters for the CCA analysis were then developed from this data.

\subsection{Waste Characterization Studies}

\subsubsection{Initial EIS Waste Studies}

Simultaneous with site characterization, Sandia began tests in early 1977 on the behavior of TRU waste forms and high-level waste (Molecke, 1978). These tests were to be used by Westinghouse, the technical support contractor for the WIPP, to develop waste acceptance criteria for the various forms of the waste (Sandia, 1979). To ensure waste acceptability, in 1976 the WIPP Project had sent guidance to the generator/ storage sites that the waste be incinerated to remove combustible and organic material. In the late 1970s and early 1980s, the major generators and storage facilities that were expected to ship directly to the WIPP were Idaho National Engineering and Environmental Laboratory; Hanford Reservation, Washington; Rocky Flats Plant, Colorado; Los Alamos National Laboratory, New Mexico; Savannah River Plant, South Carolina; Oak Ridge National Laboratory, Tennessee; and the Nevada Test Site. Other generators or storage sites such as Lawrence Livermore National Laboratory, California; Mound Laboratories, Ohio; Argonne National Laboratory, Illinois; Bettis Atomic Power Laboratory, Pennsylvania; and other smaller sites would either continue to ship their waste to the major storage sites for certification or begin their own certification programs and ship directly to the WIPP. By 1979 , results from initial tests indicated that most characteristics of the TRU waste were acceptable and so incineration was no longer recommended (Sandia, 1979; Weart, 1979). The conclusions reached included the following (Hunter, 1979):

1. Gas generated through microbial degradation of organic material or anoxic corrosion of waste containers was possible but the gas would readily dissipate as a result of the anticipated permeability of the salt, even when the highest gas-generation rates were used, as summarized by Molecke (1979).

2. Combustibility was not an issue because spontaneous internal ignition was not possible. Thus the only concern was from fires from other sources during operations. 
3. Immobilization was unnecessary because most characteristics that would be affected did not present a difficulty with regard to long-term disposal. Specifically, (a) leachability was not an issue (analysis assumed a waste leachability equivalent to salt dissolution with no adverse effects), (b) organic ligands that might reduce sorptive capacity of the host salt and Culebra dolomite were not an issue (analysis showed peak releases occurred at $10,000 \mathrm{yr}$ rather than $100,000 \mathrm{yr}$ but otherwise no effect), (c) use of sorbing materials might be desirable but was not necessary (analysis indicated improvement if a further safety margin was necessary); and (d) only sludge wastes were considered unacceptable (analysis had not been done to evaluate whether sludge waste with $60 \%$ to $80 \%$ moisture by weight would be acceptable in a dry repository).

4. Criticality was not an issue, because analysis by Los Alamos indicated criticality was not possible without dissolution and reconcentration of fissile isotopes in the Culebra and reconcentration appeared unlikely based on analogy with the natural reactors at Oklo (qualitative argument). (Criticality was formally examined and screened out for the 1996 PA; see Section 6.6.)

\subsubsection{Container Corrosion Studies}

Another conclusion reached (Hunter, 1979) was that corrosion of waste was not an issue, because longterm integrity was not considered necessary in a salt repository. Waste drums were thought to be adequate to facilitate retrieval in the first 25 years. Gas generation potential was not important in a dry repository and was of the same order of magnitude as microbial generation in a wet, anoxic environment from interstitial brine migration because of hot, high-level waste.

Later, Sandia would conduct a few tests with waste drums to evaluate their expected life, but the first corrosion studies were on candidate materials for canisters and disposal containers for high-level waste, where long-term containment might be desired. In 1981, Sandia set up a field test at a nearby potash mine owned by Mississippi Chemical Mine Co. Besides testing a few materials, the test provided experience with instrumentation and sampling techniques. In 1986, Sandia agreed to help Savannah River Laboratory test the behavior of its high-level waste canisters in a salt repository. Seven other countries asked to join, resulting in the Materials
Interface Interaction Test (MIT) project, which tested over 50 combinations of materials in Room $J$ of the experimental region and continued for the next 5 years (Wicks et al., 1993).

\subsubsection{Characterization for Performance Assessment Studies}

Based on the characterization studies for the EIS, the DOE decided in 1980 that further studies of waste characteristics such as gas generation were unnecessary. Furthermore, after passage of the 1987 amendments to the Nuclear Waste Policy Act (Public Law 100-203), most experiments on high-level waste, degradation of container materials, and influence of heat were stopped. However, the decision not to perform waste characterization studies was reconsidered after new data were presented in 1989. The new data included estimates from Brush and Anderson (1989) that anoxic corrosion of steel in the waste, if brine were available in the repository, could produce significant quantities of hydrogen gas in addition to any gas produced from microbial degradation of cellulosic material, e.g., wood, in the waste. Second, and as noted previously, in situ measurements of permeability in the Salado, taken while resolving the issue of brine flow into the repository, were found to be 1000 times smaller than those measured earlier (Nowak et al., 1988). An analysis conducted by Sandia (Lappin et al., eds., 1989), using Brush and Anderson's assumptions and the new permeability measurements, demonstrated that gas could potentially influence the overall performance of the repository.

Based on initial analysis, the DOE funded Sandia to conduct laboratory studies of gas generation in February 1989. These studies predominately comprised singleprocess experiments on anoxic corrosion, microbial activity, and radiolysis, most with nonradioactive simulated CH-TRU waste (Brush, 1990; Brush et al., 1991a, 1991b; 1993; Reed et al., 1993; Telander and Westerman, 1993; Francis and Gillow, 1994). The experiments were completed by September 1995, and the observed gas generation rates were used in the performance assessment for the CCA (Francis et al., 1997; Telander and Westerman, 1997).

Initially, a full-scale pilot phase for the repository had been envisioned by the DOE and Congress. But by the 1980s, the EEG and groups opposed to the WIPP Project saw the pilot phase as a way for the DOE to open the WIPP without certifying that it complied with regulations. They argued that institutional inertia would be so great that the WIPP would remain open, even if it 
could not comply with all EPA regulations during the transition from the pilot phase to the operational phase. To justify a pilot phase, the DOE proposed tests to reevaluate gas generation using actual TRU waste in the repository. In 1990, Sandia and Westinghouse presented operational and technical arguments for placing $0.5 \%$ of the waste capacity of the WIPP in the repository (DOE, 1990b). To resolve the issue between the DOE and opposition groups, Congress, in the 1992 WIPP Land Withdrawal Act, required the WIPP Panel of the NAS to certify a scientific need-not just operational usefulness-for the tests. The WIPP Panel did not see a scientific need for in situ tests, because the data could be obtained by laboratory tests, and so recommended in June 1992 that tests with actual waste be conducted in laboratories instead (NAS/NRC, 1992). The DOE concurred in October 1993 (Anonymous, 1993). Without a pilot phase, the DOE decided to accelerate into the compliance phase for the WIPP in October 1993, halted most of the in situ experiments, and then completely closed the in situ experimental area in October 1995.

As described in Section 8.4, an area that remained active was related to the solubility of actinides, primarily plutonium and americium, which had been shown to be important in the preliminary performance assessments (Helton et al., 1993a; 1996) along with shear strength of the waste, which influences releases after direct intrusion by exploratory drilling. The solubility data for the radioisotopes modeled in the 1991 and 1992
PAs were developed by an external expert panel, which had been convened in early 1991 (Trauth et al., 1991; 1992). At that time, experts from several disciplines were used to determine radioisotope solubility in the WIPP repository environment, particularly because disparate data from various studies had not yet been synthesized in the literature and direct experiments had only just started. The panel examined existing data and developed probability distributions of solubilities to express the uncertainty thought to pertain at the WIPP repository.

The solubility experiments initiated used one actinide (either $\mathrm{Am}, \mathrm{Np}, \mathrm{Th}, \mathrm{U}$, or $\mathrm{Pu}$ ) for each of four possible oxidation states $(+\mathrm{III},+\mathrm{IV},+\mathrm{V},+\mathrm{VI})$ at various $\mathrm{pH}$ and brine compositions. Behavior of other actinides with an equivalent oxidation state was assumed to be similar, e.g., the measured solubility of Pu(III) was assumed to be similar to the solubility of Am(III). The influence of organic ligands on solubility was also studied experimentally. However, the solubility of actinides in high ionic strength brines was modeled at Sandia using FMT, as described in Section 7.4.3. The experimental and modeling results were then combined to produce a distribution of solubility from which to sample for the 1996 PA calculations in support of the CCA. Then, the sampled dissolved concentration was combined with estimates of the amount of humic, microbial, mineral, and intrinsic colloidal concentration of actinide species to produce an "effective solubility" (Figure 4-2). 


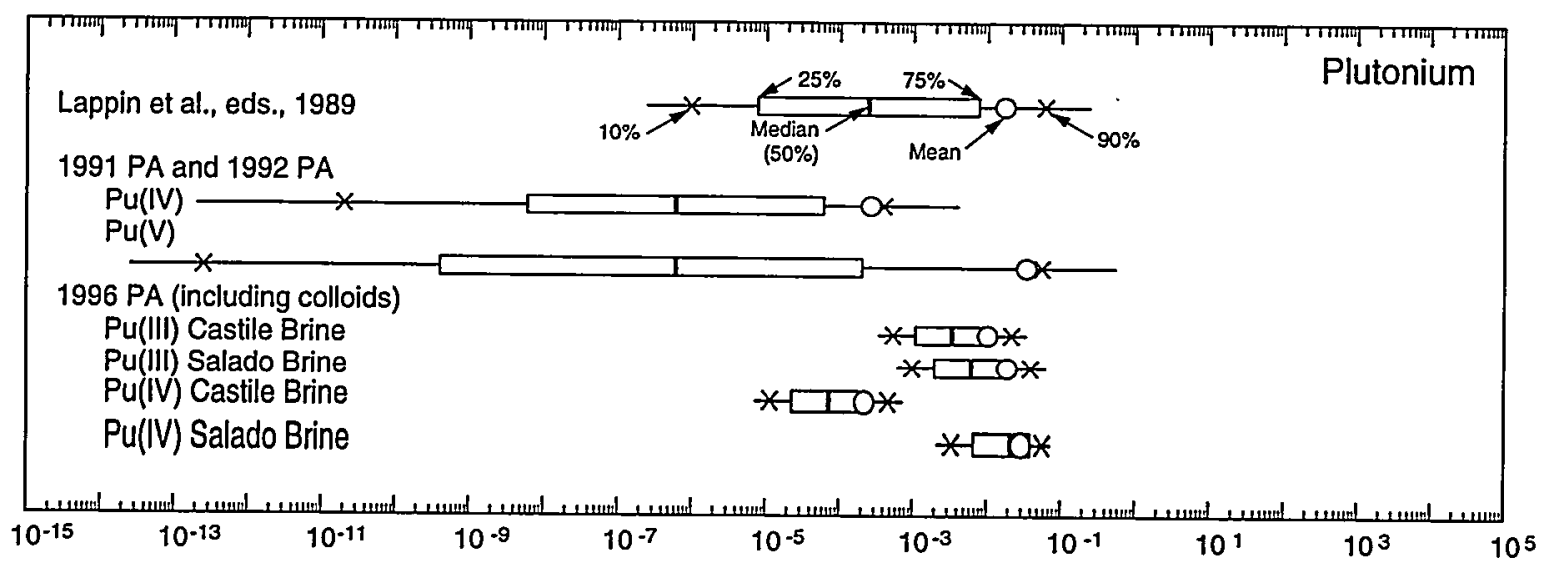

(a) Plutonium Solubility ( $\mathrm{mM}$ or $\mathrm{moles} / \mathrm{m}^{3}$ )

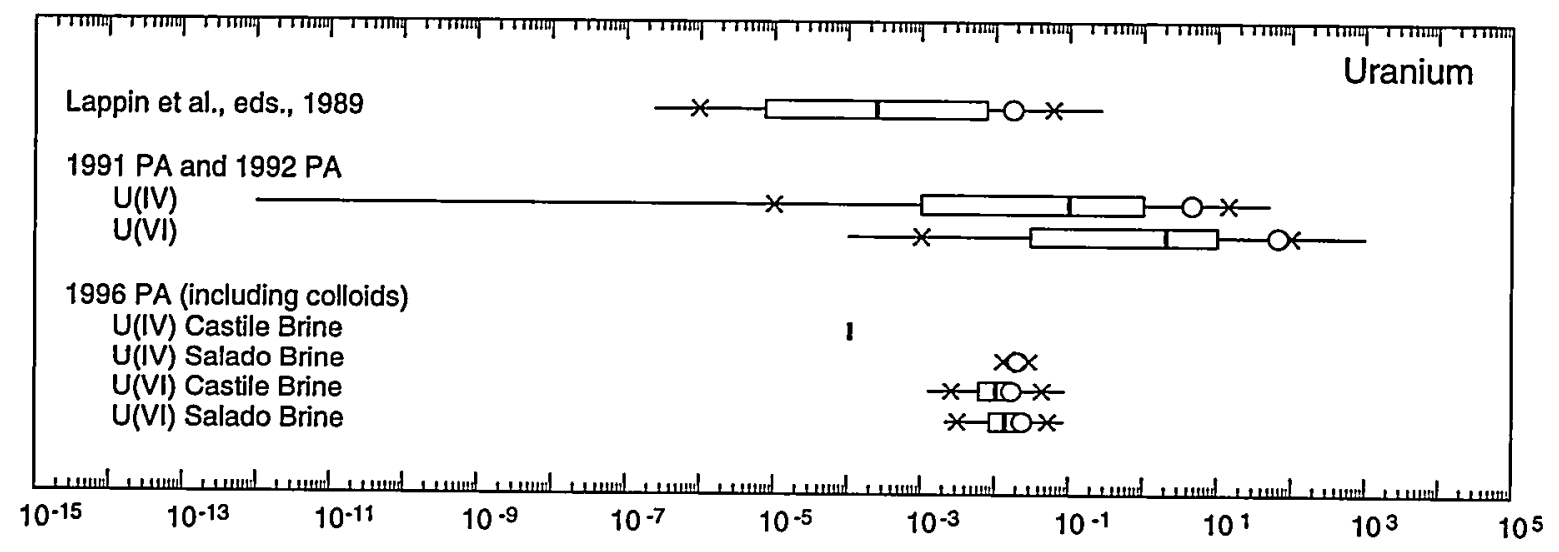

(b) Uranium Solubility ( $\mathrm{mM}$ or moles $/ \mathrm{m}^{3}$ )

TRI-6342-5846-1

Figure 4-2. Solubility of radioisotopes used in calculations between 1989 and 1996 for (a) plutonium and (b) uranium. 


\subsection{Design, Construction, and Behavior of Repository}

The repository (or underground facility) of the WIPP disposal system is $655 \mathrm{~m}$ beneath the surface at an elevation of $384 \mathrm{~m}$ above mean sea level. The room layout is essentially unchanged from the conceptual design Sandia proposed in 1977 (Sandia, 1977), although room dimensions were reduced and space between rooms was increased in 1980. In situ experiments also helped to refine constitutive equations in numerical models in the mid 1980s and to evaluate concepts such as backfilling the repository and estimating potential amounts of brine inflow to the repository in the late 1980 s and early 1990s (Tyler et al., 1988).

\subsection{Design of Repository}

\subsubsection{Early Conceptual Design}

Concurrent with site selection and writing the EIS, Sandia prepared a conceptual design of the WIPP surface and underground facilities. The conceptual design was completed in 1977 (Sandia, 1977). The basic design drew on information gained from experience with nearby potash mines in the Delaware Basin. However, the extraction ratio was dramatically reduced to $\sim 33 \%$ overall $(\sim 40 \%$ in any one disposal panel) to increase room stability and mine safety. The design for the transport containers and other hardware was based on Sandia's experience with equipment design at the Nevada Test Site.

The disposal area for the CH-TRU waste was set at $373 \mathrm{~m}$ elevation ( $666 \mathrm{~m}$ depth) and consisted of eight closely spaced panels $28 \mathrm{~m}$ apart with eight rooms in each panel, $34 \mathrm{~m}$ apart. Each room was $5 \mathrm{~m}$ high, $14 \mathrm{~m}$ wide, and $137 \mathrm{~m}$ long (Figure 5-1a). In the rooms, the $\mathrm{CH}-\mathrm{TRU}$ waste was to be stacked four barrels high. The experimental area and disposal area for the high-level waste (RH-TRU waste, high-level waste, and spent nuclear fuel) was set at a $200 \mathrm{~m}$ elevation ( $823 \mathrm{~m}$ depth), below the Infra-Cowden anhydrite strata near the base of the Salado. The repository had five shafts.

The initial conceptual design anticipated disposal of $105,000 \mathrm{~m}^{3}$ of CH-TRU waste retrievably stored since 1970 and accommodations for about $7000 \mathrm{~m}^{3}$ of CH-TRU waste produced annually. The design also anticipated disposal of $2500 \mathrm{~m}^{3}$ of RH-TRU retrievably stored since 1970 and accommodations for about
$200 \mathrm{~m}^{3}$ of RH-TRU waste produced annually. The volume of high-level waste was sufficient for about 1000 assemblies. Although expansion was contemplated, space for CH- and RH-TRU waste buried prior to 1970 and TRU waste produced from future decontamination and decommission of facilities was not included in the initial design. In December 1979, Congressional legislation limited the WIPP to the disposal of defense TRU waste. The second level, containing the experimental area and the RH-TRU waste disposal area, was abandoned and the repository was reconfigured for the final EIS as a single-level facility with four shafts (DOE, 1980a) (Figure 5-1b). RH-TRU canisters were to be placed in the repository walls, and CH-TRU drums would be placed in the large repository rooms. This concept was tested in Rooms J and T of the experimental region in the mid-1980s (Figure 5-1b) (Matalucci, 1988).

\subsubsection{Detailed Design}

In 1978, the DOE contracted with Bechtel National, Inc., to be the architect/engineer for the WIPP Project (and with Westinghouse Electric Corporation, for technical support to the DOE and Sandia) (Figure 5-2). The preliminary design of the WIPP (or "Title I design" in the language of the DOE orders) began in July 1979 and moved to a detailed design ("Title II") phase by February 1981. The detailed repository design included a waste disposal area, an experimental area, and an operations area around the shafts.

The underground operations area was designed to service and maintain underground equipment for mining and disposal operations, monitor for radioactive contamination, and allow limited decontamination of personnel and equipment. The experimental area consisted of a series of rooms north of the operations area and shafts. Bechtel's initial design placed the disposal area for the CH-TRU waste north of the experimental rooms.

The disposal area provided enough space for the disposal of the projected $176,000 \mathrm{~m}^{3}$ of waste and consisted of eight panels spaced $61 \mathrm{~m}$ apart with eight rooms in each panel, $30.5 \mathrm{~m}$ apart. Each room was $4 \mathrm{~m}$ high, $10 \mathrm{~m}$ wide, and $91 \mathrm{~m}$ long. The detailed design envisioned that waste would be emplaced in all drifts, including those that connected rooms, and not just in the rooms as shown in the conceptual design. Also plans 


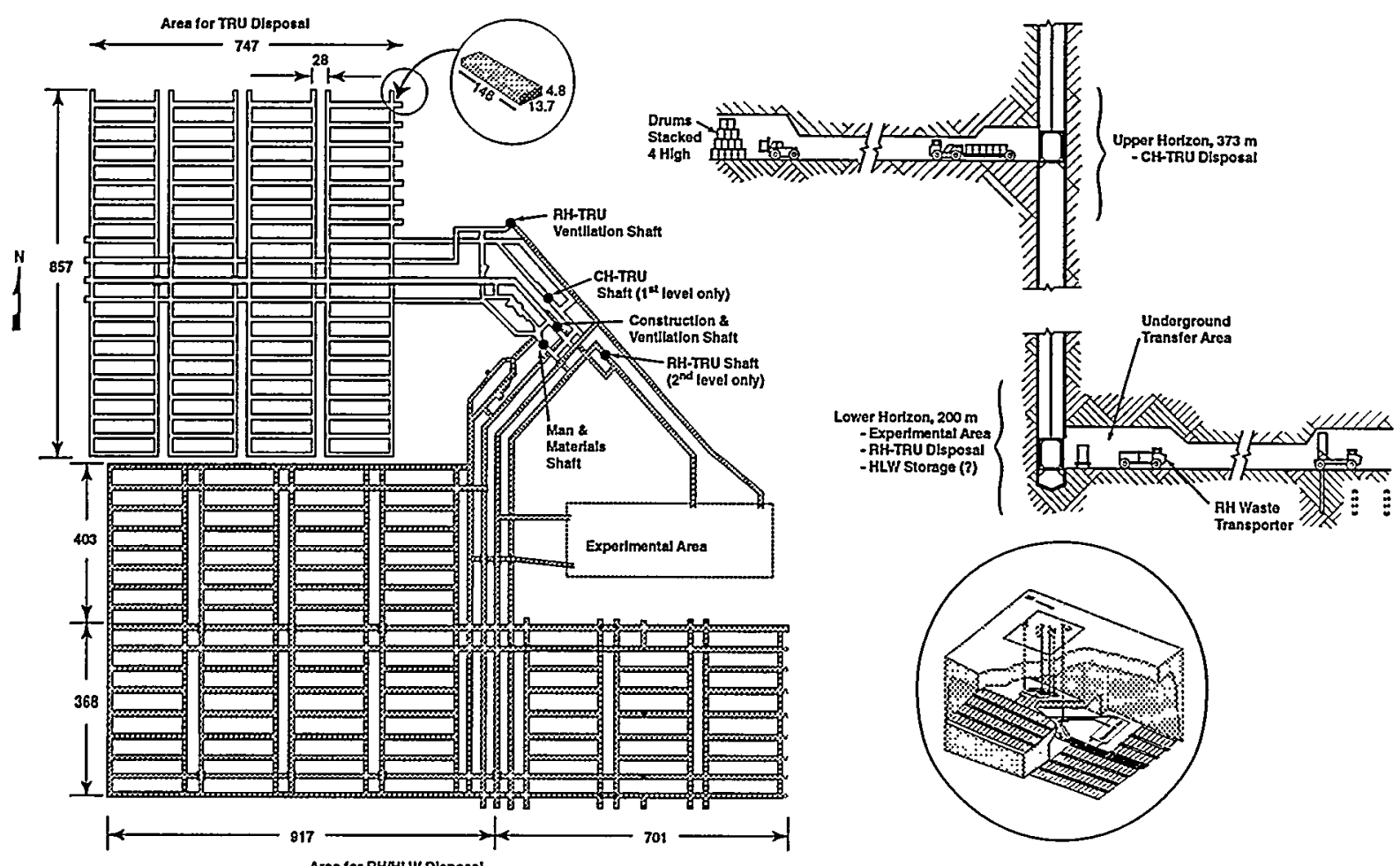

(a) 1977 conceptual design
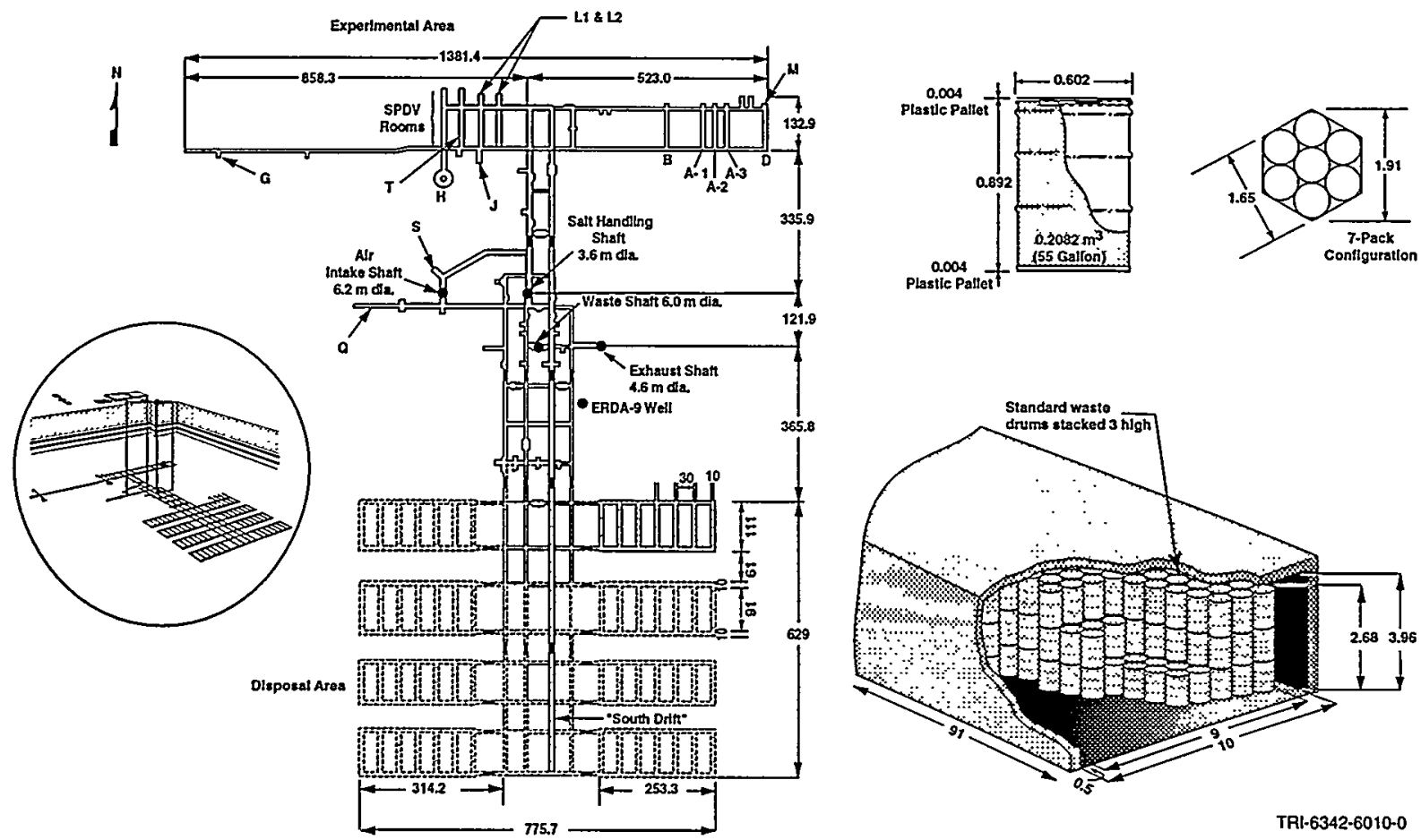

(b) Final construction plans for WIPP repository

Figure 5-1. Designs for the WIPP repository, including (a) 1977 conceptual design (Sandia, 1977) and (b) final construction plans for WIPP repository (Rechard, 1995). 


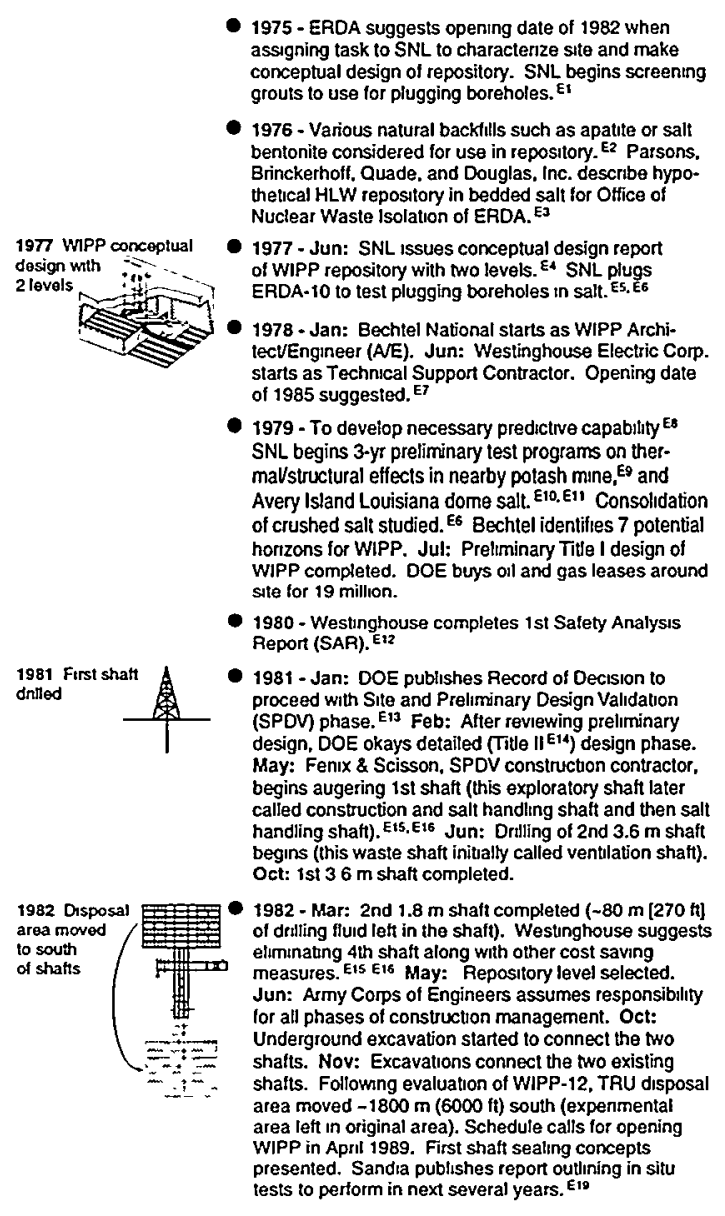

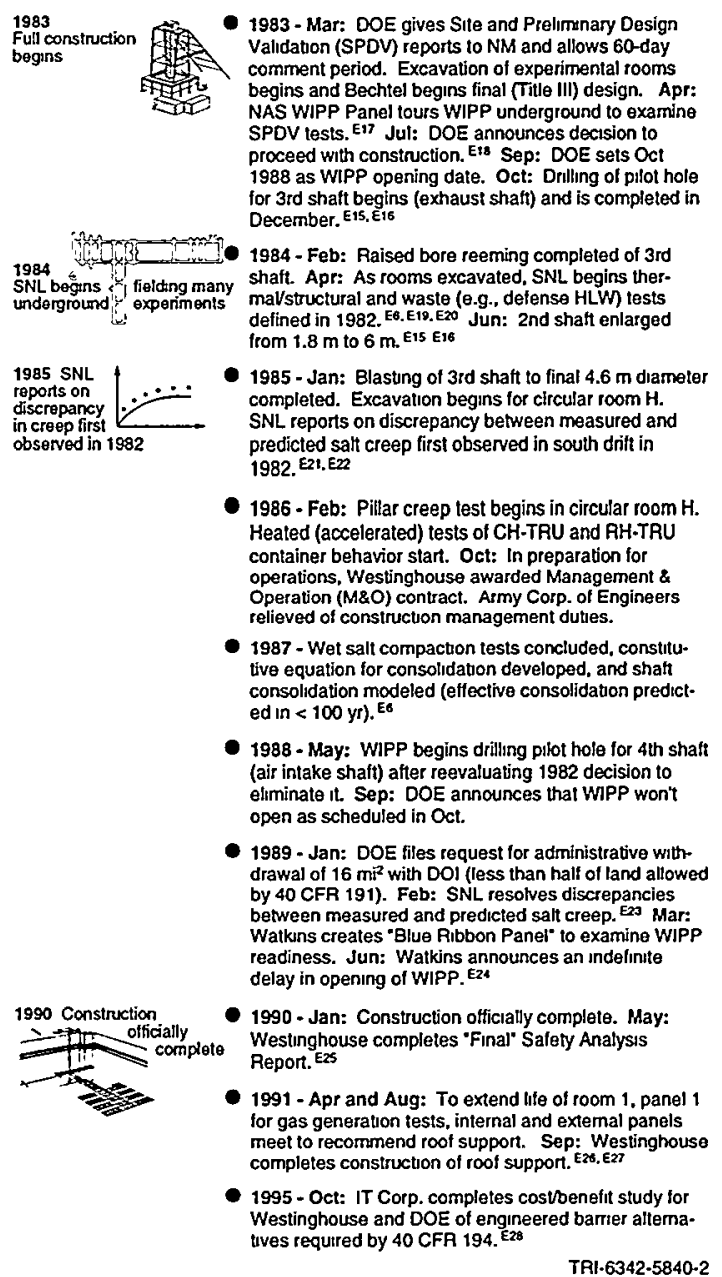

Figure 5-2. Events associated with design, construction, and modeling of the WIPP repository.

indicated that waste would fill the center section, where the panels joined the main drifts; this section was divided into southern and northern equivalent panels, bringing the panel total to 10 . The extraction ratio for a panel was similar to the conceptual design (38\%) but the overall extraction ratio of the disposal area was decreased further to $22 \%$.

In March, Bechtel began final design ("Title III") of the repository, and a design report was published in 1986 (Bechtel, 1986). Some modifications were necessary after the final report was published concerning the backfill (discussed in Section 5.4 and drum emplacement. In the design submitted for the CCA, the TRU waste is to be placed in 55-gallon drums, grouped as 7packs, 3 drums high (Figure 5-1b). The change from a 6-pack drum grouping to a 7-pack was in accordance with container modifications as they evolved from the initially proposed TRUPACT I transportation container, whose design was rejected by the EEG in 1985 (Chan- nell et al., 1986), to the TRUPACT II container certified by the NRC in August 1989. (According to the 1987 modification to the Consultation and Cooperative Agreement between the DOE and the State of New Mexico, the NRC had jurisdiction over transportation of nuclear waste to the WIPP.)

\subsection{Construction of Repository}

After publication of the final EIS in 1980 and a record of decision in January 1981, the DOE began the Site and Preliminary Design Validation (SPDV) program. The program further characterized stratigraphy near the repository and validated that rooms and tunnels, which were using dimensions specified in the preliminary design, would remain stable during the emplacement period. As part of the SPDV program, Fenix \& Scisson, Inc., Sandia's contractor for the conceptual design and DOE's SPDV contractor, drilled two shafts, 
the 3.6-m salt-handling shaft and the $2-\mathrm{m}$ waste shaft, in May and June, 1981. The first shaft, 3.6-m in diameter, was initially called the exploratory shaft, then renamed the construction and salt handling shaft, and finally referred to as the salt handling shaft. The second shaft drilled, the $1.8-\mathrm{m}$ ventilation shaft, was later renamed the waste shaft (DOE, 1996a).

In June 1982, the Army Corps of Engineers assumed responsibility for managing the SPVD and subsequent construction. Once the second shaft was completed in March 1982 and the repository level selected, excavations were begun in October to connect the two shafts, which were completed by the end of November. In the second half of the year, four full-sized disposal rooms were excavated. Although Bechtel's initial repository design placed the waste disposal area north of the experimental area, the disposal area was moved south of the shafts at the end of 1982 after the discovery of a brine reservoir in WIPP-12. Shortly thereafter, a drift to the south end of the disposal area was excavated to confirm the stratigraphy and manual measurements were taken frequently to evaluate deformation of the drift.

In March 1983, the results from in situ experiments in the SPDV rooms were reported (Tyler et al., 1988). Sandia helped analyze data from these and other geologic field activities and from geomechanical instrumentation to determine whether the design criteria were suitable and to confirm the reference design for the underground opening (Tyler et al., 1988). Also that month, excavation began on rooms for Sandia's geotechnical experiments.

The WIPP Panel of NAS toured the underground excavation for the first time in April 1983 to examine the SPVD rooms. Four months later, DOE announced its decision to proceed with full construction of surface facilities and continued excavation of the underground facility. The pilot hole for the third shaft, the exhaust shaft, was drilled in September 1983. Reeming of the pilot hole to $3.6 \mathrm{~m}$ from the underground to the surface, and then blasting to the final $4.6 \mathrm{~m}$ diameter was finished by January 1985 (DOE, 1996a). Between April and June 1984, the waste shaft diameter was enlarged from 1.8 to $6 \mathrm{~m}$. In 1988, a fourth shaft was added for increased air circulation (Figure 5-2). A pilot hole was first drilled from the surface and then reemed to a final $6.2 \mathrm{~m}$ diameter from the underground to the surface.

By the end of 1988 the surface and underground facilities were essentially complete; they were declared officially complete in January 1990 . Hence, as now built, the underground is connected to the surface by four vertical shafts: the waste shaft, the salt handling shaft, the exhaust shaft, and the air intake shaft (Figure 5-1b). All shafts except the exhaust shaft have permanent hoists capable of moving personnel, equipment, and materials between the surface and the repository. Every shaft will eventually be backfilled as described below.

\subsection{Experiments and Model Development of Repository Behavior}

Early in the history of the WIPP Project, the DOE, with Sandia as the lead national laboratory, viewed the WIPP as a research and development facility. The project was to conduct experiments that supported model development of salt creep and experiments on backfilling and sealing the repository, brine movement, and areas of interest to high-level waste disposal concepts such as canister material behavior (discussed in Section 4.3.2).

\subsubsection{Experiments with Salt Creep Behavior}

Sandia began to build a salt creep laboratory in 1974. Testing on specimens from mines and salt domes was in progress by 1975 , and creep in salt from ERDA-9 cores was studied in 1977. Sandia initiated a 3-year program in 1979 to evaluate, through in situ and laboratory experiments, salt deformations around mine openings and the effects of heat on acceleration of salt creep. The in situ experiments were conducted in a nearby potash mine owned by the Mississippi Chemical Company and at the Avery Island salt dome in Louisiana. Sandia proposed that data from these and future in situ experiments be compared with predicted behavior of the underground openings, thus partially validating the constitutive salt creep models and the numerical methods, which had been developed with model parameters obtained solely from laboratory experiments.

Laboratory creep tests were started on larger specimens from the underground workings of the WIPP in 1982; in situ salt creep manual measurements at the WIPP also began in 1982 as the main drift through the disposal area, the "south drift," was excavated. Sandia began fielding more extensive in situ salt creep experiments in 1984 as experimental rooms were completed. To measure accelerated salt creep, heat in simulated high-level waste canisters was turned on in these rooms in 1985. However, when Congress decided in 1987 to 
characterize only the Yucca Mountain site in Nevada as a commercial spent-fuel and high-level waste repository (Public Law 100-203), the DOE canceled the simulated high-level waste experiments in Rooms A1, A2, A3, and $\mathrm{B}$ at the WIPP (Figure 5-1b) (Matalucci, 1988), which had been supporting a potential commercial repository elsewhere in bedded salt.

\subsubsection{Modeling of Repository Behavior}

The first modeling efforts in 1975 reviewed empirical constitutive creep laws developed during Project Salt Vault and numerical modeling capabilities available in the mining industry. Some of the first calculations, completed in 1978, evaluated a potential concern that hot canisters would become buoyant in the plastic salt and move significant vertical distances (Dawson and Tillerson, 1978). Sandia modeled the repository, with Sandia-developed codes (SANCHO, Stone et al., 1985) and constitutive laws (Tyler et al., 1988), and used the results in 1980 (Krieg et al., 1981) to examine the reasonableness of various modifications to the room dimensions proposed in the 1977 conceptual design, which had been based on experience with the area's potash mines. Predictions from other numerical codes (e.g., SPECTROM-32, Callahan et al., 1989) were compared extensively to test data in 1980 , and more calculations on predicted room deformation were conducted in 1982 and 1985 (Morgan et al., 1985).

Although, from a practical standpoint, the predicted and measured values of salt creep were close, the manually measured salt creep in the south drift in 1982 and the automated measurements of the SPDV rooms in 1982 and 1983 and various other experimental rooms (Rooms A1, A2, A3, B1, G, and H [Matalucci, 1988]) (Figure 5-1b) were nevertheless about three times greater than predicted values (Morgan et al., 1985; 1986). Thus between 1985 and 1989 an alternate conceptual model and mathematical expression were incorporated into codes and tested. Among other adjustments, the newer expression specified the combination of vertical, horizontal and lateral stresses at which the salt yielded and began to creep, using a Tresca yield surface rather than a von Mises yield surface and steady-state analysis. Thereafter, agreement of predictions with in situ measurements was excellent (Figure 5-3) (Munson et al., 1989). The partially validated codes, SANCHO and its improved version, SANTOS (Stone 1997), were used to evaluate the reduction in porosity as the room closed by means of creep over time. The results were then used for the performance assessments conducted in the 1990s.

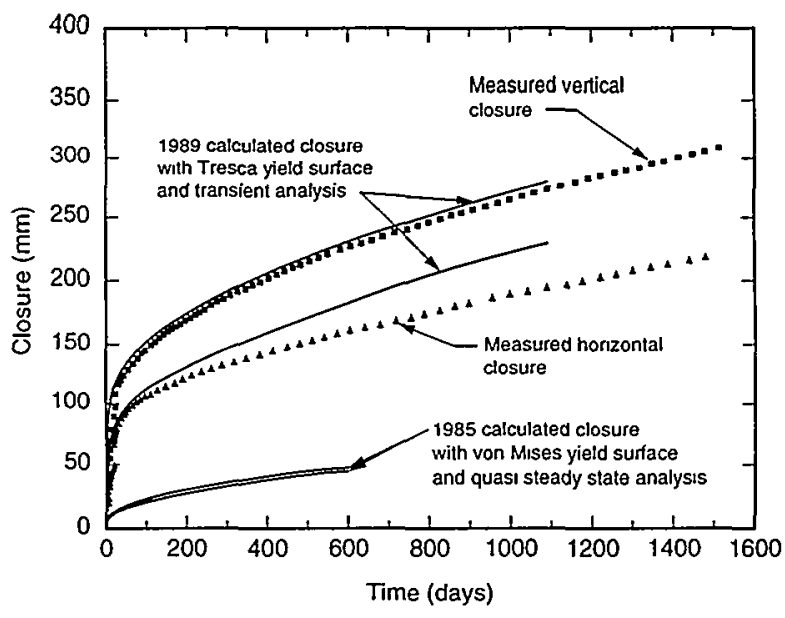

TR1-6342-6203-0

Figure 5-3. Comparison of measured and calculated creep closure in Room D (after Munson et al., 1989, Figures 3-5 and 3-6).

\subsection{Repository Backfill}

\subsubsection{Use of Backfill in Disposal Area}

The DOE had considered the use of backfill in the disposal area from the time of the initial conceptual design (Sandia, 1977). In 1976, some thought was given to placing sorptive minerals such as apatite or bentonite around the drums to sorb radioisotopes if enough brine were present to corrode the drums (Barr and O'Brien, 1976). More importantly, it was assumed that backfill would be emplaced in the repository to help fill the void space and reduce the magnitude of subsidence in overlying units, in addition to mitigating any potential risk of underground fire propagation (DOE, 1980a; 1980b). Backfill experiments were conducted in Room $\mathrm{J}$ of the experimental region (Matalucci, 1988) (Figure 5-1b).

Although backfill in the disposal area was considered part of the baseline design for the repository (Sandia, 1977; DOE, 1980a), as reported in the supporting documents for the Supplemental EIS (Lappin et al., eds., 1989 ) and the four preliminary performance assessments through 1992, the need for the backfill to mitigate subsidence and fire propagation diminished during the 1980s. These findings were formally reported in 1990 in the Safety Analysis Report (DOE, 1990a), which concluded that fire propagation in the waste disposal region was unlikely even without backfill, and in a 1994 Westinghouse study (WEC, 1994), which indicated that the addition of backfill would have a negligible impact on the subsidence of overlying units. 
For the $1996 \mathrm{PA}$ in support of the CCA, however, backfill was reconsidered and again included in the design. A chemical backfill of $\mathrm{MgO}$ was proposed that would combine with any microbially produced $\mathrm{CO}_{2}$ so that brine present in the repository would not become acidic, thereby increasing the solubility of the actinide radioisotopes. The backfill was not essential to show compliance but was an engineering measure that assured compliance and thereby met the assurance requirements of 40 CFR 191.

\subsubsection{Shaft Backfill and Sealing Methods}

Because of the problem presented by the presence of boreholes in the vicinity of the abandoned Lyons, Kansas, site, experiments on borehole plugs were immediately pursued by the WIPP Project in 1975 . By 1977 , three grouts had been selected and tested by plugging ERDA-10 drilled south of the WIPP site (near the Gnome site) (see Figure 3-1). In 1979, an experiment in AEC-7 tested the ability of a plug to withstand the 12.7-MPa pressure of the Ramsey Sands aquifer in the Bell Canyon Formation (Tyler et al., 1988).

Initial concepts for backfilling shafts were described and the first laboratory tests on compacting crushed salt conducted in 1982. Sandia presented the first conceptual design for shaft backfill in 1984, which continued to evolve during the late 1980s. Crushed salt, the primary backfill (usually referred to as "seals" in the WIPP Project) for the shafts through the Salado, was expected to limit the creation of a preferred pathway for radioisotope migration. Sandia developed a machine to build salt bricks from crushed salt in 1986 such that portions of the salt backfill in the drifts and shafts would be compacted to ensure adequate densities. Studies were conducted and reported in 1987 to estimate the density of reconsolidated salt under the lithostatic pressure from creep closure of the shaft (Nowak and Stormont, 1987). This study suggested $95 \%$ of intact salt densities could be obtained in the lower portions of the shaft in less than $100 \mathrm{yr}$, provided some brine $(-2.5 \% \mathrm{wt})$ was added to the crushed salt. Compaction of the salt through tamping was proposed to obtain a highly dense backfill during emplacement.

Stopping brine flow to the salt backfill from aquifers in the Rustler and upper units was also thought necessary because significant volumes of brine might delay or even prevent consolidation of the crushed salt. The first shaft sealing concepts near the Rustler envisioned using large seals of concrete, concrete-grout, or possibly other mixtures directly below the Rustler and halfway down the salt column to protect the lower crushed salt component prior to consolidation (Stormont, 1988; Lappin et al., eds., 1989, Figure 4-10). In 1990, bentonite clay, a swelling clay shown to be stable and with low permeability in brines in 1979 and 1984 studies, was added as a separate long-term component to the seals in the Rustler and at other seal locations in the Salado. Thus, the 1990 reference design for the shaft backfill included concrete plugs as a short-term component and bentonite clay and compacted salt as long-term components of the seals (Nowak et al., 1990). Details of the various options were developed in 1993 (Van Sambeek et al., 1993). As mentioned in Section 3, an important aspect of the backfill program between 1984 and 1988 was evaluating permeability and brine flow around the repository, but small in situ tests of seals in Rooms L1, $L 2$, and $M$ of the experimental region (Matalucci, 1988) (Figure 5-1b) were also conducted. In the 1990s, a more complete testing program was begun to demonstrate and develop confidence in the sealing concepts of the backfill, and asphalt was added as a long-term component.

\subsubsection{Panel Sealing Methods}

Initially, the repository design did not include constructed barriers to separate the waste into modules. But when the WIPP Panel of the NAS expressed concern that fire in combustible portions of the waste could pose a hazard to mine workers, barriers throughout the disposal area were proposed to enhance mine safety. By 1987, barriers between each panel (Figure 5-1b) were considered the best of several options for balancing concerns about safety, cost, and mine operations (constructing closures is both expensive and time-consuming) (Argüello and Torres, 1988). Shortly thereafter, plans called for isolating individual panels over the long term, with 30- to 40-m-long seals composed of preconsolidated salt and large concrete plugs at each end (Lappin et al., eds., 1989; Nowak et al., 1990). However, during the 1990s, the value of panel seals was questioned because of their limited ability to contain gas, given the presence of the disturbed rock zone that would develop in the anhydrite interbeds directly above and below the repository. Some consideration was given in the 1990s to grouting the anhydrite interbeds or removing the anhydrite beds entirely to improve performance. Even though long-term isolation of radioisotopes could not be fully assured, in 1997, the EPA stipulated that the DOE was to use panel seals in its design as one of several conditions for certifying compliance of the WIPP (EPA, 1997; EPA, 1998). 


\subsection{Hazard Identification and Scenario Development}

An important step in a performance assessment is to identify potential hazards that might disrupt the geologic disposal system. The first list of hazards for consideration at the WIPP was published in 1974 about the same time as site selection (Claiborne and Gera, 1974). The list was updated in 1979 for the EIS (Bingham and Barr, 1979, 1980), in 1989 for the preliminary performance assessments (Hunter, 1989), and in 1995-96 for the final performance assessment (Galson and Swift, 1995). Although the process of identifying hazards and then selecting specific hazards for modeling was relatively informal initially, with each iteration the process of identifying hazards became more rigorous. Engineering analysis can be conducted without hazard identification as an explicit step, but in performance assessment it is not only useful for the step to be formal but is also one aspect that sets it apart from small-scale analysis.

\subsection{Description of Hazard Identification}

\subsubsection{Categories of Hazardous Agents}

By the late 1980s, agents of hazards were typically categorized as features, events (i.e., short-term phenomena), and processes (i.e., continuous phenomena) or "FEPs" that act upon the system whereby a hazard might occur. The event category had already been used in the Reactor Safety Study of 1975 (Rasmussen, 1975), which inaugurated large probabilistic risk assessments. When this work was applied to a geologic disposal system in 1976, the definition of agents was broadened to include processes. Then in 1981, the IAEA formally considered "undetected features" (IAEA, 1981). Hence for assessing performance at the WIPP disposal system, hazard identification entails selecting features (e.g., a brine reservoir under the repository), events (e.g., humans drilling into the repository), and processes (e.g., generation of gas in the repository after waste disposal) relevant to repository functions. Many aspects of the characterization of the site and waste, the design of engineered components such as seals, the experimental programs, and the computer modeling capabilities were based on concerns about specific hazards.

\subsubsection{Scenarios}

In the WIPP Project, a future (or "elementary event" in the terminology of probability theory) is a hypothetical chain of physical events and processes, including particular features. A scenario (or scenario class) is a group of futures; it is sometimes represented by a key future with specific common attribute(s), e.g., human intrusion. Futures were grouped into various scenarios in the WIPP Project to focus attention on certain hazards, such as human intrusion. Grouping is feasible and practical if the probabilities of a FEP residing in the scenario class are easily calculated and if behavior within the scenario class is similar enough that a single, key future can characterize and represent the whole scenario class.

Given that a mathematical model of the disposal system exists, $R(\cdot)$, "future" and "scenario" can be precisely defined in terms of parameter space, $\mathbf{x}$, as follows. The parameter space $\mathbf{x}$ can be arbitrarily divided into two subsets: a subset defining conditions of scenarios, $\mathbf{x}^{\mathbf{s}}$, and a subset of remaining model parameters, $\mathbf{x}^{\mathrm{p}}$, i.e., $\mathbf{X}=\left[\mathbf{X}^{\mathfrak{s}}, \mathbf{x}^{\mathrm{p}}\right]$. A future is one point in parameter space for scenarios, $\mathbf{x}^{\mathbf{s}}$, and a scenario is a grouping of similar futures or subsets of $\mathbf{x}^{s}$, i.e., $S_{j} \subset \mathbf{x}^{\mathbf{s}}$, where $S_{j}$ is a scenario of what can occur to produce an unwanted outcome. For example, a scenario might be described as $S_{j}$ $=\left\{x_{1}^{s}<a\right.$ and $\left.x_{2}^{s}>b\right\}$, where $x_{1}^{s}$ and $x_{2}^{s}$ defined conditfons for human intrusion and location of a brine reservoir, respectively (Tierney, 1995). Characterization of scenarios and their uncertainty came to be known as stochastic uncertainty, $\mathbf{x}^{\mathbf{s}}$, within the WIPP Project to distinguish it from the more general epistemic (or subjective) uncertainty associated with model parameters, $\mathbf{x}^{\mathbf{p}}$.

\subsubsection{Steps of Hazard Identification and Scenario Development}

Hazard identification is a heuristic process, especially because analysts must identify potential hazards before they have developed any extensive experience with the system. This situation, in turn, suggests that continued reevaluation is necessary as the general inquiry about the disposal system continues, which has indeed occurred at the WIPP. For discussion, hazard identification and scenario development is assumed to consist of the following steps: 
1. Identifying and listing the full scope of hazardous agents (FEPs) relevant to disposal system functions. The list is called the universe.

2. Selecting from this list, based on well-defined screening criteria, those FEPs that might reasonably contribute to contaminant releases as defined in the regulations.

3. If desired, grouping the selected FEPs into scenarios that are of particular interest (or required by the regulator).

4. Choosing scenarios, again based on welldefined criteria, for consequence analysis. Scenarios with similar consequences can grouped together.

Criteria for omitting scenarios include (a) exceedingly low probabilities of occurrence, (b) exceedingly low consequences, or (c) no role in accepted specifications of the calculation (for the WIPP Project, these criteria are based on guidance from Appendix C of $40 \mathrm{CFR}$ 191).

\subsection{Hazard Identification After Site Selection}

\subsubsection{Features, Events, and Processes Considered}

After site selection in 1973-74, ORNL identified hazards not eliminated by the selection process for the WIPP (Claiborne and Gera, 1974). Natural events considered were volcanism, faulting, erosion, and meteorite impact (the latter not site specific). Climatic change and nuclear criticality were only mentioned. Anthropogenic events were drilling, sabotage, and nuclear warfare (the latter two events were not site specific). The primary process considered was groundwater transport of radioisotopes following faulting or meteorite impact. No undetected features were considered.

\subsubsection{Screening Calculations}

Claiborne and Gera (1974) also qualitatively evaluated the consequences and/or probabilities of the FEPs, although a few FEPs were analyzed deterministically. Readily dismissed were effects after closure from sabotage (which would require an occupying army to drill into the repository) and a crater from a surface blast of a nuclear weapon (which could not reach the repository). Exposure from drilling was assumed to be limited to the drilling crew. Failure of borehole plugs after a borehole had been abandoned was considered. However, potentiometric heads at the site were believed to favor flow to aquifers below the repository, and it was argued that it was unlikely that an individual would drill so deeply to obtain salty water (Culebra brine flowing through the Salado into the deep aquifers would become even more salty). Measurable consequences from a meteorite impact or faulting that moved the repository near the Culebra aquifer were estimated but the probabilities of the events were thought to be very low. The WIPP site was in one of the most tectonically stable parts of the United States and the probability of a catastrophic meteoritic impact was believed to be about $1.6 \times 10^{-13}$ per year.

\subsection{Hazard Identification and Scenario Development for EIS}

In 1976, Sandia first began to develop descriptions of potential mechanisms through which radioactive waste could be released for the safety analysis to be included in the EIS. The purpose was to enumerate which processes might need further experimental study, which should be included in computer modeling, and which could be eliminated. This activity became the foundation for scenario development conducted for the first performance assessments in the 1990s.

\subsubsection{Features, Events, and Processes Considered}

For the EIS, Sandia considered events similar to ORNL's list, such as drilling, although in a more formal manner. Sabotage, nuclear warfare, erosion, and meteroite impact were quickly dismissed as single events, although retained as initiating events for other events that would affect release. A new event added was potash mining and a new feature added was an undetected brine pocket. Hence, by the time of the EIS, four potential sources of brine had been identified for scenarios: (1) brine pockets, (2) brine aquifers, (3) interstatiscal grain brine, and (4) brine inclusions. In addition to groundwater transport, new processes included climatic change, subsidence, continued dissolution of salt directly over the site, diapirism (i.e., formation of salt domes in the strata overlying the salt beds because of repository heat), and buoyancy of canisters (i.e., vertical movement of canisters because of repository heat). 
Nuclear criticality, diapirism and buoyancy of canisters had been added because of public attention, but were dismissed after evaluation (Bingham and Barr, 1979; 1980; Dawson and Tillerson, 1978).

\subsubsection{Construction of Scenarios}

To link FEPs into futures, the WIPP Project first attempted to use fault trees but found the method untenable for three main reasons: the fault tree quickly became large and unmanageable; it was difficult to determine whether futures were mutually exclusive; and it was difficult to include time dependent events. Instead, Sandia developed a method based on event trees that began with a system that was not disrupted and subsequent events that provided mechanisms for moving radioisotopes through the disposal system (Figure 6-1a). The WIPP histories fell into three scenario classes (Bingham and Barr, 1979; 1980): (1) those that exposed waste directly to the biosphere, e.g., drilling through the repository, (2) those in which water flowed between two aquifers after borehole plugs had failed in exploratory drill holes, and (3) those in which water flowed from only one aquifer, requiring diffusion and convection to move radioisotopes through the salt. These three categories of scenarios and two other worst-case scenarios were analyzed early in 1978 for inclusion in the Draft EIS (DOE, 1979).

\subsubsection{Hazards Related to Waste Acceptance Criteria}

As described in Section 4, potential hazards from the waste were evaluated for the EIS while attempting to establish waste acceptance criteria. These hazards included combustibility, microbial gas generation and enhanced mobilization of actinides related to organic content, nuclear criticality, and excessive mobilization, corrosion, and gas generation related to volume of liquids in sludge wastes. The repository was found capable of mitigating all existing hazards, except for sludge waste with high liquid content. For sludge waste, insufficient tests had been run to estimate consequences and so free liquids in the waste were limited instead (Sandia, 1979).

\subsection{General Scenario Development}

While the DOE was examining hazards at the WIPP, the NRC funded another group within Sandia (separate from the WIPP Project) at the end of 1976 to
Drilling penetrates Upper Aquifer, Repository, Lower Aquifer (4 different intrusion times, $10^{3}, 10^{4}, 10^{5}$, and $10^{6} \mathrm{yr}$ )

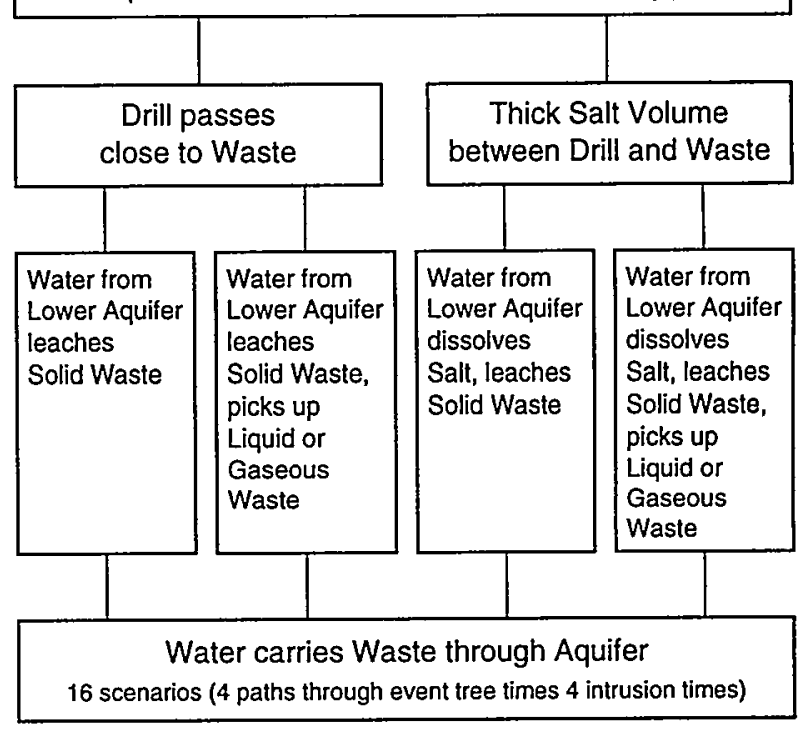

(a) Event tree approach used for scenarios in WIPP EIS in 1979 (after Bingham and Barr, 1980).

Events

$T S=$ Subsidence resulting from solution mining of potash

$E 1=$ One or more boreholes pass through waste and into a brine pocket

E2 = One or more boreholes pass through waste without penetrating a brine pocket

Combinations and nomenclature

$S_{1}=\overline{T S} \overline{E 1} \overline{E 2}=" E O "$ (base case - undisturbed pertormance)

$S_{2}=\overline{T S} \overline{E 1} E 2=$ "E2" (assumed bound by E1)

$S_{3}=\overline{T S} E 1 \overline{E 2}=$ "E1"

$S_{4}=\overline{T S} E 1 E 2=" E 1 E 2 "$

$S_{5}=T S \overline{E 1} \overline{E 2}=$ "TS"

$S_{6}=T S \overline{E 1} E 2=$ "TSE2"

$\mathrm{S}_{7}=\mathrm{TS} E 1 \overline{\mathrm{E2}}=$ "TSE1"

$S_{8}=T S E 1 E 2=$ "TSE1E2"

nS

$\sum_{j=1} P\left(S_{j}\right)=1$

(b) Combination (order unimportant) of events for scenarios in 1990 - 1992 performance calculations (after Rechard, 1995).

TRI-6342-5851-1

Figure 6-1. Technique to construct scenarios from various features, events, and processes changed between WIPP Environmental Impact Statement in 1979 and performance assessment calculations after 1989. 
pioneer work on a probabilistic risk assessment on geologic disposal of commercial high-level waste and spent nuclear fuel (Campbell et al., 1978). Their work benefited from the early work at the WIPP and the commercial disposal program conducted at ORNL until 1976 and then at Battelle when ORNL declined further involvement. Later the WIPP Project was to benefit from the NRC's efforts.

\subsubsection{Defining Universe (FEPs List)}

In 1976, the NRC funded two conferences that brought together a panel of earth scientists to generate a generic list of FEPs as a starting point in assessing the performance of a geologic repository (Cranwell et al., 1990). In a related international effort in 1981, the IAEA recommended a list of FEPs for initial consideration, along with a suggested procedure for performing an assessment (IAEA, 1981).

\subsubsection{Screening Universe and Forming Scenarios}

At first, the NRC requested that the Sandia group pursue a scenario development process similar to the Reactor Safety Study completed in 1975 (Rasmussen, 1975). However, like the Sandia WIPP Project, they found discretization of a highly coupled geologic disposal system by means of fault trees was not useful. In a draft report in 1981 (final report published in 1990) (Cranwell et al., 1990), Sandia proposed to the NRC a method to screen out unreasonable FEPs and form a limited number of scenarios. Based on its own and others' experience, the recommended procedure was a process in which the FEPs were essentially screened twice. The procedure included (1) generating an initial comprehensive list of relevant FEPs, (2) classifying the FEPs to aid in completeness arguments, (3) screening the FEPs based on well-defined criteria, (4) forming scenarios by combining specific remaining FEPs to form a scenario class, (5) screening the scenarios, and (6) selecting a final scenario set. Combinations of all events were used to construct scenarios; the time (or order) of occurrence was not considered (Figure 6-1). Hence, fewer scenarios were generated. Instead, broad classes of scenarios were developed that were convenient for modeling and construction of complementary cumulative distribution functions (CCDFs); time and order of occurrence of FEPs were to be included during modeling.

\subsubsection{Including the Human Intrusion Event}

Because injection boreholes and salt dissolution at the proposed repository at Lyons, Kansas, were discovered after site selection, human intrusion, both intentional and inadvertent, was included in the initial repository analysis for the WIPP. However, the inclusion of human intrusion eventually became controversial. For example, during the late 1970 s, each site with previously buried TRU waste and low-level radioactive waste, such as the national laboratories in Idaho or Los Alamos, prepared an EIS that evaluated disposal alternatives, e.g., leaving the waste as is, improving the trench covers, or retrieving and shipping the waste to the WIPP. The analyses examined costs and risks. Usually human intrusion of some type provided a significant portion of the calculated consequences but attaching a probability to the event was difficult. Also, no one knew how the human intrusion event related to the robustness of the disposal system (Smith, 1982), except that more varied types of intrusion would likely occur for disposal sites at shallow depths and for sites near unique mineral resources.

By 1982, in the draft of 40 CFR 191, the EPA reduced the scope of human intrusion to an inadvertent activity, specifically from exploratory drilling primarily for oil and gas deposits (EPA, 1982). Thus, the risk from human intrusion became a measure of the type of media selected, the depth of the repository, and its association with economic minerals. A natural extension, although unstated until 1996 in 40 CFR 194 (EPA, 1996a), was to assume the exploratory drilling used technology currently operating in the region. This assumption was conservative, given acceptance of the proposition that the repository presented the greatest hazard to a society with technical capabilities comparable to our own rather than to a society with less or greater technical prowess. In 1995, for the future regulation of the disposal of commercial spent nuclear fuel at Yucca Mountain, the NAS recommended that the calculation of risks from human intrusion be distinctly separate from those from natural migration of disposed waste (NAS/NRC, 1995).

\subsection{Hazard Identification for Preliminary PAs}

The preliminary performance assessments at the WIPP (Marietta et al., 1989; Bertram-Howery et al., 1990; WIPP PA Division, 1991/1992; WIPP PA Dept., 
1992/1993; Rechard, 1991; Rechard et al., 1989; 1990) used an initial screening of FEPs performed in 1989 (Hunter, 1989). The scenarios retained for consequence analysis belonged to two principal categories: undisturbed (base-case) performance and disturbed (humanintrusion) performance.

\subsubsection{Hazards Identified in 1980s}

Several natural processes that might compromise the disposal system had been postulated during the early 1980s and mandated investigations by agreements with the State of New Mexico. The possibilities of dissolution of the Salado (to form "breccia pipes") and dissolution at great depths in the Culebra at the site (causing "karst" hydrologic flow) were examined by the USGS (Snyder et al., 1982) and Sandia (Lambert, 1983). They were resolved as either not likely to occur at all or not in a manner that would impair WIPP performance, respectively. However by 1987 , the presence of a brine reservoir under the repository in the Castile could not be unequivocally dismissed and so became a potential undetected feature. In addition, the Supplemental EIS of 1989 identified gas generation as an important process to reexamine.

\subsubsection{Features, Events, and Processes Retained}

The FEPs for the WIPP were defined in 1989 (Hunter, 1989) in conjunction with a demonstration of the performance assessment methodology. The basic features retained included an undetected brine reservoir under a portion of the repository, seals in the shafts to limit downward movement of Culebra brine or upward movement of contaminated gas and brine from the repository (see Section 5, Design of Facility), an overlying, fractured brine aquifer in the Culebra, spatial variability of transmissivity fields (zones were analyzed in 1989-1990, and random fields analyzed thereafter), and fractured anhydrite beds slightly above or below the repository horizon (see Section 3, Characterization of Site) (Figure 6-2).

The primary basic event considered was human intrusion from exploratory drilling. However, disturbance of the stratigraphy from potash mining above the repository and nuclear criticality were also identified, although not included as events until the 1996 analysis for the CCA. No disruptive natural events with probabilities greater than $10^{-4}$ per $10^{4} \mathrm{yr}$ for any of the WIPP
PAs were identified (Hunter, 1989; Galson and Swift, 1995).

Natural processes retained for the preliminary PAs included climate variability (analyzed separately in 1989 and included in performance assessments after 1990), hydrologic transport in fractures of the Culebra (alternative models explored in 1992), generation of gas from container corrosion or microbial degradation of organic material such as cellulose in the waste, twophase (brine and gas) Darcy flow in and around the repository in the Salado, pressure-dependent creep of salt around the waste in 1992, and fracturing of anhydrite layers in 1994.

\subsubsection{Undisturbed Scenario}

The undisturbed scenario, E0, represented the performance of the disposal system from the time of disposal through the 10,000-yr regulatory period and incorporated all expected changes in the system and associated uncertainties (Figure 6-1b). In the demonstration PA of 1989, two potential pathways for migration of contaminants were considered. In the first path, the pressure gradient between the waste disposal panels and the Culebra was assumed to cause brine and radioisotopes to migrate either through drifts or anhydrite interbeds to the base of the shafts and then upward to the Culebra. Transport was then assumed to occur laterally in the Culebra toward the subsurface boundary of the accessible environment. In the second path, brine and radioisotopes were assumed to migrate laterally from the undisturbed repository through thin anhydrite interbeds toward the subsurface boundary of the accessible environment within the Salado (Figure 6-3). In all performance assessments conducted for the WIPP, no radioisotope releases occurred for the undisturbed scenario. In November 1996, the NAS echoed the findings of WIPP analyses that showed that the excellent isolating properties of bedded salt at the WIPP could be compromised only by human intrusion (NAS/NRC, 1996).

\subsubsection{Human Intrusion Scenarios}

In the performance assessments, the only disruptive event for scenario construction was inadvertent human intrusion. After 1990 the future inadvertent drilling events were assumed to occur randomly in time and space, that is, each drilling event was independent of every other drilling event, and mathematically described as a Poisson process (Helton, 1993c). 


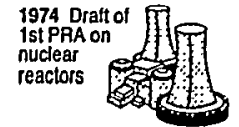

1974 ORNL conducts scenario develop-
ment and
ansequence

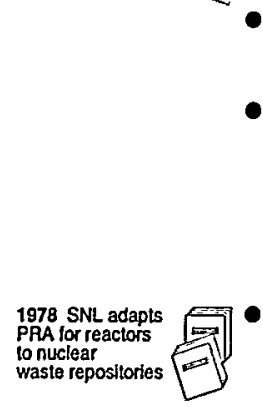

1979 Draft EIS on WIPP conducts transport analysls of Pu out

1974 - Aug: Draft of first major Probabilistic Risk Assessment (PRA) published on two reactors by $60 \mathrm{mem}$ ber team for Nuclear Regulatory Commission (NRC); method uses fauli trees to synthesize probability of total system failure. ${ }^{\mathrm{ft}}$ Oct: ORNL conducts first scenario development and deterministic analysis for WIPP F2 Probability of meteorite impact, probability of fault (and volcanism) and exploratory drilling intersecting disposal area estimated.

- 1976 - Dec: NRC funds panel of earth scientists to identify events and processes that could disrupt a generic repository, ${ }^{3}$

1977 - Apr: Second meeting of NRC panel of earth scientlsts occurs to identify events and process. ${ }^{\mathrm{F}}$ INEEL begins risk analysis of alternatives for TRU waste stored and buried at Radioactive Waste Management Complex (RWMC) over next 4 years. Ft Los Alamos, Savannah River, and Harford begin similar studies as well. Human intrusion event significant contributor to consequences in these studies.

1978 - Hydrologic and radjoisotope transport modeling for draft EIS is primarily regional and extends for 250,000 yr ( 10 half-lives of ${ }^{239} \mathrm{Pu}$ ) using large, 3-D Svift flow model. F5 NRC funds SNL to work on probabilistic PA and apply to hypothetical bedded sal repository. $\mathrm{FG}, \mathrm{FT}$

1979 - Apr: Draft EIS on WIPP published ${ }^{F S}$ SNL completes development of scenarios for release radiojsotopes from WIPP (part of EIS; process resulting method abandons fault trees and uses simple even trees). ${ }^{F B}, F 93$ major classes of scenarios identified (connection between Culebra aquifers above and below repository, Bell Canyon aquilers, U-tube connection to Culebra, and stagnant pool connection to Culebra) plus drilling intrusion. (Later U-tube split into catastrophic connection and standard U-tube connection.) ${ }^{F}$ Prob. abilities of scenarios assigned based on qualitative reasoned arguments.

1981 SNL reports 1981 - Draft of tinal report to NRC on performance on PA of assessment (PA) of hypothetical bedded salt repository thetical readily available $7, F 10$ - uses a set of loosely connected salt site codes, precursors to SWIFT_II F10 (fluid flow code), and NEFTRAN F12 (network transport code). IAEA recommends procedure for PA and potential list of events and processes for scenarios. Fi3 Jul: Stipulated Agreement (SA) between New Mexico and DOE describes disruptive scenarios (e.g.t breccia pipe. salt dissolution, and sall defomation) that are to be dismissed through further site characterization. $F_{14}$

- 1986 - Aug: DOE asks SNL, to assess periomance of WIPP against 40 CFR 191 criteria; ${ }^{\text {FIS }}$ SNL accepts PA task. ${ }^{1616}$

1987 - Mar: SNL finds that porous-media flow assumption adequately models flow in Culebra at $\mathrm{H}-3$ but that transport is best modeled as a dual porosity media ${ }^{F 17}$ (though roughly approximated as equivalent porous densitles suggest Culebra acting as leaky confined aquifer; ${ }^{17}$ subsequent models ignored suggestion until

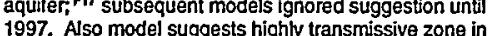
1997. Also model suggests highly transmissive zone in finds possibility of a pressurized brine reservoir below finds possibility of a pressurized brine reservoir below
the TRU disposal area cannot be nuled out. Fre, F21

1988 - SNL begins work of CAMCON to link detailed consequence models in probabilistic PA. F2 SNL also simultaneously begins work on prototype of CAMCON to meet Dec. 1989 deadline. SNL completes pumping tests at $\mathrm{H}-11^{\mathrm{Fra}}$ and begins using results to calibrate regional flow model. F24. F2s

1989 Draft supple- 1989 - Mar: SNL completes report to support Draft mental EIS Identifies Supplemental EIS; report identifies generation of gases gas generation from container and waste corrosion as issue because as lssue salt permeability lower than thought in 1979. Also, dif1989 Demo 5 ferent flow direction in past during wet climate hypothesized to explain discrepancy between geochemical analysis and current hydrologic flow in Culobra. $\mathrm{F}_{26}$ DOE Issues Draft Supplemental EIS. F27 Dec: SNL reevaluates release scenarios ${ }^{\mathrm{F} z}$ and issues WIPP PA demonstration outlining process for future $P A s$. $F 28, F 30$ No release without human lntrusion; out of 26 parameters, solubility, intrusion time, and borehole permeability most important; cuttings from direct drilling set at 3 drums.
1990 First full PA of WIPP used CAMCON
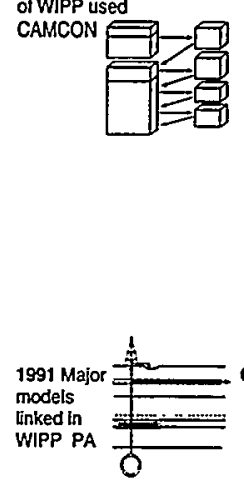

1992 Refinements to models (e.g. transmissivity

\section{de}

1992 - Dec: SNL issues 3rd PA refining models and refined, 49 parameters sampled, evaluated-time dependent $\lambda$ parameter in Poisson intrusion model disect cuttings most important pathway. ${ }^{\mathrm{F} 3 \mathrm{~B}}$

- 1994 - Mar: SNL explores possibility of linking PA with decision analysis in System Prtoritization Methodology (SPM); results form basis of Dratt Compliance Certification Application (DCCA).

- 1995 - Mar: DOE submits DCCA to EPA for review. F39 Computer specialists hired to modify CAMCON implementation to enforce software configuration manage ment and control nuns for PA calculations. NAS provides guidance on new regulation for potential Yucca Mi. repository; suggests reporting risk from human intrusion separately. Second attempt at SPM. ${ }^{\text {F40 }}$

1996 SNL completes PA 1996 - Oct: SNL completes PA for Compliance Certiffor WIPP certification; moving cation Application (CCA) of WIPP that includes MgO to EPA greater intrusion rate; except for few vectors, drill cut-
tings only release pathway; 57 parameters sampled. ${ }^{\mathrm{ft1}}$ Calculation was run 3 times with 100 samples each and took 37,000 CPU hrs on 40 DEC alpha processors and retained $100 \mathrm{GBytes}$ of data in 97,000 files. DOE sends 80,000 page, $400 \mathrm{lb}$. CCA to EPA. Nov: NAS reports that WiPP site "excellent choics" geologically. 0 DO issues 84,000-page 2nd Supplemental Draft EIS. ${ }^{\text {*45, Fs6 }}$ Dec: EPA begins detailed ovaluation of CCA and supporting information at SNL and elsewhere including PA conceptual models, computer codes, model parameters, QA records, and specific technical issues (e.g. MgO backfill and passive institutional control).

- 1997 - Jan: Conceptual Model Peer Review Group (formed in respons $\theta$ to 40 CFR 194) concludes 22 of 24 conceptual models adequate. Spallings model must be redone and $\mathrm{MgO}$ backfill description improved. Mar: SNL conducts minj PA for EPA to do parametric sensitivity analysis of PA model parameters lacking "ironslad" defense. Apr: Conceptual Model Peer Review clad" defense. Apr: Conceptual Model Peer Review Group reports that with additional information provided by $S N L$, they are satisfied that the new model of spat-
ings ${ }^{\mathrm{F} 43}$ and the model of the MgO backfill are adequate. F19 May: SNL explains apparent discrepancy between geohydrology and geochemistry by viewing flow in Culebra as a 3D regional system. ${ }^{550}$ As part EPA evaluation of CCA SNL Ins EPA-mandated PA calculations using EPA-selected values lor 26 paramoters and EPA-selected model assumptions, based on results from parameter review team comments in results from parameter review team comments in DOE secretary, EPA Administrator Browner decrees DOE application "complete"; starting the fyr clock for review of CCA.

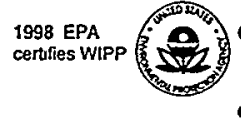

1998 - May: EPA certifies WIPP. F5I Jul: NM AG sues EPA alleging Insufficient time to comment on CCA. CARD and SWRIC also file law suits.

- 1998 - Mar: Judge Penn litts injunction: four days later WIPP receives first shipment of non-RCRA waste from

TRI-6342-5841-2

Figure 6-2. Engineering analysis of the illustrated behavior of the disposal system. 


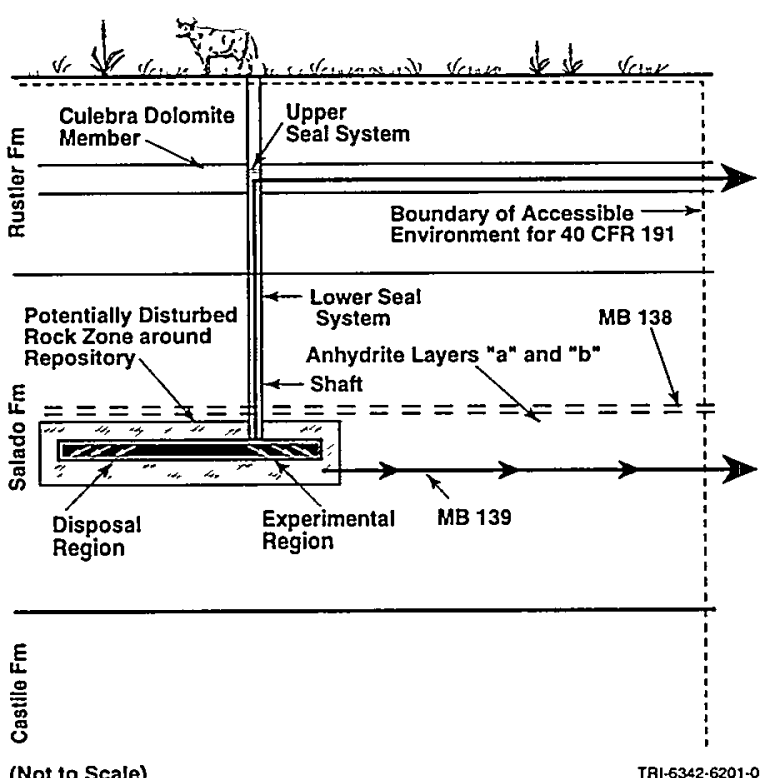

Figure 6-3. Undisturbed scenario used since 1989 (Rechard, 1995, Figure 3.2-3).

In the human intrusion scenario, it was assumed that if the disposal area of the repository was penetrated by an exploratory borehole, radioisotopes could be released in two different ways over two different time scales. First, an immediate release could occur during the drilling process, because the drill bit was assumed to bore vertically through a stack of CH-TRU waste containers or through a single RH-TRU waste container (refer to Section 4.2 and the description of TRU categories). Material within the containers could be ground up by the drill bit (called cuttings) and transported to the surface by the circulating drilling fluid. Additional material might be eroded from the walls of the borehole by the swirling action of the drilling fluid (called cavings) or the spalling of solid material into the hole as the panel depressurizes. Second, although it was assumed the boreholes would be plugged upon abandonment according to current industry standards, selective degradation of these plugs, accompanied by an eventual shift to a permeability similar to that of sand (as suggested in Appendix C of 40 CFR 191), could lead to the possibility of long-term releases by means of transport through the repository, up the boreholes to the aquifer in the Culebra, and then laterally through the Culebra toward the boundary of the accessible environment. In subsequent discussion of the models, transport through the repository and boreholes was evaluated by repository modeling, and flow and transport through the Culebra by Culebra flow and transport modeling (see Section 7).
In a refinement of FEP screening in 1990 (Guzowski, 1990), the presence of the brine reservoir in the underlying Castile was combined with exploratory drilling to produce three representative intrusion scenarios (Figure 6-1b): E1, a borehole drilled through the repository and the brine reservoir; E2, a borehole drilled through the repository only; and E1E2, a combination of the two. In the scenarios, the borehole plugs were assumed to degrade so that contact was maximized between the pressurized Castile brine and the panel of waste. For example, for the E1E2 scenario, the borehole that penetrates the Castile brine reservoir (E1 borehole) was assumed to remain plugged just above the level of the waste panel. The E2 borehole was assumed to remain plugged just above the level of the Culebra aquifer. Thus, the pressure-driven brine flows through the panel before flowing up the E2 borehole to the Culebra aquifer. These plug configurations were chosen to facilitate examination of the specific scenarios and did not reflect the most realistic conditions expected. Any brine entering through the boreholes was assumed to access all waste within one panel (Figure 6-4). For improved computational resolution in 1991 and 1992, the three scenarios were divided further into computational scenarios on the basis of time of intrusion and radioactivity of the intersected wastes starting in 1991 (Helton and Iuzzolino, 1993). In addition, E2-type intrusions were

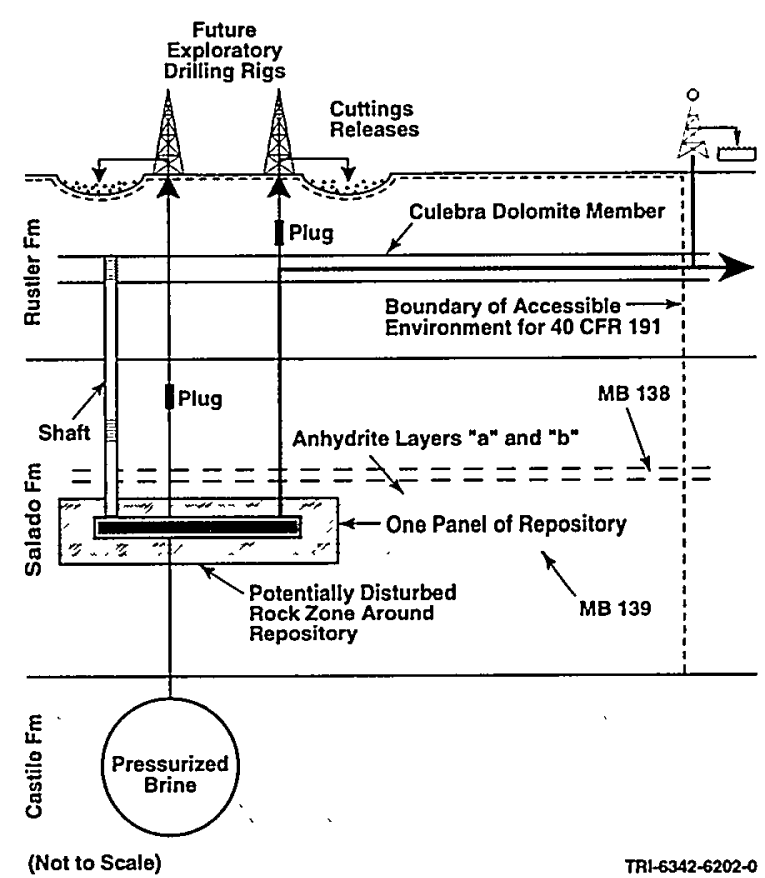

Figure 6-4. EIE2 human intrusion scenario used since 1990. Intrusion borehole plugs are placed to maximize brine flow through the repository (Rechard, 1995, Figure 3.2-4). 
not analyzed explicitly but rather assumed to have the same consequences as E1-type intrusions (WIPP PA Division, 1991/1992).

\subsection{Hazard Identification for 1996 PA}

For the $1996 \mathrm{PA}$ in support of the CCA, a formal hazard identification and screening process was conducted, as described in Galson and Swift (1995). Hazard identification began with lists developed in the 1990s for international programs and relied heavily on the comprehensive list developed by Sweden in 1993 (Stenhouse et al., 1993). Reasons for omitting or retaining specific FEPs were fully documented. For example, the low probability and low consequence arguments for not considering criticality in or around the repository were formally documented in a 100-page report
(Rechard et al., 1996). In addition, two human-initiated events were added to the initial list. (1) subsidence in the Culebra after potash had been mined above the repository, as mandated by the implementing regulation for the WIPP, 40 CFR 194, and (2) the potential for inadvertently injecting large volumes of water into the repository through anhydrite layers in the Salado because of failed casing (Stoelzel and O'Brien, 1996; Stoelzel and Swift, 1997). The latter event was based on experience in the Delaware Basin from drilling new oil wells in areas where water flooding had occurred to enhance oil recovery from deep oil reservoirs. Prior to 1996, the uncertainty about whether the most appropriate FEPs had been included for analysis had not been formally reviewed. However, during its 1997 review of the CCA, the EPA (and the EEG) closely examined the justifications for eliminating various FEPs. In particular, the removal of the water flood event was scrutinized and the EPA requested additional analysis. 


\subsection{Consequence Analysis}

Although various components of the disposal system had been analyzed independently since project startup, the first major consequence analysis of the disposal system as a whole was conducted in 1979 for the EIS (DOE, 1979; 1980a). Thereafter, the whole system was analyzed for the Supplemental EIS in 1989 (Lappin et al., eds., 1989; DOE, 1989c, 1990c), during the four preliminary performance assessments between 1989 and 1992 (Marietta et al., 1989; WIPP PA Division, 1991/ 1992; WIPP PA Department, 1992/1993), and for the 1996 PA in support of the CCA (DOE, 1996a). Currently, component and system analysis continues in preparation for recertification, which is required every five years during operation of the WIPP.

\subsection{Description of Consequence Analysis for the WIPP}

In general, a consequence analysis consists of (1) a toxicity assessment, which evaluates the response of a "receptor" (e.g., a human) to a hazard (or "stressor"), and (2) an exposure pathway assessment, which evaluates the exposure intensity of a hazard that reaches a receptor ${ }^{1}$. For the original EIS, the dose conversion factors developed by the DOE were used (DOE, 1979; 1980a). Later, the EPA performed the toxicity assessment when it established its release criteria in $40 \mathrm{CFR}$ 191, as promulgated in 1985 and 1993 (EPA, 1985a; 1993b). Evaluating the exposure pathway for the WIPP involved development of a model that is actually a mathematical function, designated herein as $q(\cdot)$ to predict exposures.

For a geologic disposal system, a challenge in consequence analysis has been understanding long-term behavior of system components, e.g., waste containers and their interaction with the host rock environment. The various physical scales in a geologic disposal system made one detailed exposure pathway model impractical. Instead $q(\bullet)$ was further divided into many component models $M_{\ell}\left(\bullet^{\circ}\right.$, that transferred variables produced by one model, $M_{\ell-1}(\bullet)$, to variables used by the next model, $M_{\ell+I}\left({ }^{\circ}\right)$. The models $M_{\ell}\left({ }^{\circ}\right)$ were dependent on the scenario $S_{j}$ (stochastic model parameters) under consideration and a subset of epistemic model parameters $\mathbf{X}^{p}$ related to that scenario. As discussed in the following sections, the component models used for the WIPP were the direct release model, repository model, source term model, Culebra flow model, and Culebra transport model.

\subsection{Analysis for Site Selection and EIS}

\subsubsection{Site Selection Analysis}

Although the consequence analysis performed during site selection by ORNL (Claiborne and Gera, 1974) is closer to a screening analysis, it influenced the assumptions and modeling techniques for the original EIS on the WIPP and so is described here. The analysis included assumptions about two component models $M_{\ell}\left(\bullet^{\circ}\right.$ : the source term model and the flow and transport model in the Culebra.

Source Term Modeling. In 1974, the radioisotope source was assumed to be high-level waste in 75,000 borosilicate glass canisters that were placed in the repository floor. Water from over- or underlying aquifers was assumed to have access to only a portion of the inventory-either 98 canisters in a short row or 765 canisters in a long row. The leach rate was set at $10^{-7} \mathrm{~g} / \mathrm{cm}^{2}$ per day, based on measured leach rates in borosilicate glass, and resulted in release rates of between $130 \mathrm{Ci} / \mathrm{yr}$ after $10^{3} \mathrm{yr}$ and $5 \mathrm{Ci} / \mathrm{yr}$ after $10^{6} \mathrm{yr}$.

Culebra Flow and Transport Modeling. In general, flow through the repository was assumed to be from the Culebra aquifer to deeper aquifers. However, transport of radioisotopes after catastrophic faulting placed the repository at the same level as the Culebra aquifer was analyzed. The radioisotope inventory was simply diluted by the volume of flow through the Culebra and by the minimum annual flow of the Pecos River at Malaga Bend. The dilution from the Culebra, as estimated from data from the Gnome site (Gard, 1968), was $1.1 \times 10^{5} \mathrm{~m}^{3} / \mathrm{yr}$ based on a $2.4-\mathrm{km}$-wide repository, 9-m-thick Culebra, and a Culebra porosity of 0.10 .

\footnotetext{
1 In essence, the consequence model is divided into two model categories: (1) a model for the human receptor, which currently is a simple linear bounding response curve, and (2) a model of the environment around the receptor, which consists of numerous complex exposure pathway models.
} 


\subsubsection{EIS Analysis}

In support of the EIS on the WIPP (DOE, 1979; 1980), the consequences of release were evaluated in terms of human exposure to radioisotopes that had reached the biosphere by some mechanism (Powers et al,, eds., 1978). As described in Section 6, three pathways to humans were of concern: direct release and two groundwater pathways. The consequences of release by these three pathways were treated deterministically and individually. The period considered for evaluating the environmental impact of the WIPP was a quarter of a million years, roughly ten half-lives of ${ }^{239} \mathrm{Pu}$. The consequence analysis used four component models $M_{\ell}(\cdot)$ : the direct release model, the source term model, the Culebra flow model, and the Culebra transport model.

Direct Release Modeling. In the EIS, consequences measured as dose were evaluated from direct release to either a geologist on the drill rig examining the core or a member of a single-family farm living $500 \mathrm{~m}$ downwind of the abandoned mud pits. Direct release to the surface from an intrusion into the repository was estimated simply as the amount of radioisotopes that would be removed by a $25-\mathrm{cm}$ (10-in) rotary drill for oil and gas exploration and deposited in the mud pit or a 7.6-cm (3-in) core drill for mineral exploration and deposited in a small pit. Exposure of a geologist examining the $7.6-\mathrm{cm}$ core was calculated to be $1 \mathrm{mrem}$. Exposure to a member of a single-family farm, who breathed the contaminated air and ate the farm's leafy vegetables, dairy products, and beef cattle, was calculated to be a maximum of $0.036 \mathrm{mrem}$, primarily from inhalation.

Source Term Modeling. Release of radioisotopes from the WIPP repository via the groundwater pathway was assumed to be congruent with dissolution of salt encapsulating the waste, regardless of the solubility of the radioisotope (DOE, 1980a, Appendix K). Disruption of the repository was assumed to occur after 1000 yr for all scenarios, except the bounding case scenario, with catastrophic flow of the Rustler aquifer through the repository, which was assumed to occur at $50,000 \mathrm{yr}$.

Culebra Flow and Transport Modeling. In the EIS, flow through the repository was assumed to be from the deep aquifers into the overlying Rustler. The Culebra and Magenta were combined and modeled by INTERA, Inc., for Sandia as a 12-m-thick layer, referred to as the Rustler aquifers, using a finite difference code, SWIFT (Sandia Waste Isolation Flow and Transport code [Dillon et al., 1978]), whose development was being funded by the NRC (see following section). The three-dimensional regional model for flow encompassed the Pecos River past Malaga Bend to the south, the town of Carlsbad to the west, Clayton Basin to the north, and the west edge of San Simon Swale to the east (Figure 7-1). Each layer was assumed to be an isotropic porous medium with several hydraulic conductivity zones. The Rustler aquifer layer was assumed to have a uniform porosity of 0.10 , a hydraulic conductivity of $0.3 \mathrm{~m} / \mathrm{s}$ above the repository and to the north, a hydraulic conductivity of $1.2 \mathrm{~m} / \mathrm{s}$ in Nash Draw and to the south of the WIPP site, and higher conductivity along the Pecos River (DOE, 1980a, Table K-2, Figure K-7). At this time, no regulatory exclusion zone or boundary had been defined, so regional flow, assumed to be toward the southwest, was discharged at Malaga Bend on the Pecos River. Transport calculations used a one-dimensional model along several flow paths to the Pecos River and included retardation.

\subsubsection{NRC Analysis}

For the NRC, Sandia initially described a consequence analysis method in 1978 (Campbell et al., 1978). In 1981 that process was applied to a hypothetical bedded salt repository (Cranwell et al., 1987) along with the scenario development procedure discussed in the previous section. The analysis process was similar to that used in the WIPP EIS and proposed at Pacific Northwest Laboratory in 1977 (Bartlett et al., 1977). The exposure pathway model, $q(\cdot)$, comprised a series of loosely connected individual codes specifically developed for the task. The study simulated a steady-state groundwater flow field using the finite-difference flow code, SWIFT (Dillon et al., 1978), evaluated a particle pathway, and then calculated radioisotope transport along this pathway using a network model, NWFT/DVM (Campbell et al., 1981). The groundwater releases to the surface were then input to a lumped parameter (compartment) model to evaluate radioisotope concentrations in surface water, sediments, and soil. These concentrations were then propagated through various food chains that eventually led to humans (Iman et al., 1978; Campbell et al., 1978; Cranwell et al., 1987).

In the mid-1980s, Sandia applied SWIFT II (Reeves et al., 1986) and NEFTRAN (Longsine et al., 1987) to a hypothetical repository in basalt similar to the geology found near Hanford, Washington (Bonano et al., 1988) for the NRC. Although the application of the numerical solution for the partial differential equations describing radioisotope transport had been implemented in SWIFT II, it remained difficult in practice so NEFTRAN, the next generation of NWFT/DVM, was used. 


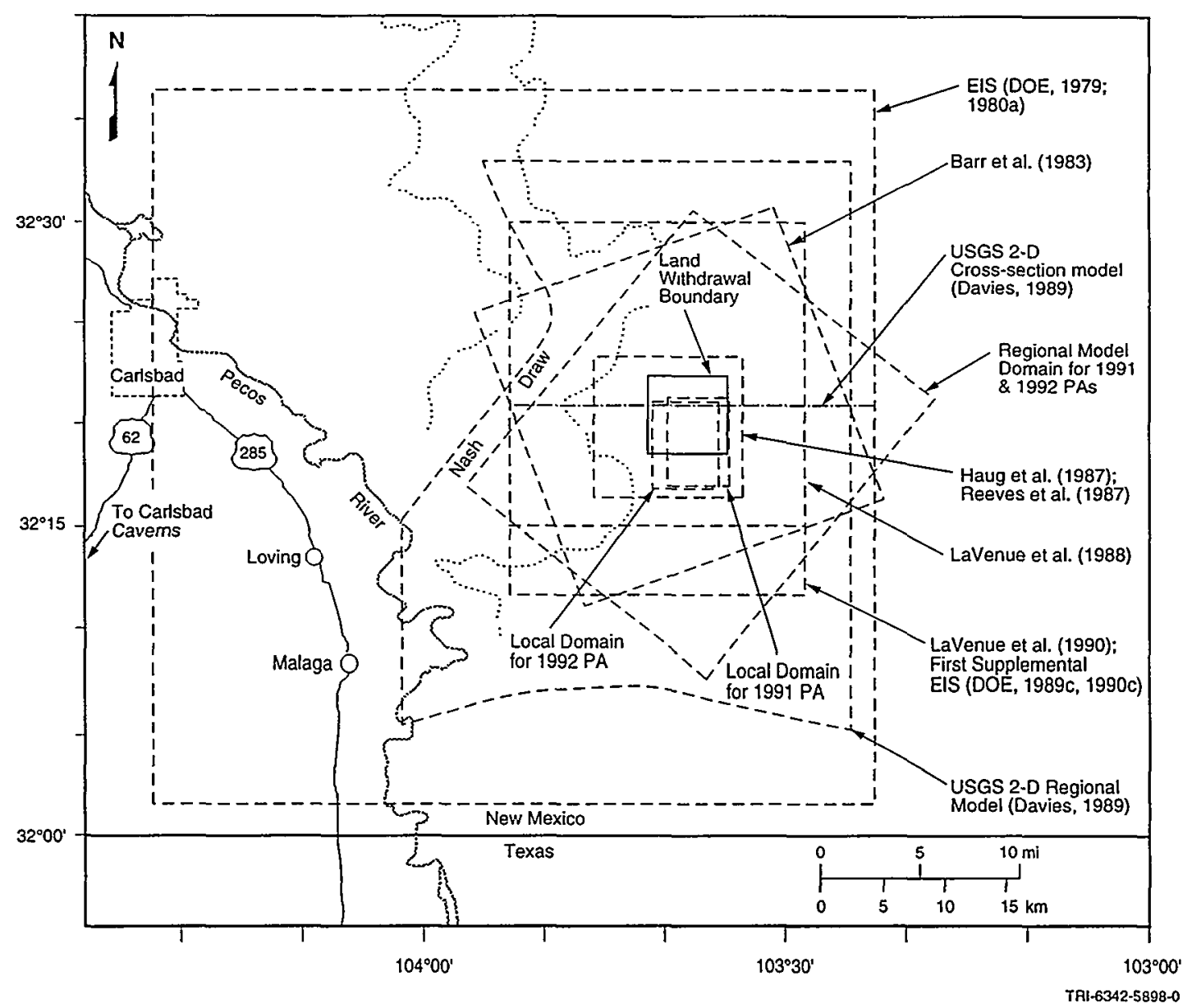

Figure 7-1. Boundaries of models constructed for analysis of groundwater flow and transport of radioisotopes in the Culebra at the WIPP (after Lappin et al., eds., 1989, Figure 3-25).

\subsubsection{Supplemental EIS Analysis}

The Draft and Final Supplemental EISs for the WIPP, completed in 1989 and 1990 (Lappin et al., eds., 1989; DOE, 1989c; 1990c), modeled release in a manner similar to that used for the original EIS, but incorporated the pressurized brine reservoir feature. As before, four major components $M_{\ell}\left(\bullet^{\circ}\right)$ of the exposure pathway model, $q(\bullet)$, were constructed: the direct release model, the Culebra flow model, the Culebra transport model, and the source term model. However, the latter model included some aspects of the repository and brine reservoir.

Direct Release Modeling. For direct release in the Supplemental EIS, an estimate was made of the volume of waste removed through erosion by the circulating drilling mud and then added to the volume removed by the drill bit, resulting in an upper bound of three full drums of $\mathrm{CH}$-TRU waste. For dose, the same pathways were used as in the EIS. The geologist dose was about the same as that calculated in the 1980 EIS, $\sim 0.08 \mathrm{mrem}$, but the farm family dose, a maximum committed dose equivalent over $50 \mathrm{yr}$ from inhalation, was more than the 1980 EIS calculation, $0.77 \mathrm{mrem}$.

Source Term/Repository Modeling. A distinct source term/repository model was developed for the Supplemental EIS, using SWIFT II (Reeves et al, 1986), to evaluate the concentration of radioisotopes injected into the Culebra. Four deterministic cases for the human-intrusion scenario were run, Cases IIa-d, using best and degraded values for parameters. The inventory was limited to either one panel (Cases IIa, IIb, IIc) or one room (Case IId) based on assumptions of the compaction and permeability of the salt backfill. Unlike the original EIS, the source term concentration was limited by a general actinide solubility in addition to the inventory. A range was established for the solubility limit for all actinide radioisotopes but in the calculations was set at either $10^{-3} \mathrm{mM}$ or $10^{-1} \mathrm{mM}$ (Cases IIb and IIc) (see Figure 4-2). 
The use of a solubility limit to determine concentration required that the amount of brine available to dissolve the radioisotopes be estimated. A constant flow from the Salado of either $1.3 \mathrm{~m}^{3} / \mathrm{yr}$ (Case IIb and IIc) or $0.1 \mathrm{~m}^{3} / \mathrm{yr}$ (Case IId) was used, based on calculations completed in 1988 in conjunction with the brine inflow controversy (Nowak et al., 1988). The amount of brine flow from the Castile brine reservoir was estimated using a well bore submodel in SWIFT II and a numerical mesh of the brine reservoir. The degraded borehole permeability was assumed to be either $10^{-12}$ or $10^{-11} \mathrm{~m}^{2}$. Other parameters of the Castile brine reservoir such as initial pressures, thickness, and diameter were varied. Given the assumption that the borehole plugs failed at $75 \mathrm{yr}$, the amount of brine from the Castile reservoir was initially either $9.9 \mathrm{~m}^{3} / \mathrm{yr}$ (Case IIa) or $98 \mathrm{~m}^{3} / \mathrm{yr}$ (Cases IIb, IIc, and IId).

Characterization Study of Culebra in 1987. In 1987, Haug et al. (1987) of INTERA, Inc., calibrated a two-dimensional flow model to the $\mathrm{H}-3$ pumping test (Beauheim, 1987) and the effects from the excavation of the shafts for Sandia. Data from several boreholes that had been drilled and tested by Sandia since 1980 were included in this model. The boundaries of the model were slightly larger than the WIPP site (Figure 7-1). As a secondary calibration target, measured brine densities were used; they were assigned at the boundaries and subsequently modified to match the observed fluid densities. Vertical leakage was included in an effort to calibrate the brine densities, which led to the recommendation that future modeling studies treat the Culebra as a leaky-confined aquifer. The transmissivity field was estimated by kriging and modified by the addition of artificial transmissivity well measurements ("pilot points"), which were positioned manually by trial and error. Haug et al. (1987) found that to match the low levels at wells $\mathrm{H}-11$ and DOE-1 required placing a highly transmissive zone south of these wells. Based on a comparison of a model at the regional scale, Haug et al. (1987) also concluded a single-porosity (matrix-only) conceptual model adequately simulated the fluid flow field.

Modeling of Culebra Fluid Flow in 1989. The 1987 study was followed by two more modeling studies by INTERA, Inc., for Sandia in 1988 and 1989 (LaVenue et al., 1988, 1990) in support of the Supplemental EIS. The differences in the models were that vertical leakage was not included and brine density varied spatially but was held constant over time. Also, the boundaries of the 1988 and 1989 studies were larger than those of the 1987 study. The 1989 study extended approximately $30 \mathrm{~km}$ north and south and $20 \mathrm{~km}$ east and west, with the WIPP site at the center (Figure 7-1).
These boundaries were selected to include the region for which head data were available and to minimize the boundary effects during simulation of the H-3, WIPP13 , and H-11 pumping tests. Fixed heads, based upon the regional head values, were assigned around all four boundaries. Transmissivities were estimated by kriging from measurements at 41 well locations (Figure 3-2, all wells except $\mathrm{H}-19$ ); the transmissivities varied over seven orders of magnitude over the model domain and three orders of magnitude within the WIPP site. As before, pilot points were added to modify the transmissivity field during steady-state and transient calibration; however, pilot point locations were selected using an adjoint sensitivity analysis technique rather than manual trial and error. Fluid flow was calculated on the basis of a fully confined Culebra with an effective thickness equal to the total average thickness of $7 \mathrm{~m}$. Flow in the Culebra was predominantly north to south at the WIPP site, and strongly affected by the high-transmissivity zone in the southeastern portion of the site first proposed by Haug et al. (1987) in 1987.

Culebra Transport Modeling. For contaminant transport, a one-dimensional model was used with a dual-porosity formulation (i.e., fracture transport with matrix diffusion) along a selected flow path (Lappin et al., eds., 1989). However, the effect of lateral dispersion was estimated. Some transport parameters such as fracture block length $(0.25$ to $7 \mathrm{~m})$ and fracture porosity $(0.0015)$ were based on best estimates from nonsorbing tracer tests at $\mathrm{H}-3$ and $\mathrm{H}-11$ wells. Other transport parameters such as matrix porosity, matrix tortuosity, and grain density were evaluated from 73 core samples taken from 15 different wells. Longitudinal dispersivity was set at a maximum of $100 \mathrm{~m}$.

\subsection{Analysis Logistics for PA}

Although the task had initially been assigned to Westinghouse, the DOE asked Sandia to assess the performance of the WIPP in 1986 in order to compare it with the criteria in 40 CFR 191 (Krenz, 1986; Beckner, 1986). The practical aspects of performing the exposure pathway calculations in a performance assessment were daunting for a system comprised of several complex model components, such as the WIPP disposal system. An important practical problem in the WIPP Project was how to link the component models together so that they were sufficiently comprehensible, traceable, and repeatable for regulatory review. Another important consideration was determining the appropriate level of detail for the individual models that comprised the exposure model. The manner in which these issues were addressed for the WIPP is discussed below. 


\subsubsection{Iteration of Calculations}

In 1989, the WIPP PA analysts adopted the idea of conducting sequential performance assessments, that is, conducting an initial performance assessment with simple or incomplete models and preliminary data, followed by other performance assessments with better data and/or more detailed models (Rechard, 1989). The idea had been used before, e.g., repeated NAS studies of ozone depletion in 1975 through 1982 (NAS/NRC, 1982; Morgan et al., 1990) or the 1975 Reactor Safety Study and its 1990 update (Breeding et al., 1992). The value of repeating the PA process was that engineers and scientists could gain an understanding about the disposal system and how best to model it and also replace weak links in the simulation chain as improved models and data became available, as discussed in Section 7.4.

In addition, multiple performance assessment iterations achieved other benefits. First, a long, multiyear project could be divided into annual tasks, with more easily agreed-upon goals and schedules. Second, iterations allowed annual peer reviews so that the project received feedback that not only provided insights on the models and engineering analysis but also facilitated communication about controversial waste disposal issues and fostered interactions among members of the multidisciplinary teams. For instance, the PA group at Sandia formed a special external review group in 1987 that met through 1992 to review the preliminary performance assessments. In addition, the WIPP Panel of the NAS and the EEG, though not set up in 1978 exclusively to review performance-assessment-like calculations (or evaluate compliance), received quarterly presentations and made comments on performance assessment calculations.

Third, later iterations based on more advanced models or newly collected data could sometimes answer critical questions posed in earlier iterations. For example, the choice of the most appropriate conceptual model (i.e., whether to use single porosity or dual porosity to model radioisotope transport) in the brine aquifer above the WIPP repository resulted in the design of a field test and a new well, $\mathrm{H}-19$, to address this specific question in 1994. Finally, in combination with sensitivity analysis (Section 8), iterative performance assessments allowed project managers, PA analysts, and experimentalists to decide how best to allocate resources for supplementary data collection and whether models should be elaborated upon or simplified in later iterations. Consequently, Sandia conducted four preliminary performance assessments from 1989 through 1992, with each building upon the others (Marietta et al., 1989;
Rechard et al., 1990; Bertram-Howery et al., 1990; WIPP PA Division, 1991/1992; WIPP PA Department, 1992/1993).

\subsubsection{Detailed Modeling Style}

The analysis that Sandia conducted for the 1979 EIS relied heavily on detailed, phenomenological mathematical modeling to evaluate potential exposures (DOE, 1979; DOE, 1980a), particularly because public expectations, expressed as comments on early nuclear reactor EISs or the promulgation of regulations, suggested a preference for "realistic" analysis. By the 1990 PA, PA analysts had also chosen to emphasize the detailed modeling style. Comments received from the EPA (Bertram-Howery et al., 1990) and the WIPP Panel of the NAS on the 1989 demonstration encouraged Sandia to move from the simplified NEFTRAN models to more detailed modeling. Another reason for using a detailed modeling style was the general acceptance in the United States of its use in probabilistic risk assessments (Rasmussen, 1975; Breeding et al., 1992). The detailed style included phenomenological details and often multiple dimensions in the model and avoided simplified or conservative models or parameter values unless required data or knowledge was unavailable (Rechard, 1995). Also, when exploring the feasibility and desirability of subseabed disposal of radioactive waste, Sandia used detailed modeling of some system components such as ocean circulation (Marietta and Simmons, 1988). Some models, such as PANEL, remained simplified, but in general phenomenological models were used extensively in 1992 and 1996. However, the phenomenological models often used fairly coarse numerical descriptions, and in a few instances, the results of some models (e.g., SANTOS and FMT mentioned in Section 7.4) were abstracted into simplified descriptions rather than used directly.

\subsubsection{CAMCON Development for PA}

The major role of modeling in a performance assessment makes computer software fundamental to the process. Modeling a detailed complex system meant that models must be linked together reliably throughout a large number of repetitive computer simulations, as in a Monte Carlo analysis. Also, results must be properly identified for traceability. In response to these needs, the WIPP Project built the computer system, CAMCON, to aid in linking software and identifying results (Rechard, 1989, 1991; Rechard et al., 1989). 
Although Sandia had developed codes that were loosely connected for the NRC in the late 1970s and early 1980s, the Canadians developed the first integrated system, SYVAC (Dormuth and Sherman, 1981; Lyon, $1982)$ in 1981. By the time Sandia was assigned the task of assessing the WIPP in August 1986, several other software systems had been built to meet the general requirements of performance assessment. One approach was to build one code with numerous submodels (e.g., SYVAC, VANDAL [Thompson, 1987], and LISA [NRC, 1983]), and another was to place one analysis code into a package that included data preparation, Monte Carlo sampling, and results display (e.g., NEFTRAN-S [Campbell et al., 1991]). Flexibility and quality assurance features, however, were especially important for radioactive waste disposal because the calculations were to be under intense scrutiny by the regulator. For the WIPP, serious work on developing a fully operational procedure that incorporated these characteristics began about mid-1987, with the CAMCON system developed primarily between 1988 and 1990. During the first year, a prototype was rapidly developed for the 1989 PA demonstration (Rechard et al., 1989). Simultaneously, a more carefully constructed version was developed for the first complete PA in 1990. The CAMCON system adopted several of the concepts that had been put forward for the NRC program, but discarded specific tools.

The original concept for CAMCON was to provide an analysis "toolbox" (more than one tool) whereby any number of either complicated numerical or simple analytical codes could be linked together (Rechard, 1989; Rechard et al., 1989). With this toolbox, any one of several interchangeable but not identical codes could be used for a model component, i.e., $M_{\ell}^{1}, M_{\ell}^{2}, \ldots M_{\ell}^{n M}$ where $n M$ designates codes that perform a similar function, and $\ell$ designates a specific model component such as the Culebra transport model mentioned earlier. Section 7.4 discusses the different codes selected for the model components. The selected model components could then be linked with other model components to form the exposure pathway model, $q(\bullet)$. The toolbox also included tools such as MATSET (Rechard, ed., 1992), ALGEBRA (Gilkey, 1988), and RELATE (Rechard, ed., 1992) to extract data from a parameter data base, to algebraically manipulate output to evaluate new parameters or results (e.g., evaluation of a line integral to calculate release across a boundary), and to interpolate results across different meshes in order to make linkages between codes practical. The toolbox also included tools to help implement software quality assurance procedures.
The early version of the CAMCON system consisted of six components (Rechard et al., 1989; Rechard, 1991; Rechard, ed., 1992) (Figure 7-2): (1) code modules (or "grouping" of codes), (2) a directory' structure that facilitated configuration control; (3) a series of procedural files, CAMCONexec, that allowed an analyst to link the individual component codes and execute portions or all of a compliance assessment; (4) a set of libraries to interface with codes and users (Rechard et al., 1993a); (5) a series of help files containing instructions on use and history of updates; and (6) two data bases-CAMDAT (Compliance Assessment Methodology DATabase), a computational data base containing code outputs in .CDB files, and a secondary database of .SDB files containing parameter values (discussed in Section 8). CAMDAT, which was based on a neutral file format that had evolved between 1980 and 1988 in Sandia's Engineering Analysis Department (Taylor et al., 1986; Mills-Curran et al., 1988), was the link between the computer modules.

The concept for the calculational system for the 1996 PA in support of the CCA was essentially the same, although details were changed. By the time of the 1996 PA, the costs of the stringent QA procedures required the selection of one code for each major component of the consequence model. Those codes specifically developed for the PA task were selected, and thus code modules were not necessary. Second, software specifically designed for configuration management was used rather than an ad hoc directory structure. Finally, a disinterested third party specialist built the batch scripts for run management and control, instead of using batch scripts built by PA analysts through CAMCONexec. Efficiency of computer use increased as the result of these changes, although the driving force behind them was to provide the EPA auditors with objective evidence that the PA process was truly traceable, understandable, and repeatable by others.

\subsection{Consequence Models in Performance Assessments}

The major categories of the WIPP consequence model components for the performance assessments were the direct release models, the repository fluid flow model, the source term model, the Culebra transmissivity model, and the Culebra flow and transport model (Figure 7-3). 


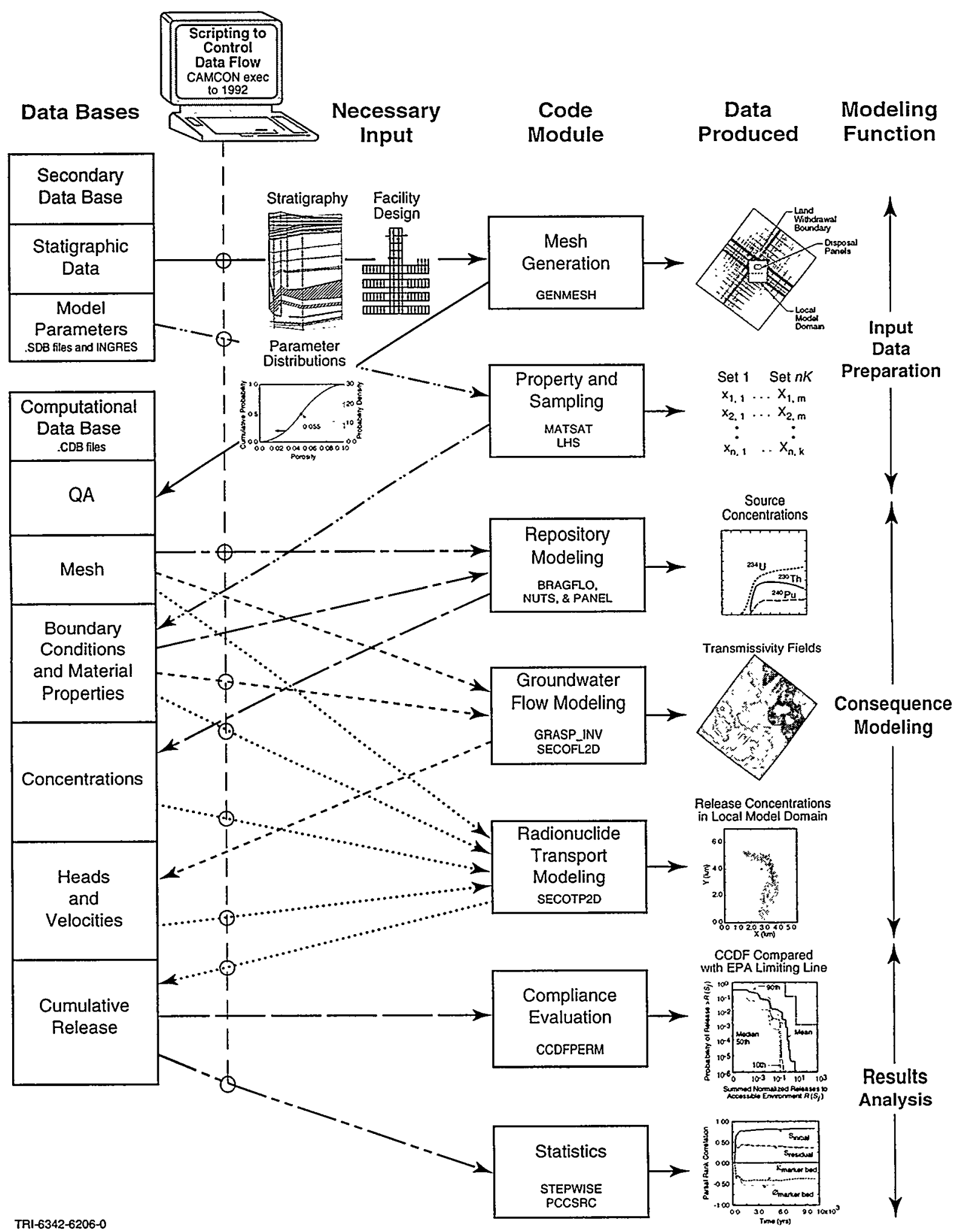

Figure 7-2. Schematic of CAMCON model system completed in 1991. By 1996, CAMCONexec was replaced by computer specialists for run control and management of files (Rechard, 1995, Figure 3.3-4). 
1989

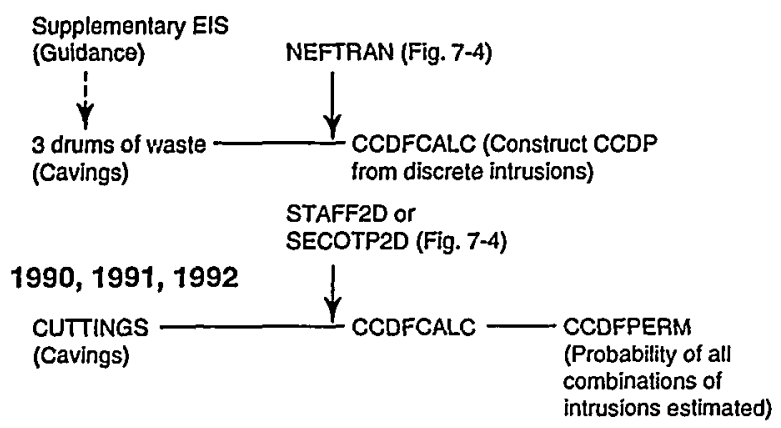

1996

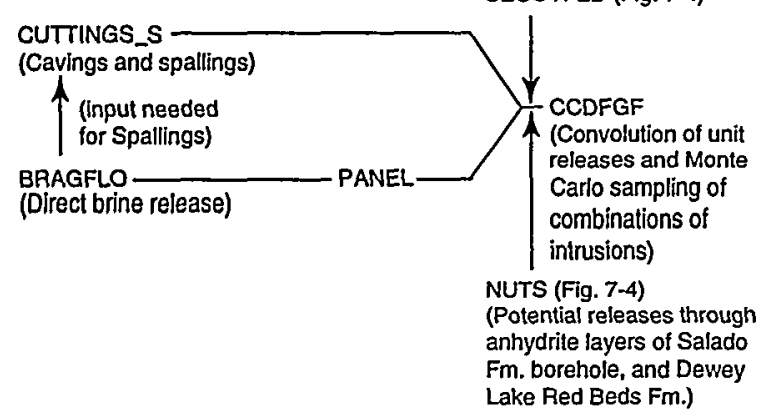

TRI-6342-5857-1

Figure 7-3. Changes in components of the exposure pathway ("consequence") model for immediate releases after exploratory drilling for evaluating compliance of the WIPP.

\subsubsection{Direct Cutting and Brine Release Modeling}

Direct Cuttings Modeling. For the 1989 PA, the direct release was the same as that estimated for the Supplemental EIS (i.e., three drums of waste). However by 1990 , the CUTTINGS model (Rechard, ed., 1992) had been developed to calculate releases caused by erosion of material from the sides of the borehole from standard rotary drilling and was used through 1992. CUTTINGS could estimate erosional removal assuming either laminar or turbulent flow in the annulus between the drill stem and borehole, based on the Reynold's number. CUTTINGS also decayed the radioisotopes based on the time of intrusion into the repository.

Spalling Modeling. Concurrent with the 1992 PA (but not part of the $1992 \mathrm{PA}$ ), the quantity of waste particulates released through the spalling of the borehole wall was estimated, i.e., waste released due to the movement of high-pressure gas generated from degradation of containers and organic material to the borehole when the repository was penetrated (Berglund, 1992). Several types of calculations were made and an experimental program was begun to more thoroughly understand the phenomenon. A conservative estimate was made initially and included in the first version of the PA for the CCA submitted in October 1996. However, in reviewing the CCA, the EPA found that the spallings model, though conservative, lacked sufficient realism to be easily defended scientifically; hence, they requested redevelopment in the supplemental analysis for the CCA. The mathematical model for spallings was included in the 1996 PA as CUTTINGS_S.

Direct Brine Release Modeling. In response to requests since 1989 by the EEG, Sandia evaluated in the 1996 PA the potential release of contaminated brine to the surface during drilling. The WIPP two-phase flow code BRAGFLO was used to simulate the direct brine releases. However, to more accurately capture the flow patterns associated with direct releases of short duration, a conceptual model different from the repository model described below was constructed to represent the excavated rooms, drift passageways, and salt pillars. The actinide source term model, PANEL, described later, was used to estimate the activity of radioisotopes in the brine released (Figure 7-3).

\subsubsection{Repository Fluid Flow Modeling}

Unlike the EIS analysis, the intrusion borehole(s) and repository in the PAs were represented as a model component, $M_{\ell}(\bullet)$ separate from the source term model. The primary purpose of the repository fluid flow model was to estimate the movement of fluids, both brine and gas, into and out of the repository. In the 1989 PA, the repository, shafts, and intrusion boreholes were represented as distinct legs in the network model NEFTRAN (Figure 7-4). In 1990, the movement of brine into the repository from the Salado was estimated using the single fluid phase finite-element code, SUTRA (Voss, 1984). Another code, PANEL (Rechard, ed., 1992), estimated, through solution of ordinary differential equations, the time history of flow from the hypothesized underlying brine reservoir in the Castile into the Culebra.

Prior to and during 1990, Sandia explored the behavior of fluid flow and radioisotope migration in and around the repository, including (a) gas flow from the disposal area to the shaft using the two-phase code BOAST (Fanchi et al., 1987), (b) Salado brine flow through a panel to a borehole using SUTRA, (c) effects of anhydrite layers on Salado brine flow through a panel 
1989

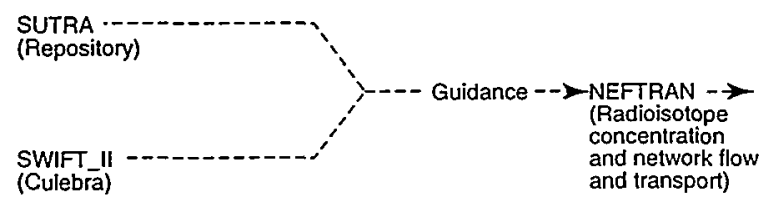

1990

Undisturbed $\{$ BOAST $\|$-..--

scenario EO ( 2 phase flow conditions) (No releases)

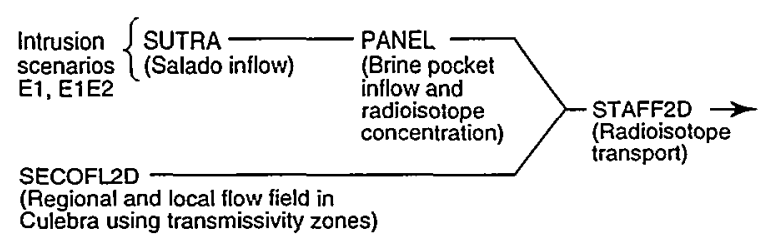

1991

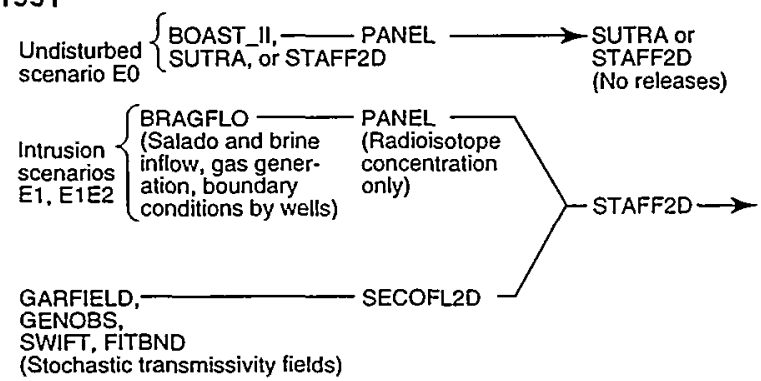

1992

SANCHO

(Salt creep and porosity

reduction averaged over repository)

I

BRAGFLO — PANEL

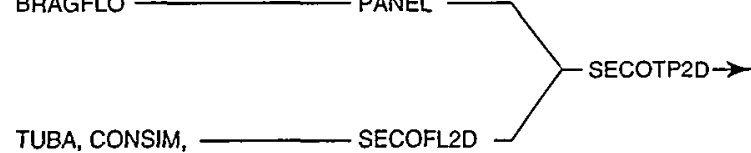

AKRIP, SWIFT II,

GRASP II, PILOTL, PAREST

(Stochastic transmissivity fields)

\section{6}

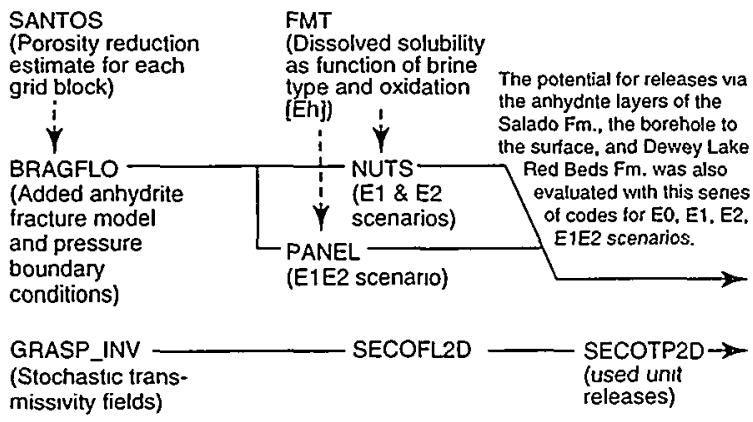

TRl-6342-5853-1

Figure 7-4. Changes in components of the exposure pathway model for long-term releases via leaking borehole and Culebra brine aquifer. using SUTRA, and (d) flow from a brine reservoir through a disposal room using PANEL (Rechard et al., 1990). A useful concept from this exploration was the practice of varying the size of the gridblocks in the third dimension, i.e., the direction perpendicular to the plane of the grid, in an otherwise two-dimensional numerical mesh. This "element flaring" allowed the analyst to approximately account for volume changes and thereby approximate the very small borehole or shaft, moderate repository volume, or the much larger volumes beyond the repository. The technique had evolved into a fine art by 1992 and was carried forward to the $1996 \mathrm{PA}$.

Although SUTRA was again used in 1991 for the undisturbed scenario to estimate flow of brine in the repository, all estimates of brine inflow for the humanintrusion scenarios were calculated by the newly developed two-phase fluid flow code, BRAGFLO (i.e., PANEL and BOAST were replaced). The roots of BRAGFLO formulation are in TSRS, a multiphase multicompositional thermal reservoir simulator developed for the DOE for modeling in situ processing of tar sand (Vaughn, 1986). BRAGFLO was developed with a fully implicit numerical formulation because no other code in the public domain, including BOAST, was then available for simulating the convergent flow of gas and brine to the intrusion borehole. Also, a gas generation submodel was incorporated into the 1991 version of BRAGFLO to account for gas generated by the anoxic corrosion of metals and the degradation of organic material in the TRU waste.

In 1992, alternative models of capillary pressure and relative permeability of the salt (Brooks-Corey and van Genuchten) were included through sampling (WIPP PA Department, 1992-1993, Vol. 3). Also, the effects of salt creep, which reduced porosity in the repository, were incorporated by using a generalized porosity reduction surface abstracted from numerous simulations using the salt creep code, SANCHO (Stone et al., 1985), previously developed for characterizing the WIPP facility (see Section 5.3). This surface was refined using SANTOS (Stone, 1997) and used for each grid block in the disposal area in 1996. Also in 1996, a submodel was added to account for brittle fracture of the anhydrite layers caused by pressure buildup from gas generated in the repository.

\subsubsection{Source Term Modeling}

The 1989 PA used a source-term submodel in the transport code NEFTRAN, as in the Supplemental EIS (Lappin et al., eds., 1989), to evaluate the radioisotope 
concentrations released into the Culebra. However, the source term model quickly evolved from a submodel within NEFTRAN to a separate, lumped parameter ("mixing cell") model, PANEL, in 1990 (Rechard, ed., 1992). PANEL determined radioisotope concentrations based on solubility limits and decayed inventory values based on brine passing through a specified volume (e.g., disposal panel). PANEL had the capability to either internally estimate the brine flow or read in external estimates. As briefly mentioned in the previous section, in 1990, PANEL internally estimated the brine flow from the hypothesized underlying brine reservoir, but used an external estimate by SUTRA for the brine flow from the Salado, In the 1991 PA and thereafter, however, only the features in PANEL (WIPP PA Department, 1996) for solubility limits and decayed inventory were used; all brine flow estimates into the repository were calculated by BRAGFLO.

The 1996 PA used the code FMT (Babb and Novak, 1995) to evaluate radioisotope solubility for the E1 and E2 scenarios as a function of oxidation state of the radioisotopes, based on the oxidation capability $(\mathrm{Eh})$ of the repository and the type of brine dominating the water chemistry (i.e., ionic strength and dominate constituents) (Figure 7-4). The dissolved concentrations of radioisotopes as evaluated by FMT were combined with the concentration estimates of four categories of colloids (mineral, intrinsic, microbial, and humic) for input to the finite difference code, NUTS (Stockman et al., 1996), in its evaluation of radioisotope transport within the repository.

\subsubsection{Culebra Transmissivity Modeling}

The transmissivity parameter of the Culebra, i.e., hydraulic conductivity times strata thickness, varies spatially across the region surrounding the WIPP site. Incorporating the uncertainty of this continuously distributed parameter was necessary to properly evaluate the uncertainty in the PA results. However, the tools to incorporate this type of parameter uncertainty did not exist within the WIPP Project in 1989 and had to be developed.

Zonation of Culebra in 1989 and 1990. Although a calibrated spatially distributed transmissivity distribution had been developed for the Supplemental EIS (Lappin et al., eds., 1989), it represented only one of several possibilities. To propagate the uncertainty represented in the transmissivity field required developing numerous calibrated fields, which would have had to have been done manually in 1989 or 1990 and so was not feasible.
Instead, the 1989 PA used the one-dimensional network code, NEFTRAN, and divided the Culebra into different legs, each with a different transmissivity distribution. Similarly, the 1990 PA used a two-dimensional finite difference code specifically developed for the WIPP, SECOFL2D (Roache, 1993; Rechard, ed., 1992), and divided the Culebra into either 8 or 13 fixed zones. Uncertainty ranges of transmissivity were developed solely from well measurements from each zone in the first case, or well measurements and pilot points of the calibrated fields from the Supplemental EIS (LaVenue et al., 1990; Lappin et al., eds., 1989). In both years, the ranges of transmissivity distributions did not overlap between zones and the distributions of each zone were not correlated.

Culebra Transmissivity Fields in 1991. In 1991, the PA group at Sandia devised a relatively simple process to generate numerous transmissivity fields that agreed with estimated transmissivity measurements in wells and, when used as input to a fluid flow code, would generate aquifer pressures that reasonably matched known pressures (or "heads") in wells around the WIPP, i.e., the fields were "conditioned" or "made coherent" with measured transmissivity and well pressure data. First, transmissivity fields were generated (with a code, GARFIELD) (Rechard, ed., 1992). Next, randomly measured transmissivity fields were conditioned with actual measurements of transmissivity. The fields were further indirectly conditioned with the measured head data by evaluating the sensitivity of changes in the specified heads at the model boundary (with GENOBS and SWIFT II) (Rechard, ed., 1992), and appropriate fixed boundary heads were assigned. The transmissivity fields were then ranked by estimated travel time from a point directly above the disposal panels to the $2.4-\mathrm{km}$ boundary of the accessible environment and then randomly selected as input for the fluid flow calculations using SECOFL2D (Figure 7-4).

Culebra Transmissivity Fields in 1992. Sandia convened an expert working group that met in 1991 and 1992 to provide advice on various ways to propagate the uncertainty represented in the transmissivity fields of the Culebra (Zimmerman and Gallegos, 1993). Based on discussion within this group, the original method of Haug et al. (1987) and LaVenue et al. (1990) was automated by 1992, which made the procedure feasible for use in a PA. First, multiple transmissivity fields were generated (using TUBA [LaVenue and RamaRao, 1992]) and conditioned on transmissivity data as in 1991 (but using CONSIM [LaVenue and RamaRao, 1992]). The fields were then conditioned directly on steady state and transient head data by the technique originally used 
for the Supplemental EIS (i.e., pilot points) (LaVenue et al., 1990). Pilot points were automatically located (PILOTL) and assigned transmissivity values (PAREST) using an optimization routine (GRASP II) (LaVenue and RamaRao, 1992). By 1996, this series of codes was tightly coupled and referred to as GRASP-INV (Figure 7-4).

\subsubsection{Culebra Flow and Transport}

For flow and transport in the Culebra, all of the WIPP PAs calculated the fluid flow field assuming a single-porosity Culebra aquifer, but then estimated radioisotope migration through this flow field, assuming advective transport in fractures and diffusion into the surrounding matrix. The flow and transport models changed from the two-dimensional flow evaluation and one-dimensional transport evaluation for the Supplemental EIS to a two-dimensional flow and transport evaluation in 1992.

Culebra Flow and Transport in 1989 and 1990. In 1989, the analysis of fluid flow and transport with SWIFT II and NEFTRAN was similar to that used in the Supplemental EIS although uncertainty was evaluated for the performance assessment. In 1990, SECOFL2D was used to evaluate numerous flow fields based on sampled values for various parameters, e.g., parameter values for each transmissivity zone as mentioned earlier. The two-dimensional, finite-element code, STAFF2D (Huyakorn et al., 1991), was used to evaluate radioisotope transport within the Culebra to the WIPP site boundary at $-2.3 \mathrm{~km}$.

Culebra Flow and Transport in 1991. The 1991 PA rotated the model mesh $38^{\circ}$ from a north-south orientation to align one boundary of the mesh with the axis of Nash Draw such that a no-flow boundary could be specified along a portion of that boundary. In addition, the northeastern corner of the model was treated as a no-flow boundary because of the low transmissivities in the area and the lack of any nearby wells to provide head estimates. SECOFL2D was used for fluid flow and STAFF2D for radioisotope transport. Three conceptual models were compared (ceteris paribus rather than sampling model weights): matrix transport only, fracture transport only, and fracture transport with matrix diffusion.

Culebra Flow and Transport in 1992. The 1992 PA used SECOFL2D to evaluate fluid flow in the Culebra, but radioisotope transport was evaluated with the newly developed, two-dimensional, finite-difference code, SECOTP2D (Roache, 1993; Ramsey et al., 1996). SECOTP2D easily read the flow fields calculated by SECOFL2D. As in 1991 analyses, the 1992 PA considered both single-porosity (fracture-flow only) and dualporosity (fracture flow with matrix diffusion). Although fracture spacing was sampled in each simulation, only a single spacing was assigned to the entire aquifer. The distribution of fracture spacing was weighted heavily toward large values, and the calculations assumed an effective thickness of the Culebra equal to its total thickness $(7 \mathrm{~m})$.

Culebra Flow and Transport in 1996. The same codes (SECOFL2D and SECOTP2D) were used in the 1996 PA, but between 1992 and 1996, the calculational procedure was modified (unit releases were evaluated for transport and convoluted with actual releases) and the hydrologic and transport parameters of the Culebra were refined and used in calibrating flow fields. The refined parameter values were based on information from the tracer test at the new $\mathrm{H}-19$ well, additional measurements at $\mathrm{H}-11$, reevaluation of transmissivity and tracer measurements at $\mathrm{H}-3$ and $\mathrm{H}-6$ (see Section 3.4), and measurements from the DOE's Water Quality Sampling Program conducted annually around the site. Also, the effective thickness for the Culebra in the 1996 PA was set at $4 \mathrm{~m}$ (Figure 3-6). Currently, Sandia has concluded that the Culebra is adequately represented by a dual-porosity continuum model on the scale of PA calculations. 


\subsection{Probability Evaluation and Sensitivity Analysis}

In general, three elements are required for a stochastic model simulation in a performance assessment (Rechard, 1995; Tierney and Rechard, 1997): a consequence model, $R(\bullet)$, which was discussed in the previous section; a space of model parameters, $\mathbf{X}=\left\{x_{1}\right.$, $\left.x_{2}, \ldots x_{n P}\right\}$, which was conceptually developed during system characterization and hazard identification; and a joint cumulative distribution function of model parameters, $F(\mathbf{x})$. However, given that the parameter space was divided into two disjoint parts (those parameters associated with scenarios and the remaining parameters, i.e., $\mathbf{X}=\left[\mathbf{x}^{s}, \mathbf{x}^{p}\right]$ ), two types of probability evaluations were necessary for the WIPP PAs. Using scenarios for the model parameters, or stochastic uncertainty, was first attempted for the initial WIPP EIS in 1979 (Bingham and Barr, 1979, 1980). Probabilistic descriptions for the model parameters, or subjective uncertainty, was not attempted until the 1989 PA (Marietta et al., 1989).

\subsection{Scenario Probabilities and Parameter Selection for the EIS}

\subsubsection{Scenario Probabilities}

The probability of a scenario occurring was evaluated to screen out those with low probabilities. The use of fault trees to develop scenarios or calculate probabilities was found to be impractical during preparations for the EIS and therefore abandoned (Bartlett et al., 1977; Bingham and Barr, 1979, 1980). Hence, the probability models for screening scenarios for the EIS were mostly subjective judgments. The remaining scenarios were grouped into three scenario classes, which were evaluated by means of consequence models. Typically, the probabilities were estimated for three or four time periods: $10^{3}, 10^{4}, 10^{5}$, and sometimes $10^{6} \mathrm{yr}$ (Bingham and Barr, 1979, 1980). However, some probability models were created from measured failure rate data. For example, historical "failure rates" based on estimates of meteorites striking the earth, extreme erosion rates of land masses, geometrical arguments on probability of striking buried canisters, or faults intersecting the repository were all used.

\subsubsection{Parameter Selection}

Like the Reactor Safety Study (Rasmussen, 1975) conducted only four years earlier, there was no attempt to evaluate how the epistemic uncertainty in the model parameters contributed to the uncertainty in results for the original EIS. Uncertainty was evaluated only using scenarios. Furthermore, the EIS did not attempt to combine the various conditional consequences into an overall distribution. Model parameters were selected for the EIS for each scenario independent of other scenarios. The overall philosophy was to present conservative results when possible. Thus, different values for the same parameter sets might be used for separate hazards in order to maximize the consequences.

\subsection{Scenario Probabilities for Performance Assessments}

As described earlier, PA analysts continued to define a few scenarios to simplify modeling and call attention to human intrusion through exploratory drilling as specifically identified in 40 CFR 191 . Therefore, the probability of the scenarios, $P_{r}\left(S_{j}\right)$, had to be calculated by some method. In concept, the probability model for a scenario evaluates the probability that parameters lie in a subset of the parameter space that defines the scenario. Hence in theory, the distribution of all the parameters, $F(p)$, of the scenario can be used to define the scenario probability, $P_{r}\left(S_{j}\right)$. However, in the $1989 \mathrm{PA}$, the probabilities of various scenarios were based on subjective judgment, with no ranges of uncertainty as in the 1979 EIS.

After 1989, the inadvertent human intrusion event was assumed to be a Poisson process and so the probability of various numbers and combinations of intrusions was analytically calculated through the Poisson probability density function (Helton, 1993c). Usually the Poisson process was assumed to have a constant expected rate of intrusion, $\lambda$, over the 10,000-yr regulatory period. The intrusion rate was constant throughout any one simulation in the preliminary performance assessments between 1989 and 1992. However, a different value between 0 and the maximum value $\lambda_{\max }$ of 30 boreholes $/ \mathrm{km}^{2}$ per $10,000 \mathrm{yr}$ was selected for each of the many simulations, and thereby accounted for uncertainty in scenario probabilities. The probability of all permutations of intrusion geometry (e.g., one intrusion only, two intrusions into one panel of the repository, two intrusions into two different panels, etc.) and permutations of fixed intrusion times (e.g., at 2000-yr intervals for a groundwater pathway as in 1991 or only one at 
$1000 \mathrm{yr}$ as in 1992) was evaluated directly with the code CCDFPERM (see Figure 7-1 in Section 7).

In 1990, as an alternative, the WIPP Project conceptually examined the influence on results when the rate of intrusion was assumed to vary with time, $\lambda(t)$ (Tierney, 1991). For the $1992 \mathrm{PA}$, an actual function $\lambda(t)$ was constructed based on input from an expert panel that had considered future societies (Hora et al., 1991) and the effectiveness of markers at the site to convey the existence of hazards (Trauth et al., 1993). As a result, the overall number of intrusions decreased dramatically in comparison to a companion 1992 analysis with a constant $\lambda$ (Helton et al., 1996). In addition, the probability of all permutations of the intrusion geometry and of the intrusion times was no longer evaluated analytically but rather estimated through Monte Carlo sampling procedures (Helton and Shiver, 1996).

In $1996, \lambda$ varied with time but used the same function for all simulations. The functions were as follows: (1) $\lambda=0$ while active institution controls, such as land control, were present, $\mathrm{t}<100 \mathrm{yr}$; (2) $\lambda=0.01 \lambda_{\max }$ while passive institutional controls, such as markers about the WIPP site, were present, $100 \mathrm{yr}<\mathrm{t}<700 \mathrm{yr}$; and (3) $\lambda=\lambda_{\max }$ thereafter where the maximum rate of intrusion, $\lambda_{\max }$, was increased to 48.5 boreholes $/ \mathrm{km}^{2}$ per 10,000 yr based on guidance in 40 CFR 194 (EPA, 1995; 1996a).

\subsection{Parameter Uncertainty in Performance Assessments}

In 1985, when 40 CFR 191 requested the DOE applicant to "assemble all of the results of the performance assessments to determine compliance with $\$ 191.13$ into a "complementary cumulative distribution function'," an important goal for performance assessment became a consistent evaluation of system consequences such that individual consequences and the uncertainty from each could be combined in an overall distribution of the consequences. To address these issues (data consistency, uncertainty description, and uncertainty propagation), the WIPP Project had to develop a traceable system for regulatory review in which distributions for the uncertain parameters could be developed and values for fixed parameters selected.

\subsubsection{Data Bases for Model Parameters and Results}

In early 1989, the WIPP Project conceptually described three categories of data bases (Rechard, 1989): the primary, secondary, and computational data bases. The several primary data bases held measured field and laboratory data gathered by investigators from experiments during characterization of the WIPP disposal system (e.g., Munson et al., 1990). In general, the information stored in the primary data base was to be controlled by the investigators. The secondary data base contained distributions of parameters that had been derived from the primary data bases specifically for the various component models of the exposure pathway model $q(\bullet)$. The computational data base, generated during each performance assessment, comprised the calculated results. By 1990, the WIPP Project used the latter two data bases directly in the performance assessment calculations; however, the computational database existed only as a collection of catalogued files rather than as a relational database.

\subsubsection{Quality Assurance Procedures}

For the 1991 and 1992 PAs, the WIPP Project developed rudimentary quality assurance procedures. The purpose was to provide a reasonable degree of assurance to those outside the PA community that the results from the performance assessment process presented a logically consistent view of WIPP performance, based on current knowledge and explicitly identified sources of uncertainty.

The early procedures specified requirements in three primary areas of the analysis process (Rechard, 1995): Parameter Selection (Rechard et al., 1992a), Software (Rechard et al., 1991), and Analysis (Rechard et al., 1992b). In addition, procedures were prepared to ensure quality in two other secondary areas: Report Review and Expert Judgment Panels. These areas were related to the primary areas because, for example, all three primary QA areas required reports and review.

The Parameter QA procedures sought to provide the PA analyst with consistent computational model parameters. The fundamental requirement was the development of a secondary data base managed by a Task Leader responsible for selecting appropriate data in consultation with investigators and PA analysts. Transferring data from investigative or experimental groups to the secondary data base was an important method by 
which the PA analysts interacted with WIPP Project investigative groups.

The Software QA procedures were designed to ensure that the software met the expectations of the PA analyst. The fundamental requirement was the development of a Software Management System (the CAMCON Modeling System; see Section 7).

The procedures initially presented in the early 1990 s were developed into a full suite of quality assurance procedures for the 1996 PA supporting the CCA.

\subsubsection{Parameter Selection}

The use of a consistent set of parameters was initiated for the $1989 \mathrm{PA}$ and had become an important aspect by the 1990-1992 calculations. The general procedure used to acquire parameter distributions in the calculations from 1990 through 1992 was as follows (Rechard et al., 1992a; WIPP PA Division, 1991/1992):

1. Identify Necessary Parameters. The PA analysts identified parameter sets $\left(\mathrm{x}=x_{1}, \ldots, x_{n P}\right)$ that were necessary for PA calculations.

2. Gather Necessary Underlying Data. The PA analysts formally requested observational data from appropriate WIPP Project investigators. The investigator may have supplemented these data with additional data and general information from various sources to bridge any data gaps. Occasionally the PA personnel also informally compiled data for preliminary calculations and documented the status of the data.

3. Construct Parameter Distributions. Probability distributions were developed to describe uncertain parameters. Based on the information gathered, the PA analysts either constructed parameter distributions or used distributions provided by investigators, as described more fully below.

4. Update Secondary Data Base. The endorsed or elicited information on the model parameters was updated or entered in the secondary data base. The model parameters in the database were described formally beginning in 1990 (Rechard et al., 1990; WIPP PA Division, 1991/1992; WIPP PA Department, 1992/1993) and contained 191 parameters. By 1996, the database contained 1561 parameters.
5. Select Parameters To Be Sampled. Specific model parameters were chosen for sampling in each performance assessment. All other parameters were kept at their median values, unless specifically noted. An important practical problem for parameter uncertainty analysis was determining the number of uncertain parameters to propagate. As the computational ability increased, the number of uncertain parameters also grew with each assessment: 28 in 1989 (Marietta et al., 1989), 39 in 1990 (Rechard et al., 1990), 46 in 1991 (WIPP PA Division, 1991/1992), 49 in 1992 (WIPP PA Department, 1992/1993), and 57 in 1996 (DOE, 1996a).

\subsubsection{Describing Parameter Uncertainty}

To evaluate the epistemic (subjective) uncertainty of PA results, a joint cumulative distribution function, $F\left(X^{p}\right)$, was required that characterized the uncertainty of model parameters, $\mathrm{x}^{p}=x_{1}^{p}, x_{2}^{p}, \ldots, x_{n}^{p}, \ldots, x_{n U}^{p}, \ldots$, $x_{n P}^{p}$, where $n U$ is the number of uncertain parameters and $n P$ is the total number of parameters. As is standard practice, $F\left(X^{p}\right)$ was approximated by the product of the cumulative distribution functions of the individual parameters, $F\left(x_{1}^{p}\right) \bullet F\left(x_{2}^{p}\right) \bullet \ldots F\left(x_{n}^{p}\right) \ldots \bullet F\left(x_{n U}^{p}\right)$, an approximation that is exact when the parameters vary independently. Parameter independence was assumed for the preliminary PAs; however in the 1996 PA, very strong correlations $(-0.99,-0.99$, and -0.75$)$ were specified between two parameters, permeability and bulk compressibility, in three materials (Salado halite, Salado anhydrite, and brine reservoir anhydrite).

The cumulative distribution function, $F_{n}\left(x_{n}\right)$, of a parameter, $x_{n}$, ideally represented what was known and not known about the parameter range and the likelihood that these values were appropriate for consequence or probability models without assuming a "conservative" bias (see Figure 3-4). The avoidance of a conservative bias was an important shift from the philosophy pursued for the EIS (DOE, 1979; 1980a) and Supplemental EIS (DOE, 1989b; 1990c).

Because each parameter distribution function must be tailored to the type of data available and to the parameter's role in the computational models, parameter distribution characterization was not guided by a rigid series of steps. In most cases, each $F_{n}\left(x_{n}\right)$ included subjective factors representing the "degree of belief" of the WIPP investigators. Beginning in 1990 (Rechard et al., 1990), a maximum entropy formalism was tried and then used extensively by 1991 (WIPP PA Division, 1991/1992) to provide a consistent procedure for 
constructing the distributions (Tierney, 1994). In practice, the maximum entropy formalism involved connecting data points or subjectively estimated points with straight lines.

The use of a consistent set of parameters was initiated for the $1989 \mathrm{PA}$ and had become an important aspect by the 1990-1992 calculations. The data preparation code, MATSET (Rechard, ed., 1992), extracted data directly from the secondary data base for use by the modeling codes. This process ensured that the same parameter values were used consistently throughout the calculation. The 1989 PA primarily used parameter values from the supplemental EIS (Lappin et al., eds., 1989). Uniform, normal, lognormal, and beta distributions were fit to available data by the PA analysts as appropriate. Each year thereafter, however, more data were elicited directly from investigators, a process that was formalized in a quality assurance procedure (Rechard et al., 1992a). In some cases, parameters were evaluated through a formal expert panel while experimental data were collected, e.g., values for solubility of actinides in the repository and retardation in the Culebra for the 1991 PA (Trauth et al., 1992; Rechard et al., 1993b).

\subsection{Sensitivity Analysis}

Sensitivity analysis is the evaluation of aspects of the system that most influence the calculated or observed results. Specifically, a sensitivity analysis determines the uncertain parameters $x_{n}$ (or model forms, e.g., $M_{\ell}^{m}$ ) that most influence the result $R(\mathbf{x})$ and its cumulative distribution function, i.e., $\operatorname{Pr}\{R \leq r\}=$ $\int \delta\left[r-R\left(\mathbf{x}^{p}\right)\right] d F\left(\mathbf{x}^{p}\right)$, where $\delta(\bullet)$ is the delta function (whose integral is zero when the argument is negative and one when the argument is positive), $d F\left(x^{p}\right)$ is the joint probability function for the $\mathrm{x}^{p}$ model parameters, $r$ is an arbitrary variable, and the integral is evaluated over the space of uncertain epistemic parameters. A sensitivity analysis can be conducted after the probability, consequence, or compliance steps.

\subsubsection{LHS Technique}

During the 1940s, the advent of computers allowed new problem-solving techniques to address issues of nuclear weapon design. An important practical tool developed at this time-the Monte Carlo solution technique-was designed to integrate the multidimensional integrals that arose in the study of the physics of weapons and first documented in 1949 (LANL, 1987; Metropolis and Ulam, 1949). But the technique applies to any multidimensional mathematical integration such as determining the distribution of $R\left(\mathbf{x}^{p}\right)$, i.e.,

$$
\operatorname{Pr}\{R \leq r\} \simeq \frac{1}{n K} \sum_{k=1}^{n K} I\left[r-R\left(\mathbf{x}_{k}^{p}\right)\right]
$$

where $I(\bullet)$ is an indicator function equal to zero when the argument is negative and one when the argument is positive, $\mathrm{x}_{p}^{p}$ is a set of sampled parameters drawn from $F\left(\mathbf{x}_{k}^{p}\right)$ and $n K$ equals the number of Monte Carlo samples. However, making a large number of samples, as is necessary with the rudimentary Monte Carlo method, is impractical when evaluation of the function $R\left(\mathbf{x}^{p}\right)$ is time consuming, as in the WIPP calculations.

Many procedures have been developed to judiciously sample the domain of parameters to reduce the required total number of samples in a Monte Carlo analysis. A simple scheme developed in 1975, Latin Hypercube Sampling (LHS) (McKay et al., 1979), has been frequently used in the United States in performance assessments and probabilistic risk assessments because sample points are easily selected and there is frequently a good matching of results from more extensive random sampling. The LHS technique for Monte Carlo analysis was developed for a 1975 study to determine the important parameters in a complex code that modeled pipe ruptures in nuclear power plants (McKay et al., 1979). LHS was later applied to a 1980 examination of important parameters of a geologic disposal system (Iman and Conover, 1980).

The robustness of the procedures conjectured in the early 1980s (Iman and Conover, 1980; Iman, 1982) and more thoroughly demonstrated in the later 1980s (Iman and Helton, 1988; 1991) encouraged the WIPP Project to adopt the LHS technique to propagate parameter uncertainty and determine the distribution of $R\left(\mathrm{X}^{p}\right)$ for comparison with 40 CFR 191. Other techniques for sensitivity uncertainty analysis, such as developing surrogate analytic expressions for the results ("response surface development") or differential analysis with normalized partial derivative of parameters (e.g., "adjoint procedure"), were also proposed in the 1980s (Helton, 1993b). However, these techniques have never been used routinely for large-scale sensitivity analyses with several complex and linked submodels. Because the Monte Carlo technique was used to propagate uncertainty in the WIPP analysis, sensitivity of the results, $R\left(\mathbf{x}^{p}\right)$, to changes in parameter values could be approximated and conveniently determined in several ways, including (1) examining scatterplots and (2) developing a statistical regression model and comparing the size of the standardized regression coefficients or the associated 
partial correlation coefficient (Helton et al., 1993a, 1996).

\subsubsection{Sensitive Parameters}

The 1989 PA used sensitivity analysis but the method was ad hoc because CAMCON was not yet ready and so there was no easy method to input parameters and results into regression analysis codes. In the $1989 \mathrm{PA}$ and in all subsequent analyses, radioisotope releases occurred only after inadvertent human intrusion. Hence, out of the 28 parameters sampled in the 1989 PA, the most important parameters were those associated with the human-intrusion scenario: solubility of radioisotopes, the time of intrusion into the repository, and the assumed permeability of the resulting but abandoned borehole. The 1989 PA did not evaluate separately the release of radioisotopes from cuttings brought directly to the surface in the drilling operation because it was set at a constant value of three drums of CH-TRU waste. Simultaneous with the 1989 PA, a sensitivity analysis was conducted on the importance of alternative conceptual models and various modeling techniques for components of the repository submodel, as mentioned previously (Rechard et al., 1990).

With the initial version of CAMCON ready in 1990, regression analysis techniques to determine sensitivity were used (Helton, 1993b). The same three parameters (solubility of radioisotopes, time of intrusion, and assumed permeability of the borehole) were again the most important out of the selected 39 uncertain parameters in the 1990 PA (Bertram-Howery et al., 1990). This performance assessment also evaluated release of radioisotopes from cuttings brought directly to the surface; these releases controlled the shape of the CCDF at probabilities greater than 0.5. Below probabilities of 0.5 , radioisotope releases from the repository by means of groundwater transport through the intrusion borehole into the brine aquifer overlying the repository were important.

In the $1991 \mathrm{PA}$, release of radioisotopes from cuttings was clearly the dominant pathway and again controlled the shape of the CCDF for probabilities greater than 0.5. Out of 46 parameters sampled, two were important for this release: the rate constant $(\lambda)$ in the Poisson distribution for modeling the rate of human intrusion, and the borehole diameter $\left(\mathrm{d}_{\mathrm{b}}\right)$. However, because other parameters-solubility of plutonium, uranium, and americium; permeability of the borehole; permeability of the halite surrounding the repository; and retardation distribution coefficients for radioisotopes during groundwater transport-could markedly vary groundwater transport releases, their ranking in importance was higher than the diameter of the intrusion borehole, which influenced the amount of cuttings brought directly to the surface (WIPP PA Division, 1991/1992; Helton et al., 1993b).

In the 1992 PA (and also in 1996), releases from cuttings again dominated total radioisotope release for the mid to highest probabilities of the CCDF. Of 49 parameters, the three most important were the rate constant $\lambda$, borehole permeability, and solubility of americium (WIPP PA Department, 1992/1993; Helton et al., 1996). A separate sensitivity study was also conducted to determine parameters important to migration of gas and brine in the vicinity of the repository, because an evaluation of the potential for migration of RCRA hazardous constituents such as volatile organic compounds (VOCs) was still required at this time (Helton et al., 1993b).

\subsubsection{Project Guidance from Sensitivity Analyses}

For the WIPP Project, the sensitivity analyses helped to (1) verify the correctness of the calculations, i.e., errors were occasionally found when unexpected behavior was examined more thoroughly, (2) gain understanding and insight about the system, and (3) evaluate the influence of various options (Rechard, 1995). In addition, sensitivity analysis, in combination with multiple iterations through the performance assessment process, provided some guidance to project managers on how to direct resources for the collection of information about significant model parameter values and model forms, based on what was already known about the site or waste. In 1990 and 1991 some general guidance was provided (Helton et al., 1991; 1992), as mentioned previously. In the 1992 WIPP PA (and also in 1996), releases from cuttings again dominated total radioisotope release for the mid to highest probabilities of the CCDF. Of 49 parameters, the three most important were the rate constant, borehole permeability, and solubility of americium (WIPP PA Department, 1992/ 1993, Vol. 3; Helton et al., 1993a).

Thus, by 1992 it was evident that required regulatory assumptions about human intrusion were dominating the results. Hence, continued, extensive evaluation of the characteristics of the disposal system was not considered to be warranted, except for specific areas such as an evaluation of radioisotope solubilities in the repository, retardation distribution coefficients, and alternate conceptual models for transport in the 
overlying brine aquifer. These results coincided with a decision by the DOE, in concert with urging from the NAS, to forego in situ testing. Thus the DOE, which was also undergoing a change in administration, decided to omit the pilot phase of the WIPP and move ahead to the compliance phase, limiting testing to only that required with regard to compliance.

Beginning in 1994, an effort was made to combine the PA process directly with decision analysis in order to more definitively determine the best combination of scientific investigations, engineered alternatives, and waste acceptance criteria to support the CCA. The first attempt, called the System Prioritization Methodology (SPM), began in March 1994. The calculations and decision analysis were completed in December (Helton et al., 1997a; 1997b). A second iteration of the methodology was conducted in 1995 (Prindle et al., 1996). The new process produced additional information and thus helped the new DOE management team at the WIPP to allocate resources in 1995. However, the SPM cost much more in time and money than a general sensitivity analysis and the additional information it supplied mainly confirmed earlier sensitivity studies. In addition, basic tenants of decision analysis, such as developing an explicit utility function, were not followed (Lee, 1996). In its practical application, the analysis was not probabilistic because the time needed to run a sufficient simulation would have been excessive. Only a deterministic simulation of each activity, using an ad hoc combination of mean and median parameter values, was run. 


\subsection{Compliance Assessment and Summary}

An important difference between risk assessments or other large-scale policy analyses (Morgan et al., 1990), which are usually conducted to elucidate understanding of the behavior of a system, and the WIPP PAs is that the WIPP PAs were specifically designed to test compliance to a set of standards so that decisions could be made about safety, rather than just to elucidate understanding.

\subsection{Assessing Compliance of the WIPP}

The focus of the extensive engineering analyses conducted over the years by the WIPP Project was initially the National Environmental Policy Act (NEPA) of 1969 and later the regulations in 40 CFR 191, Subpart B (EPA, 1993b) and 40 CFR 194 (EPA, 1996a; 1996b). The EPA regulatory criteria are the societal consensus on what constitutes acceptable risk for radioactive waste disposal to be considered safe (Lowrance, 1976). Internationally, this last step of a performance assessment is often called a probabilistic safety assessment (NEA, 1991) or safety assessment (when uncertainty is omitted).

\subsubsection{Predicted Doses for EIS}

For each EIS for the WIPP, dose to an individual has been calculated as one of several measures of evaluating the impact of the repository on humans and the natural environment. In all EISs, doses immediately after human intrusion dominated the results. The predicted dose to the geologist examining a 7.6-cm mineral core was estimated to be 1 mrem in 1979 (DOE, 1979); 0.08 mrem in 1989 (Lappin et al., eds., 1989); and 0.01 mrem in 1996, assuming the core extracted CH-TRU waste (DOE, 1996b). The predicted dose to a maximally exposed driller ingesting fragments was $0.37 \mathrm{mrem}$ in 1996 . In addition, a separate probabilistic analysis of potential radiation exposure was conducted in 1996 (Helton et al., 1998). The predicted dose (primarily through inhalation) to a farm family $500 \mathrm{~m}$ downwind from the drilling mud pit was $0.036 \mathrm{mrem}$ in 1979 (DOE, 1979); the maximum committed dose equivalent over $50 \mathrm{yr}$ from inhalation to the farm family was $\sim 0.77$ mrem in 1989 (Lappin et al., eds., 1989). No calculations were conducted for the farm family in the 1996 EIS (DOE, 1996b).

\subsubsection{Releases from Preliminary Performance Assessments}

Preliminary results in the form of CCDFs from the performance assessments were compared with the EPA regulations between 1989-1992 (Figure 9-1). Uncertainty has decreased somewhat, as indicated by the CCDFs becoming more vertical yet, over the years, the predicted cumulative releases immediately after drilling into the repository have remained similar even as more mechanisms for release were added (i.e., spallings and direct brine release in 1996). The releases have remained similar because the general required assumptions for exploratory drilling were specified in the regulations. Only when drilling assumptions were changed based on results from a "futures panel" were drilling releases dramatically reduced (see Section 8.2).

The cumulative releases from leakage through the intrusion borehole and into the brine aquifer in the Culebra, a pathway much more dependent upon scientific knowledge about the WIPP disposal system, decreased until they were practically nonexistent in 1996. Although more scientific knowledge could be acquired about the WIPP disposal system, the results, in the form of cumulative releases, currently are contingent on the modeling assumptions or "style" required by the EPA regulations. That is, the regulations require inclusion of inadvertent human intrusion through exploratory drilling using current technology, and this regulatory requirement now directly determines the maximum releases. Continued collection of information about the disposal system is not likely to change the estimated overall releases substantially (Figure 9-1); hence, the EPA requirement that the human intrusion event be included indirectly defines the point at which disposal system characterization is sufficient.

\subsubsection{Performance Assessment for CCA}

In October 1996, the calculations and description of the 1996 PA were completed for the 80,000-page Compliance Certification Application (CCA) (DOE, 1996a). The overall exposure pathway model, $q(\bullet)$, for the 1996 PA was run 100 times with LHS samples. Furthermore, the 100 LHS samples were replicated three times (using new random numbers) to demonstrate the stability of the results. Many of the phenomenological models were run many more times than 300 because of the various 


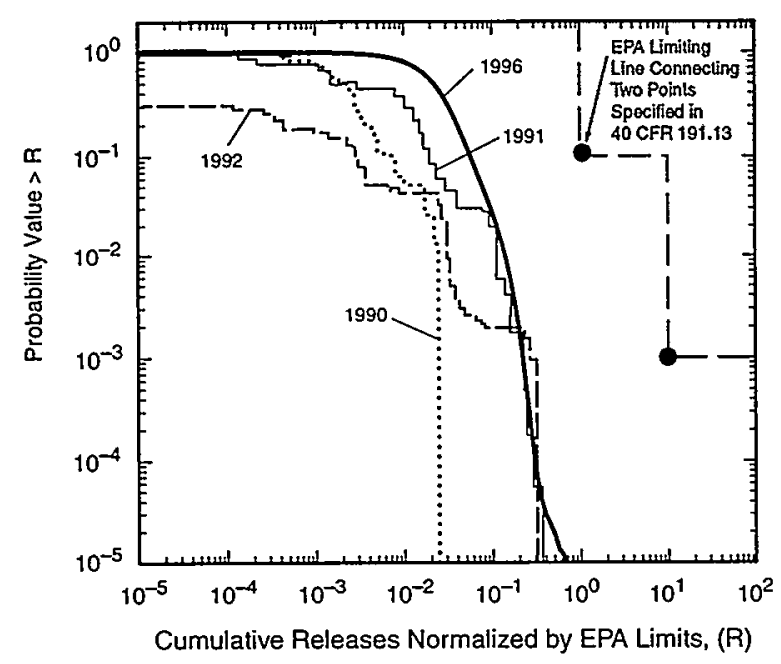

(a) Direct Releases to the Surface during Drilling

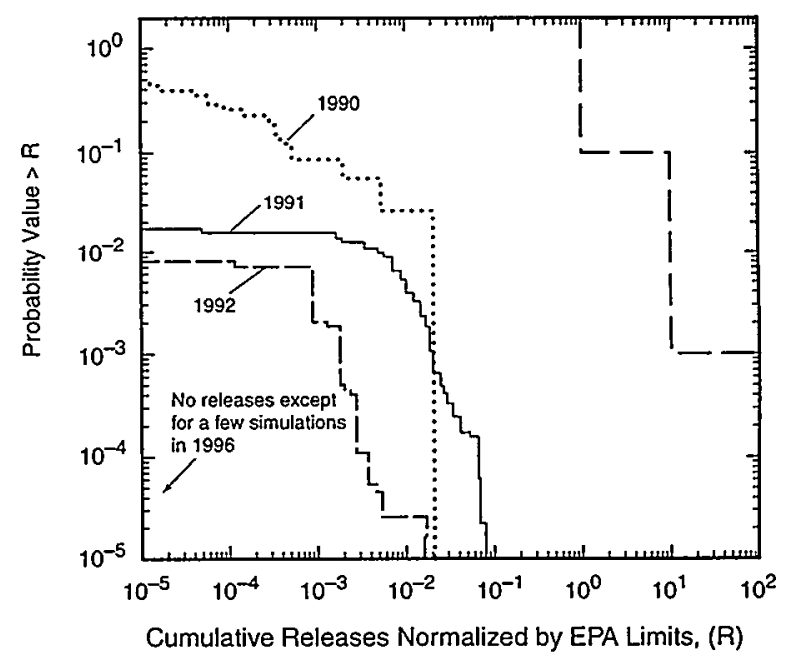

TRI-6342-6012-0

(b) Releases via Groundwater Pathway through Culebra

Figure 9-1. Changes in the distribution of cumulative releases (normalized by the EPA limits) for (a) direct releases to the surface during drilling and $(b)$ releases via groundwater pathway through Culebra. Since the first full PA in 1990, direct releases to the surface have dominated overall releases to the accessible environment of the WIPP.

pathways (e.g., direct, groundwater, anhydrite beds), scenarios (E0, E1, E2, E2E1), and times of intrusion (e.g., 350 and $1000 \mathrm{yr}$ for BRAGFLO for E1 and E2 scenarios) used in the analysis. In total, the calculations ran on $40 \mathrm{DEC}$ Alpha ${ }^{\mathrm{TM}}$ processors for $37,000 \mathrm{CPU}$ hours; although Tbytes of data were created, -100 Gbytes of data were retained in 97,000 files. The releases, which were solely from drill cuttings, cavings, spallings, and direct brine flow immediately after intrusion, showed compliance with 40 CFR 191 (Figure 9-1).

Throughout the winter and spring of 1997 (during the first six months after submittal), additional PA analysis and documentation, totaling 20,000 pages, were provided to the EPA at its request. For example, the EPA conducted an extensive review of the justifications for the parameter values and mathematical models used in the analysis, some of which required elaboration. In addition, before final submittal of the CCA, a few EPA staff members and several contractors had spent about two years becoming familiar with the models and assumptions of the WIPP PA. Separate from the formal review of the CCA but as part of the EPA's evaluation, the EPA also directed the DOE to run an abbreviated version of the PA in March 1997, varying models and parameters to bolster confidence in the WIPP disposal system. In May, the EPA directed the DOE to conduct a PA verification test PA using EPA's own selected modeling assumptions together with changes in distributions for 26 parameters (MacKinnon et al., 1997). The EPA declared the DOE's application complete in May 1997.

\subsection{Summary}

Over the decades, the United States has progressed from the burial of solid nuclear waste in shallow trenches and augered holes by the Manhattan Engineering District to the concept of deep geologic disposal. The examination of radioactive waste disposal in general and geologic disposal at the WIPP in particular started with the informal generic hazard identification by the NAS in 1955, followed by a selection of the disposal mode (deep geologic) to eliminate or mitigate those identified general hazards in some way. After repeated recommendations by the NAS for disposal in salt, the large salt beds of the Delaware Basin in southeastern New Mexico were selected in 1973 for the WIPP.

After the selection of the Delaware Basin and a specific site, ORNL evaluated the consequences of those 
hazards that remained in 1974 (e.g., meteorite impact, catastrophic faulting, etc.). A more formal hazard identification occurred in conjunction with the draft and final EIS of 1979 and 1980. Probabilities and consequences were evaluated only on aspects of the WIPP disposal system that were pertinent to the hazard under evaluation, i.e., a "scenario". Hazards (e.g., sabotage or nuclear criticality) with very small subjective estimates of probability or consequences were eliminated. Then consequences of the remaining hazards (e.g., exposure to drill cuttings containing TRU waste) were formally estimated to determine whether those remaining hazards were sufficient to disqualify the site. The Draft EIS predicted no significant adverse long-term environmental impacts to human health that would support arguments against construction in 1979. At the same time, Congress authorized the DOE to build the WIPP near Carlsbad, New Mexico, for disposal of waste contaminated with TRU radioisotopes six years after the site selection. After an exploratory phase in 1981, full construction of the WIPP began in 1983 and was officially complete by 1990 (Figure 9-2).

Modeling a nuclear waste disposal system presented not only new technical challenges for assessment but also societal challenges in developing a consensus on the criteria under which a disposal system would be accepted. Consequently, the interplay between developing criteria and creating a corresponding assessment technique was important. During this time, analysts at Sandia remained advocates for a comprehensive assessment approach, which was the indirect result of their participation on the 60-member Reactor Safety Study team between 1972 and 1975 and continued involvement with several reactor accident studies for the NRC (which culminated in the update to the Reactor Safety Study in 1990). Eventually, the method that was conceived and accepted by the engineering community and the EPA, as regulator, was a probabilistic risk assessment as specified in the criteria promulgated in 1985.

In 1986, Sandia accepted the task of evaluating the compliance of the WIPP with the EPA regulation and began construction of an analysis system for the required probabilistic simulations in about 1988 just as construction was being completed (Figure 9-3). An important goal of the analyses was to consistently examine hazards that remained after screening such that individual consequences from each could be combined in an overall distribution, i.e., the entire distribution of consequences was desired not just the expected value. Also, WIPP analysts found that explicitly defining scenarios, as had been done for the EIS, remained useful both to simplify modeling and to call attention to inadvertent human intrusion of the disposal system as specified by the EPA.

Between 1989 and 1992, Sandia conducted four preliminary performance assessments. Each iteration examined the behavior of the WIPP repository, based on current understanding, incorporated uncertainty, and then compared its preliminary results to the regulatory criteria. Because the physical and chemical processes that determine the behavior and evolution of the disposal system are complex, many of the models that represented the physical and chemical processes had become technically sophisticated by the 1992 PA and were carried forward for the 1996 PA.

In October 1996, the EPA began its review of the CCA for the WIPP. In October 1997, one year later, the EPA proposed in the Federal Register to certify that the WIPP disposal concept, based on results from the 1996 PA, complied with its regulations (EPA, 1997). In May 1998, 19 years after Congressional authorization, the EPA issued the certification (EPA, 1998). The State of New Mexico has not yet issued a RCRA permit for $60 \%$ of the TRU waste that also contains hazardous waste, but in mid 1999, the state began the necessary hearings. The permit should be issued toward the end of 1999. A few lawsuits are still pending; however, four days after Judge Penn lifted his injunction associated with a 1992 lawsuit by the State of New Mexico, the WIPP repository received its first shipment of non-RCRA waste from Los Alamos National Laboratory (Taugher and Smallwood, 1999). This auspicious opening on March 26,1999 , was the culmination of 25 years of evaluation. 


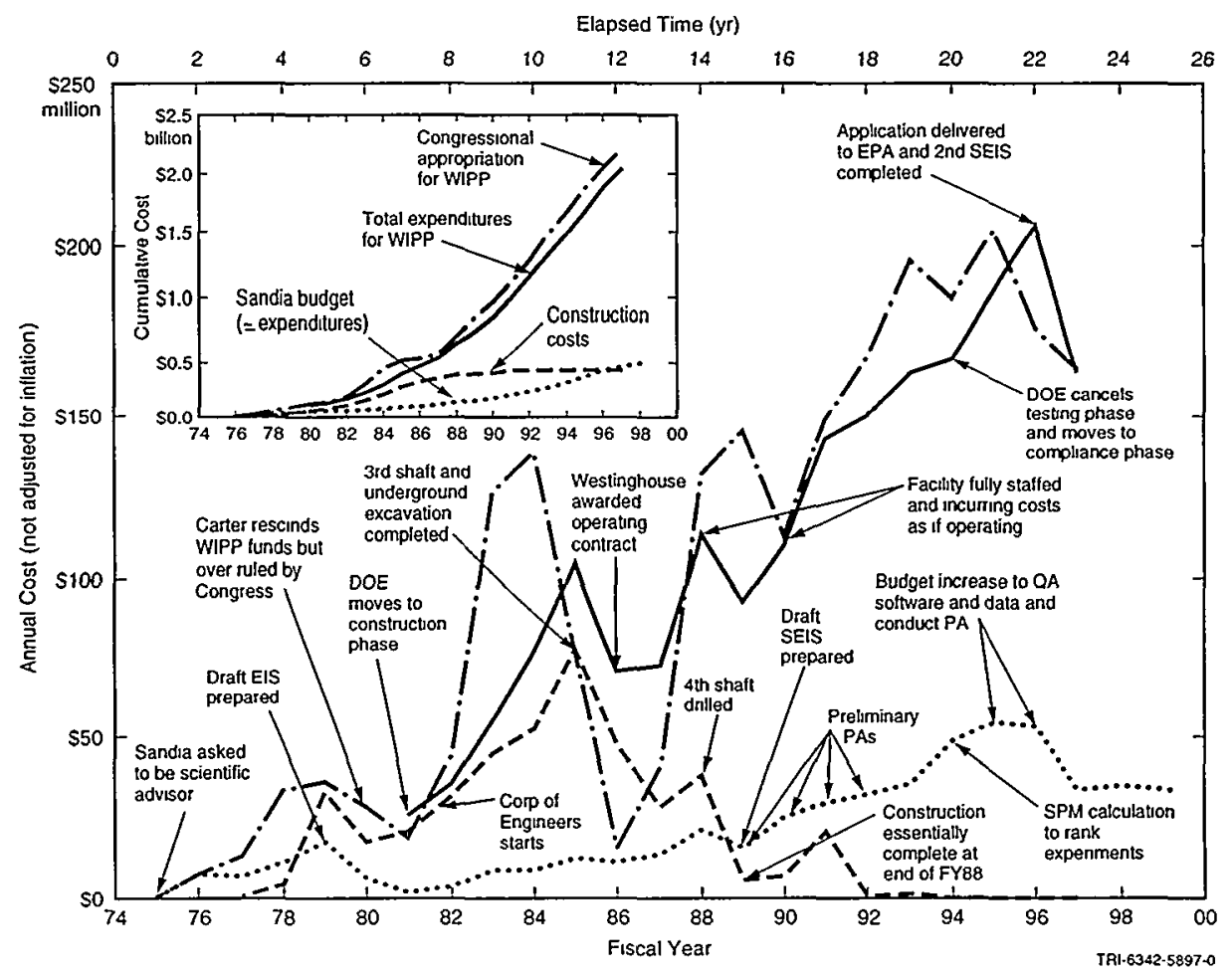

Figure 9-2. Annual outlays for construction and assessments of the Waste Isolation Pilot Plant (WIPP) (Sandia Corporation budget records).

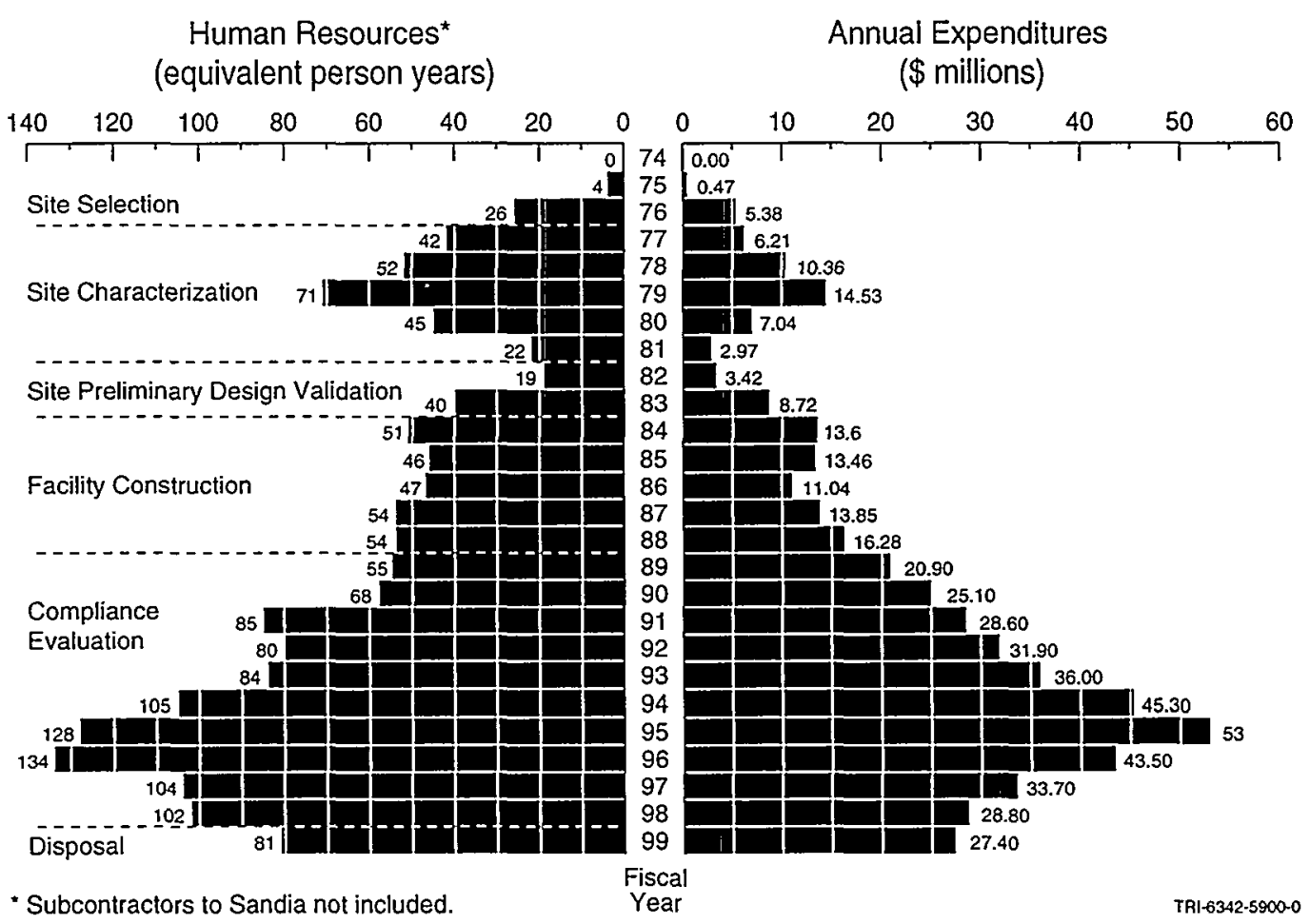

Figure 9-3. History of expenditures and human resources for WIPP Project at Sandia National Laboratories (Sandia Corporation budget records). 


\section{References}

(Note: Reference citations for Figures 2-1, 2-2, 3-5, 4-1, 5-2, and 6-2 are provided after the main reference list.)

AEC (Atomic Energy Commission). 1948. Report of the Safety and Industrial Health Advisory Board. April 2, 1948. Washington, DC: United States Atomic Energy Commission. (On file in the Sandia WIPP Central Files [SWCF] as ERMS 501097.) (Cited in Figure 2-1.)

AEC (Atomic Energy Commission). 1970. "Title 10Atomic Energy Chapter I-Atomic Energy Commission Part 50-Licensing of Production and Utilization Facilities, Siting of Fuel Reprocessing Plants and Related Waste Management Facilities," Federal Register. Vol. 35, no. 222, 17530-17533. (Cited in Figure 2-1.)

AEC (Atomic Energy Commission). 1971. Environmental Statement, Radioactive Waste Repository, Lyons, Kansas. WASH-1503. [Washington, DC]: United States Atomic Energy Commission. (On file in the SWCF as WPO 47929.) (Cited in Figure 2-1.)

Anderson, R.E., D.H. Eargle, and B.O. Davis. 1973. Geologic and Hydrologic Summary of Salt Domes in Gulf Coast Region of Texas, Louisiana, Mississippi, and Alabama. Open-File Report USGS-4339-2. Denver, CO: United States Department of the Interior, Geological Survey. (On file in the SWCF as WPO 43862.) (Cited in Figure 3-5.)

Anonymous. 1993. "Reversal on Nuclear Waste Tests," Science News. Vol. 144, no. 19, 303. (Cited in Figure 4-1.)

Anonymous. 1997. "Independent Experts: WIPP Conceptual Models Adequate," Carlsbad Current-Argus. May 11, 1997. Section A, page 3. (Cited in Figure 6-2.)

Armstrong, W.P., to W. Knowles. July 16, 1975, Book OneCorrespondence, May 14, 1975 thru June 30, 1976. Sandia Laboratories R.W.P.P., Binder 102, Box/Index No. 123291, Sandia Archives. (On file in SWCF as ERMS 500469.)

Argïello, J.G., and T.M. Torres. 1988. WIPP Panel Entryway Seal-Numerical Simulation of Seal Composite Interaction for Preliminary Design Evaluation. SAND87-2804. Albuquerque, NM: Sandia National Laboratories.

Babb, S.C., and C.F. Novak. 1995. "User's Manual for FMT, Version 2.0." Albuquerque, NM: Sandia National Laboratories. (On file in SWCF as WPO 28119.)

Bachman, G.O. 1973. Surficial Features and Late Cenozoic History in Southeastern New Mexico. Open-File Report USGS-4339-8. Denver, CO: United States Department of the Interior, Geological Survey. (On file in the SWCF as WPO 41293.) (Cited in Figure 3-5.)

Bachman, G.O., R.B. Johnson, and F.A. Swenson. 1973. Stability of Salt in the Permian Salt Basin of Kansas, Oklahoma, Texas, and New Mexico, With a Section on Dissolved Salts in Surface Water. Open-File Report USGS-4339-4. Denver, CO: United States Department of the Interior, Geological Survey. (On file in the SWCF as WPO 41298.) (Cited in Figure 3-5.)

Barnes, H. 1974. "Geologic and Hydrologic Background for Selecting Site of Pilot-Plant Repository for Radioactive Waste," Bulletin of the Association of Engineering Geologists. Vol. XI, no. 1, 83-92. (Cited in Figure 3-5.)

Barr, G.E., and P.D. O'Brien. 1976. "Selective Adsorption of Radionuclides in Geological Storage Media; Disclosure of Potentially Patentable Subject." Unpublished Memorandum from G.C. Newlin to W.D. Weart, March, 11, 1976. Albuquerque, NM: Sandia National Laboratories. (On file in the SWCF as ERMS 500136.) (Cited in Figure 5-2.)

Barr, G.E., W.B. Miller, and D.D. Gonzalez. 1983. Interim Report on the Modeling of the Regional Hydraulics of the Rustler Formation. SAND83-0391. Albuquerque, NM: Sandia National Laboratories.

Bartlett, J.W., H.C. Burkholder, and W.K. Winegardner. 1977. "Safety Assessment of Geologic Repositories for Nuclear Waste," Nuclear Systems Reliability Engineering and Risk Assessment. Eds. J.B. Fussell and G.R. Burdick. Philadelphia, PA: Society for Industrial and Applied Mathematics. 636-660. (On file in SWCF as WPO 45677.) (Cited in Figure 6-2.)

Beauheim, R.L. 1986. Hydraulic-Test Interpretations for Well DOE-2 at the Waste Isolation Pilot Plant (WIPP) Site. SAND86-1364. Albuquerque, NM: Sandia National Laboratories. (Cited in Figure 3-5.)

Beauheim, R.L. 1987. Analysis of Pumping Tests of the Culebra Dolomite Conducted at the H-3 Hydropad at the Waste Isolation Pilot Plant (WIPP) Site. SAND86-2311. Albuquerque, NM: Sandia National Laboratories. (Cited in Figure 6-2.)

Beauheim, R.L. 1989. Interpretation of $\mathrm{H}-11 \mathrm{~b} 4$ Hydraulic Tests and the H-11 Multipad Pumping Test of the Culebra Dolomite at the Waste Isolation Pilot Plant (WIPP) Site. 
SAND89-0536. Albuquerque, NM: Sandia National Laboratories. (Cited in Figures 3-4, 6-2.)

Beauheim, R.L., B.W. Hassinger, and J.A. Klaiber. 1983. Basic Data Report for Borehole Cabin Baby-1 Deepening and Hydrologic Testing. Waste Isolation Pilot Plant (WIPP) Project, Southeastern New Mexico. WTSDTME-020. Albuquerque, NM: U.S. Department of Energy, Waste Isolation Pilot Plant. (Cited in Figure 3-5.)

Beauheim, R.L., T.F. Dale, and J.F. Pickens. 1991. Interpretations of Single-Well Hydraulic Tests of the Rustler Formation Conducted in the Vicinity of the Waste Isolation Pilot Plant Site, 1988-1989. SAND89-0869. Albuquerque, NM: Sandia National Laboratories. (Cited in Figure 3-5.)

Bechtel National, Inc. 1986. WIPP Design Validation Final Report. DOE/WIPP-86-010. San Francisco, CA: Bechtel National, Inc. (Cited in Figure 5-2.)

Beckner, E.H. 1986. Letter Dated Aug. 29, 1986, to Mr. Dennis L. Krenz, Assistant Manager to Projects and Energy Programs, DOE Albuquerque Operations Office, E.H. Beckner, Vice President, Energy Programs, Sandia National Laboratories. (On file in the SWCF as PA 00820.) (Cited in Figure 6-2.)

Begley, S., and M. Miller. 1987. "A Nuclear Dump Springs a Leak," Newsweek. Vol. 110, no. 26, 65. (Cited in Figure 3-5.)

Berglund, J.W. 1992. Mechanisms Governing the Direct Removal of Wastes from the Waste Isolation Pilot Plant Repository Caused by Exploratory Drilling. SAND927295. Albuquerque, NM: Sandia National Laboratories.

Bertram-Howery, S.G., M.G. Marietta, D.R. Anderson, K.F. Brinster, L.S. Gomez, R.V. Guzowski, and R.P. Rechard. 1989. Draft Forecast of the Final Report for the Comparison to 40 CFR Part 191, Subpart B, for the Waste Isolation Pilot Plant. SAND88-1452. Albuquerque, NM: Sandia National Laboratories. (Cited in Figure 6-2.)

Bertram-Howery, S.G., M.G. Marietta, R.P. Rechard, P.N. Swift, D.R. Anderson, B.L. Baker, J.E. Bean, Jr., W. Beyeler, K.F. Brinster, R.V. Guzowski, J.C. Helton, R.D. McCurley, D.K. Rudeen, J.D. Schreiber, and P. Vaughn. 1990. Preliminary Comparison with 40 CFR Part 191, Subpart $B$ for the Waste Isolation Pilot Plant, December 1990. SAND90-2347. Albuquerque, NM: Sandia National Laboratories. (Cited in Figure 6-2.)

Bingham, F.W., and G.E. Barr. 1979. Scenarios for LongTerm Release of Radionuclides from a Nuclear-Waste Repository in the Los Medaños Region of New Mexico. SAND78-1730. Albuquerque, NM: Sandia National Laboratories.

Bingham, F.W., and G.E. Barr. 1980. "Development of Scenarios for the Long-Term Release of Radionuclides from the Proposed Waste Isolation Pilot Plant in Southeastern New Mexico," Scientific Basis for Nuclear Waste Management, Proceedings of the International Symposium, Boston, MA, November 27-30, 1979. Ed. C.J.M. Northrup, Jr. SAND79-0955C. New York, NY: Plenum Press. Vol. 2, 771-778. (Cited in Figure 6-2.)

Boffey, P.M. 1975. "Radioactive Waste Disposal: The Atomic Energy Commission Brings the Academy to Heel," The Brain Bank of America: An Inquiry into the Politics of Science. Ed. P.M. Boffey. New York, NY: McGraw-Hill Book Company. 89-111, 276-278. (Cited in Figure 2-1.)

Bonano, E.J., P.A. Davis, L.R. Shipers, K.F. Brinster, W.E. Beyeler, C.D. Updegraff, E.R. Shepherd, L.M. Tilton, and K.K. Wahi. 1988. Demonstration of a Performance Assessment Methodology for High-Level Radioactive Waste Disposal in Basalt Formations. SAND86-2325, NUREG/CR-4759. Albuquerque, NM: Sandia National Laboratories.

Borns, D.J., L.J. Barrows, D.W. Powers, and R.P. Snyder. 1983. Deformation of Evaporites Near the Waste Isolation Pilot Plant (WIPP) Site. SAND82-1069. Albuquerque, NM: Sandia National Laboratories. (Cited in Figure 3-5.)

Bradshaw, R.L., and W.C. McClain, eds. 1971. Project Salt Vault: A Demonstration of the Disposal of High-Activity Solidified Wastes in Underground Salt Mines. ORNL4555. Oak Ridge, TN: Oak Ridge National Laboratory. (On file in the SWCF as WPO 48808.) (Cited in Figure 2-1.)

Breeding, R.J., J.C. Helton, E.D. Gorham, and F.T. Harper. 1992. "Summary Description of the Methods Used in the Probabilistic Risk Assessments for NUREG-1150," Nuclear Engineering and Design. Vol. 135, no. 1, 1-27.

Brokaw, A.L., C.L. Jones, M.E. Cooley, and W.H. Hays. 1972. Geology and Hydrology of the Carlsbad Potash Area, Eddy and Lea Counties, New Mexico. Open-File Report USGS-4339-1. Denver, CO: United States Department of the Interior, Geological Survey. (On file in the SWCF as WPO 43356.) (Cited in Figure 3-5.)

Brooke, J. 1999. "Deep Desert Grave Awaits First Load of Nuclear Waste," New York Times. March 26, 1999. Section A, pp. 1, 18 .

Brush, L.H. 1990. Test Plan for Laboratory and Modeling Studies of Repository and Radionuclide Chemistry for the Waste Isolation Pilot Plant. SAND90-0266. Albuquerque, NM: Sandia National Laboratories. (Cited in Figure 4-1.)

Brush, L.H., and D.R. Anderson. 1989. "Potential Effects of Chemical Reactions on WIPP Gas and Water Budgets," Systems Analysis, Long-Term Radionuclide Transport, and Dose Assessments, Waste Isolation Pilot Plant 
(WIPP), Southeastern New Mexico; March 1989. Eds. A.R. Lappin, R.L. Hunter, D.P. Garber, and P.B. Davies. SAND89-0462. Albuquerque, NM: Sandia National Laboratories, A-3 through A-30.

Brush, L.H., and L.J. Storz. 1996. "Revised Ranges and Probability Distributions of $K_{d} s$ for Dissolved Pu, Am, U, Th, and Np in the Culebra for the PA Calculations to Support the WIPP CCA." Memo to M.S. Tierney, July 24, 1996. Albuquerque, NM: Sandia National Laboratories. (On file in the SWCF as WPO 41561.) (Cited in Figure 3-5.)

Brush, L.H., D. Grbic-Galic, D.T. Reed, X. Tong, R.H. Vreeland, and R.E. Westerman. 1991a. "Preliminary Results of Laboratory Studies of Repository Chemistry for the Waste Isolation Pilot Plant," Scientific Basis for Nuclear Waste Management XIV, Materials Research Society Symposium Proceedings, Boston, MA, November 26-29, 1990. Eds. T. Abrajano, Jr. and L.H. Johnson. SAND90-1031C. Pittsburgh, PA: Materials Research Society. Vol. 212, 893-900. (Cited in Figure 4-1.)

Brush, L.H., M.A. Molecke, A.R. Lappin, R.E. Westerman, X. Tong, J.N.P. Black, D. Grbic-Galic, R.E. Vreeland, and D.T. Reed. 1991b. "Laboratory and Bin-Scale Tests of Gas Generation for the Waste Isolation Pilot Plant," Waste-Generated Gas at the Waste Isolation Pilot Plant, Papers Presented at the Nuclear Energy Agency Workshop on Gas Generation and Release from Radioactive Waste Repositories. Eds. P.B. Davies, L.H. Brush, M.A. Molecke, F.T. Mendenhall, and S.W. Webb. SAND912378. Albuquerque, NM: Sandia National Laboratories. 2-1 through 2-13. (Cited in Figure 4-1.)

Brush, L.H., M.A. Molecke, R.E. Westerman, A.J. Francis, J.B. Gillow, R.H. Vreeland, and D.T. Reed. 1993. "Laboratory Studies of Gas Generation for the Waste Isolation Pilot Plant," Scientific Basis for Nuclear Waste Management XVI, Materials Research Society Symposium Proceedings, Boston, MA, November 30-December 4, 1992. Eds. C.G. Interrante and R.T. Pabalan. SAND92-2160C. Pittsburgh, PA: Materials Research Society. Vol. 294, 335-340.

Callahan, G.D., A.F. Fossum, and D.K. Svalstad. 1989. Docuinentation of SPECTROM-32: A Finite Element Thermomechanical Stress Analysis Program. DOE/CH/10378-2, RSI-0269. Rapid City, SD: RE/SPEC, Inc.; Argonne, IL: U.S. Department of Energy, Chicago Operations Office. Vols. 1-2.

Campbell, J.E., and R.M. Cranwell. 1988. "Performance Assessment of Radioactive Waste Repositories," Science. Vol. 239, no. 4846, 1389-1392. (Cited in Figure 62.)

Campbell, J.E., R.T. Dillon, M.S. Tierney, H.T. Davis, P.E. McGrath, F.J. Pearson, Jr., H.R. Shaw, J.C. Helton, and F.A. Donath. 1978. Risk Methodology for Geologic Dis- posal of Radioactive Waste: Interim Report. SAND780029, NUREG/CR-0458. Albuquerque, NM: Sandia National Laboratories. (Cited in Figure 6-2.)

Campbell, J.E., D.E. Longsine, and R.M. Cranwell. 1981. Risk Methodology for Geologic Disposal of Radioactive Waste: The NWFT/DVM Computer Code Users Manual. SAND81-0886, NUREG/CR-2081. Albuquerque, NM: Sandia National Laboratories.

Campbell, J.E., C.D. Leigh, and D.E. Longsine. 1991. NEFTRAN-S: A Network Flow and Contaminant Transport Model for Statistical and Deterministic Simulations Using Personal Computers. SAND90-1987. Albuquerque, NM: Sandia National Laboratories. (Cited in Figure 6-2.)

Carter, J.E. 1977. "Nuclear Power Policy. Remarks and a Question-and-Answer Session with Reporters on Decisions Following a Review of U.S. Policy. April 7, 1977," Public Papers of the Presidents of the United States, Jimmy Carter, 1977 (in Two Books). Washington, DC: United States Government Printing Office. Book 1, 581588. (Cited in Figure 4-1.)

Carter, J.E. 1982. "Appendix A: Presidential Message and Fact Sheet of February 12, 1980," The Politics of Nuclear Waste. Ed. E.W. Colglazier, Jr. New York, NY: Pergamon Press. 220-241. (Cited in Figure 4-1.)

Carter, L.J. 1978. "Trouble Even in New Mexico for Nuclear Waste Disposal," Science. Vol. 199, no. 4333, 10501051. (Cited in Figure 4-1.)

Carter, L.J. 1987. Nuclear Imperatives and Public Trust: Dealing with Radioactive Waste. Washington, DC: Resources for the Future, Inc.; [Baltimore, MD]: Distributed by Johns Hopkins University Press. (Cited in Figures 2-1, 3-5, 4-1.)

CCCC (Calvert Cliffs' Coordinating Committee, Inc.) et al., Petitioners v. United States Atomic Energy Commission and United States of America, Respondents. Nos. 24839 , 24871. 1971. 449 Federal Reporter, $2 d$ Series 1109. (On file in the SWCF as WPO 47288.) (Cited in Figure 2-1.)

Channell, J.K. 1982. Calculated Radiation Doses from Radionuclides Brought to the Surface if Future Drilling Intercepts the WIPP Repository and Pressurized Brine. EEG11. Santa Fe, NM: Environmental Evaluation Group.

Channell, J.K., J.C. Rodgers, and R.H. Neill. 1986. Adequacy of TRUPACT-I Design for Transporting Contact-Handled Transuranic Wastes to WIPP. EEG-33. Santa Fe, NM: Environmental Evaluation Group.

Chiri, T.W. 1996. "Documentation Puts WIPP Opening Closer," Carlsbad Current-Argus. November 21, 1996. Section A, pages 1, 2. (Cited in Figure 6-2.) 
Christensen, C.L., R.D. Statler, and E.W. Peterson. 1980. Downhole Television (DHTV) Applications in Borehole Plugging. SAND80-0459. Albuquerque, NM: Sandia National Laboratories. (Cited in Figure 3-5.)

Claiborne, H.C., and F. Gera. 1974. Potential Containment Failure Mechanisms and Their Consequences at a Radioactive Waste Repository in Bedded Salt in New Mexico. ORNL-TM-4639. Oak Ridge, TN: Oak Ridge National Laboratory. (On file in the SWCF as WPO 41224.) (Cited in Figures 2-1, 6-2.)

Cooper, J.B., and J.M. Glanzman. 1971. Geohydrology of Project Gnome Site, Eddy County, New Mexico. Geological Survey Professional Paper 712-A. Washington, DC: United States Government Printing Office. (Cited in Figure 3-5.)

Corbet, T. 1997. "Expedited CCA Activity: Geochemistryl Hydrology Issue in Culebra." Unpublished Report. Albuquerque, NM: Sandia National Laboratories. (On file as WPO 43215.) (Cited in Figure 6-2.)

Cranwell, R.M., J.E. Campbell, J.C. Helton, R.L. Iman, D.E. Longsine, N.R. Ortiz, G.E. Runkle, and M.J. Shortencarjer. 1987. Risk Methodology for Geologic Disposal of Radioactive Waste: Final Report. SAND81-2573, NUREG/CR-2452. Albuquerque, NM: Sandia National Laboratories. (Cited in Figure 6-2.)

Cranwell, R.M., R.V. Guzowski, J.E. Campbell, and N.R. Ortiz. 1990. Risk Methodology for Geologic Disposal of Radioactive Waste: Scenario Selection Procedure. SAND80-1429, NUREG/CR-1667. Albuquerque, NM: Sandia National Laboratories. (Cited in Figure 6-2.)

Cummings, R.G. 1988. New Mexico Waste Isolation Pilot Project (WIPP): An Historical Overview. DOE/NV/ 10461-T15, NWPO-SE-013-88. Albuquerque, NM: University of New Mexico for State of Nevada, Agency for Nuclear Projects/Nuclear Waste Project Office. 9-11. (On file in the SWCF as WPO 47158.) (Cited in Figure 2-2.)

Davies, L.E. 1969. "Fire Cleanup Keeps Plutonium Plant Busy," New York Times. June 27, 1969, p. 10.

Davies, P.B. 1989. Variable-Density Ground-Water Flow and Paleohydrology in the Waste Isolation Pilot Plant (WIPP) Region, Southeastern New Mexico. Open-File Report 88490. Albuquerque, NM: U.S. Geological Survey.

Dawson, P.R., and J.R. Tillerson. 1978. Nuclear Waste Canister Thermally Induced Motion. SAND78-0566. Albuquerque, NM: Sandia National Laboratories. (Cited in Figure 5-2.)

Dillon, R.T., R.B. Lantz, and S.B. Pahwa. 1978. Risk Met/lodology for Geologic Disposal of Radioactive Waste: The Sandia Waste Isolation Flow and Transport (SWIFT)
Model. SAND78-1267, NUREG/CR-0424. Albuquerque, NM: Sandia National Laboratories.

"Documents Related to State of New Mexico v. U.S. Department of Energy Including the Supplemental Stipulated Agreement Resolving Certain State Off-Site Concerns Over WIPP and the Opinion of the General Counsel of the Department of Energy on Application of the PriceAnderson Act to the Waste Isolation Pilot Plant Project." 1982. (On file in the SWCF as WPO 48652.) (Cited in Figure 2-2.)

DOE (U.S. Department of Energy). 1978. Report of Task Force for Review of Nuclear Waste Management. Draft. DOE/ER-0004/D. Washington, DC: U.S. Department of Energy, Directorate of Energy Research. (On file in the SWCF as WPO 47932.) (Cited in Figure 4-1.)

DOE (U.S. Department of Energy). 1979. Draft Environmental Impact Statement, Waste Isolation Pilot Plant. DOE EIS-0026-D. Washington, DC: U.S. Department of Energy. Vols. 1-2. (Cited in Figures 4-1, 6-2.)

DOE (U.S. Department of Energy). 1980a. Final Environmental Impact Statement, Waste Isolation Pilot Plant. DOE/EIS-0026. Washington, DC: U.S. Department of Energy, Assistant Secretary for Defense Programs. Vols. 1-2. (Cited in Figure 4-1.)

DOE (U.S. Department of Energy). 1980b. WIPP SAR: Waste Isolation Pilot Plant Safety Analysis Report. Washington, DC: U.S. Department of Energy. Vols. 1-5. (Cited in Figure 5-2.)

DOE (U.S. Department of Energy). 1981. "Waste Isolation Pilot Plant (WIPP): Record of Decision," Federal Register. Vol. 46, no. 18, 9162-9164. (Cited in Figure 5-2.)

DOE (U.S. Department of Energy). 1983. "Announcement of Decision to Proceed with Construction of the Waste Isolation Pilot Plant (WIPP)," Federal Register. Vol. 48, no. 128, 30427-30428. (Cited in Figure 5-2.)

DOE (U.S. Department of Energy). 1987. "10 CFR Part 962 Radioactive Waste-Byproduct Material," Federal Register. Vol. 52, no. 84, 15937-15941. (Cited in Figure 2-2.)

DOE (U.S. Department of Energy). 1989a. Waste Isolation Pilot Plant No-Migration Variance Petition. DOE/WIPP 89-003, Rev. 0. Carlsbad, NM: Westinghouse Electric Corporation, Waste Isolation Division. Vols. I-VIII. (Cited in Figure 6-2.)

DOE (U.S. Department of Energy). 1989b. "Waste Isolation Pilot Plant; Availability of Draft Supplement to the Final Environmental Impact Statement," Federal Register. Vol. 54, no. 76, 16350-16352. (Cited in Figures 2-2, 6-2.)

DOE (U.S. Department of Energy). 1989c. Draft Supplement, Environmental Impact Statement, Waste Isolation Pilot 
Plant. DOE/EIS-0026-DS. Washington, DC: U.S. Department of Energy, Assistant Secretary for Defense Programs. Vols. 1-2. (On file in the SWCF as WPO 43133.) (Cited in Figure 6-2.)

DOE (U.S. Department of Energy). 1990a. Final Safety Analysis Report, Waste Isolation Pilot Plant, Carlsbad, New Mexico. WP 02-9, Rev. 0. Carlsbad, NM: Westinghouse Electric Corporation. Vols. I-III. (On file in the SWCF as WPO 43327.) (Cited in Figure 5-2.)

DOE (U.S. Department of Energy). 1990b. WIPP Test Phase Plan: Performance Assessment. DOE/WIPP 89-011, Revision 0. Carlsbad, NM: United States Department of Energy, Waste Isolation Pilot Plant. (Cited in Figure 4-1.)

DOE (U.S. Department of Energy). 1990c. Final Supplement, Environmental Impact Statement, Waste Isolation Pilot Plant. DOE/EIS-0026-FS. Washington, DC: U.S. Department of Energy, Office of Environmental Restoration and Waste Management. Vols. 1-13. (Cited in Figure 6-2.)

DOE (U.S. Department of Energy). 1990d. "Record of Decision; Waste Isolation Pilot Plant," Federal Register. Vol. 55, no.. 121, 25689-25692. (Cited in Figure 6-2.)

DOE (U.S. Department of Energy). 1991. Report of the Geotechnical Panel on the Effective Life of Rooms in Panel 1. DOE/WIPP 91-023. Carlsbad, NM: Westinghouse Electrical Corporation, Waste Isolation Division. (Cited in Figure 5-2.)

DOE (U.S. Department of Energy). 1992a. "Waste Isolation Pilot Plant RCRA Part A Permit Application," Resource Conservation and Recovery Act Part B Permit Application. DOE/WIPP 91-005, Revision 1. Carlsbad, NM: Waste Isolation Pilot Plant. Vol. I, Chapter A. (Part A Permit Application Dated July 10, 1991.) (Cited in Figure 2-2.)

DOE (U.S. Department of Energy). 1992b. Resource Conservation and Recovery Act Part B Permit Application. DOE/WIPP 91-005, Revision 1. Carlsbad, NM: Waste Isolation Pilot Plant. Vols. I-VII. (Cited in Figure 2-2.)

DOE (U.S. Department of Energy). 1992c. "Definitive Design (Title II)," Project Management System. DOE Order 4700.1. Washington, DC: U.S. Department of Energy. V-40 through V-41. (On file in the SWCF as WPO 48333.) (Cited in Figure 5-2.)

DOE (U.S. Department of Energy). 1992d. WIPP Supplementary Roof Support System Room 1, Panel 1 Geotechnical Field Data Analysis Bi-Annual Report. DOE/WIPP 92-024. Carlsbad, NM: Westinghouse Electrical Corporation, Waste Isolation Division. (Cited in Figure 5-2.)

DOE (U.S. Department of Energy). 1993a. Test Phase Plan for the Waste Isolation Pilot Plant. DOE/WIPP 89-011,
Revision 1. Albuquerque, NM: U.S. Department of Energy, WIPP Project Integration Office. (Cited in Figure 4-1.)

DOE (U.S. Department of Energy). 1993b. Waste Retrieval Plan for the Waste Isolation Pilot Plant. DOE/WIPP-89022, Rev. 1. Washington, DC: U.S. Department of Energy. (Cited in Figure 4-1.)

DOE (U.S. Department of Energy). 1995a. Engineered Alternatives Cost/Benefit Study Final Report. DOE/WIPP 952135 Revision 0. Albuquerque, NM: IT Corporation; Carlsbad, NM: United States Department of Energy, Waste Isolation Pilot Plant, Carlsbad Area Office. (Cited in Figure 5-2.)

DOE (U.S. Department of Energy). 1995b. Transuranic Waste Baseline Inventory Report (Revision 2). DOE/ CAO-95-1121. Carlsbad, NM: U.S. Department of Energy, Carlsbad Area Office. (Cited in Figure 4-1.)

DOE (U.S. Department of Energy). 1995c. Draft 40 CFR 191 Compliance Certification Application for the Waste Isolation Pilot Plant. Phase II Review. DOE/CAO-Predecisional Draft-2056. Carlsbad, NM: United States Department of Energy, Waste Isolation Pilot Plant, Carlsbad Area Office. Books 1-2. (On file in the SWCF as WPO 21135 and WPO 21136.) (Cited in Figure 6-2.)

DOE (U.S. Department of Energy). 1996a. Title 40 CFR Part 191 Compliance Certification Application for the Waste Isolation Pilot Plant. DOE/CAO-1996-2184. Carlsbad, NM: United States Department of Energy, Waste Isolation Pilot Plant, Carlsbad Area Office. Vols. I-XXI. (CDROM of the CCA is on file in the SWCF as WPO 48940.) (Cited in Figure 6-2.)

DOE (U.S. Department of Energy). 1996b. Waste Isolation Pilot Plant Disposal Phase Draft Supplemental Environmental Impact Statement. November 1996. DOE/EIS0026-S-2. Carlsbad, NM: U.S. Department of Energy, Carlsbad Area Office. (Cited in Figure 6-2.)

DOE (U.S. Department of Energy). 1997. Waste Isolation Pilot Plant Disposal Phase Final Supplemental Environmental Impact Statement. September 1997. DOE-WIPP0026-S-2. Carlsbad, NM: Department of Energy, Carlsbad Area Office. (Cited in Figure 5-2.)

Dormuth, K.W., and G.R. Sherman. 1981. SYVAC - A Computer Program for Assessment of Nuclear Fuel Waste Management Systems, Incorporating Parameter Variability. AECL-6814. Pinawa, Manitoba: Atomic Energy of Canada Ltd., Whiteshell Nuclear Research Establishment.

Dosch, R.G. 1979. "Radionuclide Migration Studies Associated with the WIPP Site in Southeastern New Mexico," Scientific Basis for Nuclear Waste Management, Proceedings of the Symposium on "Science Underlying Radioac- 
tive Waste Management," Boston, MA, November 28. December 1, 1978. Ed. G.J. McCarthy. SAND78-1178J. New York, NY: Plenum Press. Vol. 1, 395-398.

Dosch, R.G. 1980. Assessment of Potential Radionuclide Transport in Site-Specific Geologic Formations. SAND79-2468. Albuquerque, NM: Sandia National Laboratories.

Dosch, R.G. 1981. Solubility and Sorption Characteristics of Uranium(VI) Associated with Rock Samples and Brines/ Groundwaters from WIPP and NTS. SAND80-1595. Albuquerque, NM: Sandia National Laboratories.

Dosch, R.G., and A.W. Lynch. 1978. Interaction of Radionuclides with Geomedia Associated with the Waste Isolation Pilot Plant (WIPP) Site in New Mexico. SAND78-0297. Albuquerque, NM: Sandia National Laboratories.

Earth Technology Corporation. 1988. Final Report for Time Domain Electromagnetic (TDEM) Surveys at the WIPP Site. H. Cline and M. Blohm. SAND87-7144. Albuquerque, NM: Sandia National Laboratories. (Cited in Figures 3-4, 6-2.)

EPA (U.S. Environmental Protection Agency). 1976. "40 CFR Part 260: Environmental Radiation Protection Standards for High-Level Radioactive Waste; Advance Notice of Proposed Rulemaking," Federal Register: Vol. 41, no. 235, 53363. (Cited in Figure 2-2.)

EPA (U.S. Environmental Protection Agency). 1978a. "Environmental Protection Criteria for Radioactive Wastes: Announcement of Public Forum," Federal Register. Vol. 43, no. 10, 2223. (Cited in Figure 2-2.)

EPA (U.S. Environmental Protection Agency). 1978b. "Criteria for Radioactive Wastes; Invitation for Comment: Environmental Protection," Federal Register. Vol. 43, no. 221, 53262-53268. (Cited in Figure 2-2.)

EPA (U.S. Environmental Protection Agency). 1982. "40 CFR Part 191: Environmental Standards for the Management and Disposal of Spent Nuclear Fuel, High-Level and Transuranic Radioactive Wastes; Proposed Rule," Federal Register. Vol. 47, no. 250, 58196-58206. (Cited in Figure 2-2.)

EPA (U.S. Environmental Protection Agency). 1985a. "40 CFR Part 191: Environmental Standards for the Management and Disposal of Spent Nuclear Fuel, High-Level and Transuranic Radioactive Wastes; Final Rule," Federal Register. Vol. 50, no. 182, 38066-38089. (Cited in Figure 2-2.)

EPA (U.S. Environmental Protection Agency). 1985b. Background Information Document: Final Rule for HighLevel and Transuranic Radioactive Wastes. EPA 520/185-023. Washington, DC: Environmental Protection
Agency, Office of Radiation Programs. (Cited in Figures 2-1, 2-2.)

EPA (U.S. Environmental Protection Agency). 1986. "State Authorization to Regulate the Hazardous Components of Radioactive Mixed Wastes Under the Resource Conservation and Recovery Act; Notice," Federal Register. Vol. 51, no. 128, 24504-24505. (Cited in Figure 2-2.)

EPA (U.S. Environmental Protection Agency). 1990. "Conditional No-Migration Determination for the Department of Energy Waste Isolation Pilot Plant (WIPP)," Federal Reg. ister. Vol. 55, no. 220, 47700-47721. (Cited in Figure 22.)

EPA (U.S. Environmental Protection Agency). 1993a. "Part 1-Statement of Organization and General Information," Code of Federal Regulations 40, Part 1. Washington, DC: Superintendent of Documents, U.S. Government Printing Office. (Cited in Figure 2-2.)

EPA (U.S. Environmental Protection Agency). 1993b. "40 CFR Part 191: Environmental Radiation Protection Standards for the Management and Disposal of Spent Nuclear Fuel, High-Level and Transuranic Radioactive Wastes; Final Rule," Federal Register: Vol. 58, no. 242, 6639866416. (Cited in Figure 2-2.)

EPA (U.S. Environmental Protection Agency). 1995. "40 CFR Part 194: Criteria for the Certification and Determination of the Waste Isolation Pilot Plant's Compliance With Environmental Standards for the Management and Disposal of Spent Nuclear Fuel, High-Level and Transuranic Radioactive Wastes; Proposed Rule," Federal Register. Vol. 60, no. 19, 5766-5791. (Cited in Figure 2-2.)

EPA (U.S. Environmental Protection Agency). 1996a. "40 CFR Part 194: Criteria for the Certification and Re-Certification of the Waste Isolation Pilot Plant's Compliance With the 40 CFR Part 191 Disposal Regulations; Final Rule," Federal Register. Vol. 61, no. 28, 5224-5245. (Cited in Figure 2-2.)

EPA (U.S. Environmental Protection Agency). 1996b. "40 CFR Part 194: Decision to Certify Whether the Waste Isolation Pilot Plant Complies with the 40 CFR Part 191 Disposal Regulations and the 40 CFR Part 194 Compliance Criteria; Advance Notice of Proposed Rulemaking (ANPR)," Federal Register: Vol. 61, no. 222, 5849958500. (Cited in Figure 6-2.)

EPA (U.S. Environmental Protection Agency). 1997. "40 CFR Part 194: Criteria for the Certification and Re-Certification of the Waste Isolation Pilot Plant's Compliance with the 40 CFR Part 191 Disposal Regulations: Certification Decision; Proposed Rule," Federal Register. Vol. 62, no. 210, pt. 3, 58792-58838. (Cited in Figure 2-2.)

EPA (U.S. Environmental Protection Agency). 1998. "40 CFR Part 194: Criteria for the Certification and Re-Certi- 
fication of the Waste Isolation Pilot Plant's Compliance with the Disposal Regulations: Certification Decision; Final Rule," Federal Register. Vol. 63, no. 95, 27354 27406. (Cited in Figure 6-2.)

Ewing, R.I. 1981. WIPP Test of a Radiant Heater in the Avery Island Salt Mine. SAND81-1305. Albuquerque, NM: Sandia National Laboratories. (Cited in Figure 5-2.)

Fanchi, J.R., J.E. Kennedy, and D.L. Dauben. 1987. BOAST II: A Three-Dimensional, Three-Phase Black Oil Applied Simulation Tool. DOE/BC-88/2/SP. Tulsa, OK: K and A Technology. Vols. 1-2. (On file in the SWCF as WPO 51925.)

Ford, G.R. 1976. "The White House Fact Sheet: President's Nuclear Waste Management Plan." October 28, 1976. Washington, DC: Office of the White House Press Secretary. (Available from the Gerald R. Ford Library, 1000 Beal Avenue, Ann Arbor, MI, Telephone: 313/741-2218.) (Cited in Figure 2-2.)

Francis, A.J., and J.B. Gillow. 1994. Effects of Microbial Processes on Gas Generation Under Expected Waste Isolation Pilot Plant Repository Conditions, Progress Report Through 1992. SAND93-7036. Albuquerque, NM: Sandia National Laboratories. (Cited in Figure 4-1.).

Francis, A.J., J.B. Gillow, and M.R. Giles. 1997. Microbial Gas Generation Under Expected Waste Isolation Pilot Plant Repository Conditions. SAND96-2582. Albuquerque, NM: Sandia National Laboratories. (Cited in Figure 4-1.)

Freiwald, J. 1982. "Legislature and Political Aspects of Waste Disposal," Proceedings of Alpha-Contaminated Waste Management Workshop, Gaithersburg, MD, August 1013, 1982. CONF-820845. Oak Ridge, TN: Oak Ridge National Laboratory. 35-38. (Cited in Figure 4-1.)

Galson, D.A., and P.N. Swift. 1995. "Recent Progress in Scenario Development for the WIPP," High Level Radioactive Waste Management 1995, Proceedings of the Sixth Annual International Conference, Las Vegas, NV, April 30 - May 5, 1995. SAND95-0117C. La Grange Park, IL: American Nuclear Society, Inc.; New York, NY: American Society of Civil Engineers. 391-396.

Gard, L.M. 1968. Geologic Studies, Project Gnome, Eddy County, New Mexico. Geological Survey Professional Paper 589. Washington, DC: U.S. Department of the Interior [Geological Survey; For Sale by the Superintendent of Documents], U.S. Government Printing Office. (On file in the SWCF as WPO 48945.) (Cited in Figure 3-5.)

Gilkey, A.P. 1988. ALGEBRA-A Program That Algebraically Manipulates the Output of a Finite Element Analy- sis (Exodus Version). SAND88-1431. Albuquerque, NM: Sandia National Laboratories.

Gonzalez, D.D. 1983. Groundwater Flow in the Rustler Formation, Waste Isolation Pilot Plant (WIPP), Southeast New Mexico (SENM): Interim Report. SAND82-1012. Albuquerque, NM: Sandia National Laboratories. (Cited in Figure 3-5.)

Griswold, G.B. to W.D. Weart. 1977. "Site Selection Criteria at Los Medanos May Need to be Modified Resulting in Change of Location." Sandia Laboratories R.W.D.P.P. Day File \#59, May and June 1976. (On file in the SWCF as \#500160.)

Gulick, C.W., Jr. 1978. Borehole Plugging-Materials Development Program. SAND78-0715. Albuquerque, NM: Sandia National Laboratories. (Cited in Figure 5-2.)

Gulick, C.W., Jr. 1979. Borehole Plugging Program, Plugging of ERDA No. 10 Drill Hole. SAND79-0789. Albuquerque, NM: Sandia National Laboratories. (Cited in Figure 5-2.)

Guzowski, R.V. 1990. Preliminary Identification of Scenarios That May Affect the Escape and Transport of Radionuclides From the Waste Isolation Pilot Plant, Southeastern New Mexico. SAND89-7149. Albuquerque, NM: Sandia National Laboratories. (Cited in Figure 6-2.)

Hacker, B.C. 1987. The Dragon's Tail: Radiation Safety in the Manhattan Project, 1942-1946. Berkeley, CA: University of California Press. (Cited in Figure 2-1.)

Hansen, F.D., M.K. Knowles, T.W. Thompson, M. Gross, J.D. McLennan, and J.F. Schatz. 1997. Description and Evaluation of a Mechanistically Based Conceptual Model for Spall. SAND97-1369. Albuquerque, NM: Sandia National Laboratories. (Cited in Figure 6-2.)

Haug, A., V.A. Kelley, A.M. LaVenue, and J.F. Pickens. 1987. Modeling of Ground-Water Flow in the Culebra Dolomite at the Waste Isolation Pilot Plant (WIPP) Site: Interim Report. SAND86-7167. Albuquerque, NM: Sandia National Laboratories. (Cited in Figure 6-2.)

Helton, J.C. 1993a. "Risk, Uncertainty in Risk, and the EPA Release Limits for Radioactive Waste Disposal," Nuclear Technology. Vol. 101, no. 1, 18-39.

Helton, J.C. 1993b. "Uncertainty and Sensitivity Analysis Techniques for Use in Performance Assessment for Radioactive Waste Disposal," Reliability Engineering \& System Safety. Vol. 42, no. 2-3, 327-367.

Helton, J.C. 1993c. "Drilling Intrusion Probabilities for Use in Performance Assessment for Radioactive Waste Disposal," Reliability Engineering \& System Safety. Vol. 40, no. 3, 259-275. 
Helton, J.C. 1994. "Treatment of Uncertainty in Performance Assessments for Complex Systems," Risk Analysis. Vol. 14 , no. $4,483-511$.

Helton, J.C., and H.J. Iuzzolino. 1993. "Construction of Complementary Cumulative Distribution Functions for Comparison with the EPA Release Limits for Radioactive Waste Disposal," Reliability Engineering \& System Safety. Vol. 40, no. 3, 277-293.

Helton, J.C., and A.W. Shiver. 1996. "A Monte Carlo Procedure for the Construction of Complementary Cumulative Distribution Functions for Comparison with the EPA Release Limits for Radioactive Waste Disposal," Risk Analysis. Vol. 16, no. 1, 43-55.

Helton, J.C., J.W. Garner, R.D. McCurley, and D.K. Rudeen. 1991. Sensitivity Analysis Techniques and Results for Performance Assessment at the Waste Isolation Pilot Plant. SAND90-7103. Albuquerque, NM: Sandia National Laboratories.

Heiton, J.C., J.W. Garner, R.P. Rechard, D.K. Rudeen, and P.N. Swift. 1992. Preliminary Comparison with 40 CFR Part 191, Subpart B for the Waste Isolation Pilot Plant, December 1991. Volume 4: Uncertainty and Sensitivity Analysis Results. SAND91-0893/4. Albuquerque, NM: Sandia National Laboratories.

Helton, J.C., J.W. Garner, M.G. Marietta, R.P. Rechard, D.K. Rudeen, and P.N. Swift. 1993a. "Uncertainty and Sensitivity Analysis Results Obtained in a Preliminary Performance Assessment for the Waste Isolation Pilot Plant," Nuclear Science and Engineering. Vol. 114, no. 4, 286331.

Helton, J.C., J.E. Bean, B.M. Butcher, J.W. Garner, J.D. Schreiber, P.N. Swift, and P. Vaughn. 1993b. Uncertainty and Sensitivity Analyses for Gas and Brine Migration at the Waste Isolation Pilot Plant, May 1992. SAND92-2013. Albuquerque, NM: Sandia National Laboratories.

Helton, J.C., D.R. Anderson, B.L. Baker, J.E. Bean, J.W. Berglund, W. Beyeler, K. Economy, J.W. Garner, S.C. Hora, H.J. Iuzzolino, P. Knupp, M.G. Marietta, J. Rath, R.P. Rechard, P.J. Roache, D.K. Rudeen, K. Salari, J.D. Schreiber, P.N. Swift, M.S. Tierney, and P. Vaughn. 1996. "Uncertainty and Sensitivity Analysis Results Obtained in the 1992 Performance Assessment for the Waste Isolation Pilot Plant," Reliability Engineering \& System Safety. Vol. 51, no. 1, 53-100.

Helton, J.C., W. Beyeler, and S.C. Hora. 1997a. "Conceptual Basis of a Systems Prioritization Methodology for the Waste Isolation Pilot Plant," Reliability Engineering \& System Safety. Vol. 57, no. 3, 203-222.

Helton, J.C., D.R. Anderson, B.L. Baker, J.E. Bean, J.W. Berglund, W. Beyeler, R. Blaine, K. Economy, J.W. Garner,
S.C. Hora, R.C. Lincoln, M.G. Marietta, F.T. Mendenhall, N.H. Prindle, D.K. Rudeen, J.D. Schreiber, A.W. Shiver, L.N. Smith, P.N. Swift, and P. Vaughn. 1997b. "Computational Implementation of a Systems Prioritization Methodology for the Waste Isolation Pilot Plant: A Preliminary Example," Reliability Engineering \& System Safety. Vol. 57, no. 3, 223-266.

Helton, J.C., D.R. Anderson, M.G. Marietta, and R.P. Rechard. 1997c. "Performance Assessment for the Waste Isolation Pilot Plant: From Regulation to Calculation for 40 CFR 191.13," Operations Research. Vol. 45, no. 2, 157-177.

Helton, J.C., J.D. Johnson, H.-N. Jow, R.D. McCurley, and L.J. Rahal. 1998. "Stochastic and Subjective Uncertainty in the Assessment of Radiation Exposure at the Waste Isolation Pilot Plant," Human and Ecological Risk Assessment. Vol. 4, no. 2, 469-526.

Hill, L.R., R. Aguilar, J.W. Mercer, and G. Newman. 1997. Condensed Listing of Surface Boreholes at the Waste Isolation Pilot Plant Project Through 31 December 1995. SAND96-1960. Albuquerque, NM: Sandia National Laboratories.

Hite, R.J., and S.W. Lohman. 1973. Geologic Appraisal of Paradox Basin Salt Deposits for Waste Emplacement. Open-File Report USGS-4339-6. Denver, CO: United States Department of the Interior, Geological Survey. (On file in the SWCF as WPO 48650.) (Cited in Figure 3-5.)

Hollingsworth, K.S. 1970 . "Policy Statement Regarding Solid Waste Burial." AEC Immediate Action Directive IAD No. 0511-21. March 20, 1970. [Washington, DC]: United States Atomic Energy Commission. (On file in the SWCF as \#500162.) (Cited in Figure 4-1.)

Holt, R.M. 1997. Conceptual Model for Transport Processes in the Culebra Dolomite Member, Rustler Formation. SAND97-0194. Albuquerque, NM: Sandia National Laboratories.

Holt, R.M., and D.W. Powers. 1990. Geologic Mapping of the Air Intake Shaft at the Waste Isolation Pilot Plant. DOE-WIPP 90-051. Carlsbad, NM: U.S. Department of Energy.

Hora, S.C., D. von Winterfeldt, and K.M. Trauth. 1991. Expert Judgment on Inadvertent Human Intrusion into the Waste Isolation Pilot Plant. SAND90-3063. Albuquerque, NM: Sandia National Laboratories.

Hunter, R.L. 1989. Events and Processes for Constructing Scenarios for the Release of Transuranic Waste from the Waste Isolation Pilot Plant, Southeastern New Mexico. SAND89-2546. Albuquerque, NM: Sandia National Laboratories. (Cited in Figure 6-2.) 
Hunter, T.O. 1979. "Technical Issues of Nuclear Waste Isolation in the Waste Isolation Pilot Plant (WIPP)," $87 t h$ National Meeting of American Institute of Chemical Engineers, Boston, MA, August 19-22, 1979. SAND791117C. Albuquerque, NM: Sandia National Laboratories. (On file in the SWCF as WPO 26711.) (Cited in Figure 5-2.)

Huyakorn, P.S., H.O. White, Jr., and S. Panday. 1991. "STAFF2D: Solute Transport and Fracture Flow in 2Dimensions." Version 3.1. March 1991. Herndon, VA: HydroGeologic, Inc. (On file in the SWCF as WPO 7415.)

IAEA (International Atomic Energy Agency). 1981. Safety Assessment for the Underground Disposal of Radioactive Wastes, Safety Series No. 56. Vienna, Austria: International Atomic Energy Agency. (Cited in Figure 6-2.)

IDB (Integrated Data Base). 1990. Integrated Data Base for 1990: U.S. Spent Fuel and Radioactive Waste Inventories, Projections, and Characteristics. DOE/RW-0006, Rev. 6. Oak Ridge, TN: Oak Ridge National Laboratory for U.S. Department of Energy, Office of Civilian Radioactive Waste Management, Office of Environmental Restoration and Waste Management.

Iman, R.L. 1982. "Statistical Methods for Including Uncertainties Associated with the Geologic Isolation of Radioactive Waste Which Allow for a Comparison with Licensing Criteria," Proceedings of the Symposium on Uncertainties Associated with the Regulation of the Geologic Disposal of High-Level Radioactive Waste, Gatlinburg, TN, March 9-13, 1981. Ed. D.C. Kocher. NUREG/ CP-0022, CONF-810372. Washington, DC: U.S. Nuclear Regulatory Commission, Directorate of Technical Information and Document Control. 145-157.

Iman, R.L., and W.J. Conover. 1980. "Small Sample Sensitivity Analysis Techniques for Computer Models, with an Application to Risk Assessment," Communications in Statistics. Vol. A9, no. 17, 1749-1842.

Iman, R.L., and J.C. Helton. 1988. "An Investigation of Uncertainty and Sensitivity Analysis Techniques for Computer Models," Risk Analysis. Vol. 8, no. 1, 71-90.

Iman, R.L., and J.C. Helton. 1991. "The Repeatability of Uncertainty and Sensitivity Analyses for Complex Probabilistic Risk Assessments," Risk Analysis. Vol. 11, no. 4, 591-606.

Iman, R.L., J.C. Helton, and J.E. Campbell. 1978. Risk Methodology for Geologic Disposal of Radioactive Waste: Sensitivity Analysis Techniques. SAND78-0912, NUREG/CR-0390. Albuquerque, NM: Sandia National Laboratories.
IRG (Interagency Review Group on Nuclear Waste Management). 1979. Report to the President by the Interagency Review Group on Nuclear Waste Management. TID29442. Washington, DC: U.S. Department of Energy. (On file in the SWCF as WPO 47934.) (Cited in Figure 4-1.)

Jensen, A.L., C.L. Howard, R.L. Jones, and T.P. Peterson. 1993. Room $Q$ Data Report: Test Borehole Data From April 1989 Through November 1991. SAND92-1172. Albuquerque, NM: Sandia National Laboratories. (Cited in Figure 3-5.)

Jones, C.L., M.E. Cooley, and G.O. Bachman. 1973. Salt Deposits of Los Medaños Area, Eddy and Lea Counties, New Mexico, With Sections on Ground Water Hydrology and Surficial Geology. Open-File Report USGS-4339-7. Denver, CO: United States Department of the Interior, Geological Survey. (On file in the SWCF as WPO 43835.)

Kaplan, S., and B.J. Garrick. 1981. "On the Quantitative Definition of Risk," Risk Analysis. Vol. 1, no. 1, 11-27.

Kosiewicz, S.T., B.L. Barraclough, and A. Zerwekh. 1980. Studies of Transuranic Waste Storage Under Conditions Expected in the Waste Isolation Pilot Plant (WIPP), Interim Summary Report, October 1, 1977-June 15, 1979. LA-7931-PR. Los Alamos, NM: Los Alamos Scientific Laboratory. (On file in the SWCF as WPO 48813.) (Cited in Figure 4-1.)

Krenz, D.L. 1986. Letter dated August 1986 to Evert H. Beckner, Vice President, Energy Programs, Sandia National Laboratories from D.L. Krenz, Assistant Manager for Projects and Energy Programs, DOE Albuquerque Operations Office. (On file in the SWCF as PA 00820.) (Cited in Figure 6-2.)

Krieg, R.D., C.M. Stone, and S.W. Key. 1981. Comparisons of the Structural Behavior of Three Storage Room Designs for the WIPP Project. SAND80-1629. Albuquerque, NM: Sandia National Laboratories.

Lambert, S.J. 1983. Dissolution of Evaporites In and Around the Delaware Basin, Southeastern New Mexico and West Texas. SAND82-0461. Albuquerque, NM: Sandia National Laboratories. (Cited in Figure 3-5.)

LANL (Los Alamos National Laboratory). 1987. "Stanislaw Ulam 1909-1984," Los Alamos Science. No. 15 Special Issue. Los Alamos, NM: Los Alamos National Laboratory. (On file in the SWCF as WPO 52396.)

Lappin, A.R. 1988. Summary of Site-Characterization Studies Conducted From 1983 Through 1987 at the Waste Isolation Pilot Plant (WIPP) Site, Southeastern New Mexico. SAND88-0157. Albuquerque, NM: Sandia National Laboratories. (Cited in Figures 3-4, 6-2.) 
Lappin, A.R., R.L. Hunter, D.P. Garber, and P.B. Davies, eds. 1989. Systems Analysis, Long-Term Radionuclide Transport, and Dose Assessments, Waste Isolation Pilot Plant (WIPP), Southeastern New Mexico; March 1989. SAND89-0462. Albuquerque, NM: Sandia National Laboratories. (Cited in Figures 3-4, 6-2.)

LaVenue, A.M. and B.S. RamaRao. 1992. A Modeling Approach to Address Spatial Variability Within the Culebra Dolomite Transmissivity Field. SAND92-7306. Albuquerque, NM: Sandia National Laboratories.

LaVenue, A.M., A. Haug, and V.A. Kelley. 1988. Numerical Simulation of Ground-Water Flow in the Culebra Dolomite at the Waste Isolation Pilot Plant (WIPP) Site: Second Interim Report. SAND88-7002. Albuquerque, NM: Sandia National Laboratories. (Cited in Figure 6-2.)

LaVenue, A.M., T.L. Cauffman, and J.F. Pickens. 1990. Ground-Water Flow Modeling of the Culebra Dolomite. Volume I: Model Calibration. SAND89-7068/1. Albuquerque, NM: Sandia National Laboratories. (Cited in Figures 3-5, 6-2.)

LEAF (Legal Environmental Assistance Foundation, Inc.) and Natural Resources Defense Council, Inc., State of Tennessee on behalf of Tennessee Department of Health and Environment (Intervening Plaintiff) v. Donald Hodel, Secretary, United States Department of Energy and United States Department of Energy. No. CIV. 3-83-562. 1984. 586 Federal Supplement 1163. (On file in the SWCF as WPO 48129.) (Cited in Figure 2-2.)

Lee, W.-L. 1996. "The Systems Prioritization Method for the Waste Isolation Pilot Plant: Problems with Methodology and Results," Proceedings of the International Topical Meeting on Nuclear and Hazardous Waste Management, Spectrum'96, Seattle, WA, August 18-23, 1996. La Grange Park, IL: American Nuclear Society. Vol. 1, 517522.

Lipschutz, R.D. 1980. Radioactive Waste: Politics, Technology, and Risk. Cambridge, MA: Ballinger Publishing Company, A Division of Harper and Row. 144, 199. (Cited in Figure 2-1.)

Logan, S.E. 1976. Workshop on Geologic Data Requirements for Radioactive Waste Management Assessment Models, Santa Fe, NM, June 28-July 1, 1976. Y/OWI/SUB-76/ 81726, UNM Report No. NE-27(76), Union Carbide 2971. Albuquerque, NM: University of New Mexico, College of Engineering, Bureau of Engineering Research for Office of Waste Isolation, Union Carbide Corporation, Nuclear Division. (On file in the SWCF as WPO 52833.) (Cited in Figure 2-2.)

Longsine, D.E., E.J. Bonano, and C.P. Harlan. 1987. User's Manual for the NEFTRAN Computer Code. SAND86-
2405, NUREG/CR-4766. Albuquerque, NM: Sandia National Laboratories.

Lowrance, W.W. 1976. Of Acceptable Risk: Science and the Determination of Safety. Los Altos, CA: W. Kaufmann.

Lynch, A.W., and R.G. Dosch. 1980. Sorption Coefficients for Radionuclides on Samples from the Water-Bearing Magenta and Culebra Members of the Rustler Formation. SAND80-1064. Albuquerque, NM: Sandia National Laboratories.

Lynch, A.W., R.G. Dosch, and C.R. Hills. 1981. Migration of Cesium-137 Through a Solid Core of Magenta Dolomite Taken from the Rustler Formation in Southeastern New Mexico. SAND80-1259. Albuquerque, NM: Sandia National Laboratories.

Lynch, R.W., R.L. Hunter, D.R. Anderson, F.W. Bingham, J.M. Covan, G.F. Hohnstrieter, T.O. Hunter, R.D. Klett, E.E. Ryder, T.L. Sanders, and W.D. Weart. 1991. Deep Geologic Disposal in the United States: The Waste Isolation Pilot Plant and Yucca Mountain Projects. SAND901656. Albuquerque, NM: Sandia National Laboratories. (Cited in Figure 5-2.)

Lyon, R.B. 1982. "Nuclear Waste Disposal: The Interface Between Performance Assessment and Research," Scientific Basis for Nuclear Waste Management, Proceedings of the Materials Research Society Annual Meeting, Boston, MA, November 16-19, 1981. Ed. S.V. Topp. New York, NY: North-Holland. Vol. 6, 473-480.

MacKinnon, R., G. Freeze, and H. Jow. 1997. "Summary of EPA-Mandated Performance Assessment Verification Test (Replicate 1) and Comparison with the Compliance Certification Application Calculations." Technical Data Package. Albuquerque, NM: Sandia National Laboratories. (On file in the SWCF as WPO 46674.)

Marietta, M.G., and W.F. Simmons. 1988. Feasibility of Disposal of High-Level Radioactive Waste Into the Seabed. Volume 5: Dispersal of Radionuclides in the Oceans: Models, Data Sets, and Regional Descriptions. SAND87-0753, INIS-XN-177. Albuquerque, NM: Sandia National Laboratories; Paris, France: Organisation for Economic Co-Operation and Development.

Marietta, M.G., S.G. Bertram-Howery, D.R. Anderson, K.F. Brinster, R.V. Guzowski, H. Iuzzolino, and R.P. Rechard. 1989. Performance Assessment Methodology Demonstration: Methodology Development for Evaluating Compliance With EPA 40 CFR 191, Subpart B, for the Waste Isolation Pilot Plant. SAND89-2027. Albuquerque, NM: Sandia National Laboratories. (Cited in Figure 6-2.)

Markowitz, H. 1952. "Portfolio Section," The Journal of Finance. Vol. VII, no. 1, 77-91. 
Matalucci, R.V. 1988. In Situ Testing at the Waste Isolation Pilot Plant. SAND87-2382. Albuquerque, NM: Sandia National Laboratories.

Matalucci, R.V., C.L. Christensen, T.O. Hunter, M.A. Molecke, and D.E. Munson. 1982. Waste Isolation Pilot Plant (WIPP) Research and Development Program: In Situ Testing Plan, March 1982. SAND81-2628. Albuquerque, NM: Sandia National Laboratories. (Cited in Figure 5-2.)

McAuliffe, D. 1978. "Licensing Impasse and New Mexico Emotions May Force DOE to Bury WIPP," Nucleonics Week. Vol. 19, no. 36, 2-3. (Cited in Figure 2-2.)

McClain, W.C., and R.L. Bradshaw. 1970. "Status of Investigations of Salt Formations for Disposal of Highly Radioactive Power-Reactor Wastes," Nuclear Safety. Vol. 11, no. 2, 130-141. (Cited in Figure 2-1.)

McCutcheon, C. 1989. "Embattled WIPP Won't Open in '89," Albuquerque Journal. June 28, 1989. Section A, pp. A1, A3.

McKay, M.D., R.J. Beckman, and W.J. Conover. 1979. “A Comparison of Three Methods for Selecting Values of Input Variables in the Analysis of Output from a Computer Code," Technometrics. Vol. 21, no. 2, 239-245.

McVey, D.F. 1981. Analysis of Data from Line Source Thermal Conductivity Measurements Taken In Situ in Dome Salt at the Avery Island Mine. SAND81-1232. Albuquerque, NM: Sandia National Laboratories. (Cited in Figure 5-2.)

Meigs, L., and J. McCord. 1996. "Physical Transport in the Culebra Dolomite." Letter Report, July 11, 1996. Albuquerque, NM: Sandia National Laboratories. (On file in the SWCF as WPO 39167.) (Cited in Figure 3-5.)

Meigs, L.C., R.L. Beauheim, J.T. McCord, Y.W. Tsang, and R. Haggerty. 1997. "Design, Modelling, and Current Interpretations of the $\mathrm{H}-19$ and $\mathrm{H}-11$ Tracer Tests at the WIPP Site," Field Tracer Experiments: Role in the Prediction of Radionuclide Migration: Synthesis and Proceeding of an NEA/EC GEOTRAP Workshop, Cologne, Germany, August 28-30, 1996. SAND96-2796C. Paris: Nuclear Energy Agency, Organisation for Economic Co-Operation and Development. 157-169. (Cited in Figure 3-5.)

Mercer, J.W. 1983. Geohydrology of the Proposed Waste Isolation Pilot Plant Site, Los Medaños Area, Southeastern New Mexico. Open-File Report 83-4016. Albuquerque, NM: U.S. Geological Survey. (Cited in Figure 3-5.)

Mercer, J.W., and B.R. Orr. 1979. Interim Data Report on the Geohydrology of the Proposed Waste Isolation Pilot Plant Site, Southeast New Mexico. Water-Resources Investigations Report 79-98. Albuquerque, NM: U.S. Geological Survey.
Merewether, E.A., J.A. Sharps, J.R. Gill, and M.E. Cooley. 1973. Shale, Mudstone, and Claystone as Potential Host Rocks for Underground Emplacement of Waste. OpenFile Report USGS-4339-5. Denver, CO: United States Department of the Interior, Geological Survey. (On file in the SWCF as WPO 48204.) (Cited in Figure 3-5.)

Metlay, D.S. 1978. "History and Interpretation of Radioactive Waste Management in the United States," Essays on Issues Relevant to the Regulation of Radioactive Waste Management. W.P. Bishop, I.R. Hoos, N. Hilberry, D.S. Metlay, and R.A. Watson. NUREG-0412. Washington, DC: Division of Fuel Cycle and Material Safety, Office of Nuclear Material Safety and Safeguards, U.S. Nuclear Regulatory Commission. 6-9. (Cited in Figure 2-1.)

Metropolis, N., and S. Ulam. 1949. "The Monte Carlo Method," Journal of the American Statistical Association. Vol. 44, no. 247, 335-341.

Mills-Curran, W.C., A.P. Gilkey, and D.P. Flanagan. 1988. EXODUS: A Finite Element File Format for Pre- and Postprocessing. SAND87-2997. Albuquerque, NM: Sandia National Laboratories.

Molecke, M.A. 1978. Waste Isolation Pilot Plant Transuranic Wastes Experimental Characterization Program: Executive Summary. SAND78-1356. Albuquerque, NM: Sandia National Laboratories. (Cited in Figure 4-1.)

Molecke, M.A. 1979. Gas Generation from Transuranic Waste Degradation: Data Summary and Interpretation. SAND79-1245. Albuquerque, NM: Sandia National Laboratories.

Molecke, M.A., and T.M. Torres. 1984. "The Waste Package Materials Field Test in S.E. New Mexico Salt," Scientific Basis for Nuclear Waste Management VII, Materials Research Society Symposia Proceedings, Boston, MA, November 14-17, 1983. Ed. G.L. McVay. SAND831516C. New York, NY: North-Holland. Vol. 26, 69-76.

Mongan, T.R., S.R. Ripple, G.P. Brorby, and D.G. diTommaso. 1996. "Plutonium Releases from the 1957 Fire at Rocky Flats," Health Physics. Vol. 71, no. 4, 510-521.

Morgan, H.S., C.M. Stone, and R.D. Krieg. 1985. "The Use of Field Data to Evaluate and Improve Drift Response Models for the Waste Isolation Pilot Plant (WIPP)," Research and Engineering Applications in Rock Masses, Proceedings of the 26th U.S. Symposium on Rock Mechanics, Rapid City, SD, June 26-28, 1985. Ed. E. Ashworth. Boston, MA: A.A. Balkema. Vol. 2, 769-776. (Cited in Figure 5-2.)

Morgan, H.S., C.M. Stone, and R.D. Krieg. 1986. An Evaluation of WIPP Structural Modeling Capabilities Based on Comparisons with South Drift Data. SAND85-0323. Albuquerque, NM: Sandia National Laboratories. (Cited in Figure 5-2.) 
Morgan, M.G., M. Henrion, and M. Small. 1990. Uncertainty, A Guide to Dealing With Uncertainty in Quantitative Risk and Policy Analysis. New York, NY: Cambridge University Press. 292.

MRSRC (Monitored Retrievable Storage Review Commission). 1989. Nuclear Waste: Is There a Need for Federal Interim Storage? Report of the Monitored Retrievable Storage Review Commission. November 1, 1989. Washington, DC: Superintendent of Documents, U.S. Government Printing Office. Sandia WIPP Central Files WPO 51784. (Cited in Figure 2-1.)

Munson, D.E., A.F. Fossum, and P.E. Senseny. 1989. Advances in Resolution of Discrepancies Between Predicted and Measured In Situ WIPP Room Closures. SAND88-2948. Albuquerque, NM: Sandia National Laboratories. (Cited in Figure 5-2.)

Munson, D.E., J.R. Ball, and R.L. Jones. 1990. “Data Quality Assurance Controls Through the WIPP In Situ Data Acquisition, Analysis, and Management System," High Level Radioactive Waste Management, Proceedings of the International Topical Meeting, Las Vegas, NV, April 8-12, 1990. La Grange Park, IL: American Nuclear Society; New York, NY: American Society of Civil Engineers. Vol. 2, 1337-1350.

Mytton, J.W. 1973. Two Salt Structures in Arizona: The Supai Salt Basin and the Luke Salt Body. Open-File Report USGS-4339-3. Denver, CO: United States Department of the Interior, Geological Survey. (On file in the SWCF as WPO 48691.) (Cited in Figure 3-5.)

NAS/NRC (National Academy of Sciences/National Research Council). 1957. The Disposal of Radioactive Waste on Land: Report of the Committee on Waste Disposal of the Division of Earth Sciences. Publication 519. Washington, DC: National Academy of Sciences - National Research Council. (Available from the National Technical Information Service (NTIS), Springfield, VA as DE92017903/XAB.) (Cited in Figure 2-1.)

NAS/NRC (National Academy of Sciences/National Research Council). 1970. Disposal of Solid Radioactive Wastes in Bedded Salt Deposits. Washington, DC: Committee on Radioactive Waste Management, National Academy of Sciences - National Research Council; For Sale by the Superintendent of Documents, U.S. Government Printing Office. (On file in the SWCF as WPO 43139 and available from the NTIS as PB-265 197/4.) (Cited in Figure 2-1.)

NAS/NRC (National Academy of Sciences/National Research Council). 1982. Causes and Effects of Stratospheric Ozone Reduction, An Update. Committee on Chemistry and Physics of Ozone Depletion and the Committee on Biological Effects of Increased Solar Ultraviolet Radiation, Environmental Studies Board, Commission on Nat- ural Resources, National Research Council. Washington, DC: National Academy Press.

NAS/NRC (National Academy of Sciences/National Research Council). 1984. Review of the Scientific and Technical Criteria for the Waste Isolation Pilot Plant (WIPP). Panel on the Waste Isolation Pilot Plant, Board on Radioactive Waste Management, Commission on Physical Sciences, Mathematics, and Resources, National Research Council. DOE/DP/48015-1. Washington, DC: National Academy Press. (Cited in Figures 3-4, 5-2.)

NAS/NRC (National Academy of Sciences/National Research Council). 1992. A Letter Report by the Panel on the Waste Isolation Pilot Plant, Board on Radioactive Waste Management. Washington, DC: Commission on Geosciences, Environment, and Resources, National Research Council. (On file in the SWCF as WPO 3520335204.) (Cited in Figure 4-1.)

NAS/NRC (National Academy of Sciences/National Research Council). 1995. Technical Bases for Yucca Mountain Standards. Committee on Technical Bases for Yucca Mountain Standards, Board on Radioactive Waste Management, Commission on Geosciences, Environment, and Resources, National Research Council. Washington, DC: National Academy Press. 2.

NAS/NRC (National Academy of Sciences/National Research Council). 1996. The Waste Isolation Pilot Plant: A Potential Solution for the Disposal of Transuranic Waste. Committee on the Waste Isolation Pilot Plant, Board on Radioactive Waste Management, Commission on Geosciences, Environment, and Resources, National Research Council. Washington, DC: National Academy Press. 6, 79-80. (Cited in Figure 6-2.)

NEA (Nuclear Energy Agency). 1991. Disposal of HighLevel Radioactive Wastes: Radiation Protection and Safety Criteria, Proceedings of an NEA Workshop, Paris, 5-7 November 1990. Paris, France: Nuclear Energy Agency, Organisation for Economic Co-Operation and Development. (On file in the SWCF as WPO 47928.)

Neill, R.H., J.K. Channell, L. Chaturvedi, M.S. Little, K. Rehfeldt, and P. Spiegler. 1983. Evaluation of the Suitability of the WIPP Site. EEG-23. Santa Fe, NM: Environmental Evaluation Group, Environmental Improvement Division. (Cited in Figure 3-5.)

Nichols, M.D. 1996. "Aspects of the CCA Requiring More Documentation for Completeness and Technical (Particularly Computer Codes) Concerns Before Rulemaking." Recipient: A.L. Alm. Date 12/19/96. Washington, DC: United States Environmental Protection Agency, Office of Air and Radiation. (On file in the SWCF as WPO 47192.) (Cited in Figure 6-2.) 
Nowak, E.J. 1986. "Brine Migration Studies in the Waste Isolation Pilot Plant (WIPP)," Waste Management '86 Waste Isolation in the U.S., Technical Programs and Public Education, Proceedings of the Symposium on Waste Management, Tucson, AZ, March 2-6, 1986. Ed. R.G. Post. SAND85-1987C. Tucson, AZ: University of Arizona. Vol. 2, 153-158. (Cited in Figure 3-5.)

Nowak, E.J., and J.C. Stormont. 1987. Scoping Model Calculations of the Reconsolidation of Crushed Salt in WIPP Shafts. SAND87-0879. Albuquerque, NM: Sandia National Laboratories.

Nowak, E.J., D.F. McTigue, and R. Beraún. 1988. Brine Inflow to WIPP Disposal Rooms: Data, Modeling, and Assessment. SAND88-0112. Albuquerque, NM: Sandia National Laboratories. (Cited in Figure 3-5.)

Nowak, E.J., J.R. Tillerson, and T.M. Torres. 1990. Initial Reference Seal System Design: Waste Isolation Pilot Plant. SAND90-0355. Albuquerque, NM: Sandia National Laboratories.

NRC (Nuclear Regulatory Commission). 1983. "10 CFR Part 60: Disposal of High-Level Radioactive Wastes in Geologic Repositories, Technical Criteria; Final Rule," Federal Register. Vol. 48, no. 120, 28194-28230.

NRDC (Natural Resources Defense Council, Inc.) v. United States Environmental Protection Agency, et al. 1987. 824 Federal Reporter, $2 d$ Series 1258. (On file in the SWCF as WPO 43240.) (Cited in Figure 2-2.)

Papenguth, H.W., and Y.K. Behl. 1996. "Test Plan: Evaluation of Dissolved Actinide Retardation at the Waste Isolation Pilot Plant." TP 96-02. Albuquerque, NM: Sandia National Laboratories. (On file in the SWCF as WPO 31336.) (Cited in Figure 3-5.)

Park, S.-W., J.O. Leckie, and M.D. Siegel. 1995. Surface Complexation Modeling of Uranyl Adsorption on Corrensite from the Waste Isolation Pilot Plant Site. SAND907084. Albuquerque, NM: Sandia National Laboratories.

Perge, A. 1982. "Historical Overview," Proceedings of AlphaContaminated Waste Management Workshop, Gaithersburg, MD, August 10-13, 1982. CONF-820845. Oak Ridge, TN: Oak Ridge National Laboratory. 17-30. (Cited in Figures 2-1, 4-1.)

Pierce, W.G., and E.I. Rich. 1962. Summary of Rock Salt Deposits in the United States as Possible Storage Sites for Radioactive Waste Materials. Geological Survey Bulletin 1148. Washington, DC: Geological Survey. (On file in the SWCF as WPO 48688.) (Cited in Figure 2-1.)

Popielak, R.S., R.L. Beauheim, S.R. Black, W.E. Coons, C.T. Ellingson, and R.L. Olsen. 1983. Brine Reservoirs in the Castile Formation, Waste Isolation Pilot Plant (WIPP)
Project, Southeastern New Mexico. TME 3153. Albuquerque, NM: U.S. Department of Energy, Waste Isolation Pilot Plant. (On file in the SWCF as WPO 42085.) (Cited in Figure 3-5.)

Powers, D.W., S.J. Lambert, S-E. Shaffer, L.R. Hill, and W.D. Weart, eds. 1978. Geological Characterization Report, Waste Isolation Pilot Plant (WIPP) Site, Southeastern New Mexico. SAND78-1596. Albuquerque, NM: Sandia [National] Laboratories. Vols. I-II. (Cited in Figure 3-5.)

Prindle, N.H., F.T. Mendenhall, D.M. Boak, W. Beyeler, D. Rudeen, R.C. Lincoln, K. Trauth, D.R. Anderson, M.G. Marietta, and J.C. Helton. 1996. The Second Iteration of the Systems Prioritization Method: A Systems Prioritization and Decision-Aiding Tool for the Waste Isolation Pilot Plant, Volume 1: Synopsis of Method and Results. SAND95-2017/1. Albuquerque, NM: Sandia National Laboratories. (Cited in Figure 6-2.)

Public Law 79-585. 1946. Atomic Energy Act of 1946. (60 Stat. 755). (On file in the SWCF as WPO 43711.) (Cited in Figure 2-1.)

Public Law 83-703. 1954. Atomic Energy Act of 1954. (68 Stat. 919). (On file in the SWCF as WPO 43705.) (Cited in Figure 2-1.)

Public Law 91-190. 1970. National Environmental Policy Act of 1969. (83 Stat. 852; 42 U.S.C. 4321 et seq.) (Cited in Figures 2-1, 2-2.)

Public Law 93-438. 1974. Energy Reorganization Act of 1974. (88 Stat. 1233; 42 U.S.C. 5801 et seq.) (Cited in Figure 2-2.)

Public Law 94-580. 1976. Resolurce Conservation and Recovery Act of 1976. (90 Stat. 2795 and subsequent amendments; 42 U.S.C. 6901 et seq.)

Public Law 95-91. 1977. Department of Energy Organization Act. (91 Stat. 565; 42 U.S.C. 7101 et seq.)

Public Law 96-164. 1979. Department of Energy National Security and Military Applications of Nuclear Energy Authorization Act of 1980. (93 Stat. 1259). (Cited in Figures 2-2, 4-1.)

Public Law 97-425. 1983. Nuclear Waste Policy Act of 1982. (96 Stat. 2201; 42 U.S.C. 10101 et. seq.)

Public Law 98-616. 1984. The Hazardous and Solid Waste Amendments of 1984. (98 Stat. 3221). (Cited in Figure 2-2.)

Public Law 100-203. 1987. Nuclear Waste Policy Amendments Act of 1987. (101 Stat. 1330; 42 U.S.C. 10101 et seq.) 
Public Law 102-579. 1992. Waste Isolation Pilot Plant Land Withdrawal Act. (106 Stat. 4777). (Cited in Figure 2-2.)

Public Law 104-201. 1996. National Defense Authorization Act for Fiscal Year 1997. Subtitle F-Waste Isolation Pilot Plant Land Withdrawal Act Amendments. (110 Stat. 2851). (Cited in Figure 2-2.)

Ramsey, J.L., M.G. Wallace, and H.N. Jow. 1996. "Analysis Package for the Culebra Flow and Transport Calculations (Task 3) of the Performance Assessment Calculations Supporting the Compliance Certification Application (CCA), AP-019." Analysis Plan 019. Albuquerque, NM: Sandia National Laboratories. (On file in SWCF as WPO 40516.)

Rasmussen, N.C. 1975. Reactor Safety Study: An Assessment of Accident Risks in U.S. Commercial Nuclear Power Plants. NUREG-75/014, WASH-1400. Washington, DC: U.S. Nuclear Regulatory Commission. (Available from the NTIS as PB-248 200-Set.) (Cited in Figure 6-2.)

Rechard, R.P. 1989. Review and Discussion of Code Linkage and Data Flow in Nuclear Waste Compliance Assessments. SAND87-2833. Albuquerque, NM: Sandia National Laboratories. (Cited in Figure 6-2.)

Rechard, R.P. 1991. "CAMCON: Computer System for Assessing Regulatory Compliance of the Waste Isolation Pilot Plant," Probabilistic Safety Assessment and Management, Proceedings of the International Conference on (PSAM), Beverly Hills, CA, February 4-7, 1991. Ed. G. Apostolakis. SAND90-2094C. New York, NY: Elsevier Science Publishers. Vol. 2, 899-904.

Rechard, R.P. 1995. An Introduction to the Mechanics of Performance Assessment Using Examples of Calculations Done for the Waste Isolation Pilot Plant Between 1990 and 1992. SAND93-1378. Albuquerque, NM: Sandia National Laboratories.

Rechard, R.P. 1998. Milestones for Disposal of Radioactive Waste at the Waste Isolation Pilot Plant (WIPP) in the United States. SAND98-0072. Albuquerque, NM: Sandia National Laboratories.

Rechard, R.P., ed. 1992. User's Reference Manual for CAMCON: Compliance Assessment Methodology Controller, Version 3.0. SAND90-1983. Albuquerque, NM: Sandia National Laboratories.

Rechard, R.P., H.J. Iuzzolino, J.S. Rath, A.P. Gilkey, R.D. McCurley, and D.K. Rudeen. 1989. User's Manual for CAMCON: Compliance Assessment Methodology Controller. SAND88-1496. Albuquerque, NM: Sandia National Laboratories. (Cited in Figure 6-2.)

Rechard, R.P., W. Beyeler, R.D. McCurley, D.K. Rudeen, J.E. Bean, and J.D. Schreiber. 1990. Parameter Sensitivity
Studies of Selected Components of the Waste Isolation Pilot Plant Repository/Shaft System. SAND89-2030. Albuquerque, NM: Sandia National Laboratories. (Cited in Figure 6-2.)

Rechard, R.P., P.J. Roache, R.L. Blaine, A.P. Gilkey, and D.K. Rudeen. 1991. Quality Assurance Procedures for Computer Software Supporting Performance Assessments of the Waste Isolation Pilot Plant. SAND90-1240. Albuquerque, NM: Sandia National Laboratories.

Rechard, R.P., K.M. Trauth, and R.V. Guzowski. $1992 \mathrm{a}$. Quality Assurance Procedures for Parameter Selection and Use of Expert Judgment Panels Supporting Performance Assessments of the Waste Isolation Pilot Plant. SAND91-0429. Albuquerque, NM: Sandia National Laboratories.

Rechard, R.P., D.K. Rudeen, and P.J. Roache. 1992b. Quality Assurance Procedures for Analyses and Report Reviews Supporting Performance Assessments of the Waste Isolation Pilot Plant. SAND91-0428. Albuquerque, NM: Sandia National Laboratories.

Rechard, R.P., A.P. Gilkey, H.J. Iuzzolino, D.K. Rudeen, and K.A. Byle. 1993a. Programmer's Manual for CAMCON: Compliance Assessment Methodology Controller: SAND90-1984. Albuquerque, NM: Sandia National Laboratories.

Rechard, R.P., K.M. Trauth, J.S. Rath, R.V. Guzowski, S.C. Hora, and M.S. Tierney. 1993b. "The Use of Formal and Informal Expert Judgments When Interpreting Data for Performance Assessments," Scientific Basis for Nuclear Waste Management XVI, Materials Research Society Symposium Proceedings, November 30-December 4, 1992. Eds. C.G. Interrante and R.T. Pabalan. SAND921148C. Pittsburgh, PA: Materials Research Society. Vol. 294, 943-950.

Rechard, R.P., C.T. Stockman, L.C. Sanchez, J. Liscum-Powell, and J.S. Rath. 1996. "FEPS Qualitative Screening Argument. RNT-1: Nuclear Criticality in Near Field and Far Field." Summary Memo of Record. Albuquerque, NM: Sandia National Laboratories. On file in the SWCF as WPO 40818.

Reed, D.T., S. Okajima, L.H. Brush, and M.A. Molecke. 1993. "Radiolytically-Induced Gas Production in Plutonium-Spiked WIPP Brine," Scientific Basis for Nuclear Waste Management XVI, Materials Research Society Symposium Proceedings, Boston, MA, November 30December 4, 1992. Eds. C.G. Interrante and R.T. Pabalan. SAND92-7283C. Pittsburgh, PA: Materials Research Society. Vol. 294, 431-438. (Cited in Figure 41.)

Reeves, M., D.S. Ward, N.D. Johns, and R.M. Cranwell. 1986. Theory and Implementation for SWIFT $I I$. The 
Sandia Waste-Isolation Flow and Transport Model for Fractured Media, Release 4.84. SAND83-1159, NUREG/CR-3328. Albuquerque, NM: Sandia National Laboratories. (Cited in Figure 6-2.)

Reeves, M., V.A. Kelley, and J.F. Pickens. 1987. Regional Double-Porosity Solute Transport in the Culebra Dolomite: An Analysis of Parameter Sensitivity and Importance at the Waste Isolation Pilot Plant (WIPP) Site. SAND87-7105. Albuquerque, NM: Sandia National Laboratories. (Cited in Figure 6-2.)

Reorganization Plan No. 3 of 1970. 1970. Federal Register. Vol. 35, no. 194, 15623-15626. (5 U.S.C. \$903, Paragraph 301, Section 2(a)6; 84 Stat. 2086). (Cited in Figure 2-2.)

Roache, P.J. 1993. "The SECO Suite of Codes for Site Performance Assessment," High Level Radioactive Waste Management, Proceedings of the Fourth Annual International Conference, Las Vegas, NV, April 26-30, 1993. SAND93-7007C. La Grange Park, IL: American Nuclear Society, Inc.; New York, NY: American Society of Civil Engineers. Vol. 2, 1586-1594.

SAB (EPA Science Advisory Board). 1984. Report on the Review of Proposed Environmental Standards for the Management and Disposal of Spent Nuclear Fuel, HighLevel and Transuranic Radioactive Wastes (40 CFR 191). Washington, DC: High-Level Radioactive Waste Disposal Subcommittee, Science Advisory Board, U.S. Environmental Protection Agency. (On file in SWCF as WPO 49509.) (Cited in Figure 2-2.)

Sandia [National] Laboratories. 1977. Waste Isolation Pilot Plant (WIPP) Conceptual Design Report. SAND770274. Albuquerque, NM: Sandia [National] Laboratories. (Cited in Figure 5-2.)

Sandia [National] Laboratories. 1979. Summary of Research and Development Activities in Support of Waste Acceptance Criteria for WIPP. Comp. T.O. Hunter. SAND791305. Albuquerque, NM: Sandia [National] Laboratories. (Cited in Figure 4-1.)

Sandia National Laboratories and U.S. Geological Survey. 1983. Basic Data Report for Drillhole ERDA 6 (Waste Isolation Pilot Plant - WIPP). SAND79-0267. Albuquerque, NM: Sandia National Laboratories. (Cited in Figure 3-5.)

Sandia National Laboratories. 1989. Recollections for Tomorrow. SAND89-1953. Albuquerque, NM: Sandia National Laboratories. 18-19. (Cited in Figure 4-1.)

Sattler, A.R., and C.L. Christensen. 1980. Measurements of Very Large Deformations in "Potash Salt" in Conjunction With an Ongoing Mining Operation. SAND79-2254.
Albuquerque, NM: Sandia National Laboratories. (Cited in Figure 5-2.)

Serber, R. 1992. The Los Alamos Primer: The First Lectures on How to Build an Atomic Bomb. Ed. R. Rhodes. Berkeley, CA: University of California Press.

Serne, R.J., D. Rai, M.J. Mason, and M.A. Molecke. 1977. Batch Kd Measurements of Nuclides to Estimate Migra. tion Potential at the Proposed Waste Isolation Pilot Plant in New Mexico. PNL-2448. Richland, WA: Battelle Pacific Northwest Laboratories.

Siegel, M.D., J.O. Leckie, S.-W. Park, S.L. Phillips, and T. Sewards. 1990. Studies of Radionuclide Sorption by Clays in the Culebra Dolomite at the Waste Isolation Pilot Plant Site, Southeastern New Mexico. SAND892387. Albuquerque, NM: Sandia National Laboratories.

Sjoblom, G. 1982. "Regulatory Policy of the EPA Related to Alpha-Contaminated Waste," Proceedings of Alpha-Contaminated Waste Management Workshop, Gaithersburg, MD, August 10-13, 1982. CONF-820845. Oak Ridge, TN: Oak Ridge National Laboratory. 47-58. (Cited in Figure 4-1.)

Smith, T. 1982. "Risk and Safety Analyses for Disposal of Alpha-Contaminated Waste in INEL," Proceedings of Alpha-Contaminated Waste Management Workshop, Gaithersburg, MD, August 10-13, 1982. CONF-820845. Oak Ridge, TN: Oak Ridge National Laboratory. 395436. (Cited in Figure 6-2.)

Snyder, R.P., L.M. Gard, Jr., and J.W. Mercer. 1982. Evaluation of Breccia Pipes in Southeastern New Mexico and Their Relation to the Waste Isolation Pilot Plant (WIPP) Site, with Section on Drill-Stem Tests, WIPP 31. OpenFile Report 82-968. Denver, CO: Prepared by the U.S. Geological Survey for the Albuquerque Operations Office, U.S. Department of Energy. (Cited in Figure 3-5.)

SRIC (Southwest Research and Information Center, Inc.). 1981. "Nuclear Waste Disposal," The Workbook. Vol. VI, no. 2, 44. (On file in the SWCF as WPO 47565.) (Cited in Figure 2-2.)

SRIC (Southwest Research and Information Center, Inc.), Peter Montague; Michael Rutherford; Bill Pierce; and June Naylor, Plaintiffs, v. United States Department of Energy; James Edwards, Secretary of the United States Department of Energy; United States Department of Interior; United States Bureau of Land Management; and Robert F. Burford, Director of the Bureau of Land Management, Defendants. Civil No. 81-0537-JB. United States District Court, District of New Mexico. Action filed July 10, 1981. Judgment rendered October 1, 1984, by U.S. District Judge Juan C. Burciaga. (On file in the SWCF as WPO 47567.) (Cited in Figure 2-2.) 
State of New Mexico, ex rel., Jeff Bingaman, Attorney General of the State of New Mexico, Plaintiff, v. The United States Department of Energy, et al., Defendants. 1981. "Stipulated Agreement." Civil Action No. 81-0363 JB. United States District Court for the District of New Mexico, July 1, 1981. (On file in the SWCF as WPO 42008.) (Cited in Figures 2-2, 6-2.)

Stenhouse, M., N. Chapman, and T. Sumerling. 1993. SITE94 Scenario Development FEP Audit List Preparation: Methodology and Presentation. SKI Technical Report 93:27. Stockholm: Swedish Nuclear Power Inspectorate.

Stockman, C., A. Shinta, and J.W. Garner. 1996. "Analysis Package for the Salado Transport Calculations (Task 2) of the Performance Assessment Analyses Supporting the Compliance Certification Application (CCA), AP-023." Analysis Plan 023. Albuquerque, NM: Sandia National Laboratories. (On file in SWCF as WPO 40515.)

Stoelzel, D.M., and D.G. O'Brien. 1996. "The Effects of Salt Water Disposal and Waterflooding on WIPP." Summary Memorandum of Record for NS-7a. Albuquerque, NM: Sandia National Laboratories. (On file in SWCF as WPO 40837.)

Stoelzel, D.M., and P.N. Swift. 1997. "Supplementary Analysis of the Effects of Salt Water Disposal and Waterflooding on the WIPP." Summary Memorandum of Record for NS-7a. Albuquerque, NM: Sandia National Laboratories. (On file in SWCF as WPO 44158.)

Stone, C.M. 1997. SANTOS-A Two-Dimensional Finite Element Program for the Quasistatic, Large Deformation, Inelastic Response of Solids. SAND90-0543. Albuquerque, NM: Sandia National Laboratories.

Stone, C.M., R.D. Krieg, and Z.E. Beisinger. 1985. SANCHO: A Finite Element Computer Program for the Quasistatic, Large Deformation, Inelastic Response of TivoDimensional Solids. SAND84-2618. Albuquerque, NM: Sandia National Laboratories.

Stormont, J.C. 1988. Preliminary Seal Design Evaluation for the Waste Isolation Pilot Plant. SAND87-3083. Albuquerque, NM: Sandia National Laboratories.

Taugher, M. 1996a. "Key WIPP Document Exceeds 400 Lbs," Albuquerque Journal. November 21, 1996. Section D, page 3. (Cited in Figure 6-2.)

Taugher, M. 1996b. "Scientists: WIPP Not A Threat," Albuquerque Journal. October 24, 1996. Section A, pages 1 , 10. (Cited in Figure 6-2.)

Taugher, M., and S. Smallwood. 1999. "WIPP Opening Ushers in New Nuclear Era," Albuquerque Journal. March 27, 1999. Section A, pp. 1, 2.
Taylor, L.M., D.P. Flanagan, and W.C. Mills-Curran. 1986. The GENESIS Finite Element Mesh File Format. SAND86-0910. Albuquerque, NM: Sandia National Laboratories.

Telander, M.R., and R.E. Westerman. 1993. Hydrogen Generation by Metal Corrosion in Simulated Waste Isolation Pilot Plant Environments: Progress Report for the Period November 1989 through December 1992. SAND927347. Albuquerque, NM: Sandia National Laboratories. (Cited in Figure 4-1.)

Telander, M.R., and R.E. Westerman. 1997. Hydrogen Generation by Metal Corrosion in Simulated Waste Isolation Pilot Plant Environments. SAND96-2538. Albuquerque, NM: Sandia National Laboratories. (Cited in Figure 4-1.)

Teller, E. 1959. "The Plowshare Program," Proceedings of the Second Plowshare Symposium, San Francisco, CA, May 13-15, 1959. Part I. Phenomenology of Underground Nuclear Explosions. Plowshare Series Report No. 2. UCRL-5675. Livermore, CA: Lawrence Radiation Laboratory. 8-13. (On file in SWCF as WPO 44080.) (Cited in Figure 2-1.)

Thompson, B.G.J. 1987. "The Development of Procedures for the Risk Assessment of Underground Disposal of Radioactive Wastes: Research Funded by the Department of Environment 1982-1987," Radioactive Waste Management and the Nuclear Fuel Cycle. Vol. 9, no. 1-3, 215256.

Tien, P-L., F.B. Nimick, A.B. Muller, P.A. Davis, R.V. Guzowski, L.E. Duda, and R.L. Hunter. 1983. Repository Site Data and Information in Bedded Salt: Palo Duro Basin, Texas. SAND82-2223, NUREG/CR-3129. Albuquerque, NM: Sandia National Laboratories.

Tierney, M.S. 1991. Combining Scenarios in a Calculation of the Overall Probability Distribution of Cumulative Releases of Radioactivity from the Waste Isolation Pilot Plant, Southeastern New Mexico. SAND90-0838. Albuquerque, NM: Sandia National Laboratories.

Tierney, M.S. 1994. "Using Data and Information to Form Distributions of Model Parameters in Stochastic Simulations of Performance of the Waste Isolation Pilot Plant (WIPP)," Proceedings of PSAM - II, An lnternational Conference Devoted to the Advancement of System-Based Methods for the Design and Operation of Technological Systems and Processes, San Diego, CA, March 20-25, 1994. Eds. G.E. Apostolakis and J.S. Wu. SAND931302A. Los Angeles, CA: University of California. Vol. 2, 051-9 through 051-16.

Tierney, M.S. 1995. “3. PA Methodology Overview," Performance Assessment of the Direct Disposal in Unsaturated Tuff of Spent Nuclear Fuel and High-Level Waste Owned by U.S. Department of Energ): Volume 2: Methodology' 
and Results. SAND94-2563/2. Albuquerque, NM: Sandia National Laboratories. 3-1 through 3-28.

Tierney, M.S., and R.P. Rechard. 1997. "Assessing Performance of Imprecisely Characterized Systems: A Mathematical Perspective," Advances in Safety and Reliability: Proceedings of the ESREL'97 International Conference on Safety and Reliability, Lisbon, Portugal, June 17-20, 1997. Ed. C.G. Soares. Oxford, England; New York, NY: Pergamon. Vol. 1, 569-576.

Trauth, K.M., R.P. Rechard, and S.C. Hora. 1991. "Expert Judgment as Input to Waste Isolation Pilot Plant Performance Assessment Calculations: Probability Distributions of Significant System Parameters," Mixed Waste, Proceedings of the First International Symposium, Baltimore, MD, August 26-29, 1991. Eds. A.A. Moghissi and G.A. Benda. SAND91-0625C. Baltimore, MD: University of Maryland. 4.3.1 through 4.3.9. (On file in SWCF as WPO 51803.)

Trauth, K.M., S.C. Hora, R.P. Rechard, and D.R. Anderson. 1992. The Use of Expert Judgment to Quantify Uncertainty in Solubility and Sorption Parameters for Waste Isolation Pilot Plant Performance Assessment. SAND920479. Albuquerque, NM: Sandia National Laboratories.

Trauth, K.M., S.C. Hora, and R.V. Guzowski. 1993. Expert Judgment on Markers to Deter Inadvertent Human Intrusion into the Waste Isolation Pilot Plant. SAND92-1382. Albuquerque, NM: Sandia National Laboratories.

Tyler, L.D., R.V. Matalucci, M.A. Molecke, D.E. Munson, E.J. Nowak, and J.C. Stormont. 1988. Summary Report for the WIPP Technology Development Program for Isolation of Radioactive Waste. SAND88-0844. Albuquerque, NM: Sandia National Laboratories. (Cited in Figures 34, 4-1, 5-2.)

U.S. Congress. 1970a. "National Academy of SciencesNational Research Council," Congressional Record. Vol. 116, pt. 10, 13570-13589. (Cited in Figure 2-1.)

U.S. Congress. 1970b. "Radioactive Waste Management: An Interim Report of the Committee on Radioactive Waste Management," Congressional Record. Vol. 116, pt. 10, 13592-13593. (Cited in Figure 2-1.)

Van Sambeek, L.L., D.D. Luo, M.S. Lin, W. Ostrowski, and D. Oyenuga. 1993. Seal Design Alternatives Study. SAND92-7340. Albuquerque, NM: Sandia National Laboratories.

Vaughn, P. 1986. A Numerical Model for Thermal Recovery Processes in Tar Sand: Description and Application. DOE/FE/60177-2219. Laramie, WY: Western Research Institute for Department of Energy, Morgantown Energy Technology Center, Laramie Project Office. (On file in the SWCF as WPO 51804.)
Voss, C.I. 1984. SUTRA (Saturated-Unsaturated Transport): A Finite-Element Simulation Model for Saturated-Unsaturated, Fluid-Density-Dependent Ground-Water Flow with Energy Transport or Chemically-Reactive SingleSpecies Solute Transport. Water-Resources Investigations Report 84-4369. Reston, VA: U.S. Geological Survey.

Weart, W.D. 1979. "WIPP: A Bedded Salt Repository for Defense Radioactive Waste in Southeastern New Mexico," Radioactive Waste in Geologic Storage, 176th Annual Meeting of the American Chemical Society, Miami Beach, FL, September 11-15, 1978. Ed. S. Fried. ACS Symposium Series No. 100. SAND78-0934C. Washington, DC: American Chemical Society. 13-36. (Cited in Figures 4-1, 5-2.)

Westinghouse Electric Corporation (WEC). 1994. Backfill Engineering Analysis Report, Waste Isolation Pilot Plant. Carlsbad, NM: Westinghouse Electric Corporation, Waste Isolation Division. (On file in the SWCF as WPO 37909.)

Wicks, G.G., A.R. Lodding, and M.A. Molecke. 1993. "Aqueous Alteration of Nuclear Waste Glasses and Metal Package Components," MRS Bulletin. Vol. 18, no. 9, 3239.

Wieck, P.R., and B. Spice. 1988. "Delegation Buries WIPP Bill for Session," Albuquerque Journal. October 4, 1988. Section A, pp. 1, 3 .

WIPP PA (Performance Assessment) Department. 1992-1993. Preliminary Performance Assessment for the Waste Isolation Pilot Plant, December 1992. SAND92-0700/1/2/3/ 4/5. Albuquerque, NM: Sandia National Laboratories. Vols. 1-5. (Cited in Figure 6-2.)

WIPP PA (Performance Assessment) Department. 1996. "PANEL, Version 3.60, User's Manual." Albuquerque, NM: Sandia National Laboratories. On file in the SWCF as WPO 37361.

WIPP PA (Performance Assessment) Division. 1991-1992. Preliminary Comparison with 40 CFR Part 191, Subpart $B$ for the Waste Isolation Pilot Plant, December 1991. SAND91-0893/1/2/3. Albuquerque, NM: Sandia National Laboratories. Vols. 1-3. (Cited in Figure 6-2.)

Woolfolk, S.W. 1982. Radiological Consequences of Brine Release by Human Intrusion Into WIPP. TME-3151. Albuquerque, NM: U.S. Department of Energy, Waste Isolation Pilot Plant. (On file in SWCF as WPO 41629.)

Zimmerman, D.A., and D.P. Gallegos. 1993. "A Comparison of Geostatistically-Based Inverse Techniques for Use in Performance Assessment Analyses at the WIPP Site: Results from Test Case No. 1," High Level Radioactive Waste Management, Proceedings of the Fourth Annual International Conference, Las Vegas, NV, April 26-30, 
1993. SAND92-2127C. La Grange Park, IL: American Nuclear Society, Inc.; New York, NY: American Society of Civil Engineers. Vol. 2, 1426-1436.

References cited in Figure 2-1

$\begin{array}{ll}\text { A1 } & \text { AEC, 1948 } \\ \text { A2 } & \text { Hacker, 1987 } \\ \text { A3 } & \text { Public Law 79-585, 60 Stat. 755 } \\ \text { A4 } & \text { Public Law 83-703, 68 Stat. } 919 \\ \text { A5 } & \text { Boffey, 1975 } \\ \text { A6 } & \text { NAS/NRC, 1957 } \\ \text { A7 } & \text { U.S. Congress, 1970a } \\ \text { A8 } & \text { Teller, 1959 } \\ \text { A9 } & \text { Mongan et al., 1996 } \\ \text { A10 } & \text { Claiborne and Gera, 1974 } \\ \text { A11 } & \text { Pierce and Rich, 1962 } \\ \text { A12 } & \text { McClain and Bradshaw, 1970 } \\ \text { A13 } & \text { Bradshaw and McClain, 1971 } \\ \text { A14 } & \text { Carter, 1987, p. 64 } \\ \text { A15 } & \text { U.S. Congress, 1970b } \\ \text { A16 } & \text { EPA, 1985b } \\ \text { A17 } & \text { Perge, 1982 } \\ \text { A18 } & \text { Davies, 1969 } \\ \text { A19 } & \text { Public Law 91-190, 83 Stat. 852 } \\ \text { A20 } & \text { Lipschutz, 1980 } \\ \text { A21 } & \text { AEC, 1971 } \\ \text { A22 } & \text { NAS/NRC, 1970 } \\ \text { A23 } & \text { AEC, 1970 } \\ \text { A24 } & \text { CCCC, 1971 } \\ \text { A25 } & \text { Metlay, 1978 } \\ \text { A26 } & \text { MRSRC, 1989 } \\ & \\ & \end{array}$

References cited in Figure 2-2

B1 Public Law 91-190, 83 Stat. 852

B2 EPA, 1993a

B3 Reorganization Plan, 1970, 84 Stat. 2086

B4 Public Law 93-438, 88 Stat. 1233

B5 Logan, 1976

B6 EPA, 1985a

B7 Ford, 1976

B8 Public Law 94-580, 90 Stat. 2795

B9 EPA, 1976

B10 Public Law 95-91, 91 Stat. 565

B11 EPA, 1978a

B12 McAuliffe, 1978

B13 NAS/NRC, 1984

B14 EPA, 1978b

B15 Public Law 96-164, 93 Stat. 1259

B16 SRIC, 1981

B17 State of NM, 1981

B18 SRIC, 1984

B19 EPA, 1985b

B20 EPA, 1982

B21 Documents, 1982

B22 SAB, 1984

B23 LEAF, 1984

B24 Public Law 98-616, 98 Stat. 3221

B25 NRDC, 1987
Figure 2-2 (continued)

$\begin{array}{ll}\text { B26 } & \text { EPA, 1986 } \\ \text { B27 } & \text { DOE, 1987 } \\ \text { B28 } & \text { Wieck and Spice, 1988 } \\ \text { B29 } & \text { Cummings, 1988 } \\ \text { B30 } & \text { DOE, 1989b } \\ \text { B31 } & \text { EPA, 1990 } \\ \text { B32 } & \text { DOE, 1992a } \\ \text { B33 } & \text { DOE, 1992b } \\ \text { B34 } & \text { Public Law 102-579, 106 Stat. } 4777 \\ \text { B35 } & \text { EPA, 1993b } \\ \text { B36 } & \text { EPA, 1995 } \\ \text { B37 } & \text { EPA, 1996a } \\ \text { B38 } & \text { Public Law 104-201, 110 Stat. 2851 } \\ \text { B39 } & \text { EPA, 1997 }\end{array}$

References cited in Figure 3-5

C 1 Gard, 1968

C2 Cooper and Glanzman, 1971

C3 Brokaw et al., 1972

C4 Anderson et al., 1973

C5 Mytton, 1973

C6 Bachman et al., 1973

C7 Merewether et al., 1973

C8 Hite and Lohman, 1973

C9 Jones et al., 1973

C10 Bachman, 1973

C11 Barnes, 1974

C12 Powers et al., eds., 1978

C13 Carter, 1987, p. 180

C14 Sandia and USGS, 1983

C15 NAS/NRC, 1984

C16 Lappin et al., eds., 1989

C17 Christensen et al., 1980

C18 Tyler et al., 1988

C19 Popielak et al., 1983

C20 Molecke and Torres, 1984

C21 Lambert, 1983

C22 Snyder et al., 1982

C23 Mercer, 1983

C24 Gonzales, 1983

C25 Borns et al., 1983

C26 Neill et al., 1983

C27 Beauheim et al., 1983

C28 Lappin, 1988

C29 Nowak, 1986

C30 Beauheim, 1986

C31 Earth Technology, 1988

C32 Begley and Miller, 1987

C33 Nowak et al., 1988

C34 Beauheim, 1989

C35 LaVenue et al., 1990

C36 Beauheim et al., 1991

C37 Jensen et al., 1993

C38 Meigs and McCord, 1996

C39 Meigs et al., 1997

C40 Papenguth \& Behl, 1996

C41 Brush \& Storz, 1996 
References cited in Figure 4-1

$\begin{array}{ll}\text { D1 } & \text { Sandia, 1989 } \\ \text { D2 } & \text { Perge, 1982 } \\ \text { D3 } & \text { Hollingsworth, 1970 } \\ \text { D4 } & \text { Molecke, 1978 } \\ \text { D5 } & \text { Sandia, 1979 } \\ \text { D6 } & \text { Carter (J.E.), 1977 } \\ \text { D7 } & \text { Kosiewicz et al., 1980 } \\ \text { D8 } & \text { DOE, 1978 } \\ \text { D9 } & \text { Carter (L.J.), 1978 } \\ \text { D10 } & \text { Carter (L.J.), 1987, p. 86 } \\ \text { D11 } & \text { Tyler et al., 1988 } \\ \text { D12 } & \text { IRG, 1979 } \\ \text { D13 } & \text { Weart, 1979 } \\ \text { D14 } & \text { DOE, 1979 } \\ \text { D15 } & \text { Public Law 96-164, 93 Stat. 1259 } \\ \text { D16 } & \text { Sjoblom, 1982 } \\ \text { D17 } & \text { Carter, 1982 } \\ \text { D18 } & \text { DOE, 1980a } \\ \text { D19 } & \text { Molecke and Torres, 1984 } \\ \text { D20 } & \text { Freiwald, 1982 } \\ \text { D21 } & \text { Public Law 100-203, 101 Stat. 1330 } \\ \text { D22 } & \text { Brush, 1990 } \\ \text { D23 } & \text { Brush et al., 1991a } \\ \text { D24 } & \text { Brush et al., 1991b } \\ \text { D25 } & \text { Reed et al., 1993 } \\ \text { D26 } & \text { Telander and Westerman, 1993 } \\ \text { D27 } & \text { Francis and Gillow, 1994 } \\ \text { D28 } & \text { DOE, 1990b } \\ \text { D29 } & \text { DOE, 1993a } \\ \text { D30 } & \text { DOE, 1993b } \\ \text { D31 } & \text { NAS/NRC, 1992 } \\ \text { D32 } & \text { Anonymous, 1993 } \\ \text { D33 } & \text { Francis et al., 1997 } \\ \text { D34 } & \text { Telander and Westerman, 1997 } \\ \text { D35 } & \text { DOE, 1995b } \\ & \end{array}$

References cited in Figure 5-2

$\begin{array}{ll}\text { E1 } & \text { Gulick, 1978 } \\ \text { E2 } & \text { Barr and O'Brien, 1976 } \\ \text { E3 } & \text { Dawson and Tillerson, 1978 } \\ \text { E4 } & \text { Sandia, 1977 } \\ \text { E5 } & \text { Gulick, 1979 } \\ \text { E6 } & \text { Tyler et al., 1988 } \\ \text { E7 } & \text { Weart, 1979 } \\ \text { E8 } & \text { Hunter, 1979 } \\ \text { E9 } & \text { Sattler and Christensen, 1980 } \\ \text { E10 } & \text { McVey, 1981 } \\ \text { E11 } & \text { Ewing, 1981 } \\ \text { E12 } & \text { DOE, 1980b } \\ \text { E13 } & \text { DOE, 1981 } \\ \text { E14 } & \text { DOE, 1992c } \\ \text { E15 } & \text { Bechtel, 1986 } \\ \text { E16 } & \text { DOE, 1997 } \\ \text { E17 } & \text { NAS/NRC, 1984 } \\ \text { E18 } & \text { DOE, 1983 } \\ \text { E19 } & \text { Matalucci et al., 1982 } \\ \text { E20 } & \text { Lynch et al., 1991 }\end{array}$

Figure 5-2 (continued)

$\begin{array}{ll}\text { E21 } & \text { Morgan et al., 1985 } \\ \text { E22 } & \text { Morgan et al., 1986 } \\ \text { E23 } & \text { Munson et al., 1989 } \\ \text { E24 } & \text { McCutcheon, 1989 } \\ \text { E25 } & \text { DOE, 1990a } \\ \text { E26 } & \text { DOE, 1991 } \\ \text { E27 } & \text { DOE, 1992d } \\ \text { E28 } & \text { DOE, 1995a }\end{array}$

References cited in Figure 6-2

$\begin{array}{ll}\text { F1 } & \text { Rasmussen, 1975 } \\ \text { F2 } & \text { Claiborne and Gera, 1974 } \\ \text { F3 } & \text { Cranwell et al., 1990 } \\ \text { F4 } & \text { Smith, 1982 } \\ \text { F5 } & \text { DOE, 1979 } \\ \text { F6 } & \text { Campbell et al., 1978 } \\ \text { F7 } & \text { Cranwell et al., 1987 } \\ \text { F8 } & \text { Bartiett et al., 1977 } \\ \text { F9 } & \text { Bingham and Barr, 1980 } \\ \text { F10 } & \text { Campbell and Cranwell, 1988 } \\ \text { F11 } & \text { Reeves et al., 1986 } \\ \text { F12 } & \text { Campbell et al., 1991 } \\ \text { F13 } & \text { IAEA, 1981 } \\ \text { F14 } & \text { State of NM, 1981 } \\ \text { F15 } & \text { Krenz, 1986 } \\ \text { F16 } & \text { Beckner, 1986 } \\ \text { F17 } & \text { Beauheim, 1987 } \\ \text { F18 } & \text { Lappin, 1988 } \\ \text { F19 } & \text { Haug et al., 1987 } \\ \text { F20 } & \text { Reeves et al., 1987 } \\ \text { F21 } & \text { Earth Technology, 1988 } \\ \text { F22 } & \text { Rechard, 1989 } \\ \text { F23 } & \text { Beauheim, 1989 } \\ \text { F24 } & \text { LaVenue et al., 1988 } \\ \text { F25 } & \text { LaVenue et al., 1990 } \\ \text { F26 } & \text { Lappin et al., eds., 1989 } \\ \text { F27 } & \text { DOE, 1989c } \\ \text { F28 } & \text { Hunter, 1989 } \\ \text { F29 } & \text { Marietta et al., 1989 } \\ \text { F30 } & \text { Bertram-Howery et al., 1989 } \\ \text { F31 } & \text { DOE, 1990c } \\ \text { F32 } & \text { DOE, 1990d } \\ \text { F33 } & \text { Guzowski, 1990 } \\ \text { F34 } & \text { Rechard et al., 1989 } \\ \text { F35 } & \text { Bertram-Howery et al., 1990 } \\ \text { F36 } & \text { Rechard et al., 1990 } \\ \text { F37 } & \text { WIPP PA Division, 1991-1992 } \\ \text { F38 } & \text { WIPP PA Department, 1992-1993 } \\ \text { F39 } & \text { DOE, 1995c } \\ \text { F40 } & \text { Prindle et al., 1996 } \\ \text { F41 } & \text { DOE, 1996a } \\ \text { F42 } & \text { Taugher, 1996a } \\ \text { F43 } & \text { NAS/NRC, 1996 } \\ \text { F44 } & \text { Taugher, 1996b } \\ \text { F45 } & \text { Chiri, 1996 } \\ \text { F47 } & \text { DOE, 1996b } \\ & \text { Nichols, 1996 } \\ & \end{array}$


Figure 6-2 (continued)

F48 Hansen et al., 1997

F49 Anonymous, 1997

F50 Corbet, 1997

F51 EPA, 1998

F52 Taugher and Smallwood, 1999

F53 Brooke, 1999 


\section{Federal Agencies}

US Department of Energy (4)

Office of Civilian Radioactive Waste Mgmt.

Attn: Deputy Director, RW-2

Director, RW-10

Office of Human Resources \& Admin.

Director, RW-30

Office of Program Mgmt. \& Integ.

Director, RW-40

Office of Waste Accept., Stor., \& Tran.

Forrestal Building

Washington, DC 20585

U. S. Department of Energy (3)

Yucca Mountain Site Characterization Office

Attn: Project Director

RW-3

A. Van Luik

P. O. Box 30307

Las Vegas, NV 89036-0307

US Department of Energy

Research \& Waste Management Division

Attn: Director

P.O. Box E

Oak Ridge, TN 37831

US Department of Energy (6)

Carlsbad Area Office

Attn: I. Triay

G. T. Basabilvazo

D. Galbraith

M. McFadden

J. A. Mewhinney

Mailroom

P.O. Box 3090

Carlsbad, NM 88221-3090

US Department of Energy

Office of Environmental Restoration and

Waste Management

Attn: M. Frei, EM-30

Forrestal Building

Washington, DC 20585-0002
US Department of Energy (3)

Office of Environmental Restoration and Waste Management

Attn: J. Juri, EM-34, Trevion II

Washington, DC 20585-0002

US Department of Energy

Office of Environmental Restoration and

Waste Management

Attn: S. Schneider, EM-342, Trevion II

Washington, DC 20585-0002

US Department of Energy (2)

Office of Environment, Safety \& Health

Attn: C. Borgstrom, EH-25

R. Pelletier, EH-231

Washington, DC 20585

US Department of Energy (2)

Idaho Operations Office

Fuel Processing \& Waste Mgmt. Division

785 DOE Place

Idaho Falls, ID 83402

US Environmental Protection Agency (2)

Radiation Protection Programs

Attn: M. Oge

ANR-460

Washington, DC 20460

US Nuclear Regulatory Commission (2)

Attn: N. E. Eisenberg

T. J. McCartin

MS T7F3

Washington, DC 20555-0001

\section{Boards}

Defense Nuclear Facilities Safety Board

Attn: D. Winters

625 Indiana Ave. NW, Suite 700

Washington, DC 20004

Nuclear Waste Technical Review Board (3)

Attn: Chairman

J. L. Cohon

C. Di Bella

2300 Clarendon Blvd. Ste 1300

Arlington, VA 22201-3367 


\section{State Agencies}

Attorney General of New Mexico

P.O. Drawer 1508

Santa Fe, NM 87504-1508

Environmental Evaluation Group (3)

Attn: Library

7007 Wyoming NE

Suite F-2

Albuquerque, NM 87109

NM Environment Department (3)

Secretary of the Environment

1190 St. Francis Drive

Santa Fe, NM 87503-0968

NM Bureau of Mines \& Mineral Resources

Socorro, NM 87801

\section{Laboratories/Corporations}

Battelle Pacific Northwest Laboratories Battelle Blvd.

Richland, WA 99352

Los Alamos National Laboratory

Attn: B. Erdal, INC-12

P.O. Box 1663

Los Alamos, NM 87544

Tech Reps, Inc. (3)

Attn: J. Chapman (1) Loretta Robledo (2)

5000 Marble NE, Suite 222

Albuquerque, NM 87110

Westinghouse Electric Corporation (5)

Attn: Library

J. Epstein

J. Lee

R. Kehrman

P.O. Box 2078

Carlsbad, NM 88221

S. Cohen \& Associates

Attn: Bill Thurber

1355 Beverly Road

McLean, VA 22101
J. K. Research Associates

Attn: T. Cotton

2650 Park Tower Drive, Suite 800

Vienna, VA 22180

Future Resources Associates, Inc.

Attn: R. J. Budnitz, President

2039 Schattuck Ave. Suite 402

Berkeley, CA 94704

Western Water Consultants (2)

Attn: P. A. Rechard

611 Skyline Road

Laramie, WY 82070-8909

Winston \& Strawn

Attn: F. S. Echols

$1400 \mathrm{~L}$ Street NW

Washington, DC 20005

ICF Kaiser Engineers

Attn: C. G. Whipple

1800 Harrison St. $7^{\text {th }}$ Floor

Oakland, CA 94612-3430

PLG Incorporated

Attn: B. J. Garrick

4590 MacArthur Blvd., Suite 400

Newport Beach, CA 92660-2027

\section{National Academy of Sciences WIPP Panel}

Tom Kiess (15)

Staff Study Director

GF456

2101 Constitution Ave.

Washington, DC 20418

\section{Universities}

University of New Mexico

Geology Department

Attn: Library

141 Northrop Hall

Albuquerque, NM 87131

University of Washington

College of Ocean \& Fishery Sciences

Attn: G. R. Heath

583 Henderson Hall, HN-15

Seattle, WA 98195 
University of Minnesota

Attn: C. Fairhurst

Department of Civil and Mineral Engineering

500 Pillsbury Dr. SE

Minneapolis, MN 55455-0220

University of Michigan

Nuclear Engineering and Radiological Sciences

Attn: R. C. Ewing

2355 Bonisteel Blvd.

Ann Arbor, MI 48109-2104

University of California

Department of Nuclear Engineering

Attn: T. Pigford

4159 Etcheverry Hall

Berkeley, CA 94720

\section{Libraries}

Thomas Brannigan Library

Attn: D. Dresp

106 W. Hadley St.

Las Cruces, NM 88001

Government Publications Department

Zimmerman Library

University of New Mexico

Albuquerque, NM 87131

New Mexico Junior College

Pannell Library

Attn: R, Hill

Lovington Highway

Hobbs, NM 88240

New Mexico State Library

Attn: N. McCallan

325 Don Gaspar

Santa Fe, NM 87503

New Mexico Tech

Martin Speere Memorial Library

Campus Street

Socorro, NM 87810

WIPP Public Reading Room

Carlsbad Public Library

$101 \mathrm{~S}$. Halagueno St.

Carlsbad, NM 88220

\section{Foreign Addresses}

Atomic Energy of Canada, Ltd.

Whiteshell Laboratories

Attn: B. Goodwin

Pinawa, Manitoba, CANADA R0E IL0

Francois Chenevier (2)

ANDRA

Parc de la Croix Blanche

1-7 rue Jean Monnet

92298 Chatenay-Malabry Cedex

FRANCE

Claude Sombret

Centre d'Etudes Nucleaires de la Vallee Rhone

CEN/VALRHO

S.D.H.A. B.P. 171

30205 Bagnols-Sur-Ceze

FRANCE

Commissariat a L'Energie Atomique

Attn: D. Alexandre

Centre d'Etudes de Cadarache

13108 Saint Paul Lez Durance Cedex

FRANCE

University et Marie Curie

Laboratorie de Geologie Applique

Attn: Ghislain deMarsily

4, Place Jussieu

T. 26- Se etage

7522 Paris Cedex 05

FRANCE

Bundesanstalt fur Geowissenschaften und

Rohstoffe

Attn: M. Langer

Postfach 510153

D-30631 Hannover

GERMANY

Bundesministerium fur Forschung und

Technologie

Postfach 200706

5300 Bonn 2

GERMANY

Gesellschaft fur Anlagen und Reaktorsicherheit (GRS)

Attn: B. Baltes

Schwertnergasse 1

D-50667 Cologne

GERMANY 
Bundesant fur Strahlenschutz (BfS)

Attn: P. Brennecke

Postfach 100149

D-3820 I Salzgitter

GERMANY

Shingo Tashiro

Japan Atomic Energy Research Institute

Tokai-Mura, Ibaraki-Ken, 319-11

JAPAN

Netherlands Energy Research Foundation ECN

Attn: J. Prij

3 Westerduinweg

P.O. Box I

1755 ZG Petten

THE NETHERLANDS

Svensk Karnbransleforsorjning AB

Attn: F. Karlsson

Project KBS (Karnbranslesakerhet)

Box 5864

S-102 48 Stockholm

SWEDEN

Nationale Genossenschaft fur die Lagerung

Radioaktiver Abfalle (2)

Attn: S. Vomvoris

P. Zuidema

Hardstrasse 73

CH-5430 Wettingen

SWITZERLAND

AEA Technology

Attn: J. H. Rees

D5W/29 Culham Laboratory

Abington, Oxfordshire OX14 3DB

UNITED KINGDOM

AEA Technology

Attn: W. R. Rodwell

044/A31 Winfrith Technical Centre

Dorchester, Dorset DT2 8DH

UNITED KINGDOM

AEA Technology

Attn: J. E. Tinson

B4244 Harwell Laboratory

Didcot, Oxfordshire OX11 ORA

UNITED KINGDOM
B. G. J. Thompson

20 Bonser Road

Twickenham

Middlesex, TWI 4RG

UNITED KINGDOM

\section{Internal}

$\begin{array}{lll}\underline{\text { MS }} & \text { Org. } & \\ 0612 & 0111 & \text { C. J. Mora } \\ 0706 & 6113 & \text { D. E. Munson } \\ 0701 & 6100 & \text { L. Shephard } \\ 0735 & 6115 & \text { P. B. Davies } \\ 0737 & 6831 & \text { E. J. Nowak } \\ 1127 & 6215 & \text { J. R. Tillerson } \\ 0778 & 6851 & \text { H. A. Dockery } \\ 0778 & 6851 & \text { C. T. Stockman } \\ 0779 & 6849 & \text { D. R. Anderson } \\ 0779 & 6849 & \text { R. P. Rechard (5) } \\ 0779 & 6821 & \text { M. S. Tierney } \\ 0779 & 6848 & \text { H. N. Jow } \\ 0771 & 6800 & \text { M. Chu } \\ 0771 & 6800 & \text { W. D. Weart } \\ 0733 & 6832 & \text { J. T. Holmes } \\ 1395 & 6821 & \text { M. Marietta } \\ 1395 & 6821 & \text { B. A. Howard } \\ 1395 & 6821 & \text { S. Wagner } \\ 1395 & 6810 & \text { N. Z. Elkins } \\ 1395 & 6860 & \text { R. D. Waters } \\ 1399 & 6850 & \text { S. A. Orrell } \\ 0731 & 6811 & \text { K. Hart (2) } \\ 0731 & 6811 & \text { NWM Library (75) } \\ 9018 & 8940-2 & \text { Central Technical Files } \\ 0899 & 4916 & \text { Technical Library (2) } \\ 0619 & 00111 & \text { Review and Approval Desk, } \\ & & \text { For DOE/OSTI }\end{array}$

